\title{
TWRS Vadose Zone Contamination Issue Expert Panel Status Report
}

Date Published

April 1997

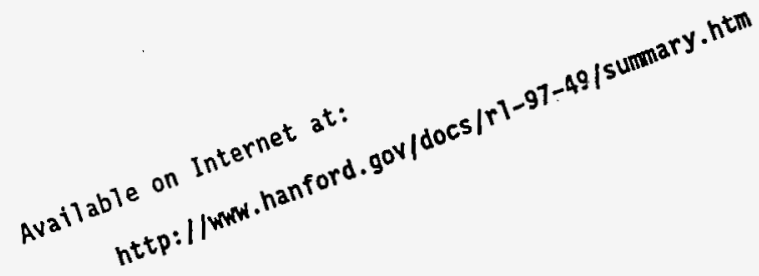




\section{RELEASE AUTHORIZATION}

Document Number: $\quad$ DOE/RL-97-49, Revision 0

Document Title: Status Report

TWRS Vadose Zone Contamination Issue Expert Panel

This document, reviewed in accordance with DOE Order 1430.1D, "Scientific and Technical Information Management," and DOE G 1430.1D-1, "Guide to the Management of Scientific and Technical Information," does not contain classified or sensitive unclassified information and is:

APPROVED FOR PUBLIC RELEASE

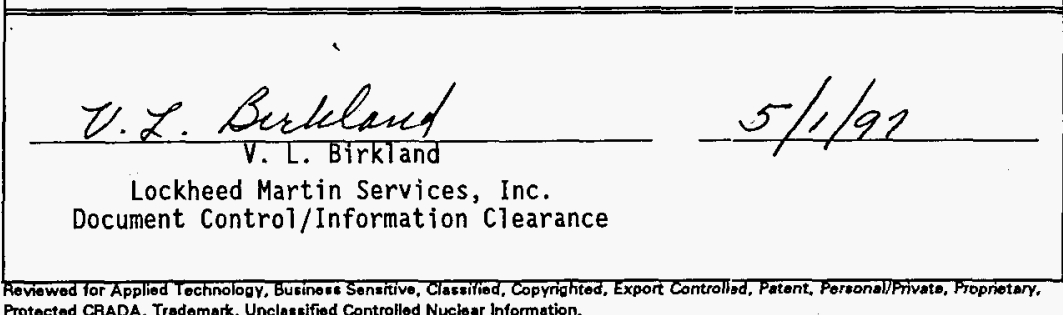
Protected CRADA, Trademark, Unclaseified Controlled Nucloar Information.

LEGAL DISCLAIMER. Thie report wse prepared as an eccount of work sponeored by an egency of the United States Govemment. Nelther the United Stetes Govemmont nor any sgency thereof, not eny of their employees, nar any of their contrectort, eubcontractors or their employees, makes any warranty, exprese or implied, or aseumes any lessl liability or nesponelbility for the sccurecy, completeness, or any third party' use or the resulte of euch ues of any information, apperatus, product. or procese diecloced, or nepresente that its tues would not infringe phvately ownod rights. Reforence herain to any specific commercial product, procese, or

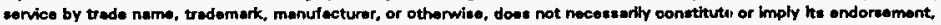
recommendation, or favoring by the United States Govemment or eny egency thereof or ite critractors or eubcontrectort. The viowe and opinione of euthore expressed herein do not necesererily tate or raflect thoes of the Unitud States Govemment or eny agency thereaf. This raport has been reproduced from the best available copy. Printed in the United states of America. Avaliable to the U.S. Department of Energy and ite contractors trom the U.S. Departinent of Eneroy Office of Scientific and Tochnical Informstion. P.O. Box 62, Ook Aidoe, TN 37831: Tolephone: 423/576-8401.

Avallable to the public from the U.S. Depertment of Commerce Netional Technical Informatiof, Service, 5285 Port Royal Roud, Spring field, VA 22161; Tolophone: 703/487-4650. 


\section{TANK WASTE REMEDIATION SYSTEM}

VADOSE ZONE CONTAMINATION ISSUE:

\section{INDEPENDENT EXPERT PANEL STATUS REPORT}

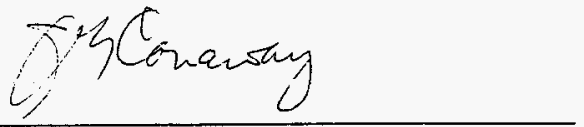

John G. Conaway, Ph.D.

Date

Los Alamos National Laboratories

Tola xuxumoere

$4 / 30 / 97$

Robert J. Luxmoore, Ph.D.

Date

Oak Ridge National Laboratories

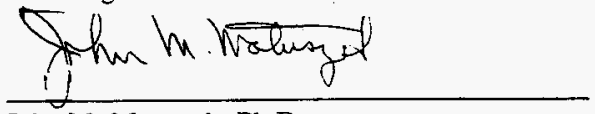

John M. Matuszek, Ph.D.

Date

JMM Consulting Services

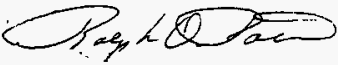

Ralph O. Patt

Date

State of Oregon, Oregon Water Resources Department

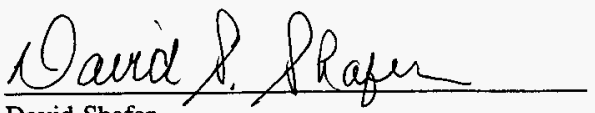

David Shafer

Date

TWRS Vadose Zone Program Manager, DOE-RL 
This page intentionally left blank. 
DOE/RL-97-49, Rev. 0

\title{
TANK WASTE REMEDIATION SYSTEM
}

VADOSE ZONE CONTAMINATION ISSUE:

\section{INDEPENDENT EXPERT PANEL STATUS REPORT}

\author{
Prepared By: \\ John G. Conaway, Ph.D. \\ Robert J. Luxmoore, Ph.D. \\ John M. Matuszek, Ph.D. \\ Ralph O. Patt \\ Under Fluor Daniel Hanford, Inc Contract NNo: \\ TDW-SBW-387700, 729
}


This page intentionally left blank. 


\section{PREFACE}

When members were first canvassed for participation in the Vadose Zone Expert Panel the stated purpose for convening the Panel was to review a controversial draft report, the SX TANK FARM REPORT. This report was produced by a DOE Grand Junction Project Office (GJPO) contractor, RUST Geotech, now MACTEC-ERS, for the DOE Richland Office (DOERL). Three meetings were planned for June, July and August, 1996 to review the draft report and to complete a Panel report by mid-September. The Expert Panel has found its efforts confounded by various non-technical issues. The Expert Panel has chosen to address some of the non-technical issues in this Preface rather than to dilute the techuical discussion that follows in the body of this INDEPENDENT EXPERT PANEL STATUS REPORT (PANEL REPORT).

Rather than performing a straightforward manuscript review, the Panel was asked to resolve conflicting interpretations of gamma-ray logging measurements performed in vadose zone boreholes ('drywells') surrounding the high-level radioactive waste tanks of the SX tank farm. There are numerous and complex technical issues that must be evaluated before the vertical and radial extent of contaminant migration at the SX tank farm can be accurately assessed. When the Panel first met in early June, 1996, it quickly became apparent that the scientific and technical issues were obscured by policy and institutional affairs which have polarized discussion among various segments of the Hanford organization.

This situation reflects the kinds of institutional problems described separately in reports by the National Research Council of the National Academy of Sciences (NAS/NRC), The Hanford Tanks: Environmental Impacts and Policy Choices (NAS Press, Washington, DC, 1966) and Barriers to Science: Technical Management of the Department of Energy Environmental Remediation Program (NAS Press, 1996). The Vadose Zone Characterization Program, appears to be caught between conflicting pressures and organizational mandates, some imposed from outside DOE-RL and some self-imposed. The institutional problems we encountered include having both Tank Waste Remediation System (TWRS), the parent organization of the Vadose Zone Characterization Program and Environmental Restoration (ER), each under different regulatory controls and different organizational units, seeking to defend the status quo and discount many of the Panel's conclusions and recommendations.

The results presented in the SX TANK FARM REPORT, especially the visualizations, have created concern in the public sector, both on a local, personal level and on a national political level. The controversy over that report points to uncertainty concerning the extent to which removal of tank wastes will add to vadose zone (and groundwater) contamination. The controversy also points to uncertainty about the effectiveness of groundwater and soil remediation at Hanford. So, the Panel found itself not so much evaluating the scientific and technical validity of the SX TANK FARM REPORT, but having to judge among conflicting interpretations of the empirical data which form the basis of the report. 
At the first Panel meeting, presentations were made to the Panel concerning background information and the findings of the SX TANK FARM REPORT. AI participants at that meeting apparently agreed that the measurements performed by MACTEC-ERS staff were not in question, but conceptual interpretations were. The MACTEC-EFS concept had the contaminant, ${ }^{137} \mathrm{Cs}$, moving as broad plume through the formation; the PNNL concept was based on the alternative that ${ }^{137} \mathrm{Cs}$ could not have moved so rapidly through the formation and therefore must have moved along the borehole(s).

Unfortunately, neither the SX TANK FARM REPORT, and presentations supporting the formation transport view, nor the presentations supporting the boreh.ole transport view provided data sufficient to resolve whether either or both of the conceptualizations (borehole transport or formation transport) represents existing conditions at the SX tank farm. The technical merits and deficiencies of the opposing positions are discussed in the body of this status report.

To resolve the issue, the Vadose Zone Panel recommended installation, with drilling resistance, gamma and temperature logging, of three new investigative boreholes, using a drilling method expected to be minimally disruptive of the formation, into regions that MACTEC-ERS indicated were likely to be contaminated. As of this writing, only two of three boreholes requested by the Panel have been completed.

The first investigative borehole was installed near tank 241-SX-112, but at a location markedly differing from that selected by the Panel. It did not intercept substantial ${ }^{137} \mathrm{Cs}$ contamination at depth, but did demonstrate the extent of downhole contamination using percussion drilling for borehole installation. The outcome of this first investigative borehole prompted a request from ER for the Panel to discuss at the September meeting that organization's "working conceptual model" for the SX tank farm "that the Cs stopped at about $80 \mathrm{ft}$ ". Because the first investigative borehole had been installed at other than the location selected by the Panel, the data were not useful for assessing competing conceptual models.

The second investigative borehole was installed at a location specified by the Panel. Substantial contamination was encountered much as predicted by MACTEC-ERS and the Panel was asked by Casey Ruud to issue a statement despite the preliminary nature of the data presented to it at that time. That statement was issued on December 17, 1996. Subsequent analysis of the complete data set confirmed that the Panel's statement was sound. Also, temperature logs made at the Panel's behest indicated a substantial temperature anomaly exists in the deep zone where substantial ${ }^{137} \mathrm{Cs}$ contamination was found, s:rongly suggesting the existence of a broadly distributed contaminant plume at depth in the region between tanks 241SX-108, $-109,-111$ and -112 . The results obtained from the second investigative borehole appear to have resolved the issues raised by ER.

As of this report, the requested third investigative borehole has not been installed; results of the first two investigative boreholes are discussed in the main body of this PANEL REPORT. 
The December 17, 1996 Panel Statement follows:

\section{VADOSE ZONE CHARACTERIZATION PROCRAM: EXPERT PANEL STATEMENT}

The Vadose Zone Expert Panel was formed to resolve a narrow technical issue: whether high apparent concentrations of ${ }^{137} \mathrm{Cs}$ discovered de's in the vadose zone based on spectral gamma-ray borehole logging at the SX Tank Farm were indicative of contaminants moving as a broad plume through the formation or moving down the borehole itself. This is an important issue, because if the ${ }^{137} \mathrm{Cs}$ is moving through the formation deep into the vadose zone, it would be clear that the standard view that cesium moves only a few feet from the leak location is incorrect. As a secondary issue, if contaminants are moving down the borehole then characterization based on borehole logging could be misleading and possibly useless.

Neither the early gamma spectral logging data nor gross-garma logs provided unambiguous evidence that ${ }^{137} \mathrm{Cs}$ has moved as a broad plume deep into the vadose zone. This should not be surprising because contaminant transport studies in the Hanford geology and other environments indicute the likely mode of transport is along preferential, vertical, possibly tortuous, pathways. Even in relatively uniform, homogeneous formations, flow tends to divide fairly quickly into fingers rather than moving as a broad plume. There art two unfortunate consequences of concentrated flow along narrow paths: (1) tinese narrow flow paths may be much more difficult to detect than a broad plume and (2) total flow rates and volumes through the narrow channels may rival or exceed those that would be expected for a broad plume. Thus, although there may not be a broadly dispersed plume of ${ }^{137} \mathrm{Cs}$ deep in the vadose zone, it is nonetheless likely that large quantities of ${ }^{137} \mathrm{Cs}$ and other contaminants are reaching those depths along narrow formation pathways.

Clearly, to understand the distribution of contaminants in the ground water, as well as in the vadose zone, it is necessary to characterize the vadose zone. There is discussion at Hanford about whether that should be done and on what time scale. But there is a far more important issue that is being ignored.

Characterization of the vadose zone is an essential step toward understanding contamination of the groundwater, assessing the resulting health risks, and defining the concomitant groundwater monitoring program necessary to verify the risk assessments. A reliable quantitative model, or even a valid conceptual model, of groundwater contamination cannot be developed without reliable data regarding contaminant transport properties of the vadose zone, a subject which is poorly understood. As a result of this lack of information at Hanford, previous and ongoing modeling efforts are inadequate and based on arguable, 
unrealistic, and sometimes optimistic assumptions. The output of such models is entirely unreliable and best described by the old axiom: garbage in, garbage out.

In its efforts to resolve the technical issue posed, the Expert Panel initially recommended installation of a borehole in the zone projected by the Grand Junction Project Office (GJPO) in its SX Tank Farm Report as most likely to exhibit formation contamination to depth. Also recommended was use of a drilling technique which should be less likely to cause borehole contamination than the cable-tool method commonly used at Hanford. The effort was expanded to three boreholes, of which two have been completed at the time of this writing.

The first borehole, 41-12-01, was installed at a location differing from that recommended by the Expert Panel. It failed to intercept a zone of substantial contaminants at depth in the formation. However, it did provide clear definition of the level of borehole contamination created by this methoc' of drilling through the contaminated zone surrounding the base(s) of the leaking tank(s). Failure to intercept a contaminant "plume" at depth is believed likely to be due to the effects of contaminant flow along preferential, vertical paths in the formation which would form narrowly-defined, highly-contaminated zones.

The second borehole has intercepted a zone of substantial contamination to a depth of $130 \mathrm{ft}$. in the formation located between tanks $S X-109$ and SX-108. The borehole location is approximately $5.3 \mathrm{ft}$. east of an old borkhole, 41-09-04. Contaminant levels in the new borehole, 41-09-39, are on the same order as those of the old well at corresponding depths.

Although the preliminary nature of the data provided by only two experimental wells limits interpretation, the Expert Panel concludes that the first clearly defines a level for borehole contamination using the selected drilling method and the second defines a zone of contamination which has moved through the formation. Concentrations in well 41-09-39 are at least two to three magnitudes greater at corresponding depths than those in 41-12-01. Whether the second borehole represents a broadly-spread contaminating plume cr one narrowly defined by a preferential, vertical pathway cannot be determined from the limited data available so far.

The Expert Panel has neither been charged nor been provided information to make a direct evaluation of the importance of the Vadose Zone Characterization Program relative to the Tank Waste Remediation System (TVRS) effort or other remediation programs at the Site. However, the Expert Panel takes note of the recently published findings of the National Academy of Scierices/National Research Council which states in its TWRS draft Environmental Impact Statement review, The Hanford Tanks: Environmental Impacts and Policy 
Choices (NAS, Washington, DC, 1996):

- "An important component of a long-term commitment to remediating the single-shell tanks at the Hanford Site is an adequate understanding of ... the extent to which the soil and groundwater beneath the tanks have been contaminated. Characterization should continue until such an understanding has been obtained" (p. 28).

- "(D)ecisions on waste in the tanks are interrelated with decisions regarding the ... soil and groundwater contaminated by past leaks and deliberate discharges" ( $p$. 36).

- $\quad$ "It is not at all evident how a preferred tank waste retrieval and treatment remediation alternative can be selected rationally without simultaneously considering what is to be done with contamination left behind" (p. 37).

- $\quad$ "Adequate characterization of the tank wastes and surrounding contaminated environment will be required for processing of waste that is removed for treatment and for in situ disposition of wastes not removed from the tanks (either by choice or necessity). A better understanding of what has already leaked and how rapidly it is moving toward the groundwater is needed for assessing risks. Significant uncertainty currently exists concerning the sources and migration paths of cesium and technetium that have been found at some depth beneath the tank farms. Leakage from the tanks caused by sluicing, as well as the risk associated with waste left in the tanks, must be analyzed during the first phase in the context of overall risks. The mechanisms and rates of migration of cesium and other radionuclides originating from the tank farms and from other waste disposal facilities at the Hanford Site also need to be better understood" (p. 52).

- $\quad$ "The analysis should also give more details about the levels of existing contamination in the soil and ground water under the tanks and estimates of long-term impact of such contamination under baseline conditions. The DEIS notes that groundwater protection standards are already exceeded for a number of radionuclides of interest, but it does not provide quantitative information" (p. 57).

The Expert Panel concurs with the NAS/NRC statements and considers that the results derived from the two experimental boreholes reinforces the NAS/NRC position on TWRS and other site remediation needs.

The importance of these findings as they affect the assessment and amelioration 
of risk cannot be overstated. Although the Expert Panel has not been provided with sufficient information to evaluate Site risks, our collective experience leads us to believe that the migration of ${ }^{137} \mathrm{Cs}$ through the formation does not necessarily indicate an immediate health risk to the surrounding population. However, the implications toward Site remediation are immense. Impressions obtained during our meetings are that the models presented as an alternative to those of the GJPO report form the conceptual framework for contaminant transport models used in Hanford risk assessments. As stated previously, the conceptual framework is inadequate and unrealistic; thus, ary risk assessments based on that framework must be equally flawed. Until rectified through the development of a better understanding of contaminant action in the vadose and saturated zones, these incorrectly conceptualized risk assessments will ultimately increase costs and interfere with DOE's ability to comply with RCRA/CERCLA or Tri-Party Agreement requirements. Furthermore, these experimental results open to question how adequately other more mobile contaminants are assessed or monitored.

\section{(End of statement)}

Reviews of the draft of this PANEL STATUS REPORT reflected the institutional perspectives, ranging from minimalist, through objective, to defensive of established positions.

The reviews by MACTEC-ERS and by DOE-RL-AME (ER) required little alteration of this PANEL STATUS REPORT. Most of the comments suggested by MACTEC-ERS were minor changes in wording or use of acronyms and were readily accommodated. The ER review provided only three comments, one of which did take mild exception to the Panel's recommendation of future modeling efforts being performed by independent groups. The ER reviewer also requested further discussion on near-field vs. far-field effects of transport mechanisms proposed by the panel in the status report. Although not identified as such, section 4 of this report describes what are mostly near-field effects. Brief mention is made in section 4.2.4 and at the end of section 4.2.6 of potential far-field effects. Because the Panel has little data concerning the deep vadose zone and below, we focused most of our efforts on the near-field environment. The Panel is not completely comfortable with the concept of nearand far-field effects, because the concept implies an "either-or" situation; the actual conditions are more likely to be a continuum.

An objective review was provided by Los Alamos National Laboratory (LANL). Revisions were made in this Preface and Executive Summary in response to that reviewer's comments. A number of the LANL technical comments, while perceptive and probably valid, could not be readily accommodated without extensive additional information, some of which may not be available or must be developed through additional research or field measurements. Since the technical positions we take in this status report probably would not be altered by the effort suggested by the reviewer, we have chosen to limit our revisions only to those comments which can be readily accommodated. Some of the LANL technical comments should be 
considered in developing a comprehensive vadose-zone characterization program.

The LANL reviewer observed that the Panel mission and scope were not well defined. Our mission changed from meeting to meeting and requests (demands?) were made for a Panel response immediately following completion and logging of each of the two investigative boreholes. Even the documentation sequence is out of order- first was a request for a statement. When that statement became the basis of a Hanford press release, we decided that a status report was appropriate. Time limits have been kept tight (at least as tight as four parttime panelists at four locations and three time zones can accomplish) so as to provide early documentation of our reasoning. Even so, the continuing flow of new information made closure difficult to achieve. So, the Panel's mission and scope had to be redefined whenever deficiencies in the underlying data bases were uncovered or remedied, and they are likely to continue to be flexible to accommodate the complexities of this problem.

Reviews submitted by Bechtel Hanford, Inc. (BHI, 6 comments) and by the Hanford Tank Initiative (HTI, 27 comments) addressed the Preface and Executive Summary and not the whole document. Most of the issues raised by BHI are addressed in various sections of this PANEL STATUS REPORT. The majority of the 27 comments from HTI express at least partial agreement with the Panel findings. There are 5 points of disagreement with Panel recommendations. HTI does not support extension of borehole 41-C9-04, use of an independent modeling group, development of high-flux spectral gamma capability, development of methods to distinguish between borehole and formation sources of contamination, or evaluation of alternative simulation models, all of which are justified in the body of this PANEL STATUS REPORT. HTI cites the system-wide basis of the Vadose Zone Characterization Program for some of the positions taken. The Panel recommendations are largely based on the SX tank farm deliberations.

A review from PNNL (34 comments) addressed the whole draft PANEL STATUS REPORT. Many points recommend clarification and correction of particular issues and these have been incorporated as appropriate. The modeling results from a recently released (February 1997) modeling report were offered in several of the reviewer's comments as clarifications to discussions of vadose zone modeling. In particular, results obtained with time-variable $K_{\mathrm{d}}$ for Cs appear to offer a step toward improved representation of Cs migration from near field to far field environments as has the concept of variable recharge offered since the Panel's first meeting. However, vadose zone modeling presented to the Panel so far oversimplifies many of the complex physical and geochemical processes that may be occurring in the vadose zone impacted by tank waste. The use of chemistry-dependent $K_{d}$ values (variable with salt concentration and species, formation species and $\mathrm{pH}$, for example) might be more representative of the differing sorbtive and transport properties of cationic ${ }^{137} \mathrm{Cs}$ and ${ }^{90} \mathrm{Sr}$, anionic ${ }^{99} \mathrm{Tc}$-pertechnetate and ${ }^{60} \mathrm{Co}$-ferrocynide, various complexes of uranium and actinides, as well as of the variety of chemical contaminants of concern at Hanford. As a better understanding is developed of the lithologies of the tank farms, more complex geohydrologic models should be used; conversely, those involved in the characterization effort must be aware of the specific chemical, lithologic and hydrologic information which must be gathered for use 
in more complex transport simulations. Finally, time dependent source term(s) must be evaluated using a combination of field characterization and increasingly complex simulation models: the current configuration of formation-borne contaminants and the mechanisms which led to it; the mechanisms which currently are altering the configuration; and the effect of various options for removing wastes from the tanks.

The vadose zone modeling efforts for tank farms appear particularly ripe for infusion of new approaches and new data. We strongly suggest that nationally know'n expertise that has not been part of the solutions to these issues be sought in support of resolving these complex technical issues. One approach to providing cost-effective means of infusing new ideas is open competition for vadose zone modeling. Due to perceived institutional influence on remediation activities and differing technical opinions on tank farm contamination, the Panel advocates as a general policy that objective and independent peer review be undertaken before initiating major phases of field investigation, laboratory research, and simulation modeling for the Vadose Zone Characterization Program.

Vadose Zone Expert Panel (alphabetical listing)

John G. Conaway, Ph.D., Los Alamos National Laboratory

Robert J. Luxmoore, Ph.D., RJL Consulting Services

John M. Matuszek, Ph.D., JMM Consulting

Ralph O. Patt, Oregon Water Resources Department 


\section{EXECUTIVE SUMMARY}

The first task of the Vadose Zone Expert Panel was to review a controversial draft report, the SX TANK FARM REPORT, which concludes that ${ }^{137} \mathrm{Cs}$ has migrated substantially deeper beneath the tank farm than DOE had previously predicted. Visualizations in the SX TANK FARM REPORT of ${ }^{137} \mathrm{Cs}$ contamination of the formation sediments beneath the SX tank farm are based on a geostatistical model which is commonly used in geologic exploration. Input data to the geostatistical model calculations for the SX tank farm are developed from recent spectral gamma-ray logs of ${ }^{137} \mathrm{Cs}$ concentrations measured in monitcring boreholes, most of which were put in place more than three decades ago. Underlying both the detector calibrations to obtain concentration values and the application of the geostatistical model is the assumption that ${ }^{137} \mathrm{Cs}$ and other contaminants are broadly distributec in both the formation sediments surrounding the boreholes and the sediments between boreholes. Logging measurements showing ${ }^{137} \mathrm{Cs}$ at depth are not at question, but quantitative concentration values and distributions predicted in the SX TANK FARM REPORT are.

Countering arguments to the SX TANK FARM REPORT visualizations, including simulations by other workers of ${ }^{137} \mathrm{Cs}$ transport, are based on an extensive data base of laboratory measurements and a modicum of field data from locations around the Hanford site, but none specific to the conditions beneath the SX tank farm. Simulations of the transport of ${ }^{137} \mathrm{Cs}$ are critically dependent on values assumed for adsorption on sediments. Measurements of the sorption parameter, $K_{d}$, are not at question, but the representativeness of the $K_{d}$ formalism and the selection of appropriate values for simulation are. The values of $K_{\mathrm{r}}$ selected for the first set of simulations presented to the Expert Panel exclude any possibility of ${ }^{137} \mathrm{Cs}$ being transported deep into the formation sediments as a broadly distributed "plume". This preordained result leads to a conclusion that the ${ }^{137} \mathrm{Cs}$ observed at depth by the spectral-gamma logging measurements could only have come about by transport down the annular space surrounding each borehole. The Expert Panel concludes that these transport simulations are symptomatic of findings by the National Academy of Sciences that technical issues are too often subsumed by institutional ones [NAS/NRC, 1996a].

Thus, the review leading to this PANEL STATUS REPORT becamc more an evaluation of the representativeness of assumptions used to create alternative simulations than one of evaluating the quality of measurement data. Data sufficient to differentiate between competing concepts were not available, so the Panel requested installation and spectral-gamma logging of three investigative boreholes, two of which now have been installed, in a zone among tanks SX-108, $-109,-111$, and -112 . Temperature, moisture and drill-resistance logs were requested for all the boreholes surrounding these tanks, as was a study of the historical gross-gamma monitoring data.

The supplemental data subsequently supplied leads us to conclude that at some locations ${ }^{137} \mathrm{Cs}$ has been transported to depth in and through the formation sediments, and indeed may still be actively moving. At other locations, ${ }^{137} \mathrm{Cs}$ is likely to have moved along the borehole. The 
data obtained so far are insufficient to quantify the amount of ${ }^{137} \mathrm{Cs}$ which has been (or is being) transported to depth relative to that which remains fixed in sediments immediately surrounding the locations where each tank leaked. Nor can these data be used to quantify the transport of other radionuclides, although they may prove useful for identifying the transport pathways and approximate travel times for other contaminants typically considered nonsorbing, or weakly sorbing. The temperature logs, though crude, hint at a broadly distributed plume of heat-generating contaminant(s) in the region below and between tanks 241-SX-108, $109,-111$ and -112 .

In this PANEL STATUS REPORT, we provide recommendations for extending these and other types of measurements so that information can be derived to properly characterize contaminant distributions and transport in the vadose zone beneath the Hanford high-level waste storage tanks. Implementation of these recommendations, especially with regard to shape-factor analysis and temperature logging, may help to focus future efforts at detailed characterization and reduce the cost of characterization relative to what has been experienced previously.

We also point to a number of potential thermal, chemical and physical effects, such as high temperature, high $\mathrm{pH}$ and high salt content, as well as colloid formation and flow along highly porous formation pathways, which may have served as confounding factors for contaminant transport. While we are unable to differentiate the relative importance of these several confounding factors, additional research in both the laboratory and the field will likely lead to selection of more representative conceptual models and input parameters for future simulations of contaminant transport in the vadose zone of the tank farms on the Hanford site.

We provide below a summary of the principle conclusions and recornmendations from Section 7.0 which derive from our evaluation of the SX TANK FARM REPORT and ancillary issues. The panel attempted to prioritize its recommendations, but found the effort meaningless without having the associated cost estimate for each.

\section{Conclusions}

- Investigative borehole $41-09-39$ revealed substantial quantities of ${ }^{137} \mathrm{Cs}$ in the formation to at least 130 feet.

- Investigative borehole 41-12-01 revealed significant drag down of contamination, apparently due to a protruding welding bead at the base of the casing.

- Borehole gamma-ray logging has been an important means of determining the distribution of gamma emitting contaminants.

- Other borehole logging techniques may enhance future monitoring.

- The draft SX TANK FARM REPORT meets reasonable standards of quality. 
- The SGLS baseline logging is valuable, but does not constitute a complete vadose zone characterization program.

- The SGLS meets professional standards and is capable of detecting ${ }^{137} \mathrm{Cs}$ to below 1 $\mathrm{pCi} / \mathrm{g}$ as found at depth in many borehole logs.

- Performance of the SGLS degrades as countrate increases and saturates in gamma environments above approximately $10^{4} \mathrm{pCi}{ }^{137} \mathrm{Cs} / \mathrm{g}$.

- In the SX TANK FARM REPORT, data obtained using the SGLS were not used to distinguish ${ }^{137} \mathrm{Cs}$ contamination along the borehole casing from that in the formation.

- Visualizations of contaminant distribution in the draft SX TANK FARM REPORT are probably unrealistic, since there is an inadequate number of closely spaced boreholes for resolving small scale (preferential) flow paths.

- Although contaminants have moved along pathways opened by borehole installation at the SX tank farm, they also have moved to depth through the formation.

- Gamma- and temperature-logging provide cost-effective methods for identifying large zones of contamination in the unsaturated soils and will reduce the cost of identifying other contaminants by providing foci for future coring/analytical efforts.

- An evaluation of a limited number of historical gross gamma logs has revealed zones with continuing ${ }^{137} \mathrm{Cs}$ contaminant movement.

- Temperature logs indicate a significant temperature anomaly (heat source) at depths below tank bases in the region between tanks $41-S X-108,-109,-111$ and -112 .

- Earlier than previously anticipated transport of ${ }^{137} \mathrm{Cs}$ to grourdwater along preferential flow paths through the vadose zone is plausible.

- Observed deep movement of ${ }^{137} \mathrm{Cs}$ implies similar movement of other contaminants normally considered to be readily adsorbed.

- Preferential flow is common in vadose zone environments, but vadose zone characterization at Hanford has not adequately defined preferential pathways for use in predictive modeling.

- The Panel is surprised that simulations which include the parameters described in the 1997 PNNL report were not undertaken years earlier; the PNNL simulations seem to have been conducted in reaction to Panel critique and suggestions of initial modeling concepts. 
- Development of more representative simulation models requires better characterization of the vadose zone.

- Vadose zone characterization is needed to help estimate the distribution of contaminants in groundwater.

- Contaminant transport in the vadose zone at Hanford is poorly understood.

- The vadose zone between and beneath tanks $241-\mathrm{SX}-108,-109,-111$ and -112 offers an experimental site on which to develop and test concepts for contaminant transport in Hanford sediments.

- The Panel concurs with the key conclusions from recent National Academy of Sciences/National Research Council (NAS/NRC) findings regarding vadose zone contamination (see Panel statement in Preface).

- The Panel is concerned that preordained organizational priorities may exert inappropriate influence on remediation analyses, in concert with NAS/NRC concerns that: "What happens is driven too often by the internal needs of the organization charged with the remediation work rather than by the overall goal of environmental remediation".

- Percussion drilling is a relatively low cost method of obtainirig logging data.

- The drilling-resistance measurements requested by the Panel seem to provide useful information about formation properties.

\section{Recommendations}

- It is imperative that a comprehensive characterization of the vadose zone be undertaken to give clear focus and definition for computer simulations.

- Extend boreholes 41-09-39 and 41-09-04 to groundwater writh logging, sampling and analysis of contaminants and transport properties.

- Steps should be taken to minimize and monitor drag down during drilling.

- Drilling through known contamination zones should be avoidied by slant drilling, unless deliberate sampling and analysis of the zones is to be undertaken.

- Hanford should acquire or develop a high-flux spectral gamma-ray measurement capability. 
- Methods, such as shape-factor and spatial-response analysis, should be developed to distinguish between borehole and formation contamination.

- Hanford should obtain a capability for accurate logging of formation temperature.

- Heat transport calculations should be performed to establish the relationship between formation temperature and casing temperature under various conditions.

- Preferential flow must be part of the conceptual model and be included in simulation models of the vadose zone.

- Vadose zone characterization at Hanford must provide data sufficient to make use of predictive models which include small-scale (preferential) flow.

- Relevant concepts from petroleum, geothermal, and other suitable sources should be incorporated into transport models for simulation of near-field tank farm phenomena.

- The Vadose Zone Characterization Program should extend its efforts through the unsaturated zone to groundwater.

- Evaluation of gross-gamma logs should be extended to other boreholes including laterals for indications of contaminant movement.

- Periodic gamma-ray logging of existing boreholes should be reinstituted using calibrated equipment.

- Records of contaminant movement developed from gross-gamma logs should be considered when developing and performing transport simulations.

- When the data bases from vadose zone characterization reach a sufficient level to support renewed predictive simulation modeling, the modeling effort should be put to a request for proposals (RFP).

- Field and laboratory characterization efforts should be coordinated to provide the types of data bases which will support comprehensive simulation modeling.

- A slant borehole passing beside borehole 41-09-39 should be installed, including logging and sampling during installation, from the west side of the SX tank farm to avoid contaminant drag down from the high-contamination zone.

- Other non-nuclear borehole logging techniques should be evaluated and used where appropriate for future monitoring; included are temperature, soil-water and density logs.

- The SGLS gamma logging should be continued, adding technical enhancements such as 
shape-factor and spatial-response analyses, as appropriate.

- $\quad$ Percussion drilling should be considered for investigative boreholes in lieu of drilling techniques more commonly used at Hanford.

- Drilling resistance measurements should be made when the percussion drilling method is used. 


\section{CONTENTS}

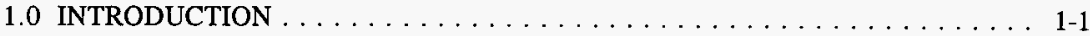

2.0 SX TANK FARM HISTORY $\ldots \ldots \ldots \ldots \ldots \ldots \ldots \ldots \ldots \ldots . \ldots \ldots$. . . . . . . . .

2.1 TANK DESIGN AND CONSTRUCTION $\ldots \ldots \ldots \ldots \ldots \ldots .2-1$

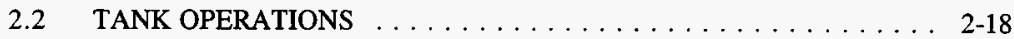

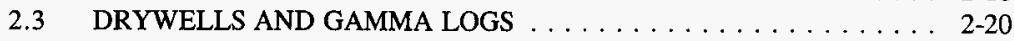

2.4 PANEL EVALUATION OF TANK LEAKS . . . . . . . . . $2-20$

3.0 ASSESSMENT OF SX TANK FARM REPORT . . . . . . . . . . . 3-1

4.0 TRANSPORT AND DEPOSITION OF CONTAMINANTS . . . . . . . . . . 4-1

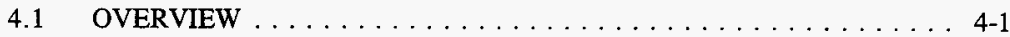

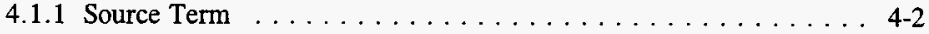

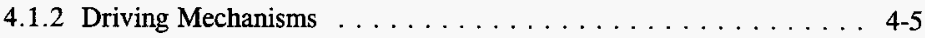

4.2 FORMATION PATHWAYS $\ldots \ldots \ldots \ldots \ldots \ldots \ldots \ldots \ldots \ldots$. . . . . . .

4.2.1 Conventional Conceptual Models . . . . . . . . . . . . . . 4-9

4.2.2 ${ }^{137} \mathrm{Cs}$ Transport Under High Temperature and High $\mathrm{pH}$ Flow Conditions

4.2.3 Analogy with Corrosion of Glass . . . . . . . . . . . 4-15

4.2.4 Role of Colloids in Preferential Flow . . . . . . . . . 4-26

4.2.5 Preferential Pathways in Porous Media . . . . . . . . . . 4-30

4.2.6 Influence on Groundwater Monitoring and Rernediation . . . . . 4 4-43

4.2.7 Contaminant Transport Scenarios Simulated With STOMP . . . . 4 4-43

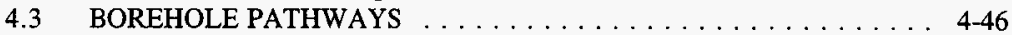

4.3.1 Solids Falling Down the Casing Exterior . . . . . . . . . 4-48

4.3.2 Contaminated Liquids Moving Down the Casing Exterior . . . . 4 4-48

4.3.3 Contaminants Falling or Dribbling Down the Casing Interior . . . 4.49

4.3.4 Near-borehole Drilling Effects . . . . . . . . . . . . . . . 4 4-49

5.0 BOREHOLE LOGGING . . . . . . . . . . . . . . . . . . 5-1

5.1 SPECTRAL GAMMA-RAY LOGGING: OVERVIEW $\ldots \ldots \ldots \ldots$ 5-2

5.2 HIGH-RESOLUTION SPECTRAL GAMMA-RAY LOOGGING $\ldots \ldots \ldots 5-5$

5.3 LOW-RESOLUTION SPECTRAL GAMMA-RAY LOGGING . . . . . . . 5-9

5.4 GROSS-COUNT GAMMA-RAY LOGGING $\ldots \ldots \ldots \ldots \ldots \ldots$. $\ldots \ldots$

5.5 TEMPERATURE LOGS . . . . . . . . . . . . . . . . . 5-14

5.6 OTHER LOGGING TECHNIQUES $\ldots \ldots \ldots \ldots \ldots \ldots \ldots \ldots$. . . . . . . . . .

6.0 MEETINGS AND TELECONFERENCES/INVESTIGATIVE BOREHOLES . . . . 6-1

6.1 MEETING OF JUNE $3-4,1996 \ldots \ldots \ldots \ldots \ldots \ldots \ldots \ldots \ldots \ldots \ldots .2$

6.2 MEETING OF JULY $16-17,1996 \ldots \ldots \ldots \ldots \ldots \ldots \ldots \ldots$

6.3 TELECONFERENCE OF AUGUST $21,1996 \ldots \ldots \ldots \ldots \ldots$. . . . . . 6

6.4 MEETING OF SEPTEMBER $11-12,1996 \ldots \ldots \ldots \ldots \ldots \ldots .6 .14$

6.5 TELECONFERENCE OF NOVEMBER $21,1996 \ldots \ldots \ldots \ldots$. . . . . 6-15

6.6 TELECONFERENCES OF DECEMBER $16-18,1996 \ldots \ldots \ldots$. . . 6 6-17

6.7 MEETING OF JANUARY $14-16,1997 \ldots \ldots \ldots \ldots \ldots \ldots \ldots .6 \ldots$

6.8 TELECONFERENCE OF APRIL $10,1997 \ldots \ldots \ldots \ldots \ldots \ldots$ 6-23 
7.0 CONCLUSIONS AND RECOMMENDATIONS $\ldots \ldots \ldots \ldots \ldots \ldots \ldots$ 7-1

8.0 REFERENCES . . . . . . . . . . . . . . . . . . . 8 1 


\section{LIST OF FIGURES}

Figure $1.1{ }^{137} \mathrm{Cs}$ Distribution $(5 \mathrm{pCi} / \mathrm{g})$ - SX Tank Farm . . . . . . . . . . 1-2

Figure 1.2 Two Principle Conceptual Models Can Result in the Observed Data . . . . . . 1-3

Figure 2.1 Map of Hanford Site Showing SX Tank Farm [GJPO, 1996]. . . . . . . . . 2-2

Figure 2.2 Typical 241-SX 1,000,000-Gallon Single Shell Tank [WHC, 1992]. . . . . . 2-4

Figure 2.3 Sketch Showing Section of Lower Corner of Tank as Built

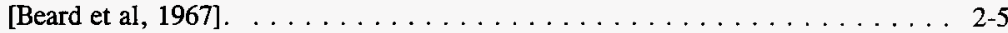

Figure 2.4 Sketch of Lower Corner After Partial Filling and Flow of Mastic . . . . . . . 2-6

Figure 2.5 Sketch of Lower Corner After Vapor Produces Bulge in Bottom

[Beard et al, 1967] . . . . . . . . . . . . . . . . . . . . . . . . . . 2-7

Figure 2.6 Sketch Showing Possible First Stage of Instability of Bottom

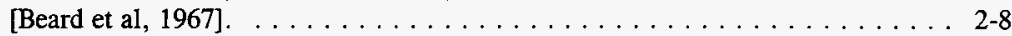

Figure 2.7 Sketch of Second Stage of Inability of Bottom With Reversal of

Curvature [Beard et al, 1967]. . . . . . . . . . . . . . . . . . . 2-9

Figure 2.8 Sketch Showing Maximum Bulge and Some of the Measurements

[Beard et al, 1967]. . . . . . . . . . . . . . . . . . . 2-10

Figure 2.9 Sketch of Final Condition of Tank Liner After the Tank was

Empty and Shell Cooled [Beard et al, 1967]. . . . . . . . . . . . 2-11

Figure 2.10 Sketch of Vapor Escape Through Rupture at Joint

[Beard et al, 1967]. . . . . . . . . . . . . . . . . . 2-12

Figure 2.11 108-SX Reflux Condenser Flow Schematic [Raymond and

Shdo, 1966]. . . . . . . . . . . . . . . . . . . . . . . . . 2-14

Figure 2.12 Tank 108-SX Subsurface $\mathrm{Cs}^{137}$ Concentration 1st Plane, $55 \mathrm{ft}$.

[Raymond and Shdo, 1966]................... 2-15

Figure 2.13 Tank 108-SX Subsurface $\mathrm{Cs}^{137}$ Concentration 2nd Plan, $60 \mathrm{ft}$.

[Raymond and Shdo, 1966]..................... 2-16

Figure 2.14 Tank 115-SX Subsurface $\mathrm{Cs}^{137}$ Concentration [Raymond and

Shdo, 1966]. . . . . . . . . . . . . . . . . . . . . 2-17

Figure $3.1{ }^{137}$ Cs Point Source Intensity Vs. Count Rate (3.1a);

Apparent Uniform ${ }^{137} \mathrm{Cs}$ Concentration Vs. Count Rate (3.1t) . . . . . . . . . 3-2

Figure 4.1 Map of the SX Tank Farm Area [GJPO, 1996]. . . . . . . . . . . . . 4-3

Figure $4.2{ }^{99} \mathrm{Tc}$ Concentrations in Groundwater Monitoring Wells . . . . . . . . . . 4 4-6

Figure 4.3 Technetium/Uranium Ratio in Groundwater Near the S-SX

Waste Managment Area [Caggiano, 1996]. . . . . . . . . . . . . 4-7

Figure 4.4 Hypothetical Sources and Potential Pathways to Groundwater

in WMA S-SX [WHC-SD-EN-AP-191, Rev. 0; H96020243.13] . . . . . . . 4 4-8

Figure 4.5 Predicted Contaminant Concentration for the No Action Alternative

$\left(\mathrm{K}_{\mathrm{d}}=0\right)$ at the Vadose Zone/Groundwater Interface [DOE, 1996] . . . . . 4 4-12

Figure 4.6 Predicted Contaminant Concentration for the No Action Alternative

$\left(\mathrm{K}_{\mathrm{d}}=1\right)$ at the Vadose Zone/Groundwater Interfaces [DOE. 1996]. . . . . . 4-13

Figure 4.7 Example of Groundwater Model Input Development from

Vadose Model Results [DOE, 1996]. . . . . . . . . . . . . . . . . . . 4-14 
Figure 4.8 Rate of Dissolution of Albite as a Function of $\mathrm{pH}$ (after

[Wollast and Chou, 1985]) [Drever, 1988] . . . . . . . . . . . . . 4-16

Figure 4.9 Rate Constant for SRL 165 Simple Analog Glass (SRL-165SA)

vs. $\mathrm{pH}$ at 25,50 , and $70^{\circ} \mathrm{C}$ Measured in Flow-Through Appsiratus . . . . . 4-17

Figure 4.10 Dissolution Data from Temperature Dependence Studies Used to

Derive Activation Energies (adapted from WESTSIK-1981])

[Cunnane et al, 1994]. . . . . . . . . . . . . . . . . . . . . . 4-18

Figure 4.11 Schematic of Surface Layers on Corroded Glass (adapted from

[MENDEL, 1984]). [Cunnane et al, 1994] . . . . . . . . . . . . . . . . . . 4-19

Figure 4.12 Arrhenium Diagram of Leaching Data for SRL 131 Glass

(adapted from BARKATT, 1986]). [Cunnane et al, 1994]. . . . . . . . . . . 4-20

Figure 4.13 Arrhenium Diagram of Leaching Data for R7T7 Glass i: a

Soxhlet Device (adapted from [DELAGE, 1991]). [Cunnane et al, 1994]. . . . 4 4-21

Figure 4.14 Schematic Illustration of the Polymerization of Monosilicic

Acid to Form Seed Particles. . . . . . . . . . . . . . . . . . . . . 4 4-24

Figure 4.15 Boron Release from SRL TDS-131 as a Function of Flow

Rate (adapted from [BARKATT, 1984a]) [Cunnane et al, 1994]. . . . . . . . 4 4-25

Figure 4.16 Breakthrough curves for ${ }^{137} \mathrm{Cs}$ Transport Under Varying

Conditions of Influent Kaolinite Concentration. . . . . . . . . . . . . . . 4-28

Figure 4.17 Schematic Representation of Colloid-facilitated Contaminant

Transport Within a Pore of Water-saturated Porous Medium in the Subsurface . . 4-29

Figure 4.18 An Interpretation of the ERT Results that the Panel Believes

Consistent with Other Data Available [Daily et al, 1992]. . . . . . . . . . 4-32

Figure 4.19 Hydrologic Model and Numerical Simulation Results of Point

Infiltration Experiment. . . . . . . . . . . . . . . . . . . . 4 4-33

Figure 4-20 Variability of the Vertical Flow Pattern Between Two

Profiles Within the Same Plot after a Sprinkling Application

of $40-\mathrm{mm}$ Colored Water. . . . . . . . . . . . . . . . . . . . 4 4-35

Figure 4.21 Vertical Flow Patterns of Brilliant Blue FCF and

One-dimensional Profiles of Dye Coverage after Sprinkling Application

of 40 -mm Colored Water in Four Different Soils . . . . . . . . . . . . . 4-36

Figure 4.22a Location of Boreholes and Their Deviation Projected on

the Horizontal Plane [Landström et al, 1983] . . . . . . . . . . . 4-37

Figure 4.22b Cutaway View of the In Situ Test Site [Landström et al, 1983]. . . . . . 4 4-38

Figure 4.23 Field Experiment $\mathrm{H}-3$ and $\mathrm{Sr}-85$ Break-through Curves:

[Landström et al, 1983].

Figure 4.24 A Schematic Diagram of the Funnel Effect on Water Flow [Kung, 1990].

Figure 4.25 Influence of Point Recharge at the Water Table on Solute

Sampling with Single Well. [Kung, 1990]. . . . . . . . . . . . . . 4 4-44

Figure 4.26 Simulated ${ }^{137} \mathrm{Cs}$ Concentration ( $\left(\mathrm{pCi} \mathrm{g}^{-1}\right.$ ) in 1983 Showing the Impact of $\mathrm{Kd}$ on Plume Migration Under a Variable Recharge Rate . . . . . 4-45

Figure 4.27 Contaminant Distribution at $\mathrm{t}=2 \mathrm{yr}$ for Tank Leak Simulation (4.27a);

Contaminant Distribution at $\mathrm{t}=5 \mathrm{yr}$ for Tank Leak Simulation (4.27b). 
Figure 5.1 Simulated SGLS Detector Pulse-Height Response . . . . . . . . . . . . . 5 5-7

Figure 5.2 Normalized Spacial Response of Gamma Logs as a Function of

Source-to-Detector Distance [Price, 1996]. . . . . . . . . . . . . . . . . . 5-8

Figure 5.3 Analysis of Surveillance Logs from Borehole 41-07-08 [Price, 1996]. . . . . 5-11

Figure 5.4 Analysis of Surveillance Logs from Borehole 41-11-10 [Price, 1996]. . . . . 5-13

Figure 5.5 Repeat Runs of Temperature Logs. . . . . . . . . . . . . . . . . 5-17

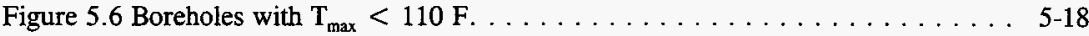

Figure 5.7 Boreholes with $\mathbf{T}_{\max }>110 \mathrm{~F} \ldots \ldots \ldots \ldots \ldots \ldots \ldots \ldots \ldots . \ldots \ldots$. $5 \ldots \ldots$

Figure 5.8 Temperature Maxima Plotted as a Function of Borehole Location. . . . . . . 5-20

Figure 6.1 SX Tank Farm Pipeline/Utility GPR Investigation. . . . . . . . . . . . 6-6

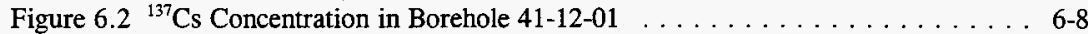

Figure $6.3{ }^{137} \mathrm{Cs}$ Concentration Near Borehole 41-12-02 . . . . . . . . . . . . . . 6-9

Figure 6.4 ${ }^{137} \mathrm{Cs}$ Concentration in Borehole 41-12-01 (Rerun Detail). . . . . . . . . 6 6-10

Figure $6.5{ }^{137} \mathrm{Cs}$ Data at the SX Tank Farm (Data Distribution). . . . . . . . . . . . 6-11

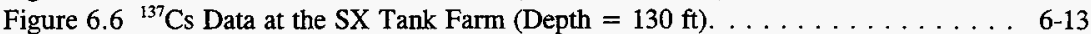

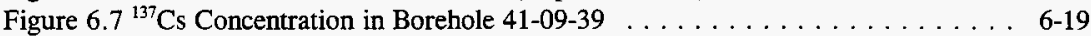

Figure $6.8{ }^{137} \mathrm{Cs}$ Concentration in Borehole 41-09-39 (Detail of Rerun Sections). . . . . 6 6-20

Figure 6.9a-f Gamma Spectra Selected from RLS Log of Borehole 41-09-39

to Show the Influence of Pulse Pile Up and Distortion on Srectral

Resolution and Counting Efficiency. . . . . . . . . . . . . . . 6-21

Figure 6.10 Dead-time vs Concentration Relation (Borehole 41-09-39). . . . . . . . 6-22

Figure 6.11 Correlation of Log Data for Boreholes 41-09-39 and 4i-09-04. . . . . . 6 6-25

Figure 6.12 Air Temperature Logs for Boreholes 41-09-39 and 41-1)9-04

[GJPO, 1996] . . . . . . . . . . . . . . . . . . . . . . 6-26

\section{LIST OF TABLES}

Table 4.1 Current Status of the SX Tanks [Caggiano, 1996 (Appendix G)] . . . . . . . . 4 4-4

Table 4.2. Glass Corrosion Reactions [Cunnane et al, 1994]. . . . . . . . . . . . . 4 4-23 


\section{LIST OF TERMS}

\begin{tabular}{ll} 
ALC & Air-Lift Circulators \\
BHI & Bechtel Hanford, Inc. \\
CERCLA & Comprehensive Environmental Response, Compensalion, and Liability Act \\
DEIS & Draft Environmental Impact Statement \\
DOE & Department of Energy \\
EDTA & Ethylenediaminetetraacetic acid; also ethylenediaminetetraacetate \\
EIS & Environmental Impact Statement \\
ER & Environment Restoration \\
ERT & Electrical Resistivity Tomography \\
GAO & General Accounting Office \\
GJPO & Grand Junction Project Office \\
HTI & Hanford Tank Initiative \\
HTO & Tritiated water \\
KBS & Division KBS, a division of the Swedish Nuclear Fuel Supply Company \\
LANL & Los Alamos National Laboratories \\
LLNL & Lawrence Livermore National Laboratory \\
MCL & Maximum Contaminant Level \\
MWD & Measurement While Drilling \\
NAS & National Academy of Sciences \\
NRC & National Research Council \\
NURE & National Uranium Resources Evaluation \\
OGI & Optimized Geostatistical Inversion \\
PFN & Prompt Fission Neutron \\
PNNL & Pacific Northwest National Laboratories \\
QA & Quality Assurance \\
RCRA & Resource Conservation and Recovery Act \\
REDOX & Reduction-Oxidation Plant (S-plant); also the process used in S-plant \\
RFP & Request for Proposal \\
RLS & Radioelement Logging System \\
SGLS & Spectral Gamma-Ray Logging System \\
SGR & Spectral Gamma Ray \\
STOMP & Subsurface Transport Over Multiple Phases \\
TDT & Thermal Decay Time \\
TWRS & Tank Waste Remediation System \\
VAM2D & Variably-saturated Analysis Model in Two Dimensions \\
& \\
\hline
\end{tabular}




\subsection{INTRODUCTION}

The Vadose Zone Expert Panel was convened to review a controversial draft report, the SX TANK FARM REPORT, produced by a DOE Grand Junction Project Office (GJPO) contractor, Rust Geotech, now MACTEC-ERS [GJPO, 1996]. There seems to be general agreement that the Spectral Gamma-Ray Logging System (SGLS) used by MACTEC-ERS is capable of detecting ${ }^{137} \mathrm{Cs}$ unambiguously even at levels below $1 \mathrm{pCi} / \mathrm{g}$, and that ${ }^{137} \mathrm{Cs}$ has reached the depths along the various boreholes indicated by the SGLS. The major disagreement is over how the ${ }^{137} \mathrm{Cs}$ reached substantial depths below the tanks.

The draft SX TANK FARM REPORT presents three-dimensional graphical visualizations from a geostatistical model based on the SGLS logging data (Figure 1.1). The authors of the report conclude that the ${ }^{137} \mathrm{Cs}$ has traveled through formation pathways to reach depths below 125 feet. Others maintained that the only way ${ }^{137} \mathrm{Cs}$ could have traveled to those depths is along the borehole, either down the inside or along the outside of the casing (Figure 1.2).

The mission of the Vadose Zone Expert Panel has been stated various ways at different times. The initial statement of work has the following statements:

Objective: The Panel members are "to interface with a WHC'RL Issue Management Team (IMT) and Working Group (WG) to analyze data to determine whether cesium contamination is moving through the Vadose Zone beneath the SX Tank Farm in the 200 West Area of the Hanford Site."

Scope of Work: "...provide technical expertise and support WHC Tank Farm Transition Projects for all activities related to resolution of vadose zone contamination issues related to the close out of Occurrence Report (OR) 96-(1016."

In his charge to the Panel, Casey Ruud (Vadose Zone Characterization Program Manager for DOE-RL/EM-30) stated the Panel's mission as follows:

"Expert Panel Mission: The identification of the specific isotope Cs-137 has raised several significant issues. The first to be addressed: Is Cs-137 migrating downward through the Vadose Zone under the SX Tank Farm at such a rate that it will contaminate the groundwater? The first step for the expert panel will be to evaluate and validate one (or both) of two conceptual models: did the Cs-137 migrate down the boreholes to its present position and/or did it migrate through the formation."

More recently, as evidence mounts that ${ }^{137} \mathrm{Cs}$ has moved substantially deeper than predicted in DOE's models, the panel mission has been evolving towards providing technical review of programs to characterize the vadose zone under the tank farms at Hanford. 
Figure 1.2 Two Principle Conceptual Models Can Result in the Observed Data

\section{* AERIALLY EXTENSIVE Cs MIGRATING THIROUGH THE SOIL COLUMN AS DEPICTED IN RUST FIGURES, CREATING DEEP AND EXTENSIVE Cs PLUMES.}

\section{* Cs MIGRATING A SHORT DISTANCE IN THE SOIL COLUMN, BUT ALSO "SHORT CIRCUITING" THE SOIL COLUMN BY MIGRATING DOWN PREFERENTIAL PATHWAYS PROVIDED BY UNSEALED DRYWELLS; ADDITIONAL CONTRIBUTION BY:}

- DRYWELLS ARE UNSEALED, DRILLED THROUGH TANK LEAKS, BY CABLE-TOOL METHODS - UTILIZING A DIVE SHOE LARGER THAN THE CASING, CREATING AN ANNULAR SPACE BETWEEN THE CASING AND THE FORMATION;

- DRILLERS REPORT "FLOWING SANDS" IN THE HANFORD FORIMATION, INDICATING SLOUGHING DURING DRILLING (POTENTIAL FOR CONTAMINATED MATERIAL MIXING WITH CUTTINGS), POTENTIAL CREATING ADDITIONAL ANNULAR SPACE FOR CONTAMINANT MIGRATION;

- SMEARING OF CONTAMINANTS ON OUTSIDE OF THE CASING DURING DRILIING; WELLS 41-09-04 \& 41-12-02 WERE DEEPENED BY DRIVING THE EXISTING, CONTAMINATED CASING DEEPENED, USING INADEQUATE CONTAMINANT CONTROL (POTENTIAL FOR SLOUGHING AS DESCRIBED ABOVE);

- Cs ENTERING INSIDE OF CASING BY AIRBORNE OR WATERBORNE PATHWAY;

- POORLY REMEDIATED GROUNDWATER MONITORING WELLS:

- ENHANCED RECHARGE BY GRAVEL SURFACE TREATMENT AND "UMBRELLA" EFFECT OF THE TANKS;

- POOR LIQUID HANDLING PRACTICES SUCH AS UNCONTROLLED WATER LINE LEAKS AND COMPACTION OF TRENCHES BY WATER;

- SURFACE FLOODING DURING SNOWMELT EPISODES;

- LATERAL SPREADING OF LIQUIDS DISPOSED TO ADJACENT CRIBS;

- CLASTIC DIKES ALSO SERVING AS VERTICAL PREFERENTIAL PATHWAYS. 
This page intentionally left blank. 


\subsection{SX TANK FARM HISTORY}

Documentation of the history of the SX tank farm, including design, construction details, tank operations and contamination estimates, appears to be a work in progress as records are still being declassified or retrieved from storage. The Panel was supplied with volumes of material, some still in preliminary or draft form and other drawn from old files.

We have not made an independent, in-depth evaluation of all the historical documentation, so an extensive discussion in this report of the history of the SX tank farm is not appropriate. Instead, we provide a brief summary of our understanding of the relevant issues as described in the various histories we have received. We have no way of evaluating the accuracy of much of the information supplied to us.

The SX TANK FARM REPORT provides a brief description of tank construction, contents, unplanned releases, and monitoring and preliminary gross-gamma logging efforts; references to a few of the recent tank farm studies are provided, as well. A letter report [ICF Kaiser, 1996a] provides some incomplete historical information regarding tanks 241-SX-108, -109, 111 , and -112 , the four tanks which frame the region on which the Panel has focused. An extensive compendium [ICF Kaiser, 1996b] of recent and past reports describes operations and contamination incidents. Another compendium [Jo and Jones, 1990] of old reports and memoranda provides several descriptions and evaluations of tank corditions, especially of waste temperature and pressure which led to overpressurization incidents, or "bumps" [Beard et al, 1967]. Tank content estimates are provided in three reports [Brevick et al, 1994; Agnew, 1995; Agnew, 1996]. Caggiano [1996] provides a record of groundwater monitoring for the S and SX tank farms. The summary which follows is based on only a very limited part of the historical and interpretive information supplied to us. Apparently, there exists voluminous documentation from which our references are drawn, but review of that documentation is beyond the scope of this report.

\subsection{TANK DESIGN AND CONSTRUCTION}

The SX tank farm is located in the south-central section of the 200 West Area on the Hanford Site (Figure 2.1). Two sedimentary formations overlie the basalt basement rock. The Hanford formation, composed of unsaturated sand, silt and gravel, overlies the Plio-Pleistocene unit and Ringold formation and is the formation into which the tanks have been placed. The lower portion of the Ringold formation immediately above the basement basalt is composed of saturated sand and gravel. The upper portion of sand and lacustrine deposits is unsaturated and is topped a unit of calcium carbonate and evaporite overlain by a high-clay content lacustrine silt (the Plio-Pleistocene unit). Despite local discontinuities and cuts by washout zones and clastic dikes, the Plio Pleistocene unit seems to be considered a barrier against transport of adsorbed contaminants to groundwater. 
Figure 2.1 Map of Hanford Site Showing SX Tank Farm [GJPO, 1996].

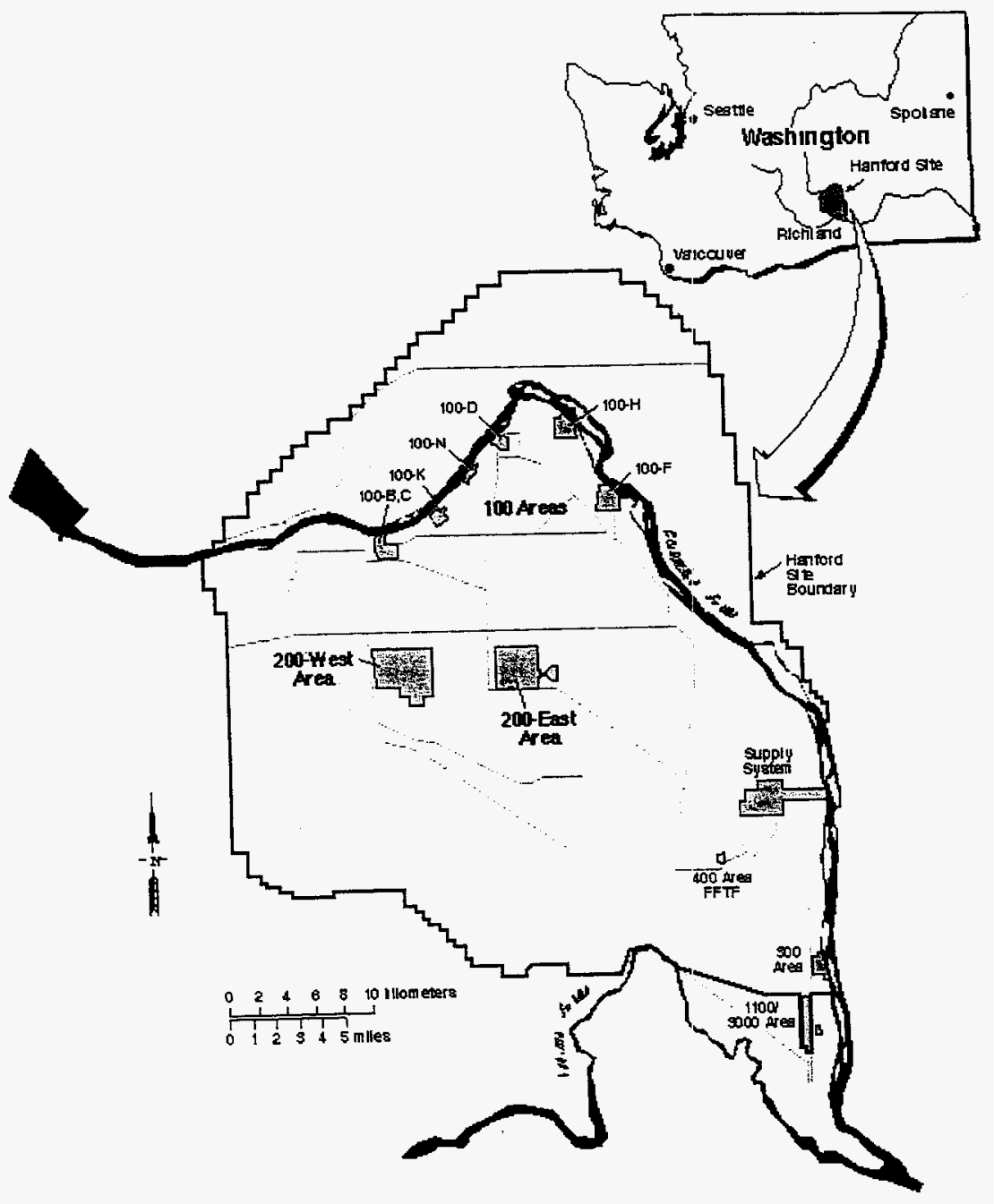


The tank construction details (Figures 2.2 and 2.3) which seem most influential on the potential for and magnitude of leaks from the SX tanks are: the single-shell design, unreinforced butt-end $\left(90^{\circ}\right)$ welding of the liner wall to the liner base [Beard et al, 1967], the use of potentially vapor-generating material between the steel liner and the reinforced-concrete shell [Beard et al, 1967], and a 30-ft. hydrostatic head created by a dense liquid.

The single-shell design of the SX tanks (single steel liner inside a single reinforced concrete shell) does not provide secondary containment if the primary liner fails. Nor can the concrete wall and base be expected to form anything more than support for the steel liner. The concrete base was poured and allowed to set, then was overlain by an asphaltiz coating and a sand-based cement grout on which the liner base of welded steel plates was plactd. After the steel liner wall was welded onto the steel base plates and an exterior wooden form constructed, the reinforced concrete wall was poured onto the lip of the concrete base using the liner as the inner form for the wet concrete [GJPO, 1996]. Thus, the joint between the concrete wall and the composite base (concrete/membrane/grout) apparently is not sealed against fluid flow should the liner fail. The above description of the concrete wall-concrete base joint from the SX TANK FARM REPORT is based on photos of SX tank construction, rather than the sketch of Figure 2.3, which was developed for a 1967 report on the 1965 bump in tank TX-105-A [Beard et al, 1967 in Jo and Jones, 1990].

The simple butt-end weld of the liner wall to the liner base, without added support against differential thermal expansion and/or flexing, meant that the liner joint was highly vulnerable to failure. Figures 2.3 through 2.10 [Beard et al, 1967] provide what seems to be the accepted sequence for such disruptive events, although stress corrosion of the steel liner may also have contributed, at least for tank 241-SX-115 [Raymond and Shdo, 1966].

The rush to construction, due to needed waste storage capacity, apparently led to emplacement of the liner bases prior to complete curing of the grout underlayment. The pressure created from vaporization of the water trapped under the liner by waste-generated heat caused at least some, possibly all, of the tank bases to buckle and bulge upward, flexing the welds. Even had the grout been allowed to cure, temperatures at the tank base apparently became great enough to have caused vaporization of the hydration water anyway. Furthermore, the asphaltic membrane ("mastic" in Figure 2.3) was diluted with volatile compounds which may have increased the vapor pressure generated beneath the liner base.

Finally, with heavy salt content of the wastes producing specific gravity approximately 1.5 , a full tank of entering liquid (maximum 30-ft depth in SX tanks) would have resulted in a hydrostatic head of nearly 20 psi. Since the liquid waste in the SX tanks was allowed to concentrate by evaporation from self-heating, the specific gravity of the liquid apparently increased to as much as 2.2 . The corresponding volume reduction raay have been sufficient to maintain a constant hydraulic head, although the magnitude of the change in head as more waste was added is not clearly indicated. Potentially, the hydrostatic head in some tanks could have been as great as $30 \mathrm{psi}$. These combinations of specific gravity (viscosity) and depth 
Figure 2.2 Typical 241-SX 1,000,000-Gallon Single Shell Tank [WHC. 1992].

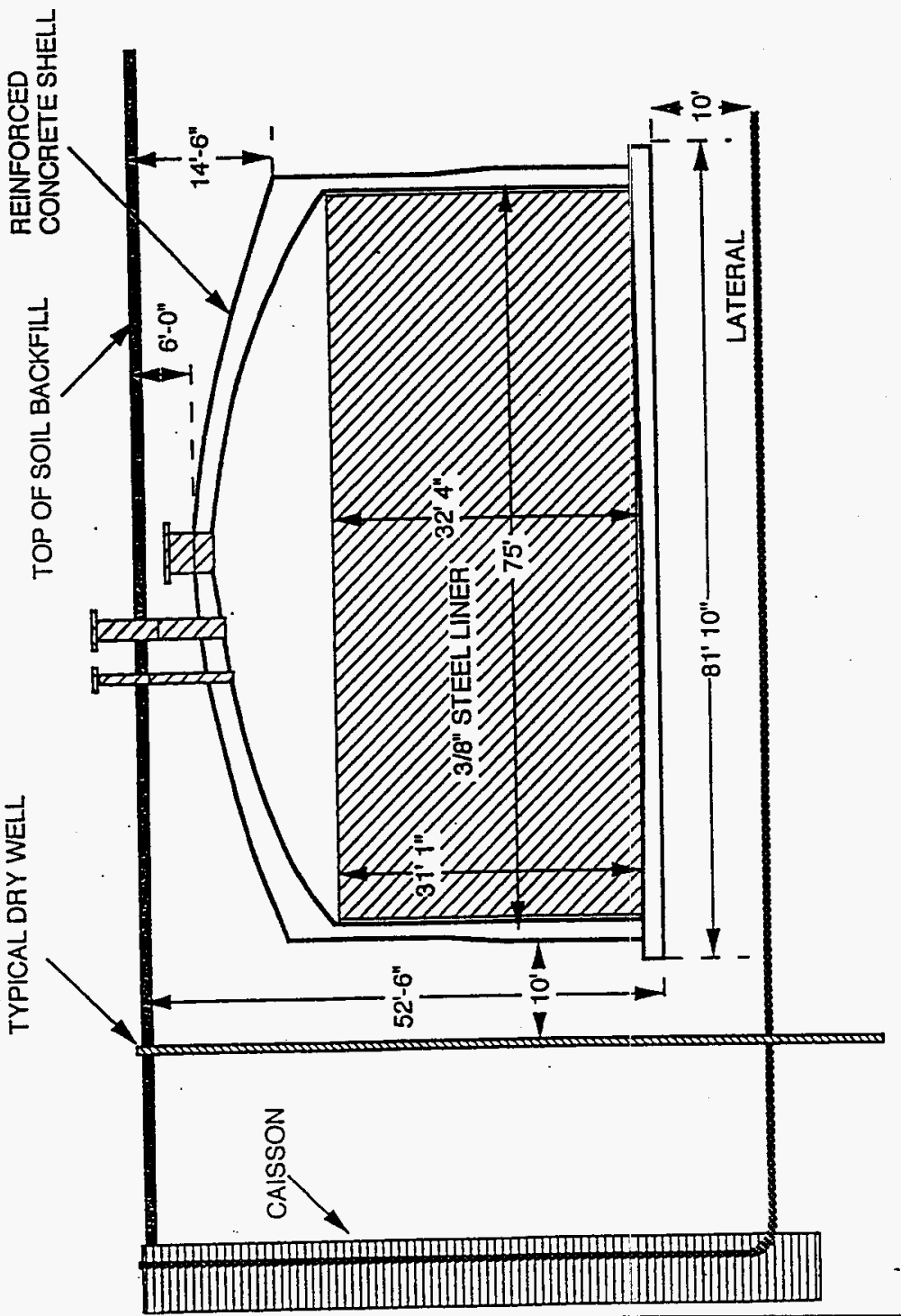


Figure 2.3 Sketch Showing Section of Lower Corner of Tank as Built [Beard et al, 1967].

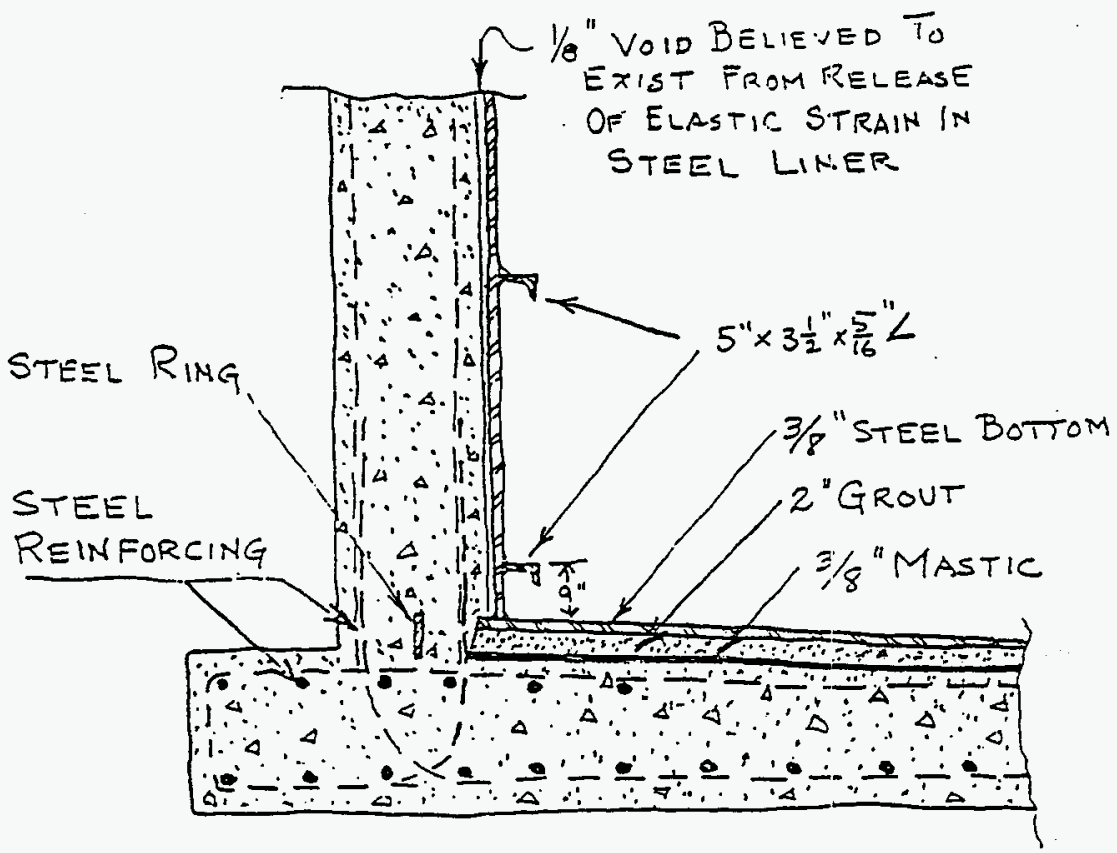


Figure 2.4 Sketch of Lower Corner After Partial Filling and Flow of Mastic

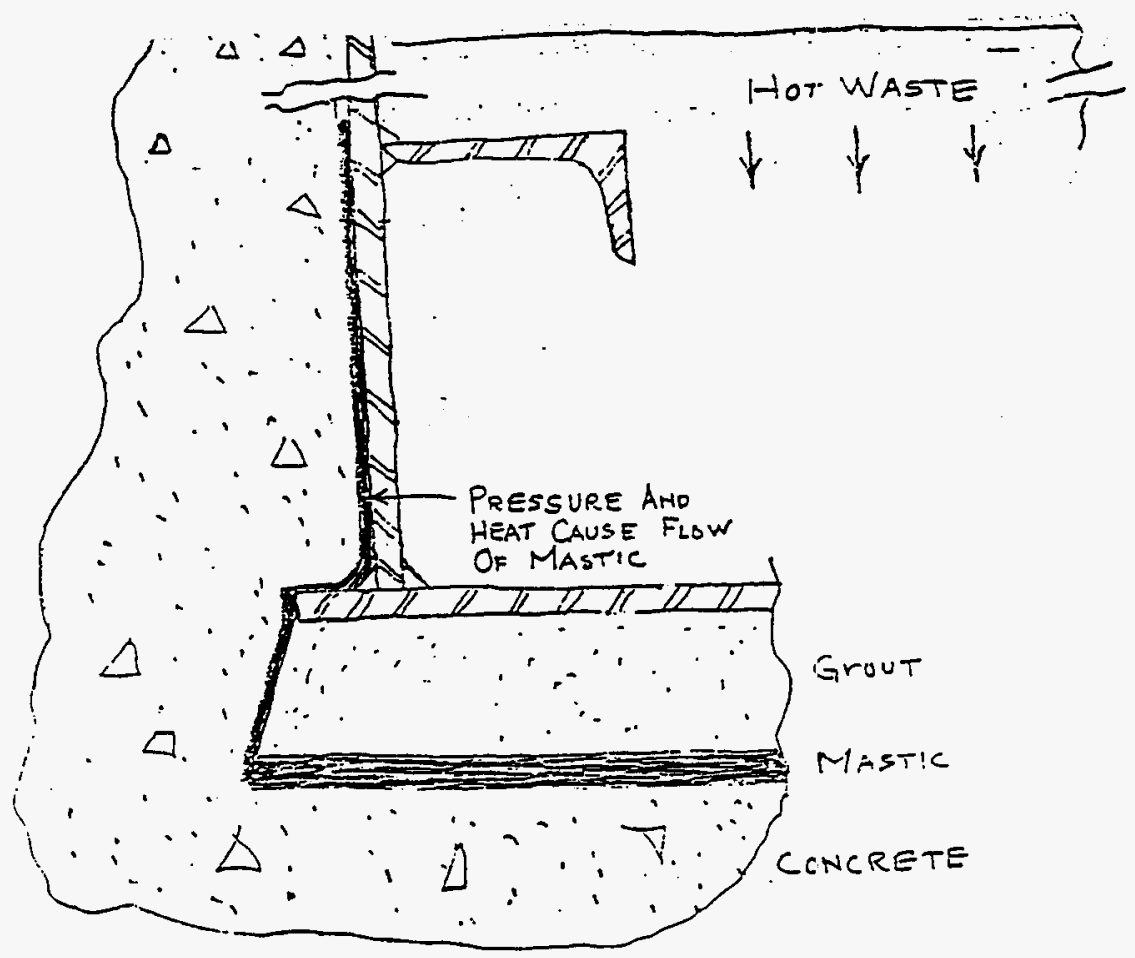


Figure 2.5 Sketch of Lower Corner After Vapor Produces Bulge in Bottom [Beard et al, 1967]

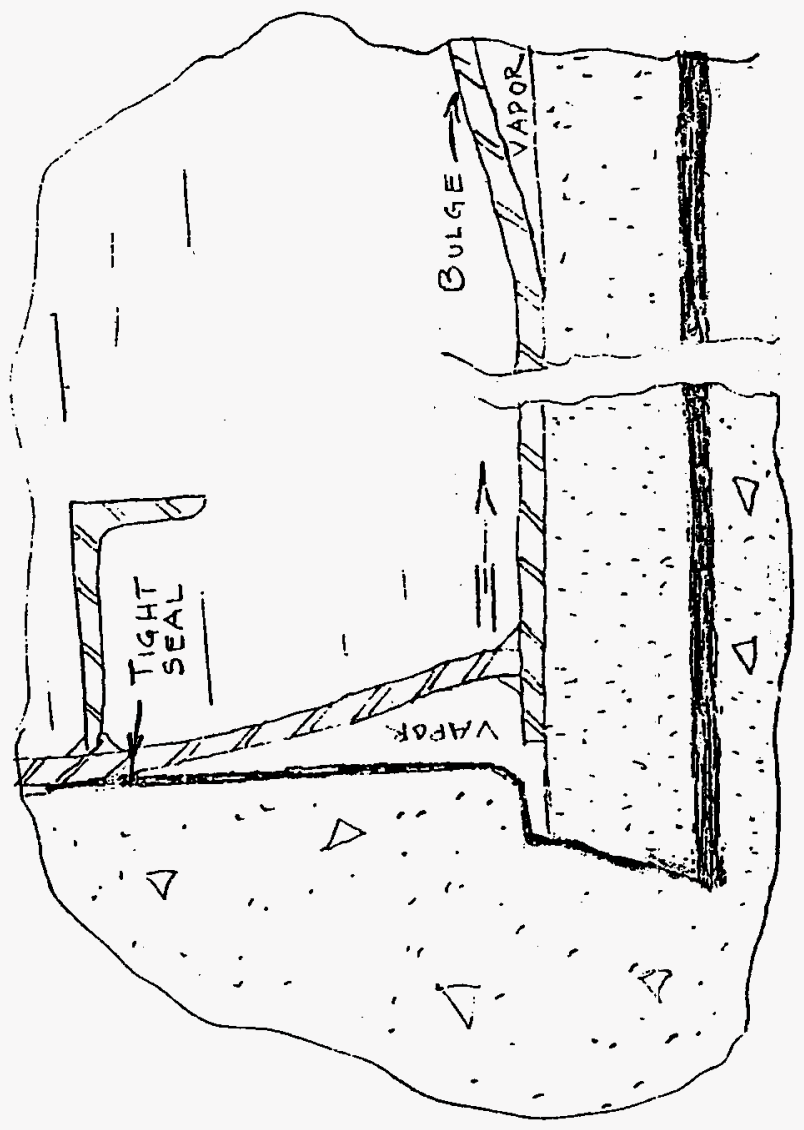


Figure 2.6 Sketch Showing Possible First Stage of Instability of Bottom [Beard et al, 1967].

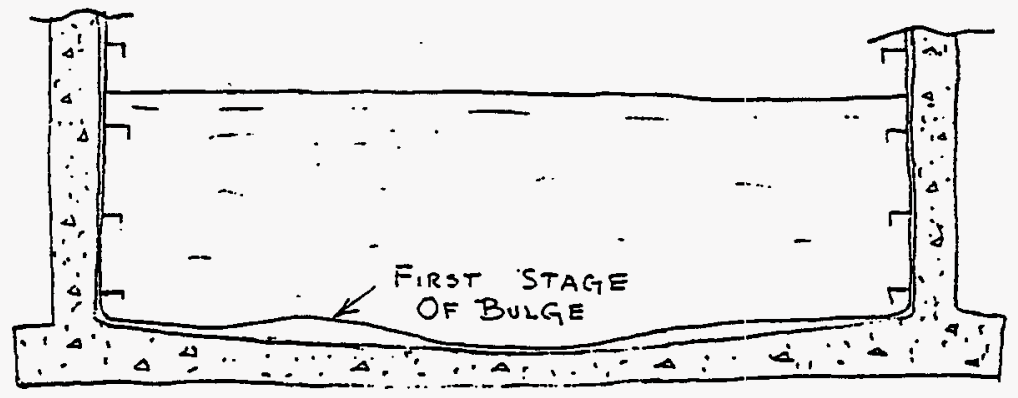


Figure 2.7 Sketch of Second Stage of Inability of Bottom With Reversal of Curvature [Beard et al, 1967].

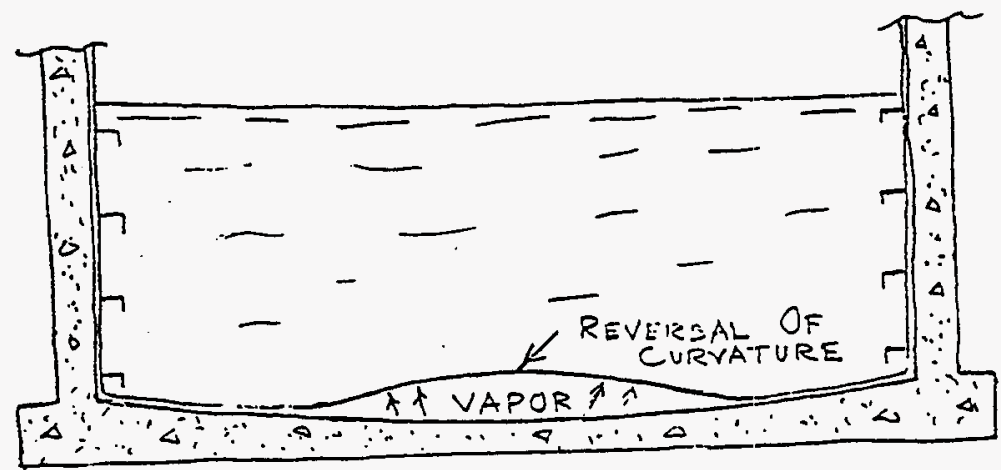


Figure 2.8 Sketch Showing Maximum Bulge and Some of the Measurements [Beard et al, 1967].

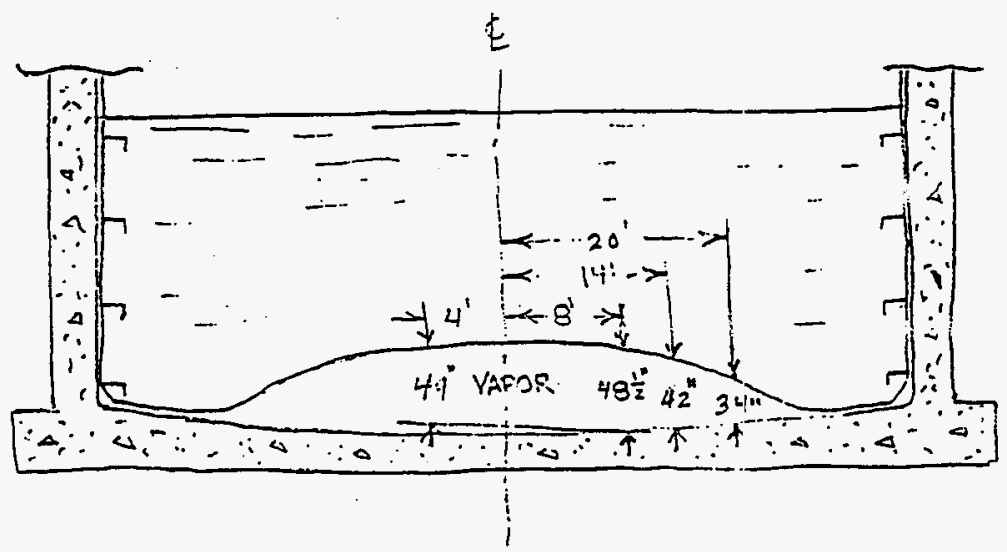


Figure 2.9 Sketch of Final Condition of Tank Liner After the Tank was Empty and Shell Cooled [Beard et al, 1967].

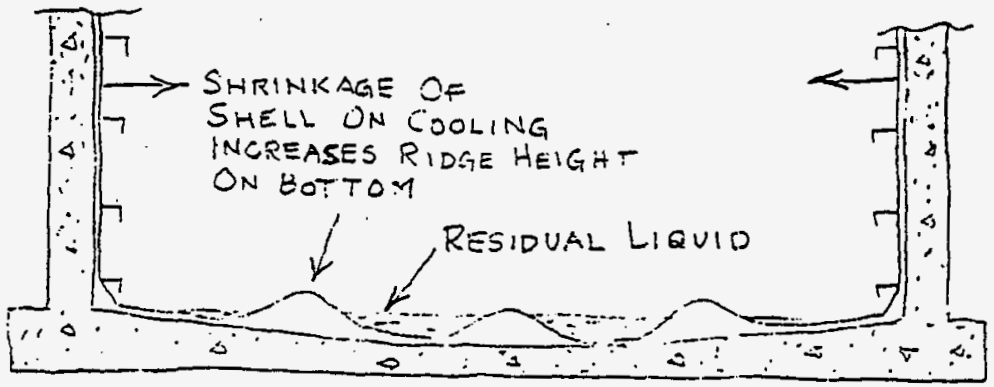


Figure 2.10 Sketch of Vapor Escape Through Rupture at Joint [Beard et al, 1967].

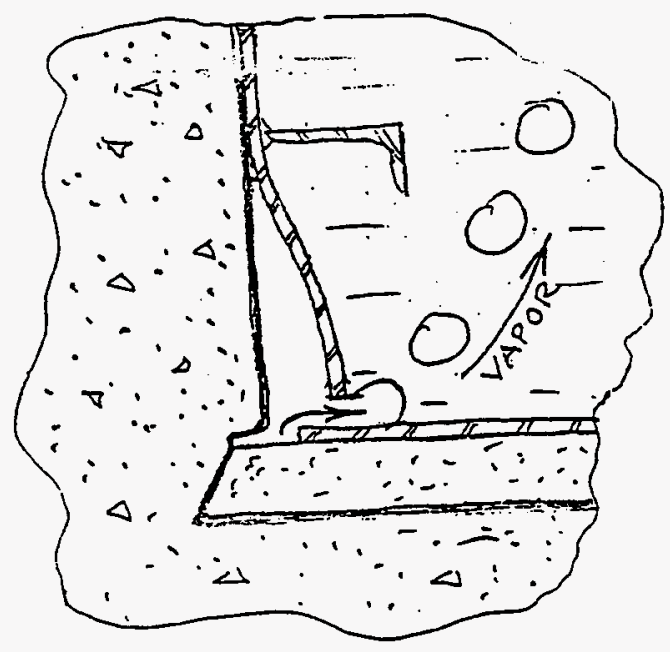


(hydrostatic head) were referenced [Jo and Jones, 1990] to be sufficient to maintain a vapor pressure in the base liquids of at least 5 psig to perhaps 7 or 8 psig. Records [ICF Kaiser, 1996b] indicate that tank 241-SX-108 was filled only to levels equivalent to the lower vapor and hydrostatic head pressures, but that tanks $241-\mathrm{SX}-109,-111$, and -112 were at times filled to the maximum level as self-evaporation was ongoing.

A potentially confounding construction detail is that the entire SX tark farm was excavated as a unit from the virgin formation [GJPO, 1996]. Tank base levels were established by backfilling and compacting added fill (crushed stone or new gravel?) onto which each concrete base was poured. The space between tanks was filled with excavated formation soil, compacting at 4- $\mathrm{ft}$ intervals as the concrete tank walls were poured. While this construction detail would not affect either the probability or magnitude of leaks from a tank, it could influence the direction and rate of flow of leaked fluids. If a porous crushed stone or gravel pad was created for each concrete tank base, and that pad was limited in lateral extent, leaked fluids would tend to migrate under the tank, as seems to be the case for leaks from tanks 241-SX-108 and -115 [Raymond and Shdo, 1966; Nielson, 1992]. Similar studies for the other SX tanks could not be found. Also, tank placement was designed for liquids to cascade (Figure 2.11) from the easternmost to the westernmost tank (241-SX-107 $\rightarrow-108 \rightarrow-109)$. So questions arise as to the east-to-west pitch of the excavation into which the tanks were placed. According to the SX TANK FARM REPORT, the base elevation of the second tank in a cascade sequence is lower by a foot than that of the first and the third lower by a foot than the second. Was there a continuous grade, or were discontinuous plateaus excavated to develop an east-west slope? What was the difference in east-west elevation(s) of the base sediments? Or, were tank elevations established by depth of fill on a flat excavation? How thick were the pads onto which the concrete bases were poured? What was the hydraulic conductivity of each of the horizons which might contribute to migration of leaked fluids; i.e., of undisturbed formation sediments, excavated and recompacted formation sediments, and compacted pad material(s)?

Interpretation of spectral gamma-ray logs and development of conceptual models for contaminant migration may differ according to the answers about tank-base and formation elevations. For example, the SX TANK FARM REPORT suggests that ${ }^{137} \mathrm{Cs}$ contamination measured in boreholes 41-09-03 and 41-09-04 was due at least in part to leaks in tank 241-SX108. The Raymond and Shdo study suggests that escaping liquids tended to flow under the tanks (Figure 2.12 through 2.14). The thirty years which intervene between the two studies, as well as the unknowns concerning potential flow pathways created by tank construction, make difficult any comparison of the MACTEC-ERS interpretation to that of Raymond and Shdo. Another issue which requires clarification for any comparison of gamma-logs in the laterals (horizontal monitoring boreholes) beneath some tanks is whether the lateral casings were inserted into virgin sediments or compacted fill. 
Figure 2.11 108-SX Reflux Condenser Flow Schematic [Raymond and Shdo, 1966].

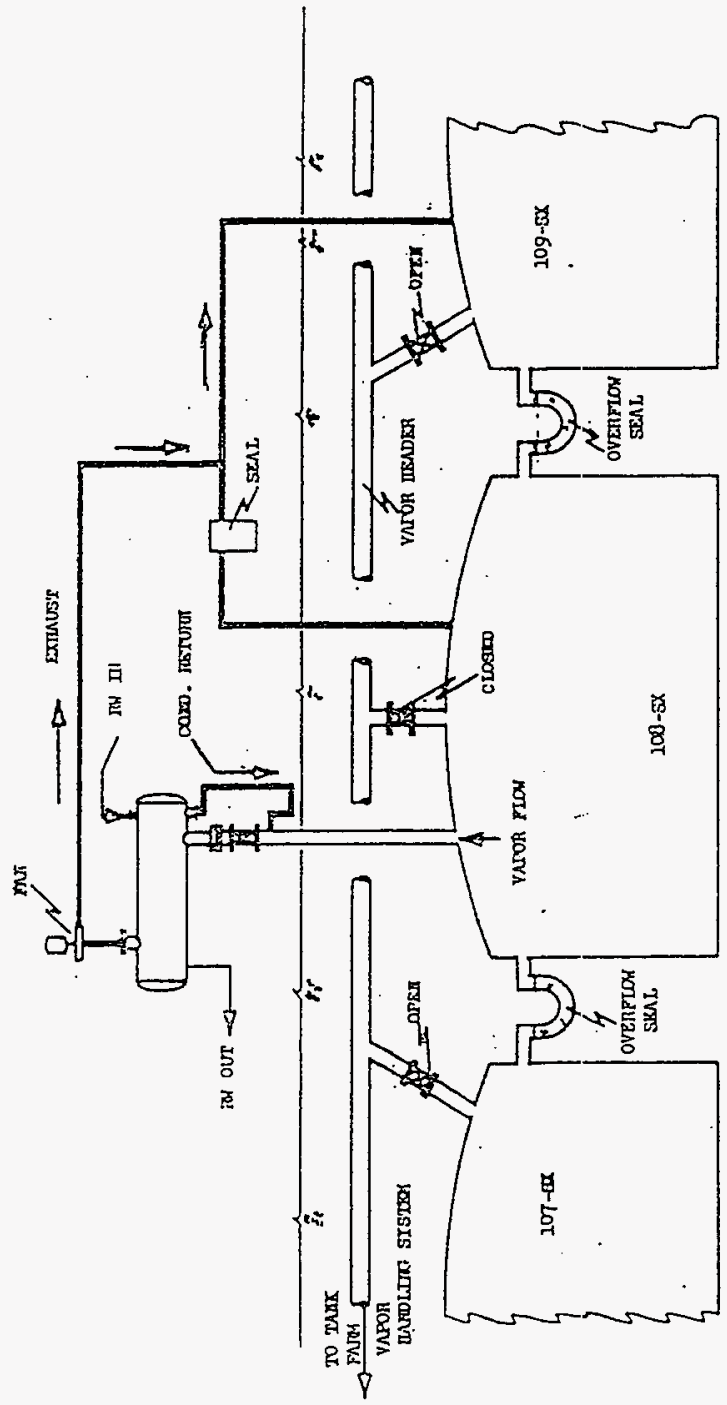


Figure 2.12 Tank 108-SX Subsurface $\mathrm{Cs}^{137}$ Concentration 1st Plane, $55 \mathrm{ft}$. [Raymond and Shdo, 1966].

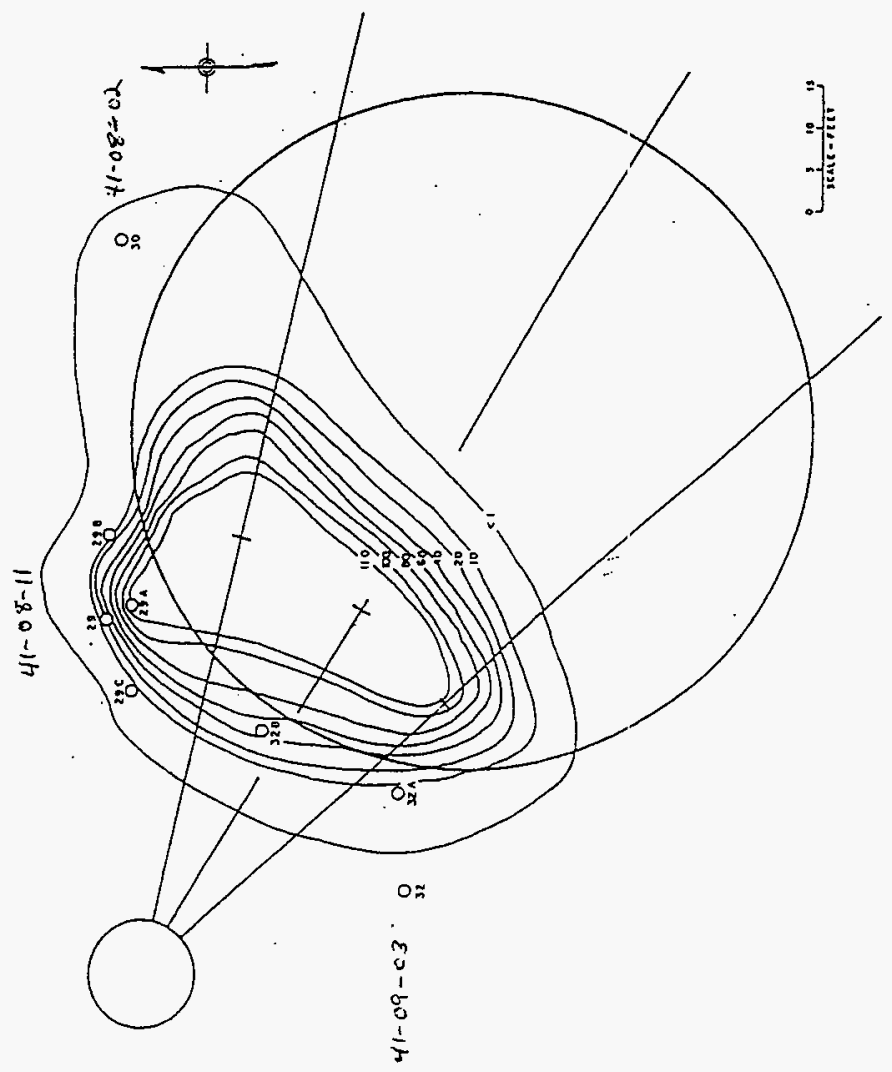


Figure 2.13 Tank 108-SX Subsurface $\mathrm{Cs}^{137}$ Concentration 2nd Ple.n, $60 \mathrm{ft}$. [Raymond and Shdo, 1966].

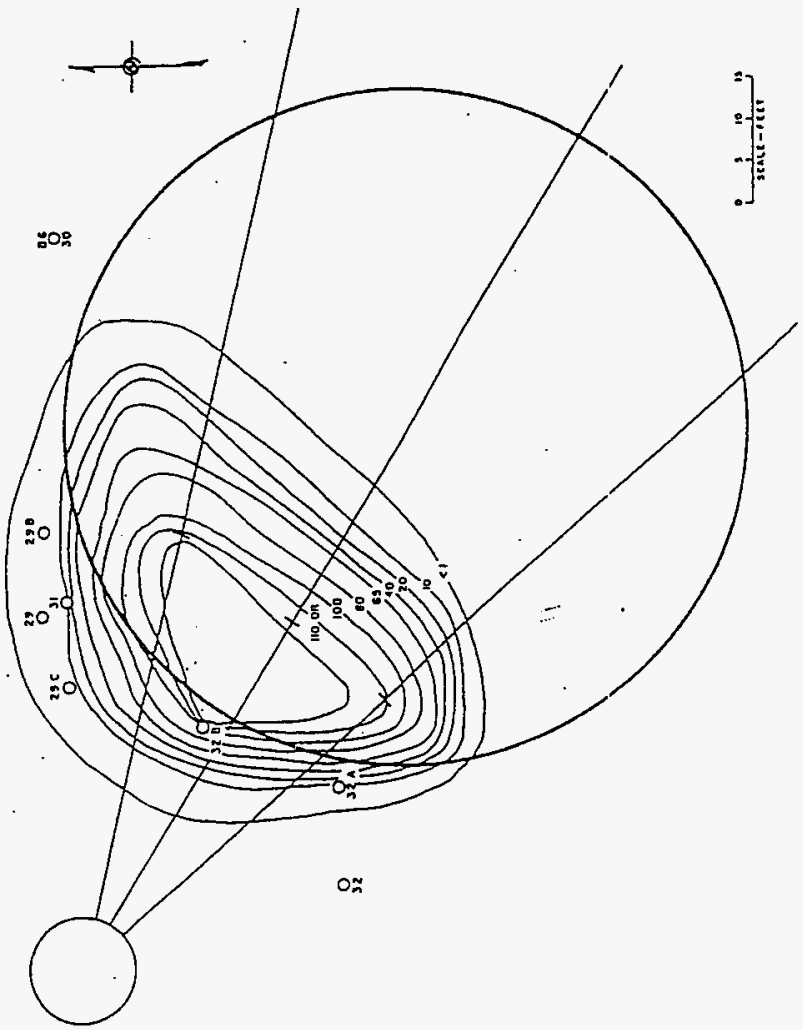


Figure 2.14 Tank 115-SX Subsurface $\mathrm{Cs}^{137}$ Concentration [Rayrnond and Shdo, 1966].

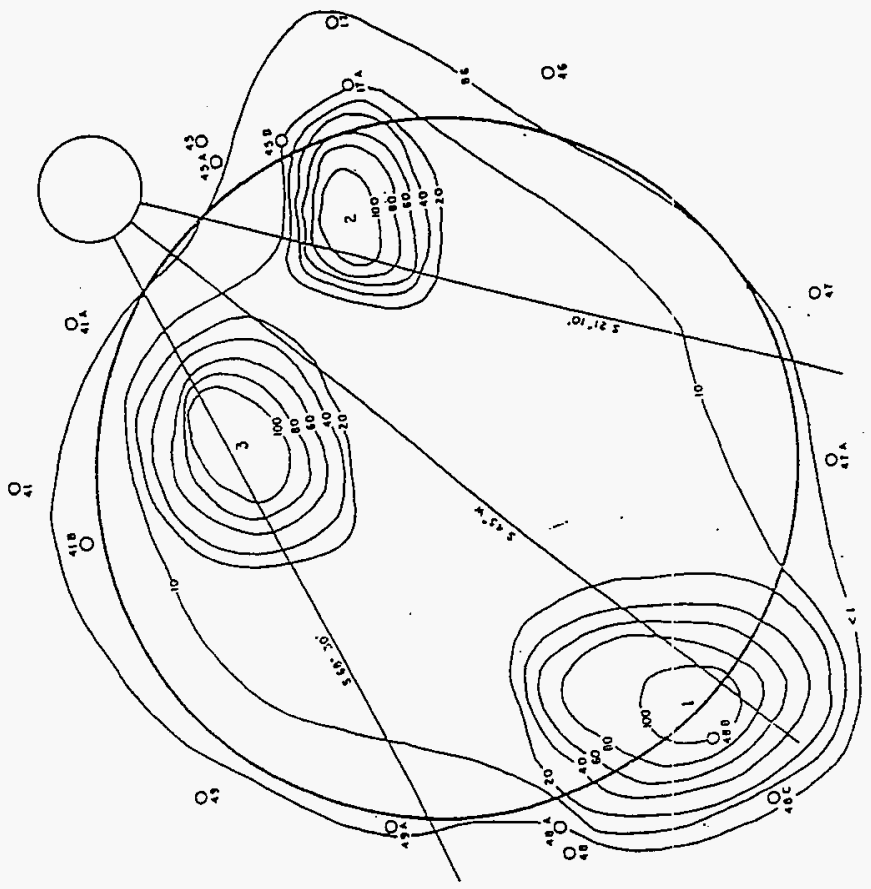




\subsection{TANK OPERATIONS}

The SX tanks were constructed during 1953 and 1954 and the tanks of immediate interest to the Expert Panel, 241-SX-108, -109, -111, and -112, apparently were filled during the last quarter 1955 and first quarter 1956. Leak detection and measurement of the magnitude of any leak was difficult. Measurements of liquid levels were crude, so the size of the tanks created a large uncertainty in volume estimates; a one inch change in level corresponds to a $2750 \mathrm{gal}$ change in volume. Tank levels were continually changing from evapiorative losses due to selfheating, additions of waste and/or cooling water, distortion of the liner base, sedimentation, formation of surface crusts, temperature changes from agitation of the waste liquid, and the physical action of agitators (air-lift circulators). Leak detection appears to have occurred mostly after the fact, when gross-gamma logs of the surrounding boreholes and especially of the underlying lateral casings (see Figures 2.12 through 2.14) showed increases of radioactivity in the surrounding soil. So, we surmise that all four tanks may have leaked soon after they were filled, even though confirmation of leakage generally was delayed for several years after the tanks were first filled. The documents provided to the Panel seem to show that a general lack of waste storage capacity may have influenced the decisions about leaks; tank TX-105-A continued to be filled even after an 8.5 - $\mathrm{ft}$ bulge of the line: base was identified [Beard et al, 1967].

The settling of solids is recorded [Brevick et al, 1994] as having occurred almost immediately after initial filling of tanks 241-SX-108, -111 and -112; tank 241-SX-109 has no such indication, but the reliability of not observing solids is questionable, especially considering the histories of the other eight high-heat tanks in the SX tank farm. Presence of solids appears to be an important factor in leak development. According to documents in Jo and Jones [1990], the exceptionally high heat-load generated by radionuclides incorporated into the precipitating solids is the prime source of thermal instability of the liquid wastes that led to buckling of the liner bases.

In the case of liner-base distortion, it appears that the settled heat-generating solids created temperatures in the grout/concrete/soil underlayment as high as $357^{\circ} \mathrm{F}$. The consensus of the reports furnished to us appears to be that the high-heat solids which settled on the base liner caused volatilization of free water in the underlayment and of light-organic compounds in the asphaltic coating. At the highest temperatures, even some of the hydrated concrete would be restructured to add to the vapor pressure beneath the liner. When the vapor pressure under the liner exceeded the hydrostatic head, the liner buckled upwards (Figures 2.5 through 2.8), presenting a convex base surface as opposed to the concave surface originally constructed. Here again, operational practices may have contributed. For example, pumping liquid out of the tank would have reduced the hydrostatic head, while the heat supply from the precipitated solids remained constant or increased. Deflection of the center of the base liner of as much as four feet in the SX tanks has been estimated, while the tank TX-105.A liner deformed upward 8.5 feet. Once the vapor pressure under the liner was released through fractured welds (Figure 2.10), liquids and solids could have flowed between the liner and the concrete base [Beard et al, 1967] only to be ejected into the surrounding formation sediments as waste and/or cooling 
water added to the tank increased the hydrostatic pressure. The ejected fluids would be superheated (perhaps 5 psig or more vapor pressure), possibly carrying a heat source (radioactive solids), into an already hot, dry soil. So the fluids would be expected to flash to steam and create even a greater overpressure in the formation.

Another mechanism which could result in the ejection of hot fluids, cnce the liner is breached, is that of non-uniform boiling which produced pressure/temperature excursions, or so-called "bumps". Early in 1955, a series of five to twenty-five abrupt pressure surges of about 30 seconds each occurred in tank 241-SX-101. Flow rates from steam condensers in the headers increased eighteen-fold. Periodic agitation of the liquid in 241-SX-101 with a hand-auger triggered bumping episodes, as did the addition of fresh waste. Similar circumstances prevailed in other tanks. Overpressure in the tank head space was as great as 50 inches of water. In order to reduce the possibility of bumping, air-lift circulators (ALC) were installed in the highheat tanks.

During August 1958, tank 241-SX-114 experienced a temperature excursion despite four ALCs operating at $10 \mathrm{cfm}$ each. Tank solids were found to be at $357^{\circ} \mathrm{F}$, so water was introduced at $15 \mathrm{gal} / \mathrm{min}$ to cool the solids. The tank bumped three times over the following weekend and steam escaped through the risers. This and other bumping tanks caused intermittent surface contamination as radioactivity entrained in the escaping steam was blown out the risers and deposited on the ground.

In the reports supplied to us, the action postulated as leading to bumps was that as the highheat solids settled out of the liquid phase, their temperature increased over time from a lack of sufficient liquid to dissipate heat by boiling. Eventually, the liquid at the solid-liquid interface exceeded the instantaneous vapor pressure and formed steam bubbles which rose, releasing 2.5 million to 5-million BTU/hr to the tank head-space. Bumps occurred over time periods of as little as a few minutes to as long as eight hours. The ALCs generally helped to reduce the frequency and magnitude of bumps, but, when the ALCs were turned on after being shut down, violent bumping often occurred as precipitated hot sediments were resuspended into the liquid phase.

So, both vapor disruption of the liner base and vapor bubbles rising from superheated tank liquids could have contributed to overpressures inside the tanks, to as much as the maximum measured value of 70 inches of water ( $2.5 \mathrm{psi})$. Tank overpressure would be puised and additive with the hydrostatic pressure at the tank base. Release or condensation of vapor under the liner, and subsequent collapse of the liner, may have acted as a frump to force superheated liquids and solids into the formation sediment. Steam bumps inside the tanks may have added to the pumping action as internal tank overpressures would have caused flexing of distorted liner bases. Increased hydrostatic pressure from added liquids could have forced superheated liquids and suspended solids trapped beneath the liner to escape to the formation sediments.

Deciding which of the mechanisms is likely to produce the greatest level of contamination is beyond the scope of this report. Sufficient for our purpose is the fact that disruption of the 
liner welds early during tank filling is likely to have occurred and plausible mechanisms exist which explain how superheated liquids could have been forced from the tanks into the formation sediments. Finally, the records show that the released fluids are dense (specific gravity approximately 2 ), hot (as much as $357^{\circ} \mathrm{F}$ ), overpressured (approximately $5 \mathrm{psig}$ ), highly basic $\left(0.5 \mathrm{M} \mathrm{NaOH}\right.$ or more), and highly saline $\left(10 \mathrm{M} \mathrm{Na}^{+}\right.$or more). Along with these extreme conditions, it is important to note that the powerful, episodis nature of the tank liner ruptures and pressure-driven surges may have resulted in occasional large liquid losses from the tanks over relatively short periods of time. This possibility should not be neglected in any future efforts to define current conditions, because it would probably tend to produce temporary saturated flow conditions and deeper penetration of contaminants through the vadose zone than would gradual seepage.

\subsection{DRYWELLS AND GAMMA LOGS}

The records we have reviewed, especially of tanks 241-SX-108, $-109,-111$, and -112 , suggest that although tank-volume measurements may have indicated that the high-heat tanks were likely to have leaked early after having first been filled, the volume ineasurements were considered insufficient to classify the tanks as anything more than "assumed" leakers. It was only after gross-gamma logs of drywells surrounding each tank, and of lateral casings beneath the high-heat tanks, showed unequivocally that contaminants had leaked to the formation sediments that tanks were reclassified as confirmed leakers, taken out of service, and emptied of liquids (most still contain some solids). For a decade or more (18 years for tank 241-SX111) the tanks were filled, pumped and refilled, all the while, they may have been ejecting contaminants to the formation sediments underlying the tanks.

The gross-gamma logs of drywells and laterals were obtained using a variety of detectors, which were not calibrated to produce quantitative estimates of contaminant concentrations in the formation sediments. Excessive levels of contamination were clearly identified by the gross-gamma logs, but the sensitivity for small contaminant concentrations was relatively poor. Also, radionuclide mixtures could not be differentiated. Furthermore, if most of the ejected contaminants flowed beneath the tanks [Raymond and Shdo, 1966], accurate vertical profiles would be difficult to measure from the vertical boreholes. Raymond. and Shdo estimated that they could account for only $60 \%$ of the contaminants released from tank $241-\mathrm{SX}-115$ as part of the total leak volume of 50,000 gallons.

\subsection{PANEL EVALUATION OF TANK LEAKS}

The Panel postulates that soon after filling, the dense, caustic, superheated liquid waste was ejected through openings at the base of each of the tanks 241-SX-103, $-109,-111$ and -112 into formation sediments and that leaks could have continued for several years afterward. Although the evaluation we have made is not exhaustive, the presentations ancl discussions during Panel meetings, as well as the referenced supporting documentation, indicate that this scenario is 
credible and consistent with current thought on the subject. It forms part of the basis for our judgments concerning the SX TANK FARM REPORT and the modeling calculations presented to the Panel. It also weighed into our considerations for the drilling of two investigative boreholes and recommendation to drill a slant or horizontal borehole beneath the SX tank farm. A request was made by the Panel for reports evaluating measurements of radioactivity in the lateral casings beneath the high-heat tanks. A screening by Hanford personnel of available databases did not uncover any titles other than that by Raymond and Shdo. There is brief mention in the SX TANK FARM REPORT (subsection 10.2.9) of an evaluation of grossgamma logging measurements beneath tank 241-SX-109, but neither: details nor references are provided.

The gross-gamma logs measured in the lateral casings beneath the high-heat tanks appear to be a valuable resource for evaluating both depth and direction of contaminant flow beneath and between tanks. Dates of interception of the laterals by the migrating front should be considered when developing conceptual models of contaminant transport, as should any record which can be found of lateral movement of observed contaminant fronts. If the lateral casings have been inserted into virgin sediments, perhaps insights can be gained about the existence of preferential pathways in the sediments by searching the data for ind:cations of "hot" zones, much as has been done with the gamma-logs collected in vertical casings.

The Panel recommends that the historic record of gross-gamma logs in the lateral casings be evaluated to determine the value of that data base toward developing, conceptual models for contaminant transport in the SX tank farm. 
This page intentionally left blank. 


\subsection{ASSESSMENT OF SX TANK FARM REPORT}

The borehole logging system used to identify and map ${ }^{137} \mathrm{Cs}$ below he SX tank farm is the SGLS, operated by MACTEC-ERS (formerly RUST Geotech). General information on spectral gamma-ray logging is given in Section 5 of the SX TANK FARM REPORT.

A review of the data-processing software was conducted and a report issued in 1994 [Stromswold, 1994]. This report recommends several minor enhancements to the software, but concludes: "The technical review has confirmed the appropriateness, correctness, completeness, and coding accuracy of algorithms used to process spectral gamma-ray data, leading to a calculation of subsurface radionuclide contaminants." If anyone disputes this conclusion, it has not come to the attention of the Panel. Another peer review is currently ongoing.

Two SGLS systems were built in 1993 for use at Hanford and an older system (the Radioelement Logging System, or RLS) has been in use there for some years. All three systems use a cryogenically-cooled, high-purity germanium detector systems in borehole sondes [Koizumi et al, 1994]. Pulses from a preamplifier in the downhole sonde are transmitted up a cable to laboratory-grade spectral resolution instrumentation in a logging truck, producing a 4096-channel energy spectrum.

The SGLS is calibrated and its accuracy verified using generally-accepted procedures and techniques. The calibration procedures for the earlier RLS and the SGLS are well documented [e.g., Brodeur et al, 1991; Koizumi et al, 1992; Koizumi, 1996]. The calibration is accomplished primarily using borehole calibration models located a: the DOE Grand Junction compound. These models were built mostly for use in uranium exploration and evaluation and are fairly well suited to the task of calibrating the SGLS. The models contain various amounts of the natural radioelements potassium, uranium, and thorium, along with uranium and thorium daughters. For radioactive contaminants like ${ }^{137} \mathrm{Cs}$, which is not present in the Grand Junction models, the system response is calibrated as a function of energy by interpolating among a dozen or so relatively prominent photopeaks, ranging from the combined $185.7 \mathrm{keV}$ peak of ${ }^{235} \mathrm{U}$ and $186 \mathrm{keV}$ peak of ${ }^{226} \mathrm{Ra}$ to the $2614.5 \mathrm{keV}$ peak of ${ }^{218} \mathrm{Tl}$ [Koizumi, 1996]. This is a simple and cost-effective approach that is sufficiently accurate considering the other uncertainties such as the distribution of radioactive material in the formation and borehole environment. Calibration measurements with the SGLS have also been made at the standard models used by the petroleum industry [Koizumi et al, 1991].

Calibrations used for the SX tank farm logs implicitly assume that contaminants are dispersed in the formation rather than representing borehole contamination. This limitation is discussed in the SX TANK FARM REPORT. At the request of the Panel, a point-source calibration (Figure 3.1a) was prepared by MACTEC-ERS to provide an indication of the magnitude of downhole contamination when it is encountered. Figure $3.1 \mathrm{~b}$ provides comparable countrates for dispersed sources; the maximum countrate limit of the SGLS (equivalent to approximately 


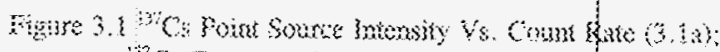

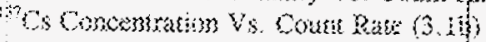

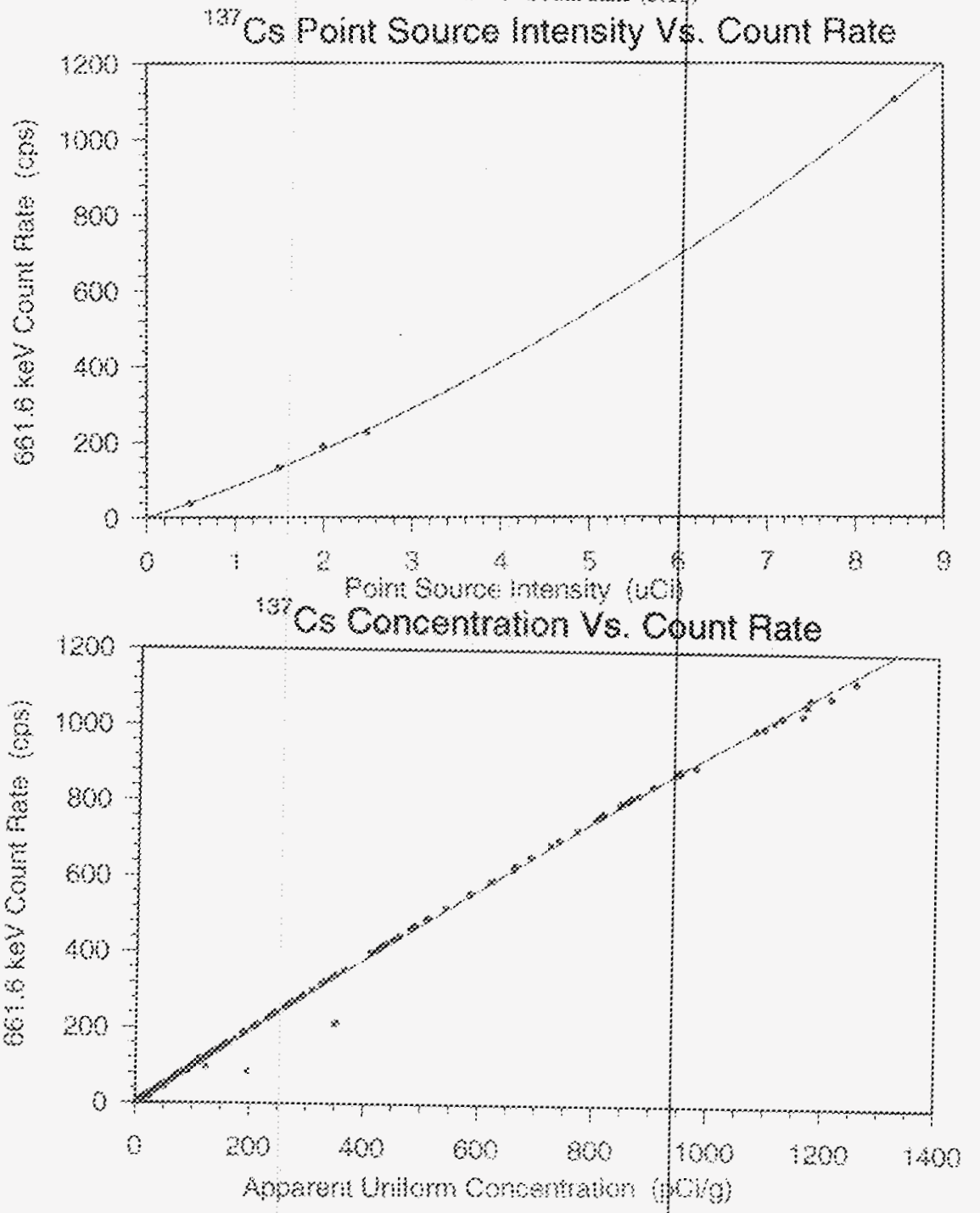




\section{8,000 to $12,000 \mathrm{pCi} / \mathrm{g}$ ) is achieved by a point source of only about $60 \mu \mathrm{Ci}$.}

Secondary calibration and verification of functionality of the SGLS take place using calibration models at Hanford. These doped-concrete models were also initially used for uranium logging in the NURE program, located at Spokane, Washington, and were later moved and installed at the Hanford site specifically for use in calibrating the SGLS [Koizuni, 1996].

Field procedures with the SGLS system appear to be consistent with accepted practice. System functionality is verified in the field, before and after logging each borehole, using a portable field check source [Koizumi, 1996]. Typically, data are accumulated for $100 \mathrm{~s}$ at each sample point in the borehole, usually at one-half foot intervals. The extraciion of ${ }^{137} \mathrm{Cs}$ concentration data is based on an analysis of the recorded gamma-ray energy spectra. The spectra are analyzed to identify the $661 \mathrm{keV}$ photopeak diagnostic of ${ }^{137} \mathrm{Cs}$, if present, and to determine the photopeak countrate (since the photopeak extends over several spectral channels, the countrates in those channels are summed to give the photopeak countrate). That peak countrate is corrected for background and for borehole conditions that differ from the instrument calibration conditions, such as different casing thickness. The corrected photopeak countrate is converted to a concentration value. This last step is sensitive to the calibration limitations described above.

The geostatistical analysis presented in the SX TANK FARM REPCRT is consistent with current professional practice. The geostatistical model is used to generate visualizations suggesting massive transport of ${ }^{137} \mathrm{Cs}$ in large, balloon-shaped contamination zones around and below some of the tanks (Figure 1.1). This interpretation is presented with suitable caveats concerning the conceptual assumptions that underlie the analysis. Flowever, we consider this contaminant transport scenario unlikely although the underlying assimptions were properly explained in the report. A more likely contaminant transport scenario would involve preferential flow paths through the formation. This is considered further in the following section. 
This page intentionally left blank. 


\subsection{TRANSPORT AND DEPOSITION OF CONTAMINANTS}

\subsection{OVERVIEW}

The Panel was convened because available evidence did little to resolve whether the movement of ${ }^{137} \mathrm{Cs}$ indicated by the SGLS logs in the SX tank farm was largely along formation pathways or down boreholes. Any of the ${ }^{137} \mathrm{Cs}$ concentration logs presented in the SX TANK FARM REPORT could be produced either by contaminants distributed in the formation or by contaminants that moved along the outside surface of the casing during or after the drilling.

The possibility of borehole transport in particular cases must not be allowed to divert attention from the broader issue of formation transport. By the close of the second Panel meeting (July $16-17,1996)$, it was the Panel's unanimous view that it is entirely flausible that ${ }^{137} \mathrm{Cs}$ could travel along preferential formation pathways to the depths observed on the SGLS logs, and probably beyond (see meeting Consensus Summary and Recommeniations in Section 6.2 of this report). Such preferential pathways could include discontinuities such as clastic dikes or more subtle variations in formation properties that could concentrat: the flow. Furthermore, the combination of high temperature, $\mathrm{pH}$, sodium-ion concentration and density of fluid exiting the tanks could enhance pollutant transport along such pathways by forcing the fluid down openings, enhancing openings by dissolution of siliceous material and occupying exchange sites. Especially likely to be affected are the fine-grained materials commonly associated with ${ }^{137} \mathrm{Cs}$ fixation in soils.

The validity of the MACTEC-ERS visualizations depends on the validity of the spatial structure of the geostatistical model. Although there are a relatively large number of logged boreholes in the SX tank farm, there are too few closely-spaced boreholes for resolving small scale changes in Cs distribution. Thus, the visualizations show Cs widely distributed throughout large regions of the SX tank farm. This seems unlikely considering the inhomogeneities of soil structure and porosity present in the formation. While the concept of large, homogenous pockets of contaminant moving more or less uniformly through the formation is unlikely, the more likely alternative of contaminant transport along preferential formation pathways also can be a threat to groundwater.

As a counter-argument to the visualizations of ${ }^{137} \mathrm{Cs}$ distribution shcwn in the SX TANK FARM REPORT, contaminant transport simulations were presented to the Vadose Zone Expert Panel at the second Panel meeting by Pacific Northwest National Liaboratories (PNNL) personnel. At that meeting, the PNNL modelers insisted that ${ }^{137} \mathrm{Cs}$ could not have moved several tens of feet down through the formation as implied by the SGLS logs, using their simulations to support that view. Their interpretation of the SGLS logs was that all of the ${ }^{137} \mathrm{Cs}$ at depth was borehole contamination. However, the model pirameters used by PNNL were unrealistic, including source terms, initial conditions, and probable transport mechanisms, and the approach was not consistent with current research indicating the likelihood of preferential flow in unsaturated media. 
Like the geostatistical model, the PNNL contaminant transport simulations presented to the Panel also depend heavily on a simplistic conceptual model where large quantities of sorbing contaminant can only be transported short distances in essentially a lirge chromatographic column in which formation heterogeneities are treated in the aggregate as a more or less uniform soil. The solute retardation coefficients were based on empirical evidence, but not for conditions representative of leaks from the SX tanks. The only allowed alternative to ${ }^{137} \mathrm{Cs}$ transport through this "average" soil column is that of migration along the void between borehole casing and the formation, an alternative in which a small quantity of ${ }^{137} \mathrm{Cs}$ can produce a relatively high gamma count rate in the spectral logging system (see Figure 3.1). The potential for large quantities of ${ }^{137} \mathrm{Cs}$ and other contaminants to the transported along preferential formation pathways appears to have been ignored. Also ignored is the likelihood that chemical reactions involving the hot, saline, caustic brine exiting a tank may drastically alter the interactions between ${ }^{137} \mathrm{Cs}$ and binding sites on the soil partisles. Finally, colloidassisted transport of ${ }^{137} \mathrm{Cs}$ through formation soils or preferential pathways has been ignored.

After the Panel pointed out those deficiencies, the input parameters were revised by PNNL. The new simulations showed the ${ }^{137} \mathrm{Cs}$ much deeper in the formation, demonstrating that the transport simulations were biased according to the input data and unclerlying assumptions selected for the simulation program. This implies that any simulation models using similar assumptions for contaminant transport could be equally deficient. For example, the recently issued Environmental Impact Statement (EIS) for TWRS may be based on equally unrealistic parameters and assumptions.

Thus, the Panel finds it necessary to discuss in some detail the deficiencies of the conventional conceptual models presented to it as alternatives to the findings presented in the SX TANK FARM REPORT.

\subsubsection{Source Term}

The soil column was used to retain low-concentration contaminants in liquid effluents by dispersal principally into cribs: 216-S-1/2, 216-S-8, 216-S-21 and 216-S-25 (Figure 4.1) with total transfer volumes of approximately $4 \times 10^{7}, 3 \times 10^{6}, 2 \times 10^{7}$, ancl $8 \times 10^{7}$ gallons, respectively. In addition to the known leaking tanks in SX Farm (Table 4.1) contaminants in the vadose zone below the SX tank farm were suggested to have been contributed principally from several of these cribs. Although other cribs in the area were also used for liquid waste disposal, they are not believed to have contributed to the vadose zone beneath the SX tank farm, because measured hydraulic gradients in the area indicate flow away from the SX tank area. U-Pond, several hundred feet northwest of crib 216-S-21 also appears to be downgradient $\left(10^{10}\right.$ gallons of low-concentration liquid waste dumped there). 


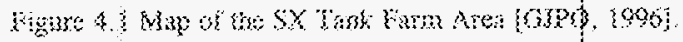
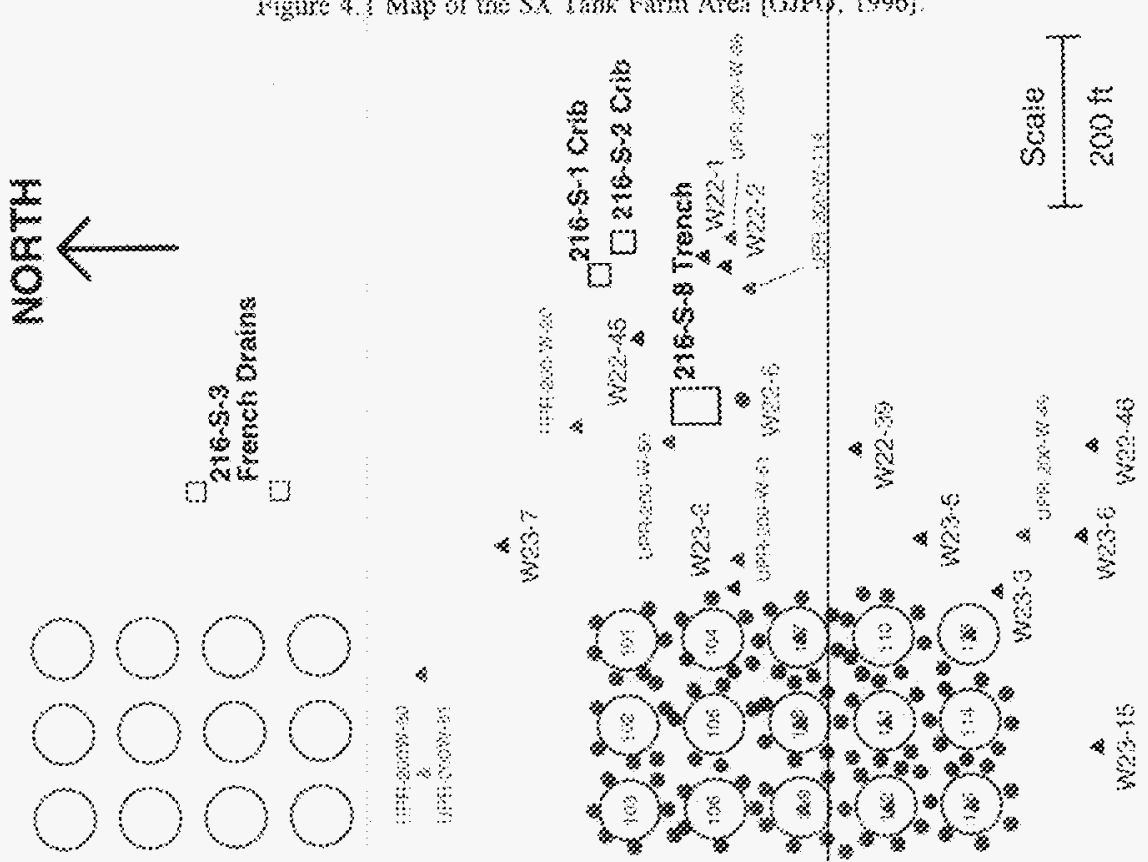

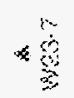

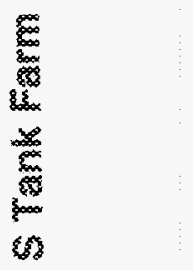

:

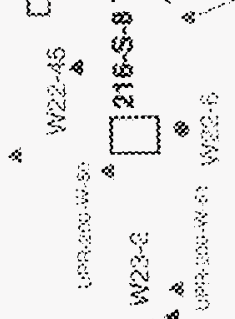

$8 \hat{y}$
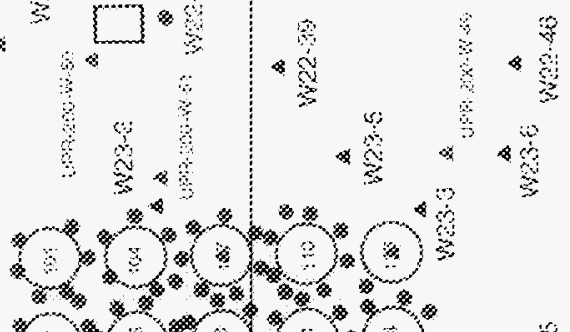

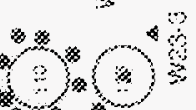

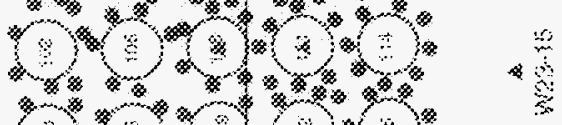

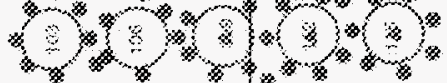

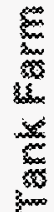

$\stackrel{3}{3}$

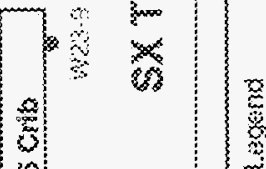

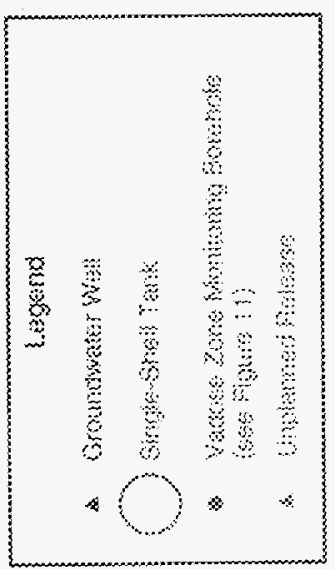


Table 4.1 Current Status of the SX Tanks [Caggiano, 1996 (Appendix G)].

\begin{tabular}{|c|c|c|c|c|c|}
\hline Tank & $\begin{array}{c}\text { Brevick } \\
\text { [1995] } \\
\text { Designation } \\
\text { and Date of } \\
\text { Leak }\end{array}$ & $\begin{array}{c}\text { GJPO [1996] } \\
\text { Designation }\end{array}$ & $\begin{array}{c}\text { Drainable } \\
\text { Liquid in } \\
\text { Tank } \\
\text { Today } \\
\text { (Gallons) }\end{array}$ & $\begin{array}{c}\text { Brevick } \\
\text { [1995] } \\
\text { Estimated } \\
\text { Leak } \\
\text { (Gallons) }\end{array}$ & $\begin{array}{c}\text { GJPO [1996] } \\
\text { Estimated } \\
\text { Leak } \\
\text { (Gallons) }\end{array}$ \\
\hline SX-101 & sound & sound & 146000 & & \\
\hline SX-102 & sound & leaker & 183000 & & \\
\hline SX-103 & sound & unsure & 223000 & & \\
\hline SX-104 & leak, 1988 & unsure & 201000 & 6000 & \\
\hline SX-105 & sound & sound & 261000 & & \\
\hline SX-106 & sound & sound & 233000 & & \\
\hline SX-107 & leak, 1964 & leaker & 0 & $<5000$ & \\
\hline SX-108 & leak, 1962 & leaker & 0 & 2400 to & \\
\hline SX-109 & leak, 1965 & leaker & 0 & $<10000$ & 250000 \\
\hline SX-110 & leak, 1976 & sound & 0 & 5500 & \\
\hline SX-111 & leak, 1974 & leaker & 0 & 500 to 2000 & \\
\hline SX-112 & leak, 1969 & leaker & 0 & 30000 & \\
\hline SX-113 & leak, 1958 & leaker & 0 & 15000 & \\
\hline SX-114 & leak, 1972 & leaker & 0 & 8000 & \\
\hline SX-115 & leak, 1965 & leaker & 0 & 50000 & \\
\hline
\end{tabular}


The principal radioactive contaminant from the cribs to reach the groundwater monitoring wells around the SX tank farm appears to be tritium $\left({ }^{3} \mathrm{H}\right)$ in the form of tritiated water (represented as HTO in this report). Since ${ }^{3} \mathrm{H}$ is bound in water molecules, it is expected to be as mobile as any water in the formation. HTO concentration in groundwater monitoring wells has exceeded the drinking water maximum contaminant level (MCL) of $20,000 \mathrm{pCi} / \mathrm{L}$ by more than tenfold.

Another relatively mobile contaminant, uranium (U), is present in the groundwater, partly from naturally occurring sources and partly from waste transfers to cribs and leaking tanks. The Panel has not been provided specific concentration values for uranium in the SX area groundwater monitoring wells. Yet another mobile radioelement, ${ }^{99} \mathrm{Tc}$ (probably as pertechnetate anion), also has been intercepted by the SX tank farm groundwater monitoring wells (Figure 4.2) with concentrations in wells 299-W23-7, 299-W23-2, and 299-W23-15 having exceeded the $\mathrm{MCL}$ of $900 \mathrm{pCi} / \mathrm{L}$ for ${ }^{99} \mathrm{Tc}$ (Figure 4.2).

At the Panel's first meeting, staff from the State of Washington Department of Ecology presented ${ }^{99} \mathrm{Tc} / \mathrm{U}$ and $\mathrm{HTO} /{ }^{99} \mathrm{Tc}$ concentration ratios (Figure 4.3) which they interpret as an indication that ${ }^{99} \mathrm{Tc}$ in the groundwater below the SX tank farm is contributed primarily by sources differing from those that contribute to the HTO and U plumes. They conclude that ${ }^{99} \mathrm{Tc}$ is from leaking tanks in the S/SX tank farms, and not from cribs.

The Ecology presentation drew attention to the need for a more extersive effort to characterize contaminant migration in the vadose zone. If ${ }^{99} \mathrm{Tc}$ in the groundwater is from the $\mathrm{S}$ or $\mathrm{SX}$ tanks, where are the other contaminants that should be associated with tank leaks; i.e., ${ }^{129} I, U$, ${ }^{3} \mathrm{H}$, ${ }^{90} \mathrm{Sr}$, and mobile actinides? What is the source and migration pathway of ${ }^{137} \mathrm{Cs}$ in well 299W23-7? These are important issues for evaluation of the hazards crested by leaked contaminants.

\subsubsection{Driving Mechanisms}

Water that carried the vadose zone (and groundwater) contaminants out of the leaking tanks, and possibly water from the surrounding cribs, trenches and ponds, s one obvious driver for contaminant migration in the vadose zone. Water-budget simulations presented by PNNL personnel suggest that water from natural recharge is likely to be a nuch more significant contaminant driver than believed in the past. Estimates of drainage :ates up to $10 \mathrm{~cm} / \mathrm{yr}$ [Gee et al, 1992] have been confirmed in lysimeter tests. Enhanced flow down tank walls from precipitation draining off tank domes may also serve to increase migration of contaminants away from the leak location (see Figure 4.4). With some $50 \%$ of the surface area of the SX tank farm located above tank domes, the resulting concentrated precipitation-driven drainage immediately below the tank walls may prove to be an important driving mechanism. 
Figure 4.2 ${ }^{99} \mathrm{Tc}$ Concentrations in Groundwater Monitoring Wells [Thompson, 1996].

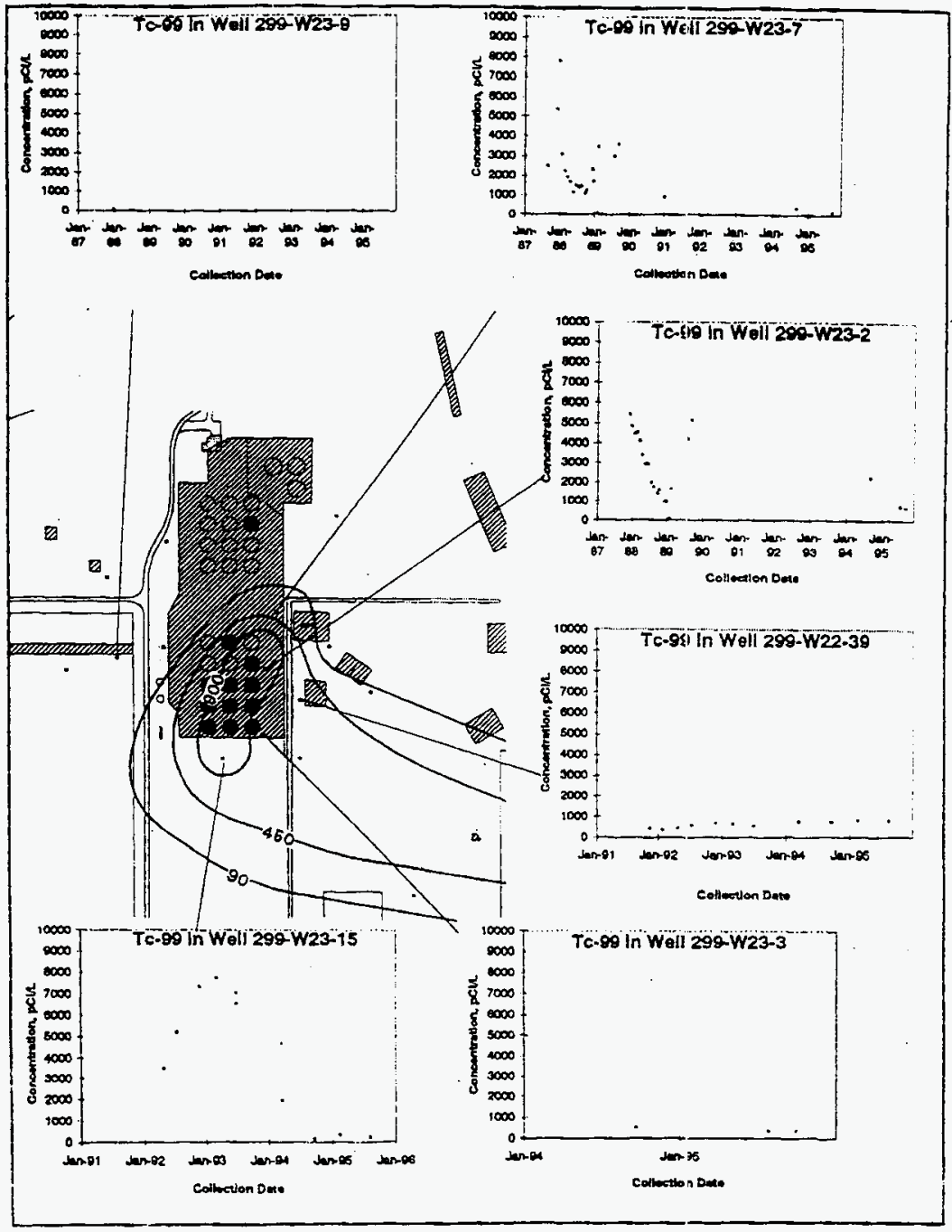


Figure 4.3 Technetium/Uranium Ratio in Groundwater Near the S-SX Waste Managment Area [Caggiano, 1996].

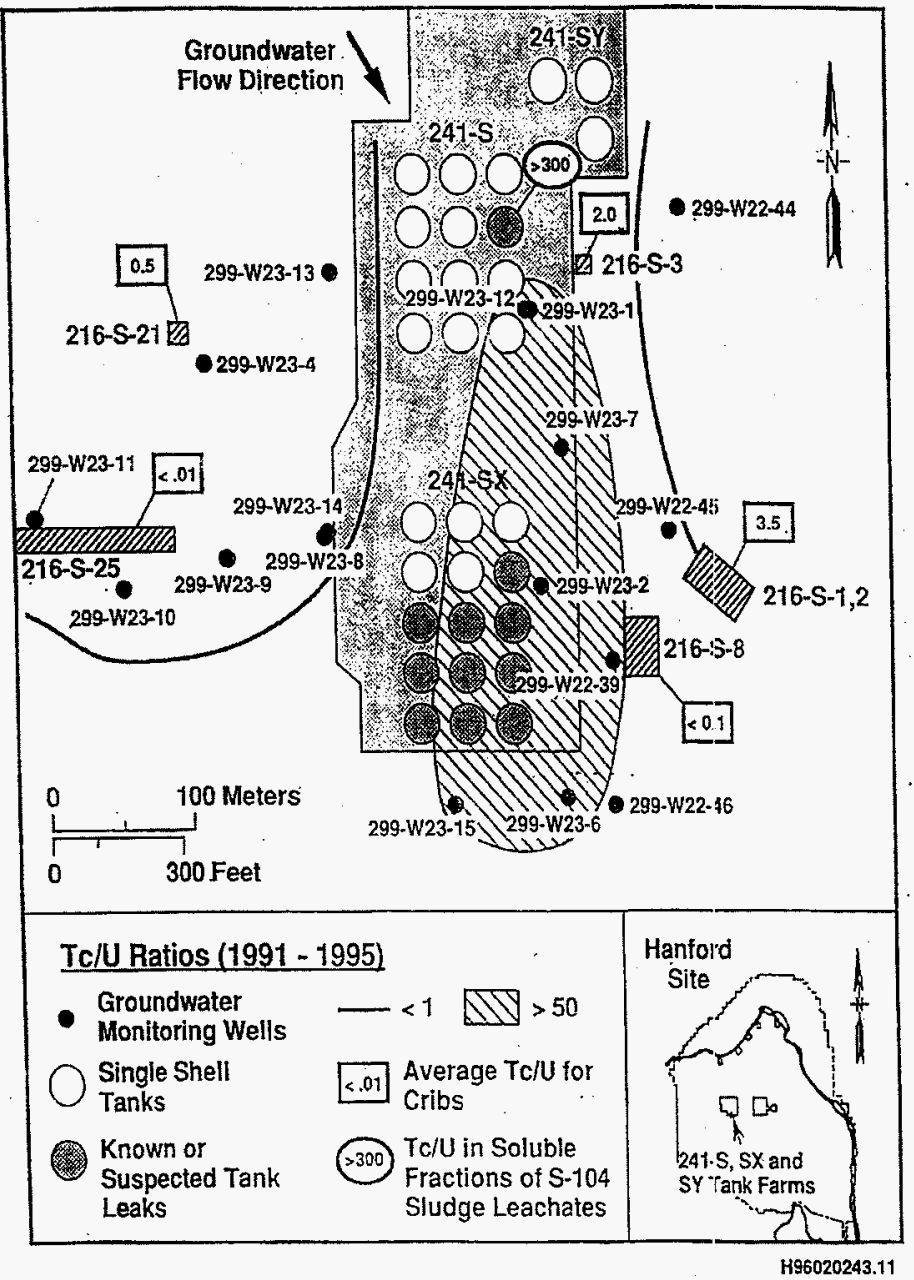




\section{Hypothetical Sources and Potential Pathways to Groundwater in the S-SX Waste Management Area}

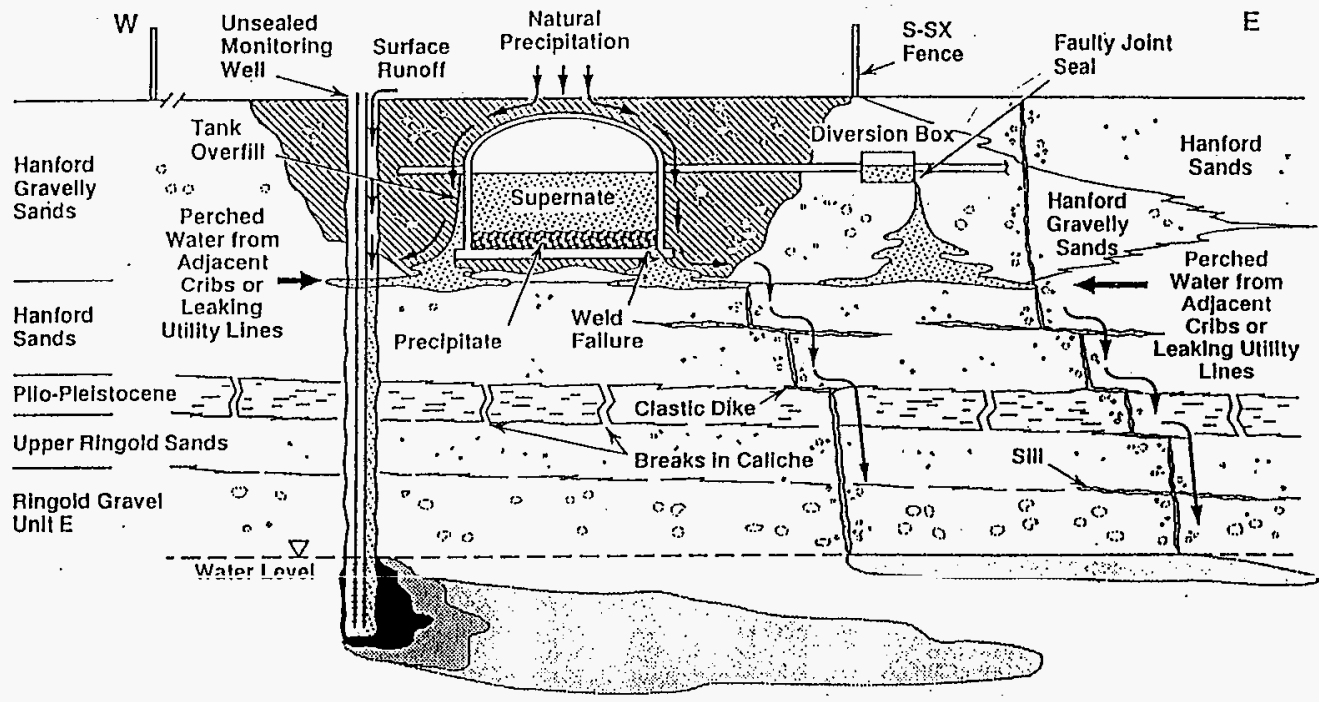

${ }^{137} \mathrm{Cs}$ Backill ${ }^{90} \mathrm{Sr}$ Mobile Constituents in Tank Waste, ${ }^{3} \mathrm{H}, \mathrm{Na}^{+}, \mathrm{TCO}_{4} ; \mathrm{UO}_{2}\left(\mathrm{CO}_{3}\right)_{3}=\mathrm{CrO}_{4}=$ 궁 High Level Wasle Supernate or Liquid Phase

Wor. Solids Phase of High Level Wasie $\left(\mathrm{Fe}(\mathrm{OH})_{3}\right.$, etc. - Natural Preclpitation and Movement Along Culturally Dlsturbed and Natural Palhways and Other Preclpitated Phases) Surface Runoff and Artificial Sources of Water 
A potentially important driving mechanism that the panel has not seen in any model of contaminant migration in the vadose zone is that of an overpressure caused by superheated water flashing to steam on contact with heated soil. Such overpressure may drive liquids and contaminants through fractures and other low-impedance pathways in the formation. The SX tanks were filled with high-heat generating wastes, apparently sufficient to raise bottom liquids, tank bases and surrounding soils to $357^{\circ} \mathrm{F}$ and possibly higier. When the tank bottoms and walls buckled, breaking welds, the superheated brine would be expected to flash to steam. The resulting steam pressure may have forced hot brine far into the formation. This driving mechanism should be evaluated further for its importance relative to the other driving mechanisms.

\subsection{FORMATION PATHWAYS}

\subsubsection{Conventional Conceptual Models}

The conceptual contaminant sources and transport pathways to groundwater are depicted in Figure 4.4, which was presented at Panel meetings; similar figures are presented in the TWRS EIS and the other reports. The similarities of the figures lead us to conclude that contaminant transport in the Hanford vadose zone is calculated using much the same conventional concepts regardless of the specific algorithms adopted to solve the generalized mass transport equation. Descriptions of the VAM2D model [DOE, 1996] support that conclusion. The STOMP model includes sophisticated multi-phase transport modeling capability, but. until recently, the Panel saw only simplistic use of STOMP in the vadose zone work. Recent STOMP calculations [Ward et al, 1997] are somewhat more realistic, but still do not adequately represent vadose zone conditions. This is considered further in Section 4.2.7.

A key consideration by those opposed to the MACTEC-ERS interpretation is their contention that ${ }^{137} \mathrm{Cs}$ is highly sorbed on sediments under all conditions. A critical parameter for calculating how rapidly and how far ${ }^{137} \mathrm{Cs}$ or other contaminants might be transported is the activity or mass distribution coefficient, $K_{d}$, because of its relation to the retardation coefficient, $R_{d}$, in the general mass transport equation. $K_{d}$ (units of $\mathrm{mL} / \mathrm{g}$ ) is the quantity of radionuclide sorbed by a solid per unit weight of the solid divided by the concentration of the radionuclide dissolved in water; i.e., $\mathrm{pCi} / \mathrm{g} \div \mathrm{pCi} / \mathrm{mL}=\mathrm{mL} / \mathrm{g}$; an equivalent calculation in mass units applies for non-radioactive contaminants. It is an empirical value, usually determined in the laboratory under conditions presumed to represent those for which the model calculation is being performed. Typical $\mathrm{K}_{\mathrm{d}}$ values for ${ }^{137} \mathrm{Cs}$ in Hanford sediments were reported to the Panel as ranging to a few thousand $\mathrm{mL} / \mathrm{g}$, with the conditions at the $\mathrm{SX}$ tank farm likely to result in values from 0.5 to $20 \mathrm{~mL} / \mathrm{g}$. 
$R_{d}$ represents the degree to which a solute will be retarded relative to the migrating solvent and; is related to $K_{d}$ by

$$
R_{d}=\frac{n}{n_{e}}+\frac{\rho_{b}}{n_{e}} K_{d},
$$

where $\mathrm{n}$ is total porosity, $\mathrm{n}_{\mathrm{e}}$ is effective porosity, and $\rho_{\mathrm{b}}$ is bulk density $\left(\mathrm{g} / \mathrm{cm}^{3}\right)$ [Till and Meyer, 1983].

Assuming $\mathrm{n}_{e}=\mathrm{n}$, equation 4.1 can be approximated as

$$
R_{d}=1+\frac{\rho_{b}}{n_{e}} K_{d}
$$

Only those contaminants or conditions that result in $\mathrm{K}_{\mathrm{d}}$ values approaching zero will produce solute transport times approaching that of the transport medium. For saturated formations at Hanford, $\rho_{b} / n_{e}$ typically is between 4 and 7 , and for unsaturated formations may be as much as eight-fold greater due to low $n_{e}$ values. Thus, the effect of the selected $K_{d}$ value on calculated contaminant transport time is magnified in the vadose zone.

The effect of even relatively small values of $K_{d}$ is exemplified in the transport simulations performed for the TWRS EIS, where a $\mathrm{K}_{d}$ of $50 \mathrm{~mL} / \mathrm{g}$ was selected for ${ }^{137} \mathrm{Cs}$. The results exemplified in Figures 4.5 and 4.6 show time of first arrival at the groundwater surface as 150 years and 1200 years for $K_{d}=0$ and $K_{d}=1$, respectively, in the 2WSS area. The corresponding peak arrival times are 260 years and 1980 years, and the maximum concentration at the longer time is reduced nearly threefold from that at the shorter, presumably by dispersion and by sorbtive losses to the soil column. The vadose zone results produce a concomitant effect on the groundwater model results becalse they serve as input to the groundwater model calculations (Figure 4.7).

A comparable set of assumptions for simulations using the STOMP model was presented to the Panel. At the first Panel meeting, $K_{d}$ values of 2 to $6 \mathrm{~mL} / \mathrm{g}$ for ${ }^{137} \mathrm{Cs}$ and $R_{d}$ of 30 to 100 were justified by the presenters as conservative despite the fact that experimental conditions are not representative of those likely for SX tank leaks. In response to the Panel's suggestions that their selected values were not representative, the modelers produced for the second meeting a set of calculations using $K_{d}$ values of 0.5 and $3 \mathrm{~mL} / g$ and $R_{d}$ approximately 20 . This second set was also considered by the Panel to be unsatisfactory, because the change in $K_{\mathbf{r}}$ values produced only trivial changes in ${ }^{137} \mathrm{Cs}$ transport times, while still failing to account for chemical, thermal and physical effects identified by the Panel as potentially influencing contaminant transport in the vadose zone beneath the SX tanks. 


\subsection{2 ${ }^{137} \mathrm{Cs}$ Transport Under High Temperature and High pH Flow Conditions}

Leakage of hot alkaline slurry produced by REDOX wastes into the Hanford formation is likely to dissolve silica and silicate minerals. The solubility of silica and silicates reaches a minimum at $\mathrm{pH} 6$ to $\mathrm{pH} 7$ and increases exponentially with both decreasing and increasing $\mathrm{pH}$ (Figure 4.8); in the case of the REDOX waste, the high-pH data are relevant.

At the SX tank farm, the original source may have been a hot, caustic, saline solution, initially 8 to 10 molar sodium at $350^{\circ} \mathrm{F}$ or more, leaking into a hot formation, and including self heating by the radionuclides leaking into the formation. Add to that scenario the possibility of superheated tank liquid flashing into steam as it enters the unsaturated formation at lower static pressure, and all of the conditions seem to be present for artificial stimulation and enhanced flow at least somewhat analogous to petroleum industry practice for artificial stimulation of petroleum reservoirs. In cases where petroleum in reservoirs cannot be produced economically because of low permeability conditions, various combinations of high pressure, high temperature, and forced injection of corrosive materials are used to enlarge existing pores and fractures or induce artificial fracturing. Petroleum engineering departments at universities or major oil companies could be consulted to determine if computer sirnulation codes developed for modeling artificial stimulation procedures might be applied to the SX tank farm environment during the period of active leakage to provide definition of current conditions.

The extreme conditions described above also suggest the possibility of localized geothermal convection systems driven by heat and steam from the tanks and by leaking self-heating fluids. Such a system may drive contamination upward through the formation in addition to the downward migration already considered. Geochemists familiar with geothermal areas may be able to provide valuable insights on the effects and reaction rates of hot alkaline slurry in the Hanford geologic environment. 


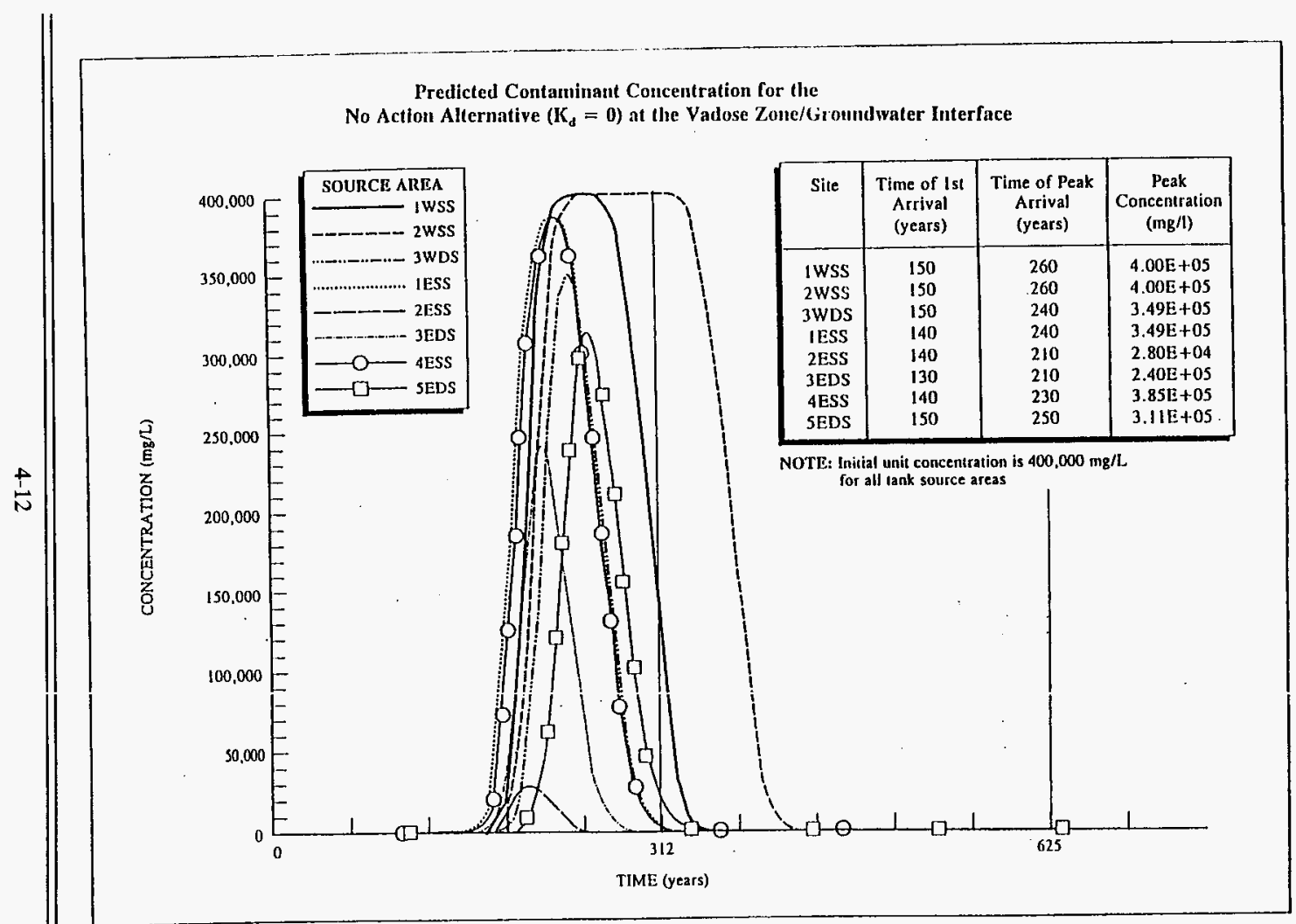


Figure 4.6 Predicted Contaminant Concentration for the No Action Alternative $\left(\mathrm{K}_{\mathrm{d}}=1\right)$ at the Vadose Zone/Groundwater Interfaces [DOE, 1996].

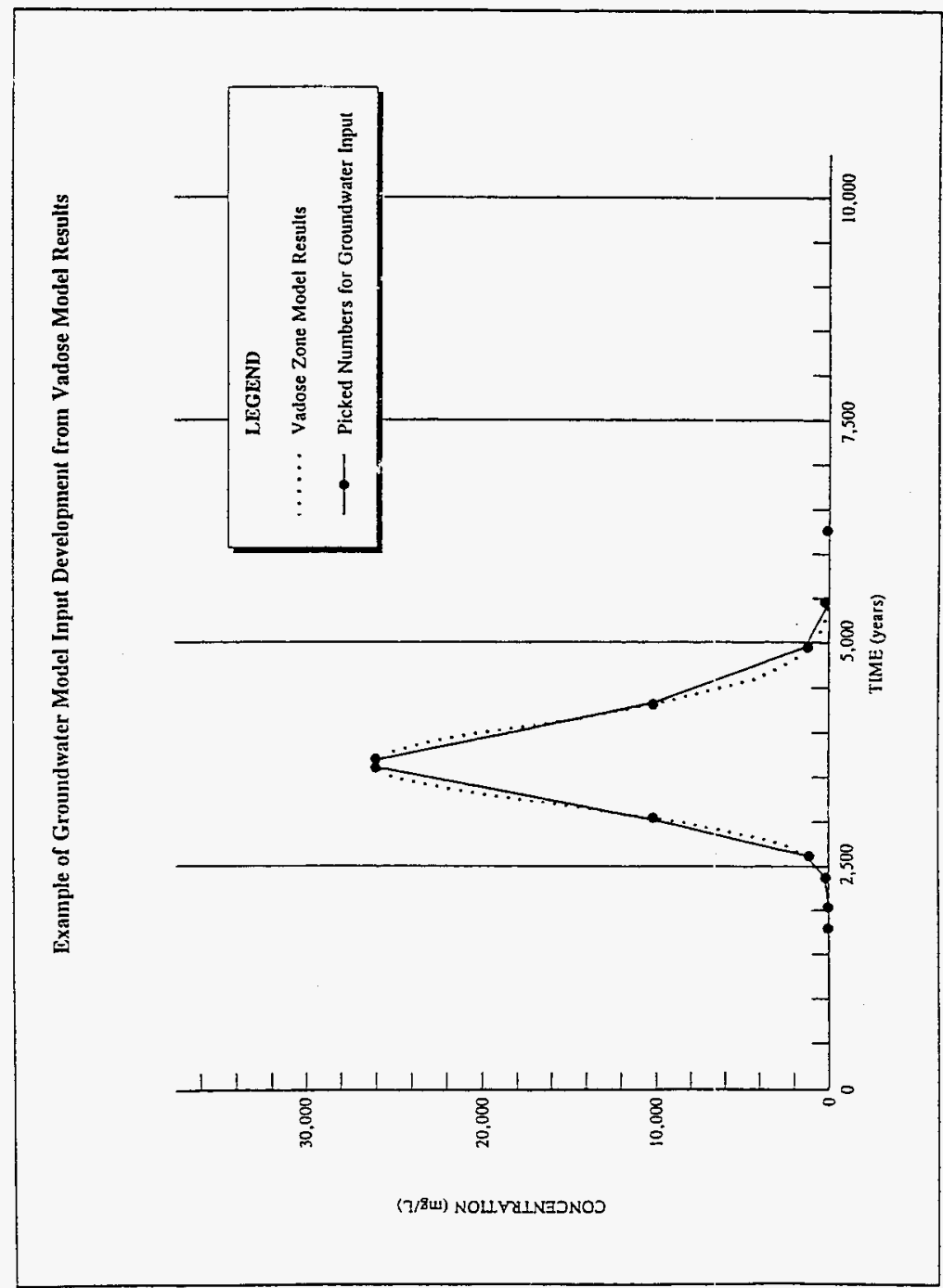


Figure 4.7 Example of Groundwater Model Input Development from Vadose Model Results [DOE, 1996].

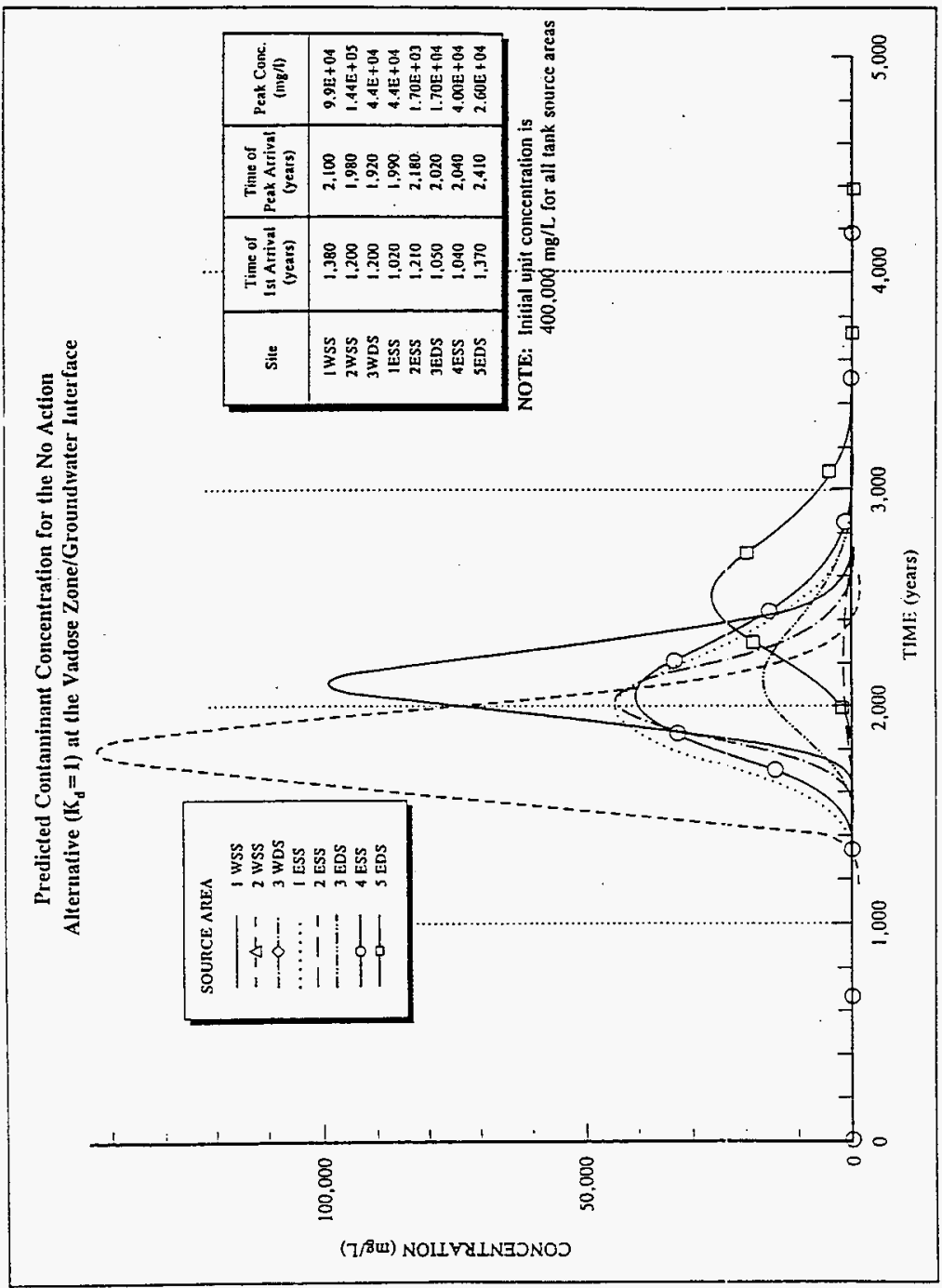




\subsubsection{Analogy with Corrosion of Glass}

For canistered, vitrified high level waste, the fraction, F, of glass that would corrode per year is given by:

$$
F=\frac{R A}{W}
$$

where $\mathbf{R}$ is the glass corrosion rate $\left(\mathrm{gm}^{-2} \mathrm{y}^{-1}\right), \mathrm{W}$ is weight of glass in a canister, and $\mathrm{A}$ is the surface area $\left(\mathrm{m}^{2}\right)$ of glass exposed to water [DOE, 1995]. Equation 4.3 can equally be applied to dissolution of soil contaminated by leaking tank wastes, if appropriate values for $R, A$ and W can be established.

Estimates of W and A can be established from straightforward geoplyysical logging methods coupled (in the case of $\mathrm{W}$ ) to some estimate of the affected volume of soil, using either the MACTEC-ERS geostatistical method or a contaminant transport simulation method. Values for $R$, however, depend on a number of experimental conditions, which in turn provide some insights into mechanisms which the Panel believes to have been inadequately considered by those performing the transport simulations at Hanford.

Research on the effects of temperature, hydroxide ion and salt concentrations, and vapor-phase attack of silicate glasses [Cunnane et al, 1994] may also provide valuable insights into the concepts necessary to develop models that more closely represent the dissolution processes that can develop when leaking corrosive wastes contact formation soils (compare Figures 4.8 and 4.9). With the large amounts of hydroxide ion (high $\mathrm{pH}$ ) present even when the leaking brines are diluted somewhat by infiltrating precipitation, hydrolysis and dissolution of silicate glassforming structure will dominate (equations 4 and 6 in Table 4.2). Increasing the $\mathrm{pH}$ of the reacting solution from approximately 6 or 7 to 14 increases the glass dissolution rate at a given temperature by a factor of roughly $10^{4}$ (Figure 4.2 ) and for albite by roughly $10^{3}$. Increasing temperature by $80^{\circ} \mathrm{F}$ to $90^{\circ} \mathrm{F}$ at constant $\mathrm{pH}$ increases the glass dissolution rate by a factor of roughly 100 (Figure 4.9 ).

The temperature logs for SX tank farm boreholes place current conditions in zones with high concentrations of ${ }^{137} \mathrm{Cs}$ at approximately those of the $50^{\circ} \mathrm{C}$ data line, probably still at an elevated $\mathrm{pH}$. When considered in the context of the large surface area of soil particles available for dissolution within the leak-contaminated zones under the SX tanks, large quantities of soil silica and silicate materials were dissolved in those zones, with dissolution of the smaller particles (most sorbing) favored over dissolution of the larger particles. Research into mechanisms which dissolve waste and other glasses in warm, unsaturated environments [Cunnane et al, 1994] suggest that dissolution of siliceous sediments is continuing even now.

The dissolution rate, $\mathbf{F}$, whether as grams, mole or fraction of glass or some constituent per unit of time, is normalized on the total surface area of the glass or other silicate material 
Figure 4.8 Rate of Dissolution of Albite as a Functior. of $\mathrm{pH}$ (after [Wollast and Chou, 1985]) [Drever, 1988].

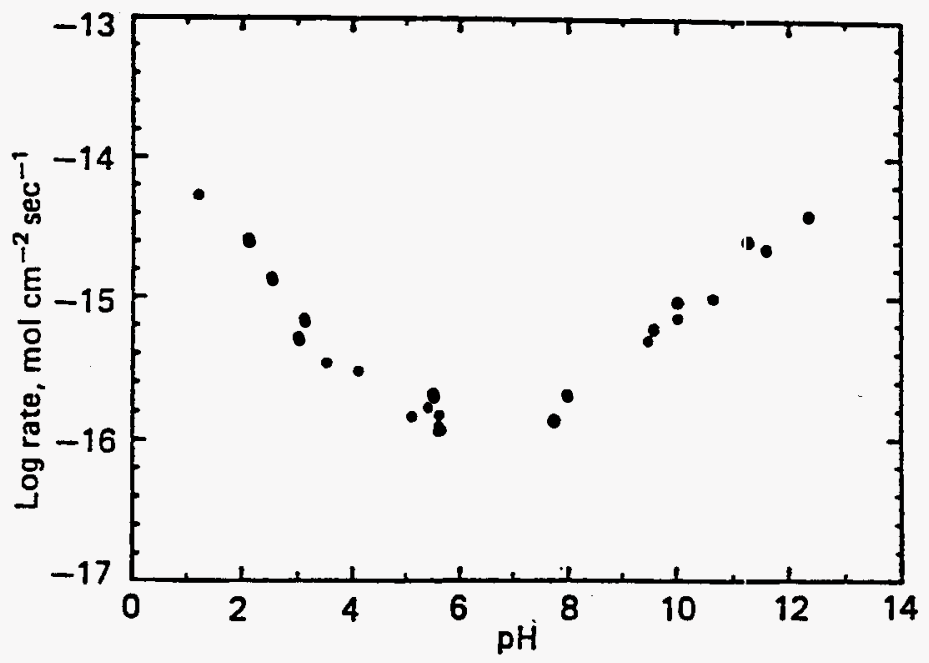


Figure 4.9 Rate Constant for SRL 165 Simple Analog Glass (SRL-165SA) vs. pH at 25, 50, and $70^{\circ} \mathrm{C}$ Measured in Flow-Through Apparans.

Under these conditions, no secondary phases form and release rate cre maximum values (adapted from [KNAUSS-1990]). SRL-165A glass composition is $\mathrm{SiO}_{2}=55.7, \mathrm{Al}_{2} \mathrm{O}_{3}=11.7$, $\mathrm{B}_{2} \mathrm{O}_{3}=8.4, \mathrm{Na}_{2} \mathrm{O}=18.2, \mathrm{CaO}=6.0$ wt. \% [Cunnane et al, 1994].

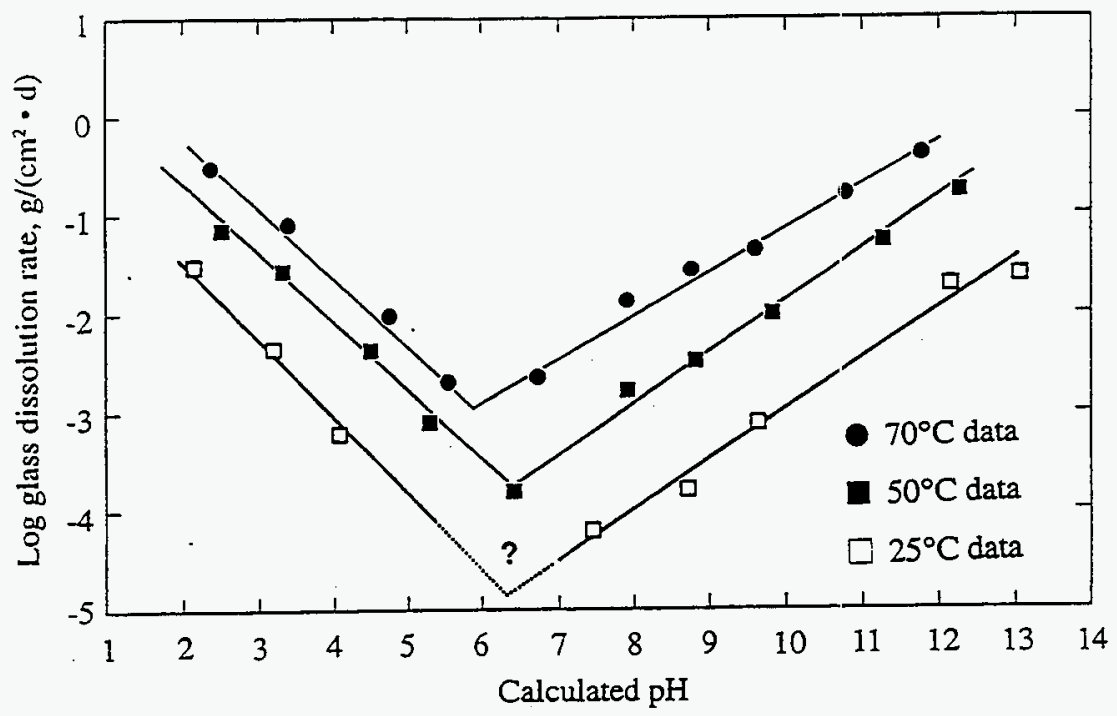


available for leaching to account for the extent of fracturing and decomposition which might develop for canistered waste glass. Tests to determine the normalized glass dissolution rates under various conditions of exposed area are performed either by suspending in water a polished glass disk of known surface area (low surface area test) or ty adding to water ground glass of various sieve sizes (moderately large surface area test) or powdered glass (very large surface area test). The soil dissolution tests leading to Figure 4.8 are likely to fall in the midrange of particle size fractions tested for waste-glass dissolution. The normalized network dissolution rate resulting from tests using such disparate glass surface area will be reasonably reproducible at some fixed solution volume and temperature. So, the smaller the particles (greater surface area) presented for dissolution, the greater the fraction which will be dissolved at any set of conditions of temperature or solvent volume.

If waste products are incorporated into a glass waste form, dissoluticn rates of various components can vary markedly from that of glass network. For example, in Figure 4.10, network-forming components of borosilicate waste glass ( $\mathrm{Si}, \mathrm{Na}$, or $\mathrm{K}$ ) are shown to dissolve at rates which are magnitudes greater than those of many of the incorporated waste elements ( $\mathrm{Fe}, \mathrm{U}, \mathrm{Sr}$ or $\mathrm{Ba}$ ). A key for our consideration is that the incorporated $\mathrm{Cs}$ is dissolved at approximately the same rate as the network forming elements; in fact, the Cs dissolution rate exceeds that of $\mathrm{Si}$. This last effect is due to the relative transport efficiency through a gel layer which forms on the surface of a glass surface undergoing dissolution (Figure 4.11). If Cs which has been incorporated into a glass waste form is among the elements which are preferentially released as the glass is dissolved, Cs which is adsorbed onto particle surfaces, as is likely for clayey sediments, must also be easily mobilized.

The conditions exemplified in Figures 4.8 and 4.9 cannot be readily extrapolated to the extreme conditions likely to have been experienced when leaks first developed in the SX tanks. An Arrhenius diagram for dissolution under neutral to slightly alkaline conditions exhibits for glass leaching four magnitudes increase in leach rate for a $180^{\circ} \mathrm{F}$ tenperature increase (Figure 4.12). An Arrhenius diagram for boron release rate (Figure 4.13), indicates that the line in Figure 4.12 can be extended to temperatures as high as those observed for the SX tank farm wastes. Dissolution rates at $357^{\circ} \mathrm{F}$ would be approximately a million-fold greater than those at ambient environmental temperatures.

The combined effect of $\mathrm{pH} 14$ and $357^{\circ} \mathrm{F}$ temperature is likely to have increased the dissolution rate of silicates in the Hanford sediments by up to ten orders of magnitude above those normally experienced under typical ambient environmental coriditions. Even at $140^{\circ} \mathrm{F}$, soil dissolution rates could be a million times ambient. If the soil particles are altered by such large dissolution rates from the time leaking began even to now, the process must be incorporated in conceptual models. One ramification is that porosity and hydraulic conductivity may be markedly changed at different locations in the formation. Porosity will increase as fine-grained materials are dissolved from the formation. It also will decrease at depth as dissolved silicates are precipitated under conditions of lowered temperature 
Figure 4.10 Dissolution Data from Temperature Dependence Studies Used to Derive Activation Energies (adapted from WESTSIK-1981]) [Cunnane et al, 1994].

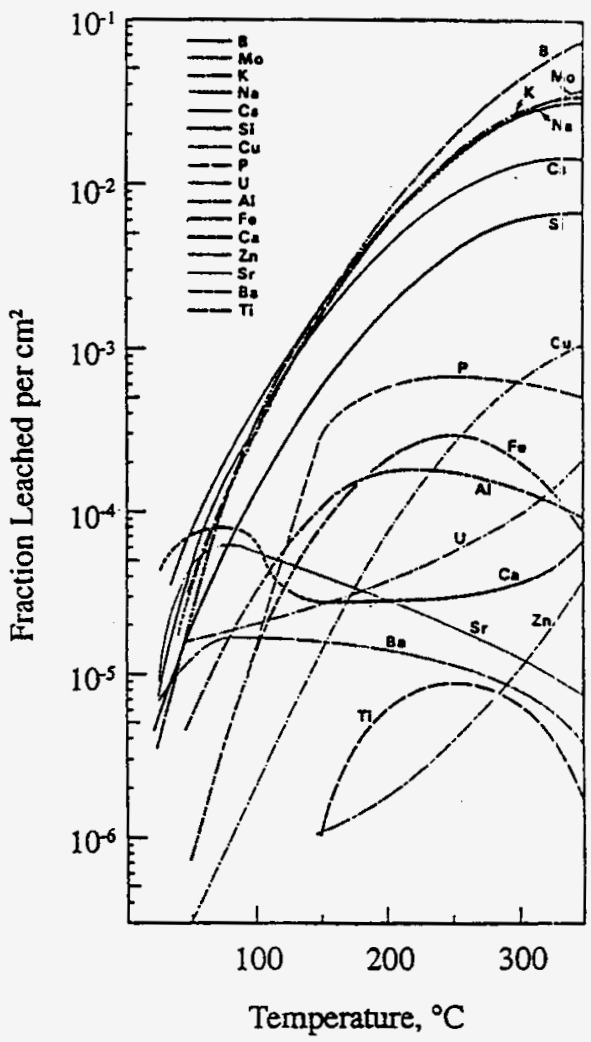




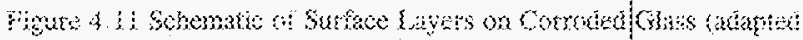
from \{MENOEX, 3984\}, Cuntane at at. 3994 \}.

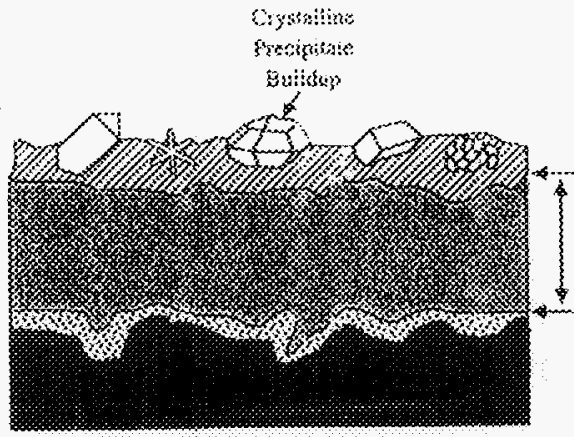

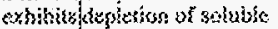
tement $\{$ B. Li, Na\} 
Figure 4.12 Arrhenium Diagram of Leaching Data for SRL 131. Glass (adapted from BARKATT, 1986]). [Cunnane et al, 1994].

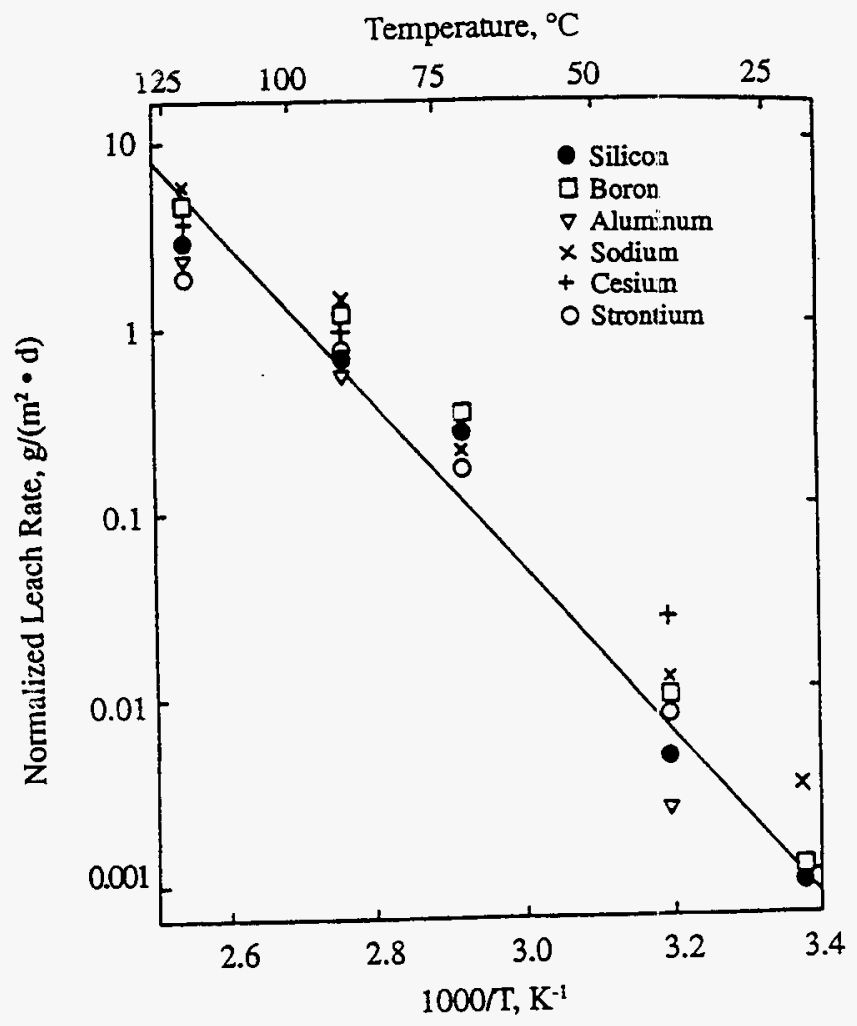


Figure 4.13 Arrhenium Diagram of Leaching Data for R7T7 Glass in a Soxhlet Device (adapted from [DELAGE, 1991]). [Cunnane et al, 1994].

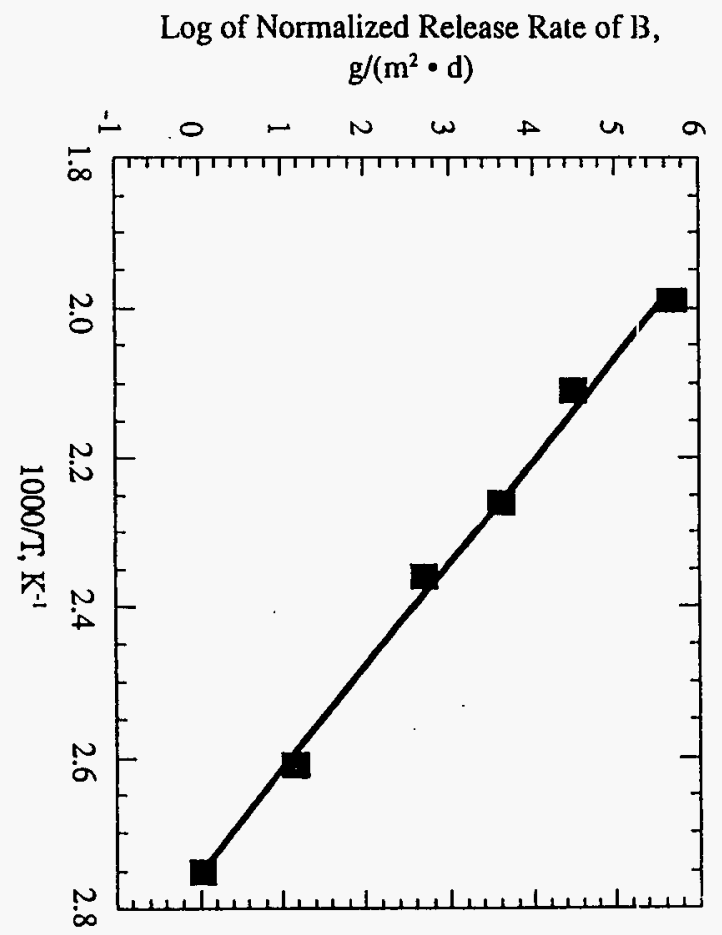


and $\mathrm{pH}$ (see below).

A second ramification is that rapid matrix dissolution or hydration will cause colloid-sized particles that form on the surface of dissolving glass or soil particles to slough off (Figure 4.11) and be carried downstream. Under conditions of $\mathrm{pH}$ greater than 7, the particles will have either a negative surface charge, as for most colloids, or have no charge (Table 4.2). Any ${ }^{137} \mathrm{Cs}$ sorbed on colloids can be carried downstream with an effestive $\mathrm{K}_{\mathrm{r}}$ of zero, i.e., it can move at least at the velocity of the transporting water. Also, the dissolved silica will repolymerize as the temperature and $\mathrm{pH}$ of the solution decrease (Figure 4.14), either remaining as suspended colloids that can retain ${ }^{137} \mathrm{Cs}$ in mobile form or precipitating downstream if the $\mathrm{pH}$ decreases sufficiently. The stability of any colloids or pseudocolloids formed in this manner does not appear to have been studied under conditions representative of the vadose zone and groundwater systems under the SX tank farm. If the colloids or pseudocolloids are stable, however, any ${ }^{137} \mathrm{Cs}$ and other contaminants sorbed on them may be transported at the velocity of the water in either the vadose or groundwater zone. Thus, assumptions that dilution will cause any mobilized ${ }^{137} \mathrm{Cs}$ or other high- $\mathrm{K}_{\mathrm{d}}$ contaminants to become immobile may be incorrect. On the other hand, the ${ }^{137} \mathrm{Cs}$-bearing colloids or pseudocolloids may precipitate downstream in the vadose zone when dissolved silicates are precipitated there. The possibility of formation and transport, as well as immobilization at depth, of any colloids or pseudocolloids, results in a serious uncertainty in the development of a representative conceptual model for transport of ${ }^{137} \mathrm{Cs}$ and other contaminants. The processes described above are consistent with the spectral-gamma logs obtained by MACTEC-ERS.

Alteration and dissolution of glass structure have been shown to occtr from the action of water vapor as well as liquid [Cunnane et al, 1994], with the vapor-phase reaction rate increasing as temperature increases. The "crust" which forms readily sloughs off as colloids and/or pseudocolloids when the glass surface is wet. The effect of vapor-phase attack on salt/hydroxide-coated soil-particle surfaces has not been studied, to our knowledge.

Yet another uncertainty which must be addressed is the degree to which flowing brine or water will affect the dissolution rate of soil particles. Barkatt [1984] performed a laboratory experiment which simulated potential leaching of HLW glass in a repository. He found that as the repository-equivalent flow rate of distilled water leachant was reduced from $1 \mathrm{~m} / \mathrm{yr}$ to 0.01 $\mathrm{m} / \mathrm{yr}$ the leach rate of boron (assumed to be the dissolution rate of glass) decreased approximately forty-fold (Figure 4.15). The decrease in dissolution rate as flow rate decreased was explained as due to an increase in concentration of silicic acid near the glass surface (see reactions 6 and 7 in Table 4.2) which would shift equilibrium toward a more stable glass form. Whether the extremely high hydroxide concentration of the hot brine would overwhelm this flow rate effect is unknown. A related unknown is the degree to which dilution by infiltrating precipitation and reaction with formation sediments will alter the hydroxide concentration and therefore the dissolution rate of soil particles. 
Table 4.2. Glass Corrosion Reactions [Cunnane et al, 1994].

\begin{tabular}{|c|c|c|}
\hline & Reaction & Nomenclature \\
\hline 1 & $\equiv \mathrm{Si}-\mathrm{O}-\mathrm{Na}+\mathrm{H}_{3} \mathrm{O}^{+} \rightleftharpoons \equiv \mathrm{Si}-\mathrm{OH}+\mathrm{Na}^{+}+\mathrm{H}_{2} \mathrm{O}$ & Ion exchange \\
\hline 3 & $\begin{array}{l}2(\equiv \mathrm{Si}-\mathrm{O}-\mathrm{Na})+\mathrm{H}_{2} \mathrm{O} \rightleftharpoons 2(\equiv \mathrm{Si}-\mathrm{OH})+\mathrm{Na}_{2} \mathrm{O} \\
\equiv \mathrm{Si}-\mathrm{O}-\mathrm{Na}+\mathrm{H}_{2} \mathrm{O} \rightleftharpoons \equiv \mathrm{Si}-\mathrm{OH}+\mathrm{Na}^{+}+\mathrm{OH}^{-}\end{array}$ & $\begin{array}{l}\text { Hydrolys s reactions at } \\
\text { nonbridging oxygen sites }\end{array}$ \\
\hline 4 & $\equiv \mathrm{Si}-\mathrm{O}-\mathrm{Si} \equiv+\mathrm{OH}^{-} \rightleftharpoons \equiv \mathrm{SiOH}+\equiv \mathrm{Si}-\mathrm{O}^{-}$ & $\begin{array}{l}\text { Network hydrolysis (forward } \\
\text { reaction) }\end{array}$ \\
\hline 5 & $\equiv \mathrm{Si}-\mathrm{O}-\mathrm{Si} \equiv+\mathrm{H}_{2} \mathrm{O} \rightleftharpoons \equiv \mathrm{SiOH}+\equiv \mathrm{Si}-\mathrm{OH}$ & Condensation (reverse reaction) \\
\hline 7 & 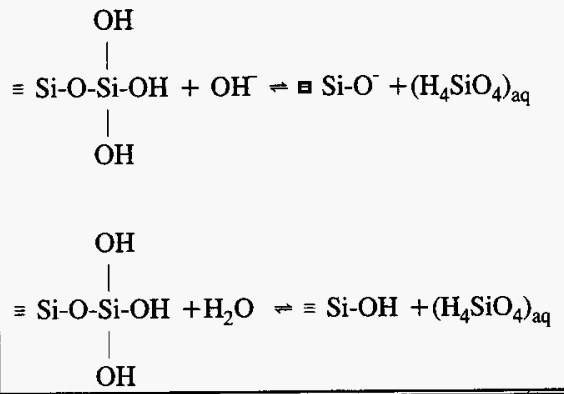 & $\begin{array}{l}\text { Network dissolution (forward } \\
\text { reaction) } \\
\text { Condensation (reverse reaction) }\end{array}$ \\
\hline
\end{tabular}

Note: Although the reactions are written explicitly for $\mathrm{Si}$ and $\mathrm{Na}$, similar reac:ions occur for other networkforming and network-modifying elements.

Source: Adapted from [ABRAJANO-1989]. 
Figure 4.14 Schematic Illustration of the Polymerization of Monosilicic Acid to Form Seed Particles.

In basic Solutions, seeds can grow to give sols of different particle sizes (viz. Ostwald ripening), whereas aggregation occurs in acidic solutions or in the presence of electrolytes, which can lead to the formation of three dimensional gel networks (adapted from [ILER1979]). [Cunnane et al, 1994].

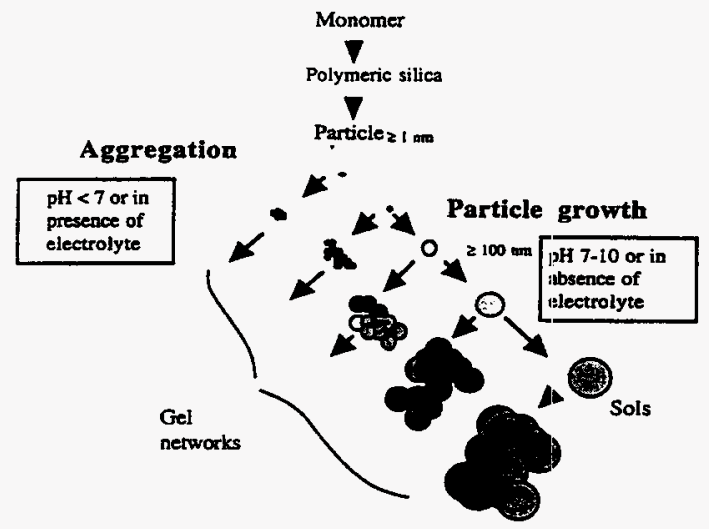


Figure 4.15 Boron Release from SRL TDS-131 as a Function of Flow Rate (adapted from [BARKATT, 1984a]) [Cunnane et al, 1994].

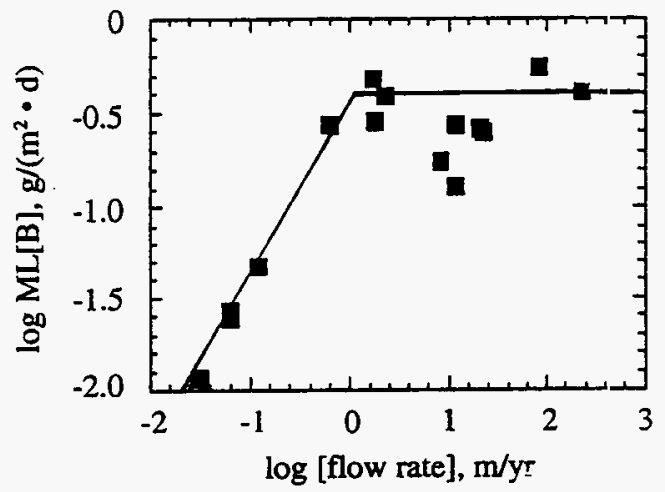


Recent research on the mineral-water geochemistry of silica polymojphs has been described and interpreted in an extensive review by Dove and Rimstidt [1993]. The studies described in the review do not deal directly with the mobilization of incorporated radionuclides, but they do provide a geochemical basis for questioning the representativeness of the $K_{v}$ formalism for simulating solute transport or immobilization in formation soils under the conditions which apply beneath the Hanford waste tanks. Use of the $\mathrm{K}_{\mathrm{d}}$ formalism implies that the soil column is assumed to act as a large chromatographic column, with various cations competing for exchange sites on the surfaces of soil particles. The PNNL modelers described to the Panel how in their simulations, and also in their supporting research, ${ }^{137} \mathrm{Cs}$ mobilization and transport was considered to depend on how effectively $\mathrm{Na}^{+}, \mathrm{K}^{+}$and $\mathrm{NH}_{4}{ }^{+}$ions competed with the ${ }^{137} \mathrm{Cs}$ for exchange sites on the surface of soil particles. However, the dissolution of silica particles and the subsequent nucleation and precipitation of the resulting silicat polymorphs are geochemical processes which are active even at room temperature, neutral $\mathrm{pH}$ and low salinity, and would cause morphological alteration of silica particles even at some distance from a leak. The morphological and chemical aiterations which result from these geochemical reactions serve to reduce available exchange sites even if the leaked brines are diluted, cooled and transported by meteoric water or depleted of free hydroxide by reaction with the formation sediments.

The key concept that derives from the research on waste-glass and geochemical silica is that ${ }^{137} \mathrm{Cs}$ carried with the tank waste will be dispersed by both chemical and physical processes. Some fraction (probably large) will have been adsorbed reasonably near the leak location, some of that to be mobilized later as more supernate is leaked or by meteoric water. Another fraction is likely to have been carried to some depth, possibly along permeable zones, by the tank waste, there to undergo much the same reactions as the ${ }^{137} \mathrm{Cs}$ trapped near the leak. Yet another fraction (probably small) may be mobilized on colloidal particles either at the time of release from the tank or later as material which may have been trapped at some distance from the leak if peptized. Finally, any mobile fraction is likely to be depleted by nucleation or precipitation, or perhaps supplemented as upstream fractions are peptized by electrolytecontaining formation water. This concept is not readily simulated by the $\mathrm{K}_{\mathrm{g}}$ formalism, where solutes are treated in an all-or-nothing manner, i.e., transport of all the ${ }^{137} \mathrm{Cs}$ from a particular leak is simulated using a specific value for $\mathrm{K}_{\mathrm{d}}$ for some selected time: period.

Great uncertainties limit the quality and value of the contaminant-transport simulations presented to the Panel.

\subsubsection{Role of Colloids in Preferential Flow}

Numerous studies have been published to describe the effects of cornplexing agents or colloid formation on the migration of various contaminants. Cesium does not form complexes with natural (e.g., fulvic or humic) acids or artificially-introduced (e.g., EDTA) chelating agents. Nor does cesium form anionic species, as does technetium $\left(\mathrm{TcO}_{4}^{-}\right)$, for example. 
Retardation during transport of soluble, radioactive, inorganic species is conventionally simulated as a reaction of the cationic contaminant (in this case ${ }^{137} \mathrm{Cs}^{+}$) with negatively charged surfaces of the formation soil. Thus, the soil column acts as a large-capacity cationexchange column. However, the soil particles in sizes less than $10 \mu \mathrm{m}$ diameter are most effective in adsorption of cesium. As described above, hot, caustic brine is likely to alter the distribution of particle sizes in the formation, dissolving some of the fine, colloidal particles already present while breaking down some of the larger particles to colloidal size.

Determining whether the action of the hot, caustic brine on soil particles increases or decreases the fraction of colloidal particles will require some experimental effort, as will determination of the effect on soil particles of electrolyte-enhanced formation water.

An example of the colloid fraction (in this case, kaolinite) increasing the migration rate of ${ }^{137} \mathrm{Cs}$ in a saturated medium illustrates one of the effects possible during active tank leakage. Saiers and Hornberger [1996] injected ${ }^{137} \mathrm{Cs}$ tracer into columns of mineralogically pure, wellrounded quartz sand. Well-rounded sand is used to minimize the exchange capacity of the sand, much as described in 4.2 .3 above when a soil column has been morphologically altered according to processes described by Dove and Rimstidt [1994]. In addition to ${ }^{137} \mathrm{Cs}$, the influent consisted of kaolinite colloid at $0,50,100$, or $200 \mathrm{mg} / \mathrm{L}$. The results show that breakthrough for ${ }^{137} \mathrm{Cs}$ in the presence of kaolinite occurred 15 pore volumes sooner than that in which colloids were absent from the conducting fluid (Figure 4.16). Breakthrough for the colloid-containing influent occurred in the very first fractions collected from the columns, followed by a plateau region of 5 to 10 pore volumes in which the ${ }^{13 i} \mathrm{Cs}$ concentration increased slowly. The concentration values in the plateau region increased with increasing kaolinite concentration. Time scales for transport of the principal volume (peak) of the ${ }^{137} \mathrm{Cs}$ influent varied inversely with kaolinite concentration; e.g., the ascerding limb for the 200 $\mathrm{mg} / \mathrm{L}$ influent develops approximately 7 pore volumes earlier than does that for the $50-\mathrm{mg} / \mathrm{L}$ influent.

The Saiers and Hornberger experiment is one key toward developing; conceptual models for ${ }^{137} \mathrm{Cs}$ (and other solute) transport in the vadose zone during tank leaks and flooding incidents or in the groundwater system. Clearly, ${ }^{137} \mathrm{Cs}$ transport through the columns increased for both the early-arrival, small-concentration portion and the peak-concentration portion of the influent breakthrough pattern. Since the experiment was conducted in a homogeneous, small-grained sand, there are no preferential pathways in the column. The only requirement is that colloidalsized, cesium-sorbing particles be present. In the case of Hanford tank farms, such particles might occur naturally in the formation or be artificially-produced by the action of the hot, caustic brine on soil particles. For continuing leaks, previously sorbed ${ }^{137} \mathrm{Cs}$ may be remobilized by dissolution of soil particles on which the ${ }^{137} \mathrm{Cs}$ was deposited.

Once mobilized, colloidally-supported ${ }^{137} \mathrm{Cs}$ may continue to migrate with the transporting fluid, agglomerate into larger particles that can settle as sediments, or be "filtered" by adhesion to the formation materials (Figure 4.17). Studies such as that by Saiers and Hornberger and representations as in Figure 4.15 are more representative of processes that should occur in saturated systems. These are important concepts because they show that ${ }^{137} \mathrm{Cs}$ 
Figure 4.16 Breakthrough curves for ${ }^{137} \mathrm{Cs}$ Transport Under Varying Conditions of Influent Kaolinite Concentration. The ordinate axis is presented in terms of the total mobile ${ }^{137} \mathrm{Cs}$ concentration in the column effluent, $\mathrm{C}_{\mathrm{at}}$, normalized to the total masss concentration of ${ }^{137} \mathrm{Cs}$ in the column influent, $C_{a 0}$, such that $C_{a t} / C_{a o}=\left(C_{a}+C_{c} C_{a m c 1}+C_{c} C_{a m c 2}\right) / C_{a o}$ [Saiers and Hornberger, 1996].

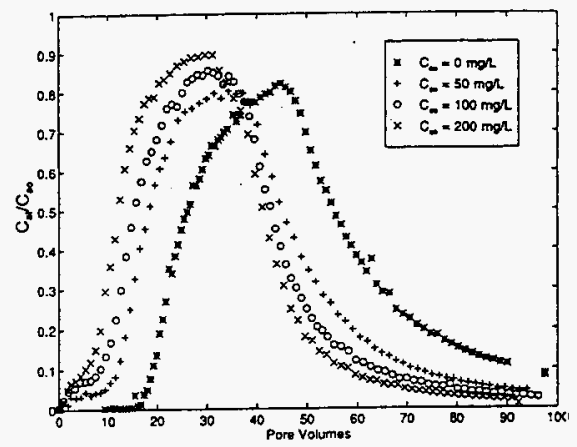


Figure 4.17 Schematic Representation of Colloid-facilitated Contaninant Transport Within a Pore of Water-saturated Porous Medium in the Subsurface. Contaminants (•) are either dissolved in the liquid phase or adsorbed to the surfaces of the solid phase. The entire particulate phase is commonly assumed to be at rest, but it is possible that colloidal particles disperse in the liquid phase and provide a rapid transport pathway for the contaminant

[Grolimund et al, 1996].

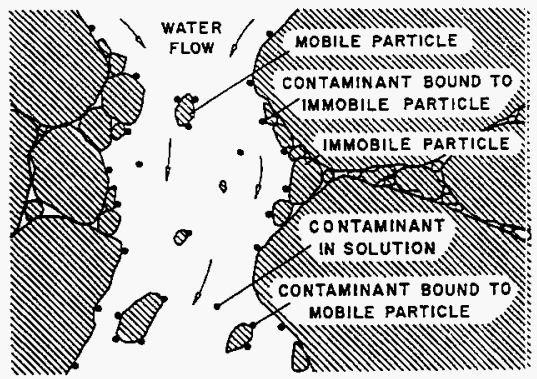


sorbed on colloids would be much more mobile in the groundwater system below the tanks than has been suggested in presentations to the Panel; the groundwater models now in use may not be representative of actual conditions.

Research into the effects of colloid transport in the vadose zone apptars to be sparse. A dry period would tend to precipitate colloidal ${ }^{137} \mathrm{Cs}$, either as agglomerate or filtrate. A wetting front could peptize some of the precipitated ${ }^{137} \mathrm{Cs}$, carrying fresh portions of colloidal ${ }^{137} \mathrm{Cs}$ through the formation pores while also mobilizing fractions that had precipitated previously. The process is likely to be complex and requires study.

The Saiers and Hornberger study indicates that soil formations containing clay can provide a multi-phase system which increases the ${ }^{137} \mathrm{Cs}$ migration rate. From the descriptions provided of the STOMP calculations [Caggiano, 1996; Ward et al, 1997] and VAM2D model [DOE, 1996], it appears that colloids were not considered for the work presented to the panel or for the EIS. Unless the conceptual models properly account for all potential transport phases, or provide sufficient evidence for neglecting them, the results cannot be considered representative of conditions in either the vadose zone or groundwater beneath the $S X$ tank farm or elsewhere on the Site.

\subsubsection{Preferential Pathways in Porous Media}

The simplistic view of uniform migration of contaminants through the formation has been replaced in published current research by the concept that flow in ursaturated porous formations is likely to be along preferential pathways. Such preferential pathways could include discontinuities, such as clastic dikes, or more subtle variations in formation properties that could concentrate the flow. It is the Panel's unanimous view that it is entirely plausible that ${ }^{137} \mathrm{Cs}$ could travel to the depths observed on the SGLS logs, and probably beyond, along preferential formation pathways.

Among the published studies of preferential formation flow, a field study [Daily et al, 1992] near the Lawrence Livermore National Laboratory (LLNL), designed for the primary purpose of studying the capabilities and limitations of electrical resistivity tomography (ERT), appears to be especially appropriate to this $\mathrm{SX}$ tank farm contaminant transport issue. The similarities in geologic, hydrologic and climatologic settings between the Livernore Valley and Hanford sites are important, and so is the scale of the Livermore study. Using ERT to define a virtual plane $6 \mathrm{~m}(20 \mathrm{ft})$ wide by $17.3 \mathrm{~m}(57 \mathrm{ft})$ deep, $1900 \mathrm{~L}$ (500 gal) of ap water were injected over a period of 2.5 hours into the formation at the center of the virtual plane; the formation water-content was measured over a 23 -hour period. The results depicted in Figure 4.18 are suggestive of the type of preferential formation flow we believe may have taken place under the SX tank farm. The observed travel time of 23 hours for the injected water to reach the maximum depth of $20 \mathrm{~m}$ was more than a hundred-fold less than the one-month travel time 
predicted using a homogeneous model consisting of sandy soil. A computer simulation of the experimental data is presented in Figure 4.19, indicating that an LL.VL simulation model can perform preferential-flow calculations which are representative of field measurements. 


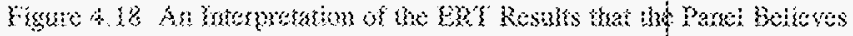

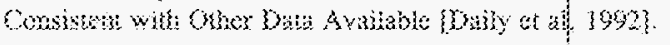

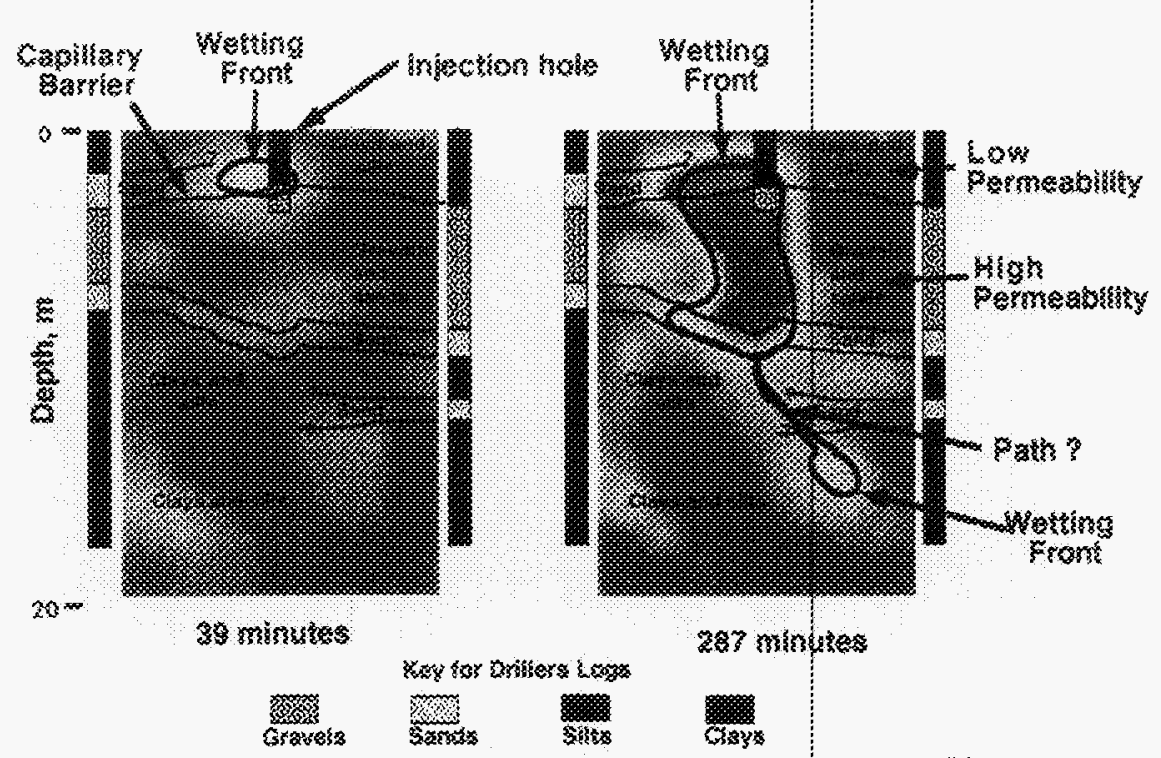

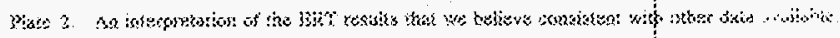




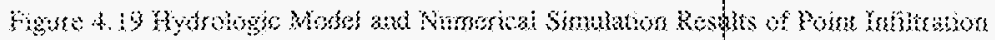

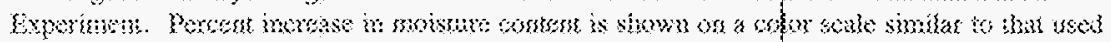

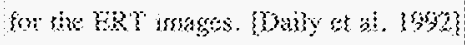

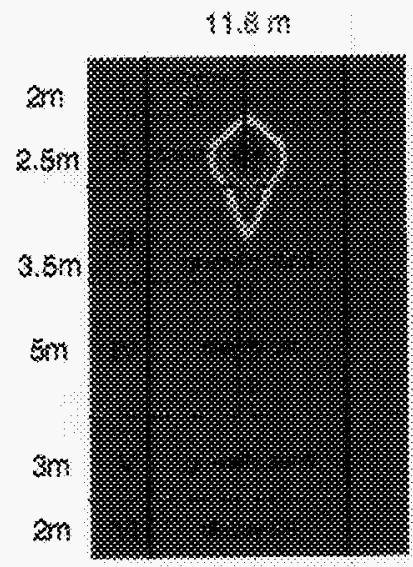

澡. 70 rimusto

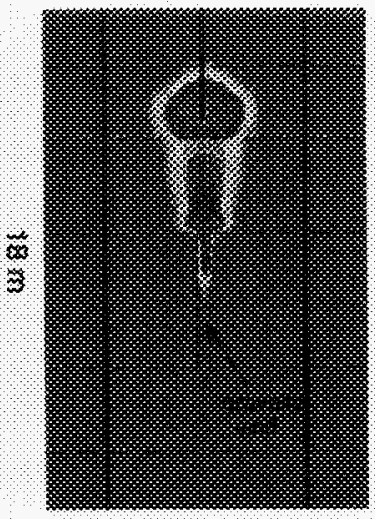

$b$. 2z: minutes

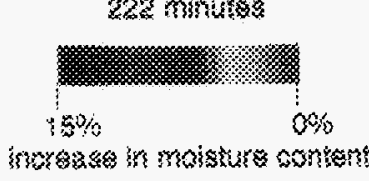

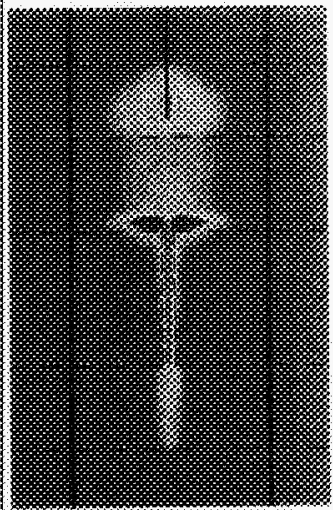

c.

23 houss 
Flury et al [1994] set up 14 plots, each $100 \mathrm{~cm}$ square, in soil at various locations in Switzerland representative of the principle agricultural soils in that country. A solubilized dye was sprinkled along a centerline of each plot and the plot then sprayed to simulate a set volume of precipitation. Each plot was then excavated to form a face $100 \mathrm{~cm}$ deep; one face at $20 \mathrm{~cm}$ from and parallel to the injection line and the other along the injection line. The dye patterns along each face were photographed, the photographs manually digitzed and profiles developed. The profiles for three plots show that flow pathways in the various soils formed distinct patterns even within the short distances of this experiment (Figure 4.20). In most soil columns, water bypassed the soil matrix; macropore structure was the prime cause. Structured soils were more prone than nonstructured soils to produce bypass-type dye penetrations and pulse-splitting flow. The Flury et al study was prompted by several earlier studies which found that strongly sorbing pesticides had penetrated to groundwater, providing indirect evidence of bypass flow. This result is not explained by chromatographic transport through the soil matrix and appears to be analogous to the SX tank farm situation. Figure 4.20 provides an example of the variability of vertical flow patterns among 3 soils and replicated profiles 20$\mathrm{cm}$ apart within each plot. At other plots (Wülflingen and Wetzikon 1 in Figure 4.21) the soil is stained in isolated spots; the increase in dye coverage in the Wulflingen soil at a depth of 60 $90 \mathrm{~cm}$ corresponds to a structural and textural change in soil material (structureless and course granular below $60 \mathrm{~cm}$ ).

Flury et al, and others, have also found that fractures can play an important role in enhancing the movement of water even in porous media, an effect that varies vith water content. At Hanford, clastic dikes may contribute in much the same way as fractures do to flow through the porous unsaturated media, although the properties of these structures do not seem to be well understood. Openings in the formation may have been enlarged by steam-generated overpressure and by the action of the hot, caustic brine released from the tank. Such openings provide a pathway for solvent and solute to move rapidly to depth, perhaps even to groundwater. The fact that ${ }^{137} \mathrm{Cs}$ has not been detected in groundwater below the SX tank farm does not guarantee that ${ }^{137} \mathrm{Cs}$ has not reached groundwater.

The influence of natural preferential formation pathways such as fractures or clastic dikes, on solute migration rates may be particularly important because they lessen the opportunity for contact between exchangeable contaminant and the exchange sites in the formation. Landstrom et al [1983] performed an experiment (Figure 4.22) that quantified this effect in fractured granite. Figure 4.23 shows the transport times for ${ }^{3} \mathrm{H}$ and ${ }^{85} \mathrm{Sr}$ tracers injected into one borehole $(\mathrm{B} 1 \mathrm{~N})$ as water and cation respectively, and collected in two boreholes parallel to the injection borehole and several meters away. $K_{d}$ values for strontium conventionally are somewhat less than those for ${ }^{137} \mathrm{Cs}$, but are usually greater than one. A significant portion of the ${ }^{85} \mathrm{Sr}$ tracer arrived at each sampling station approximately the same time as the ${ }^{3} \mathrm{H}$ tracer $\left(\mathrm{K}_{\mathrm{d}}=0\right)$. A similar response by the tank waste in parts of the $\mathrm{SX}$ tank farm vadose zone seems more likely than not. 
Figure 4-20 Variability of the Vertical Flow Pattern Between Two Profiles Within the Same Plot after a Sprinkling Application of 40-mm Colored Water. The three examples represent

"wet" initial conditions. The solid bar at Obermumpf indicates the maximum depth of excavation. [Flury et al, 1994].
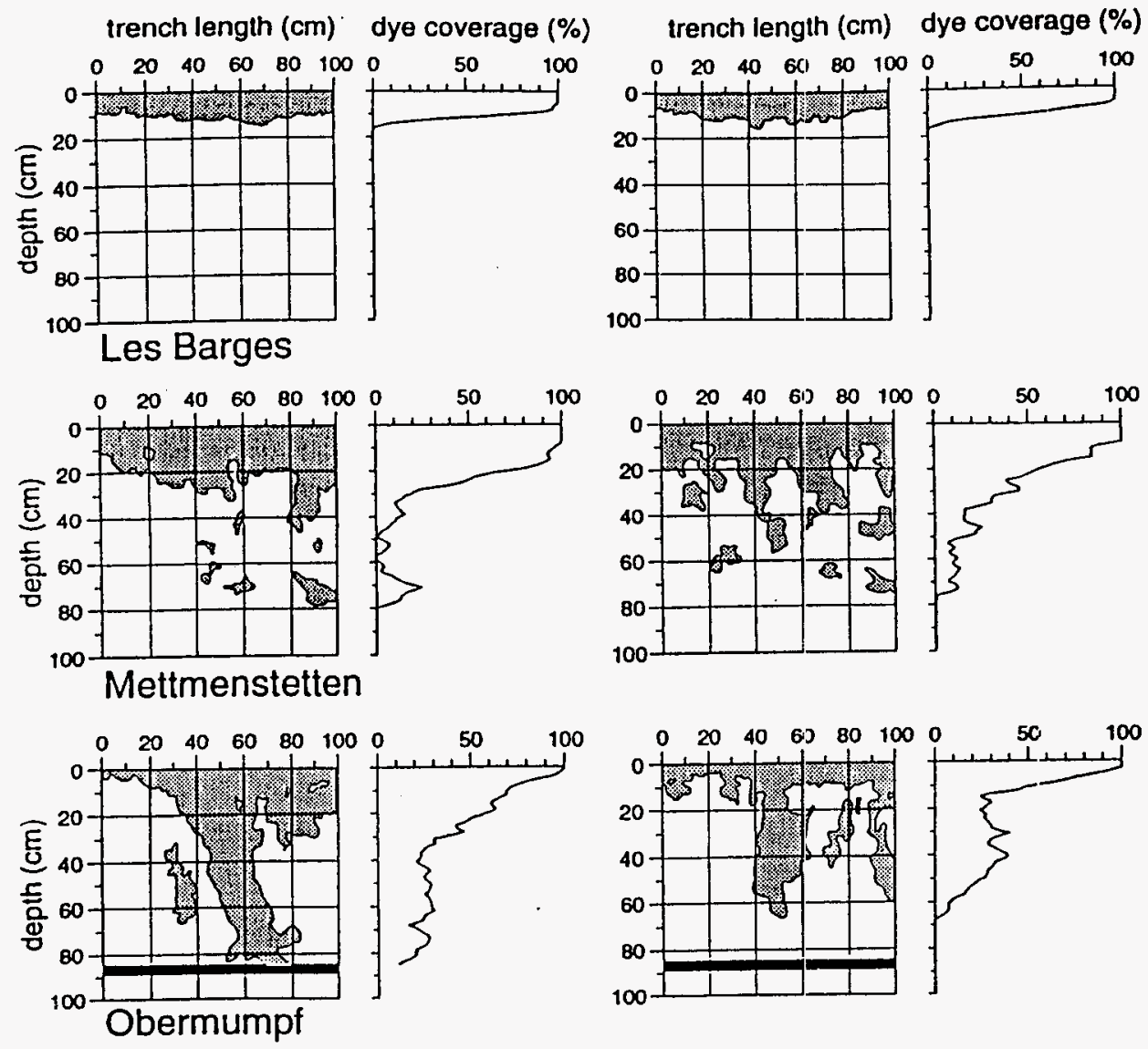
Figure 4.21 Vertical Flow Patterns of Brilliant Blue FCF and One-dimensional Profiles of Dye Coverage after Sprinkling Application of 40-mm Colored Water in Four Different Soils. These examples represent "wet" initial conditions. The solid bar at Obermumpf and Wülflingen indicates the maximum depth of excavation. [Flury et al, 1994].
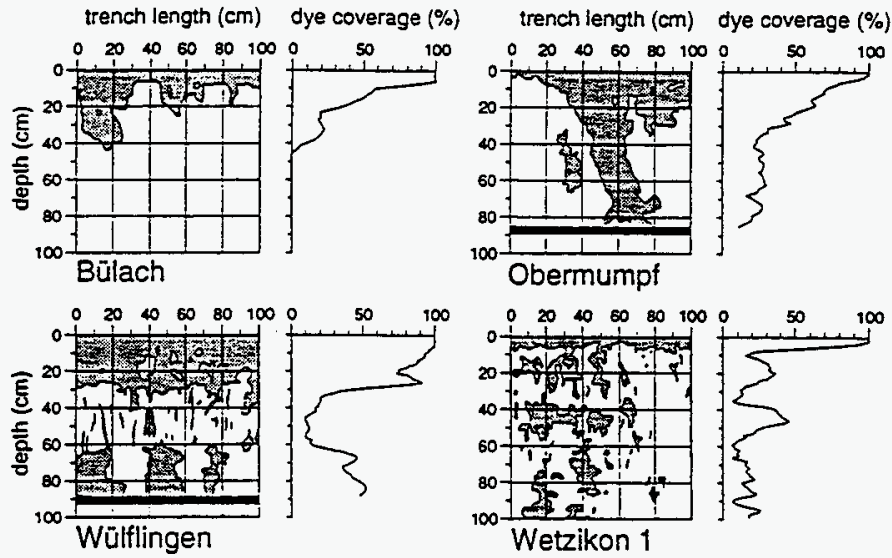
Figure 4.22a Location of Boreholes and Their Deviation Projected on the Horizontal Plane [Landström et al, 1983].

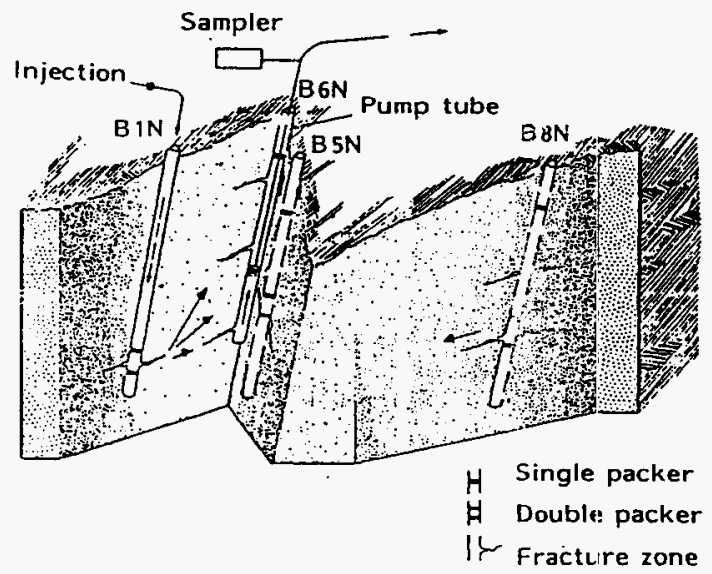


Figure 4.22b Cutaway View of the In Situ Test Site [Landström et al, 1983].

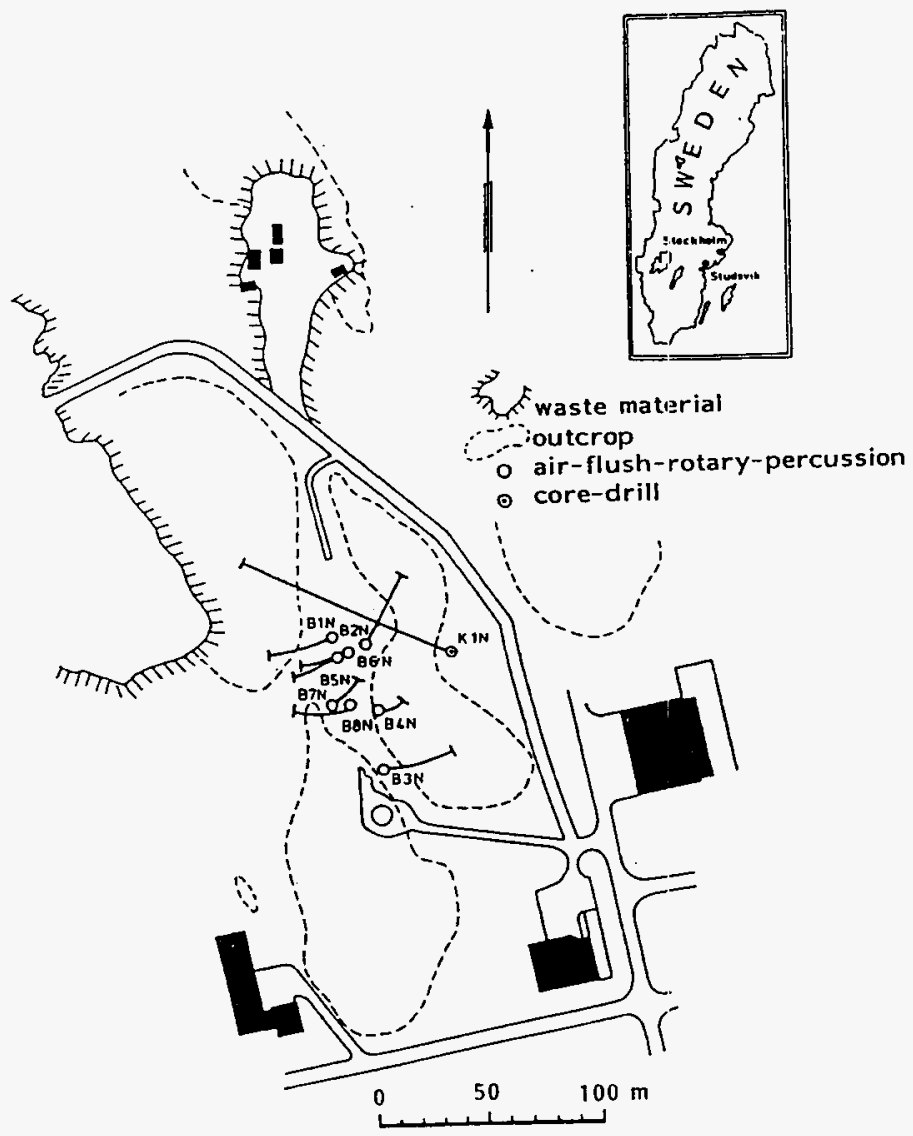


Figure 4.23 Field Experiment $\mathrm{H}-3$ and Sr-85 Break-through Curves [Landström et al, 1983].

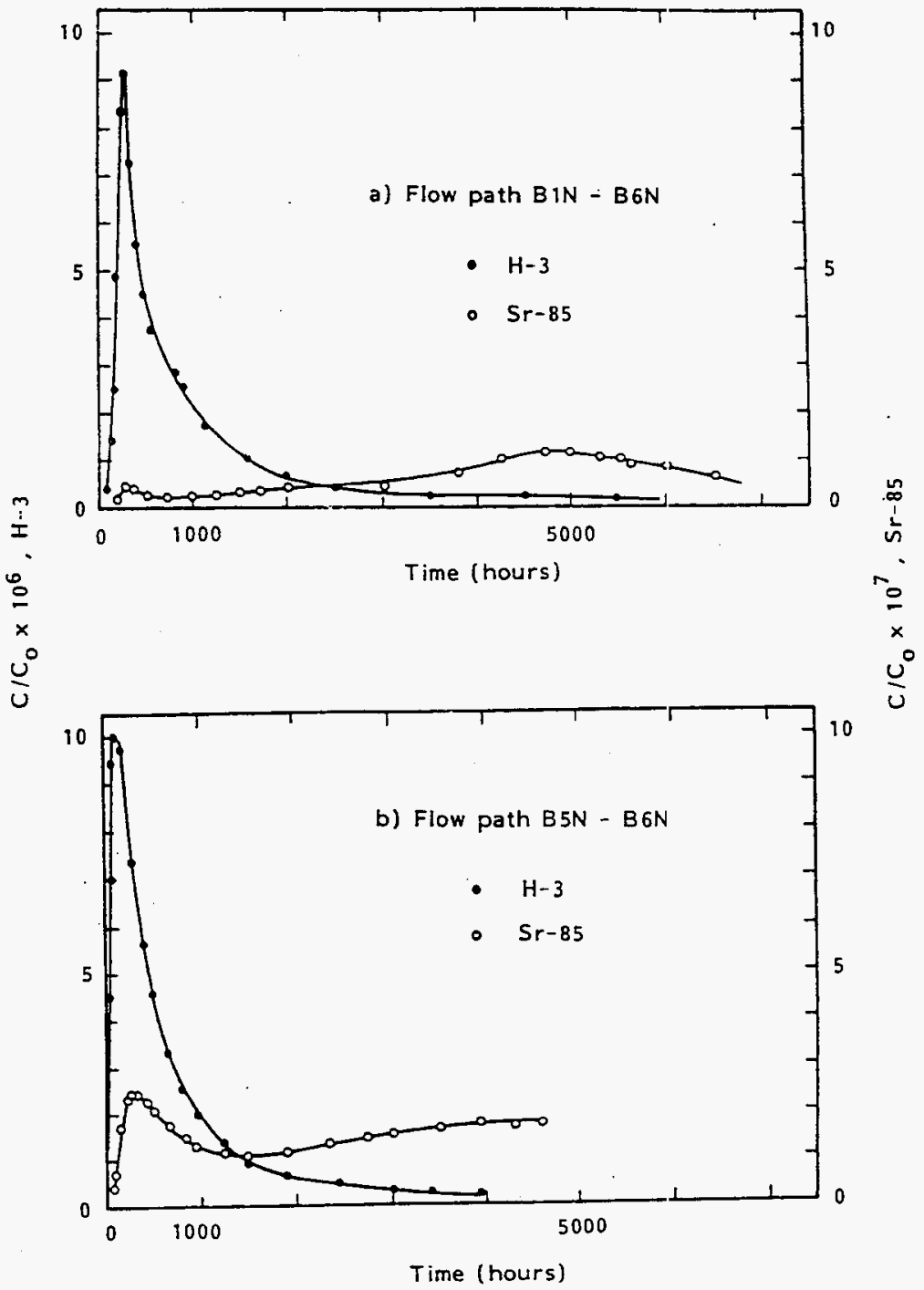


While the effect of natural preferential pathways is to speed the migiation of an otherwise slow-moving solute, their impact on contaminant mass transport is likely to be small, especially in the case of clastic dikes where transport of fluid and solute depends on whether the clastic dikes are open to entry and/or exit of the fluid and contaminating solute.

Kung [1990] has distinguished among various of the types of flow exemplified above as either "short circuiting" flow or "fingering flow". He defines short-circuiting flow as generally related to soil macro-pores and/or fractures. Fingering flow is defined as the splitting of uniform flow into fingers by instability associated with soil-air compression or at a horizontal boundary where a finer soil overlies a course and dry sand layer. Either is an example of formation conditions that can hasten the migration of an otherwise slow-moving (or even "fixed") contaminant. The hazard caused by either short-circuiting or fingering may not be greatly increased for ${ }^{137} \mathrm{Cs}$ because of limits these preferential pathways impose on the mass of solute transported; this remains to be tested, however.

Kung describes a third type of preferential pathway, called "funneled" flow, which he considers a more severe contributor to the potential downward movement of contaminants because it not only increases the fluid and solute migration rates, but also results in high contaminant mass transport (Figure 4.24). Kung demonstrated funnel flow in a dye-tracing experiment in a sandy soil (some similarity with the Hanford formation) and estimated that the flow area can shrink as much as one or two orders of magnitude. Because of tortuosity, flow velocity is not necessarily increased in inverse proportion to the shrinkage in area, but contaminant mass transported by the increased flow rate will be increased, so the hazard created by funneled flow also may be significantly increased over predictions using homogeneous-flow models.

Conceptual models for each of the three types of preferential pathways described by Kung will likely differ, so no single algorithm is likely to be sufficient to evaluate the hazard presented. Nor is a single model likely to provide satisfactory estimates of the rate at which migration will occur.

It is important to consider the probability of leaked waste intersecting a preferential pathway that can transport the waste to depth. Each of the potential preferential pathways described above differs in cross-section available for intersecting ${ }^{137} \mathrm{Cs}$ leaked from tank wastes. Colloidassisted preferential flow provides the greatest probability of intersection, because the entire formation area below the leaked waste is available for migration. There is not enough information to quantify either the time required for transport through the vadose zone or the amount of released ${ }^{137} \mathrm{Cs}$ that may be transported on colloids. The formation water content for this pathway (fluid flow) may be adequately represented by the simulation models now applied to the site, but solute transport is not likely to be well represented. 
Figure 4.24 A Schematic Diagram of the Funnel Effect on Water Flow [Kung, 1990].

NCOMNG UNEORM UNSATURATED FLOW

DIDTDIDTITIB]

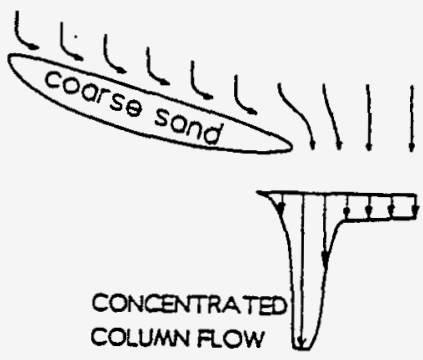


If appropriately-tilted, coarse-grained formations are available below the SX tank farm, funneled flow appears to provide the most likely mechanism to move large quantities of ${ }^{137} \mathrm{Cs}$ to depth, especially if ${ }^{137} \mathrm{Cs}$ is adsorbed on colloids. We assume tha: combining cesium sorbtion on colloids with the ten- to hundred-fold greater flow rates likely to develop with funneled flow will increase the migration rate of both the initial ${ }^{137} \mathrm{C}$ is front and the bulk contamination zone. Efforts to model vadose zone transport of pollutants at the SX tank farm and elsewhere on the Hanford site do not appear to take this phenomenon into account; whether that omission is justified remains to be proven.

Fingering flow may have contributed to waste migration during the active phase of leaking. As described earlier in this report, a plausible scenario is one where the hot brine flashed to steam on contact with hot soil and the resulting overpressure forced the fluid into the more permeable segments of the formation. Enhanced flow through the vadose zone is expected from drainage around tank roofs. In a discussion that follows we will provide support for this scenario in the form of a preliminary evaluation by Hanford contractors of borehole grossgamma logs indicating that fingering flow is contributing even now to changes in ${ }^{137} \mathrm{Cs}$ concentration at depth.

Finally, short-circuiting flow along such natural preferential pathways as fractures or clastic dikes appears to provide a plausible mechanism for rapid migration of ${ }^{137} \mathrm{Cs}$ and other contaminants with minimal retardation, especially if further enhanced by colloidal flow. While this type of preferential path increases flow rate, it is less likely to intersect large segments of leaked wastes, and when it does the cross-sectional area of the intersection is small. Therefore, short-circuiting flow in unsaturated soil appears unlikely to contribute much to the transport to groundwater of the bulk quantity of leaked tank wastes. Conceptual and calculational models must account for this phenomenon to assure that it does not contribute significantly to bulk transport of contaminants.

The probability of a borehole intercepting a contamination plume must also be considered. For example, many boreholes intercepted the large horizontal plume of ${ }^{137} \mathrm{Cs}$ near the base of the SX tanks. Such massive flooding, especially if contaminants flowed through a homogeneous formation, would be relatively likely to be intercepted by a borehole and would probably be well-represented by the visualizations of the SX TANK FARM REPORT. Funneled, fingering and short-circuiting flows are less likely to be intercepted by a borehole, with the probability decreasing in the order presented. Failure to include these potential pathways in conceptual and calculational models for vadose zone transport at the Site would compromise the use of those models for evaluating pollutant transport, either at the SX tank farm or elsewhere onsite. Also, preferential flow makes the job of characterizing the vadose zione more difficult because of the smaller cross-section such flow paths present to a new borehcle being emplaced compared to massive plumes. 


\subsubsection{Influence on Groundwater Monitoring and Remediation}

Kung [1990] provides an example (Figure 4.25) of why accurate mcdeling of flow in the vadose zone is important in establishing adequate programs for groundwater monitoring and remediation. Whether funneled, fingering or short-circuiting flow is considered, recharge is likely to enter at the water table at specific areas rather than being uniformly distributed. Depending on the zone of influence of a groundwater monitoring we:ll, it may or may not intercept a solute source entering the groundwater system. Until an improved conceptualization of vadose zone flows is developed, particularly for tank wastes, groundwater monitoring results showing absence (or low concentrations) of contaminants should not be considered representative. The same limitation applies to any well(s) installed to treat contaminated groundwater. Installation of water-treatment wells on the basis of solute concentration data developed from monitoring wells may be only partially effective, at best.

\subsubsection{Contaminant Transport Scenarios Simulated With STOMF'}

The Panel first was presented with examples of simulations performed using a version of STOMP (Subsurface Transport Over Multiple Phases) representative of those in the preliminary modeling analyses given in Appendix $F$ of the Assessment Groundwater Monitoring Plan for the SX Tank Farm [Caggiano, 1996]. A series of sensitivity analyses by Wart et al [1997], using STOMP for modeling the vadose zone near tank 241-SX-109, shows the influence of some physical and chemical factors contributing to contaminant migration from a leak of 132,000 gallons from tank 241-SX-109. Available information on stratigraphy for the area is used to discretize layers of hydraulic properties. The simulations examine factors including the influence of liquid density, variable recharge rates, alternative $\mathrm{K}_{\mathrm{d}}$ values, and a water line leak, and demonstrate their effects on the transport of ${ }^{137} \mathrm{C} \cdot \mathrm{s},{ }^{99} \mathrm{Tc}$ and nitrate. However, the simulations do not include the effects on flow of formation water or on solute transport induced by fingering, short-circuiting or funnel-flow highlighted by the Panel (Section 4.2.5) as potential contributors to ${ }^{137} \mathrm{Cs}$ migration to depth.

In simulations using a liquid specific gravity of 1.4 and variable recharge $(10 \mathrm{~mm} / \mathrm{y}$ during the first twenty years and $40 \%$ of annual precipitation thereafter), Cs trinsport was shown to reach groundwater if a $\mathbf{K}_{\mathbf{d}}$ of zero was selected (Figure 4.26a). The modelers [Ward et al, 1997] do not consider this result is realistic. Using time varying $\mathrm{K}_{\mathrm{f}} \mathrm{s}(0.5,3,37)$ in association with varying stages of leakage and dilution of high saline conditions with meteoric water, the cesium transport did not reach groundwater (Figure 4.26b). The modelers suggest that this result gives the closest agreement with the SGLS results of the various simulations conducted. However, neither the second investigative borehole 41-09-39 nor bcrehole 41-09-04 have yet been extended to groundwater, so comparison to SGLS data is not warranted at this time. The modelers acknowledge that mineral dissolution and precipitation are not part of their simulations; nor are preferential pathways of the types described by Kung [1990] and others. The Panel recommends that these processes be critically evaluated for inclusion in future modeling efforts. 
Figure 4.25 Influence of Point Recharge at the Water Table on Solute Sampling with Single Well. [Kung, 1990].

PREFERENTIAL FLOW IN A SANDY VADOSE ZONE: 2

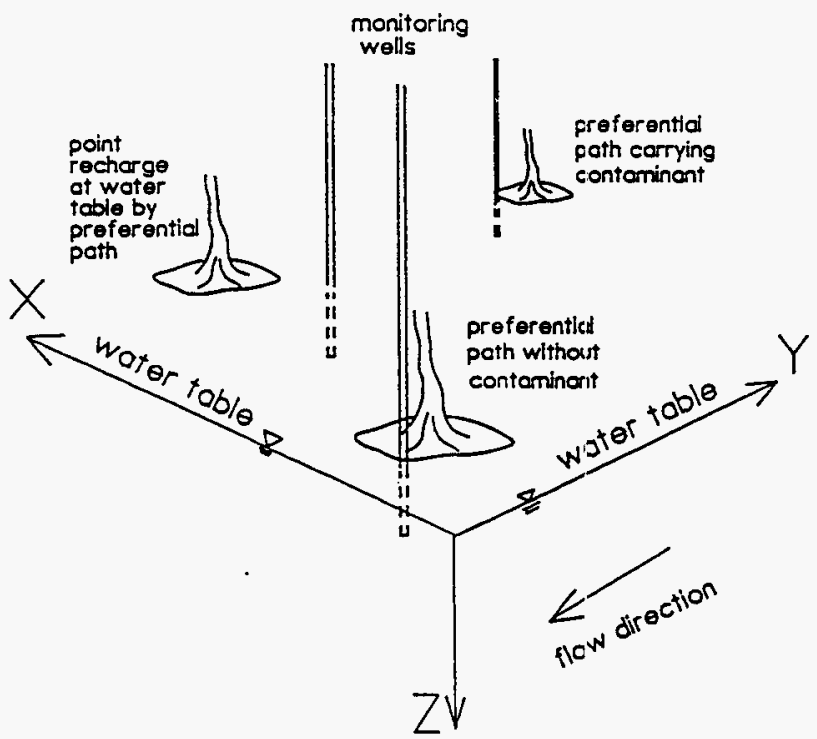


Figure 4.26 Simulated ${ }^{137} \mathrm{Cs}$ Concentration (pCi g ${ }^{-1}$ ) in 1983 Showing the Impact of $\mathrm{Kd}$ on

Plume Migration Under a Variable Recharge Rate: (a) Case $3 \mathrm{~K}_{\mathrm{q}}=0 \mathrm{~mL} \mathrm{~g}^{-1}$, (b) Case 8,

$\mathrm{K}_{\mathrm{d}}=3.0 \mathrm{~mL} \mathrm{~g}^{-1}, \mathrm{~mm} \mathrm{yr}^{-1}$, (c) Case $11, \mathrm{~K}_{\mathrm{d}}=0.5$ and $3.0 \mathrm{~mL} \mathrm{~g}^{-1}$, and (d) Case 12 , $\mathrm{K}_{\mathrm{d}}=0 / 0.5 / 37 / 3.0 / 37.0 \mathrm{~mL} \mathrm{~g}^{-1}$. The borehole is shown at $17.6 \mathrm{~m}$. on the X-axis. The bold isopleth is $10 \mathrm{pCi} \mathrm{g}^{-1}$. [Ward et al, 1997].
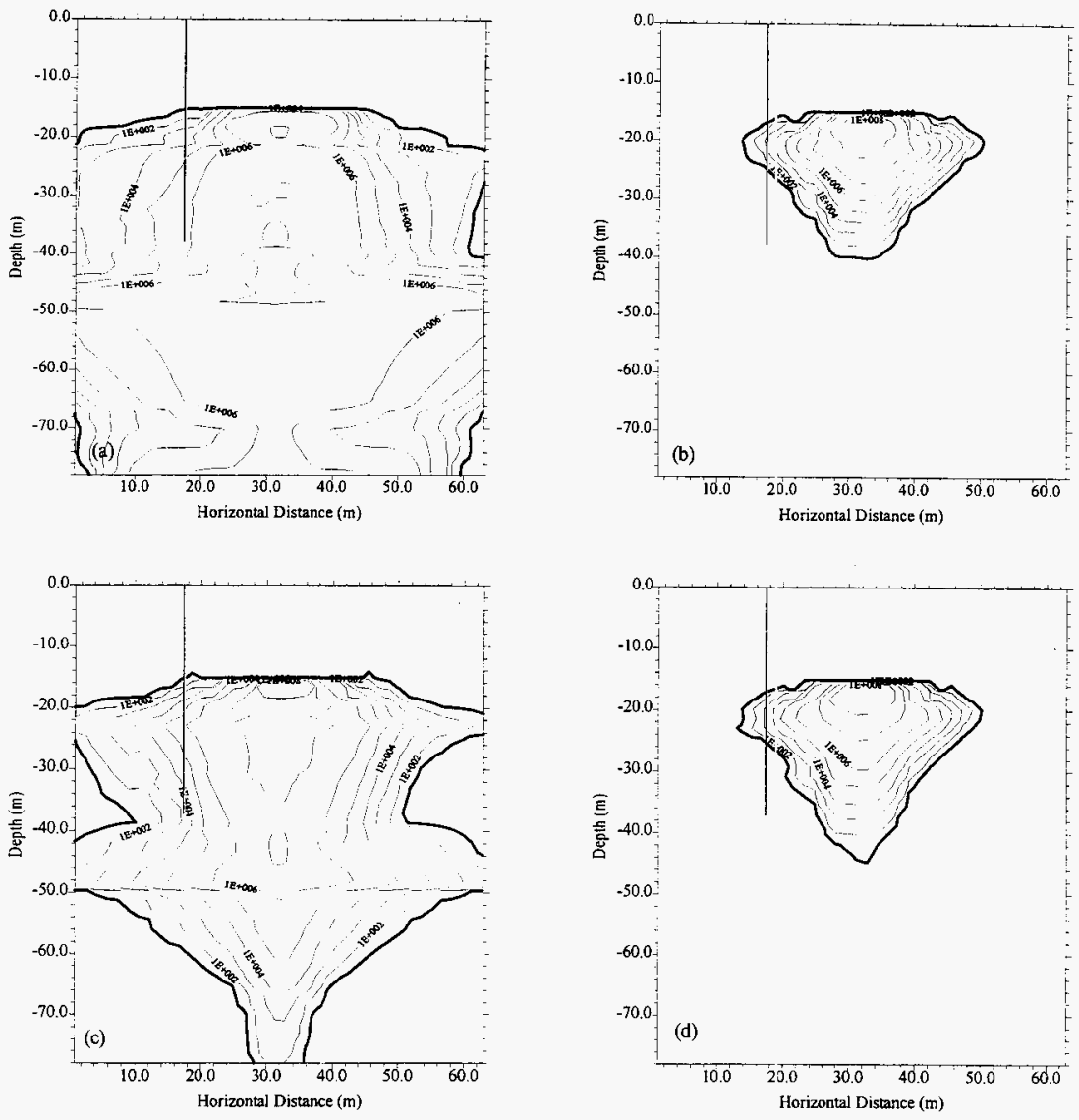
Since such a wide range of contaminant transport results can be generated simply by changing input variables, as shown by the results in Figure 4.26, it is imperative that comprehensive characterization of the vadose zone be undertaken to give clear focus and definition for computer simulations. As much as is feasible, sedimentation lenses should be identified. Lenses of fine textured material or gravel in a formation can induce preferential flow of formation water and solutes. Because identification of sedimentation lenses is a difficult task which may never provide more than sparse data, a reasonable modeling approach would be to assume a range of stratigraphic scenarios, including pessimistic ones, similar to those used for simulations by Nichols et al [1995]. Lenses of clay and gravel belo' a leaking tank were assumed to induce zones of preferential flow of formation water and organic contaminants, with results of the type exemplified in Figure 4.27. It is also notable in these simulations that contaminants reaching the water table in preferential flow zones in year 5 show a significant component of transport within the capillary fringe above the watertable (approximately $3 \mathrm{~m}$ depth, Figure $4.27 \mathrm{~b}$ ). The capillary fringe zone should be an important zone of monitoring and characterization in both the vadose zone and groundwater monitoring programs. Simulations of the type described by Nichols et al [1995] for transport of immiscible organic fluids apparently have not been conducted for ${ }^{137} \mathrm{Cs}$ and other inorganic species present at the SX tank farm; at least none have been presented to the Panel.

\subsection{BOREHOLE PATHWAYS}

The conceptual model offered to the Panel of ${ }^{137} \mathrm{Cs}$ transport in the vadose zone beneath the SX tank farm was based on the premise that $\mathrm{K}_{\mathrm{d}}$-driven retardation factors alone control depth of contaminant penetration of the formation soils. The PNNL modelers presented various scenarios wherein the borehole serves as the conduit to explain the logging data. The bulk of the ${ }^{137} \mathrm{Cs}$ is still assumed to be retained by exchange reactions with the formation.

We do not doubt that borehole transport has contributed in some instances to the reported apparent contaminant concentrations at depth. However, the possibility of borehole transport in particular cases must not be allowed to divert attention from the broader issue of formation transport. The borehole scenarios in essence are another version of the short-circuiting flow pathways described for natural preferential pathways such as highly permeable formations, fractures or clastic dikes. It is the Panel's view that preferential pathways, including borehole pathways and natural formation pathways such as fractures and clastic dikes, provide credible routes for movement of contaminants to depth. None of these preferential pathways seems to be well enough understood to allow representation in modeling calculations with confidence. This deficiency will need to be addressed as part of the vadose zone characterization.

The precise mechanism of borehole transport has not been addressecl by its proponents, or at least has not been presented to the Panel. The Panel has not considered these mechanisms at length, but some relevant issues can be mentioned here. 
Figure 4.27 Contaminant Distribution at $\mathrm{t}=2 \mathrm{yr}$ for Tank Leik Simulation (4.27a);

Contaminant Distribution at $\mathrm{t}=5 \mathrm{yr}$ for Tank Leak Simulation (4.27b).
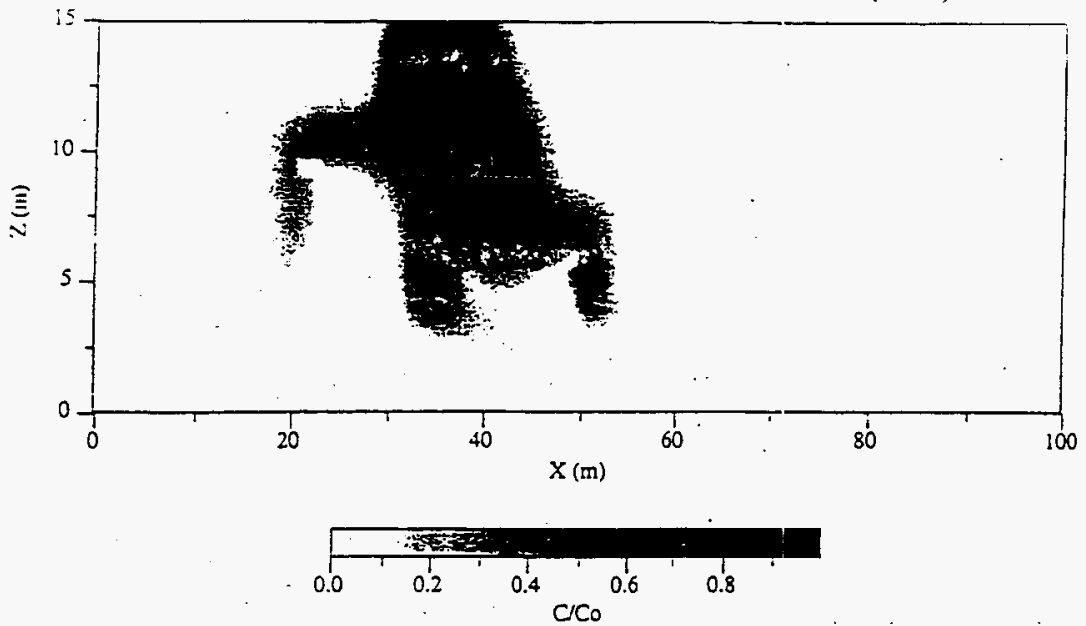

Contarninant Distribution at $t=2 \mathrm{yr}$ for Tank Leak Simulation
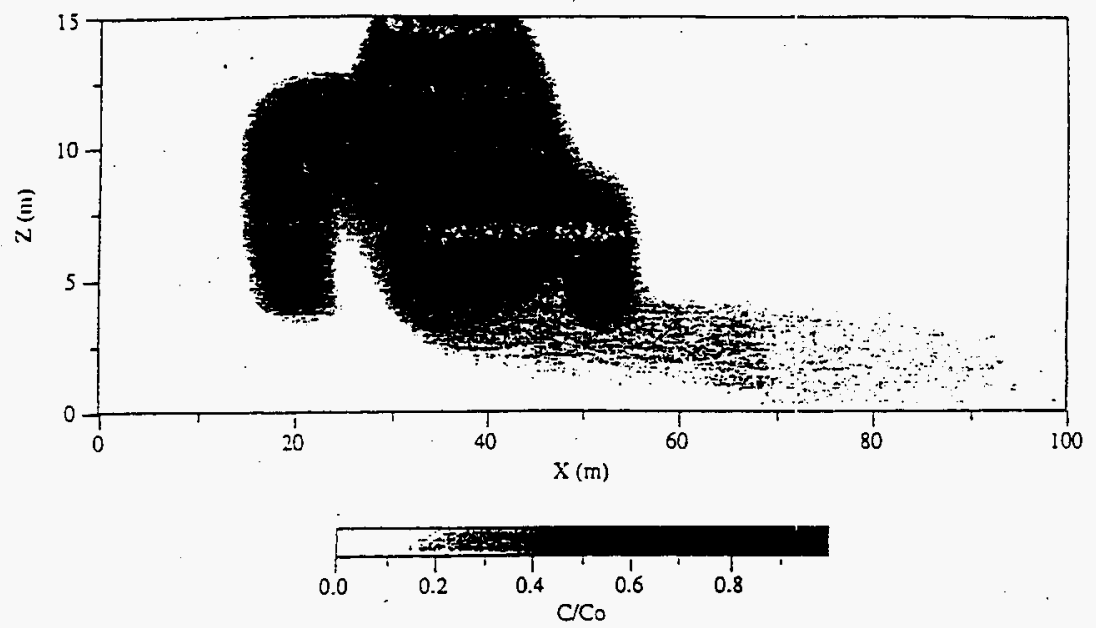

Contaminant Distribution at $t=5 \mathrm{yr}$ for Tank Leak Simulation 


\subsubsection{Solids Falling Down the Casing Exterior}

If the region outside the borehole casing is visualized as an air-filled annulus, both liquids and solid materials could move down the outside of the borehole. Considering solids first, materials dislodged during the process of drilling and setting casing, or after the borehole is completed, could fall down through the air-filled annulus, collecting at the bottom and at narrow or blocked points along the borehole. Larger materials might tend to bridge and fill the anmulus with the fill material having a higher effective porosity than the native formation, a process known as bulking. Since many boreholes were driven through a heavily contaminated zone, the probability is high that contaminants were carried down during installation of at least some boreholes; this effect was observed during installation of the first investigative borehole.

If the source of the falling material is contaminated with ${ }^{137} \mathrm{Cs}$, then a corresponding contamination zone would be indicated on the SGLS log. For highly contaminated material, the indicated concentration on the SGLS log is likely to be lower than the source material because of dilution by less contaminated material also dropping down the borehole. If uncontaminated material falls into relatively large annular space around the casing, then it could affect the SGLS results by blocking some of the gamma radiation coming from contaminated zones in the formation, resulting in an underestimate cf contamination. The scenario of falling solids is not likely to account for the zones at depth which exhibit such great gamma-ray fluxes that the gamma-logging system saturates (i.e., loses pulse counting capability).

\subsubsection{Contaminated Liquids Moving Down the Casing Exterior}

The movement of liquids down the outside of the casing is more coraplicated. First, the mechanism of how the liquid moves from the formation into the air-filled annulus is not obvious. While this movement may be possible under locally saturated conditions in, for example, a funneled flow zone; under unsaturated conditions the liquid would tend to be retained by capillary attraction in the formation. Similarly, if the annulus is filled with bulked material, capillary attraction should tend to retain the liquid in the lower-porosity formation.

Assuming that liquid is able to enter the annulus and run down the cutside of the casing, particularly under saturated flow conditions, the effect on the SGLS results could be quite different than in the case of solid contamination. For example, whether as a cation or colloidal suspension, liquid-borne ${ }^{137} \mathrm{Cs}$ contamination could be concentrated in specific zones to relatively high levels even from a low-concentration source, as long as the liquid deposits more ${ }^{137} \mathrm{Cs}$ than it removes from a given zone. As was shown by the point-source calibration performed on the SGLS, relatively low activity point sources just outside the casing produce activity levels comparable to high concentrations of ${ }^{137} \mathrm{Cs}$ distributed in the formation surrounding a borehole. It is also possible that contaminant-bearing liquids could be wicked back into the formation wherever formation material touches the casing, mimicking a formation source that shape-factor analysis, for example, might be unable to identify as borehole-borne contamination. Finally, we would not expect to see a shielding effect as in the 
case of falling solids, other than the relatively minor shielding that could result from an increase in water content of the material near the casing.

\subsubsection{Contaminants Falling or Dribbling Down the Casing Interior}

There is some evidence that ${ }^{137} \mathrm{Cs}$ may have entered the top of the borehole or through joints in the casing and flowed down the inside of the casing in some borehoies. In those instances where ${ }^{137} \mathrm{Cs}$ moved down the interior of a casing, the standard pract.ce of wipe testing the interior casing wall should easily detect the contaminants and shoulcl allow an estimate of the effect on the logging results, if any. Usually, boreholes with intericr contamination indicated from wipe tests are not logged to avoid contamination of the logging sonde. This form of contaminant transport is likely to result in ${ }^{137} \mathrm{Cs}$ activity at the base of the well, but is unlikely to produce the high activity levels observed in many boreholes at depths between the tank leak zone and the bottoms of the boreholes.

\subsubsection{Near-borehole Drilling Effects}

One of the concerns of the Panel is the extent to which contaminants: may have been carried down each borehole during borehole installation. The Panel designed a drilling program for the first two investigative boreholes installed in the SX tank farm at the Panel's recommendation. These percussion-drilled boreholes were repeatedly logged with the SGLS during the drilling process, providing overlapping data for determining if ${ }^{137} \mathrm{Cs}$ activity increased at particular depths after each stage of borehole emplacement. The first investigative borehole provided valuable data demonstrating borehole carry-down of contamination in the case of driven-casing borehole emplacement, although carry-down cf contaminants may have been exacerbated by a small weld-lip protruding from the bottom of the tool. The weld-lip was removed for the second investigative borehole. We have not seen similar studies for other borehole emplacement techniques such as sonic or cable drilling. Any drilling program for vadose zone characterization or groundwater monitoring should include safeguards to minimize and, if possible, quantify contamination transport up or down the bcrehole during drilling. 


\subsection{BOREHOLE LOGGING}

Geophysical borehole logging techniques are generally used for the in-situ determination of subsurface chemical, physical, geological and hydrological parameters. A variety of geophysical borehole logging methods have been used or tested at Hanford. In this section of the Panel report, some of the possible benefits and deficiencies of borehole logging for investigating the vadose zone at Hanford are discussed. An earlier $r$ eview of DOE capabilities for vadose zone logging is also available [Hearst et al, 1993]. Atternpts by commercial logging contractors to adapt several standard techniques to Hanford conditions have recently been described [Gadeken et al, 1995; Ellis et al, 1995].

In general, borehole logging techniques have advantages and disadvantages that tend to complement those of physical sampling and can help address the drawbacks of physical sampling. The potential drawbacks of physical sampling include: (a) high costs, (b) delays in obtaining results of analyses from laboratories, (c) under sampling, (d) sample handling problems, and (e) ambiguity in long-term monitoring [Conaway and Hearst, 1993]. Borehole logging techniques, on the other hand, are limited in terms of the physical, chemical, and nuclear properties that can be determined and may be adversely affected by near-borehole conditions; relatively few contaminants can be directly and unambiguously detected with reasonable sensitivity, with the notable exception of gamma-emitting nuclides.

For investigating the vadose zone at Hanford, borehole logging makes sense because a great deal of data can be obtained economically in the hundreds of boreholes already available. The fact is that all of the boreholes in a tank farm (about 100 boreholes in the case of SX tank farm) can be logged for roughly the same cost as drilling and extensively simpling a single new borehole. Of course, logging cannot provide all the information neetled to characterize the vadose zone, or even most of it, and most of the existing boreholes are relatively shallow, 130 $\mathrm{ft}$ or less, so only the upper half of the vadose zone is interrogated. Thus, some combination of logging of existing boreholes along with judicious drilling and sampling will be needed for vadose zone characterization.

Borehole logging has an important advantage in long-term monitoring in that the same borehole can be revisited periodically to assess changes in the contaninated or remediated environment. Physical sampling is not well suited for monitoring; if you extract and analyze samples repeatedly and find that the results are significantly different from earlier samples, you do not know if the environment has changed or if the material you are analyzing is simply different from the earlier samples. In the case of long-term monitoring for contaminants, insitu logging measurements offer continuous coverage, reasonably large sample volume, and the ability to run repeat measurements in the same borehole year after year at reasonable cost. Once the borehole is cased, extraction of further samples becomes difficult, but most nuclear measurements [Schweitzer, 1991; Tittle, 1989] and some other measurements, such as temperature and moisture content, can be made through casing. 
Before collecting extensive amounts of data with a variety of logging techniques, it is important to establish which logging techniques provide useful data under these conditions. This implies that some sort of physical modeling and pilot study should be performed to verify the utility and cost-effectiveness of a given logging technique. Some logging techniques that may be useful are discussed briefly in this chapter.

\subsection{SPECTRAL GAMMA-RAY LOGGING: OVERVIEW}

Spectral gamma-ray (SGR) logging and certain other nuclear borehole logging techniques [Conaway and Hearst, 1993] are capable of identifying and mapping, specific nuclides in the rock or soil through which a borehole passes. SGR logging can identify particular gammaemitting nuclides based on characteristic gamma-ray energy spectra. Some of the benefits of borehole measurements, such as SGR logging, are described in a Gineral Accounting Office Report [GAO, 1992] in which it is stated that, "A simple 200-foot well currently costs over $\$ 150,000$ and a full analysis of soil samples every 5 feet costs aboul $\$ 200,000$. Given that the estimated cost of spectral gamma analysis is about $\$ 2,400$ per well, potential savings from using vadose zone technology [i.e., in-situ borehole measurements] in existing and new wells as a substitute for physical sampling are large." It is further stated that, "This technology can also reduce the risks of contaminating groundwater and exposing workers to radiation during the drilling of wells."

Passive SGR logging is a mature and well-understood technique thal: can be both sensitive and accurate in identifying gamma-emitting contaminants. SGR logging typically analyzes some 10,000 times more material than does sample analysis, and that material has not been subject to possible modification during sample extraction and handling. SGR logging can be used through casing, including steel casing, with reduced sensitivity.

A major cost factor in SGR or other nuclear borehole logging techniques is the cost of calibrating each system for each specific combination of conditions that will be encountered. To understand the scale of the calibration problem, it is helpful to draw a comparison with the calibration of laboratory analytical instrumentation. To calibrate laboratory gamma ray spectrometers, for instance, a number of calibration standards must be prepared containing accurately known constituents in the same geometry as the unknowi samples which are to be analyzed, and any deviation of the samples from the standards (for instance, different density) must be understood and corrections applied.

Precisely the same calibration requirements apply to borehole instrumentation except, instead of small cans or bottles of material, standards that simulate the borehole environment are needed. In the case of gamma-ray spectrometry, that typically means a physical "model" at least one meter in diameter by two meters high with a borehole of the appropriate diameter down the center. The model must be homogeneous or contain a known distribution of radioactive material. The model must be carefully analyzed and characterized, with all physical and chemical properties that affect gamma ray attenuation understood. Ideally, a 
number of such models representative of the range of environments expected to be encountered in actual boreholes are needed, possibly including different borehole diameters, casing and borehole fluid, formation porosity and saturation, and all other factors that affect gamma-ray attenuation. The models should be traceable to recognized standards. Any deviation of the actual borehole environment from the models must be understood and corrections applied as required; the process of determining such correction factors is generally more difficult than in the case of laboratory instruments because of the difference in scale.

Physical models may be composed of doped concrete or other material, such as quarried rock, designed to simulate the borehole environment as needed to meet the calibration requirements of a particular logging system. Many physical calibration models of that type already exist, including a number in the DOE complex and at other government facilities. For instance, doped concrete models were used extensively in the NURE Program in the U.S. [Steele and George, 1986] and similar programs in other countries [Killeen and Conaway, 1978], as well as in the petroleum industry [Koizumi, 1993; Belknap et al, 1959]. The SGR calibration models used at Hanford were originally developed for the NURE program and later moved to Hanford [Arnold and Butler, 1988]. Quarried rock models have been established at the U.S. Geological Survey in Denver [Mathews et al, 1985], at the Nevada Test Site [Mathews et al, 1987], in the petroleum industry and elsewhere. In some cases, models are made of loose material encased in a shell of aluminum, plastic or other material. Suitable experiments or computer modeling can be used to account for the effect of the shell. This approach has been used at the Nevada Test Site [Hearst, 1979] and elsewhere.

Due to cost and other constraints, the number of physical models available for calibration is usually not sufficient to cover all conditions encountered in the field. Frequently, computer simulations are used to supply additional information [e.g. Sanders and Kemshell, 1984; Pinault and Gataer, 1989; Verghese et al, 1988; Wilson and Conaway, 1993; Conaway et al, 1993; Conaway et al, 1995a]. Experimental data from physical models can be used to benchmark computer simulation programs for parameters that are easy to model physically. Other parameters that are difficult or impossible to model physically can then be studied using the computer simulations. For instance, it is a relatively straightforward task to evaluate the response of a given logging system in a totally dry physical model and a second model totally saturated with water, but achieving known, intermediate values of saturation using physical models can be difficult or impossible (this is not an issue with SGR logging, but can be for some other nuclear logging techniques). However, computer simulation programs, once benchmarked at $0 \%$ and $100 \%$ saturation, can extend the calibration results to intermediate values. Such models can also extend the calibration to include such factors as trace elements, different formation densities, and many other real-world conditions which may need to be studied and included in the calibration, data reduction and interpretation.

As a spectral gamma-ray logging instrument approaches the center of a thick layer of uniform composition, the instrument response reaches a constant value such that increasing the thickness of the layer will not change that value significantly. In such a thick, homogeneous layer, the countrate under the spectral peak corresponding to a given gamma-emitting nuclide 
is proportional to the concentration of that material in the layer [Scott et al, 1961]. In principle, the instrument response in a thick zone can be corrected by multiplicative and additive calibration and correction algorithms for non-standard borehole conclitions such as casing, mudcake, or borehole diameter different from the calibration conditions, to yield an accurate estimate of the property that the instrument is intended to measure [Wilson et al, 1979; Czubek, 1962; Czubek, 1969; Conaway et al, 1991a; Koizumi, 1996i].

A properly calibrated SGR logging instrument can give accurate results in thick zones or regions where rock properties vary slowly if appropriate correction tactors are applied for nonstandard borehole conditions. However, the logs will still be distorted in the vicinity of bed boundaries [Conaway, 1989]. Thin zones, in particular, give rise to data which can be very inaccurate, resulting in underestimated radioelement concentrations and overestimated contaminated zone thicknesses. The calculated product of concentration times zone thickness, however, will be correct under the assumption that concentration is a function of depth only. To correct for such distortion, additive and multiplicative correction factors are not sufficient. Methods have been developed, mostly for uranium logging, that are capable of improving the estimates of contaminant concentration and zone thickness [Scott, 1963; Conaway, 1983; Czubek and Zorski, 1976; Conaway et al, 1980a]. Such methods were not used in evaluating the SX tank farm SGR data.

If more detailed vertical resolution is desired, inverse theory must be applied to correct for the "smearing" effect of the spatial response of the logging instrument; this is sometimes called spatial deconvolution. In the case of SGR logging, this smearing effect is due largely to the fact that rock is translucent to gamma rays, so gamma rays from a thin bed are "seen" before the detector reaches the bed. This effect is a non-linear function of at number of borehole and formation parameters, including borehole diameter, casing type and thickness, and borehole fluid, as well as formation density, porosity and water saturation, and other factors that affect the passage of gamma radiation through matter [Conaway, 1980; Conaway, 1981; Wilson et al, 1979].

The application of linear inverse theory to nuclear borehole data requires some assumption regarding how the radioactive material is distributed. Generally, the; assumption is made that the material is distributed in homogeneous layers of arbitrary thickness. Spatial deconvolution techniques, which have proven superior to detector collimation and isther approaches, were used to detect substantial errors in the published radionuclide concentrations of a thin-zone gamma-ray logging test and calibration facility at DOE's Grand Junction installation during the NURE program [Bristow and Conaway, 1984]. Those errors, whic 7 had gone undetected throughout twenty years of logging instrument tests and calibrations in that model, were confirmed by subsequent physical sampling and laboratory analysis. In the air-filled boreholes commonly found at Hanford, gamma-radiation "singe" from a highly contaminated zone can affect the log for some distance from that zone. Here, collimation nay help improve log accuracy.

While SGR logging typically investigates much greater volumes of material than physical 
samples, it is still limited to a region near the borehole. Thus, contamination near the casing surface can be confused with formation-distributed contamination. It may be feasible to address this ambiguity by more sophisticated analysis of the data, such as spectral shape factor analysis or spatial response analysis or using other logging data suck as temperature logs to help resolve the issue; each is discussed below.

The spectral shape factor analysis technique is based on the fact that the contribution of secondary (Compton-scattered) gamma-rays to the spectrum resultinis from a gamma-ray source in the formation increases relative to the peak contribution as the distance of the source from the borehole increases (Figure 5.1). MACTEC-ERS personnel are currently attempting to develop spectral shape factor analysis into a practical tool. Although firmly grounded in theory, shape factor analysis is a difficult practical problem, because there are many potential sources of error that can affect this analysis. Nonetheless, because it addresses the key issue of distinguishing between borehole contamination and formation contanination, spectral shape factor analysis should be carefully investigated.

Another method that in principle can help distinguish borehole contamination from formationdistributed contamination is spatial response analysis. The radial distribution of radioactive material affects the spatial response of the instrument; a source close to the borehole produces a relatively sharp, narrow spatial response while the same source farther from the borehole produces a broad response (Figure 5.2). Similarly, a small source at any distance from the borehole produces a spatial response differing from that of a thin layer. Analysis of the spatial response of the logging system through zone can in principle help resolve the issue of borehole contamination versus formation-distributed contamination. Whether this spatial response analysis will be a practical tool for this purpose remains to be deternined.

An earlier project funded by DOE/EM-50 had the goal of coupling spatial response analysis with spectral shape factor analysis for investigating non-homogeneous distributions of gammaemitting contaminants in the Hanford environment; that project was discontinued because of changing priorities. In that project, an approach was being pursued called Optimized Geostatistical Inversion (OGI), intended to integrate nuclear geophysics, contaminant transport modeling, geostatistics, and other site data such as physical sample analyses [Conaway, 1995]. The OGI approach was designed to help explain the relationship between SGR borehole logs and physical sample data, how well the physical sample data and the SGR data predict the actual distribution of contaminants in the ground, and what the trade-offs are among sample density, data quality, and cost. This approach would also provide statistical quality control tools to describe the confidence limits of both SGR logging data and physical sample data.

\subsection{HIGH-RESOLUTION SPECTRAL GAMMA-RAY LOGGING}

As discussed earlier in this report, the SGLS, operated at Hanford by MACTEC-ERS, is a high resolution (narrow energy response function) SGR logging system. High-resolution SGR systems use cryogenically cooled germanium detectors and tend to be costly and relatively 
complicated. Nonetheless, they are unparalleled in their ability to identify gamma-emitting nuclides, because the photopeaks characteristic of particular radionuclides have a very narrow bandwidth and are typically well resolved and separated from other photopeaks in the spectra; in other words, the identification is generally unambiguous. 
Figure 5.1 Simulated SGLS Detector Pulse-Height Response

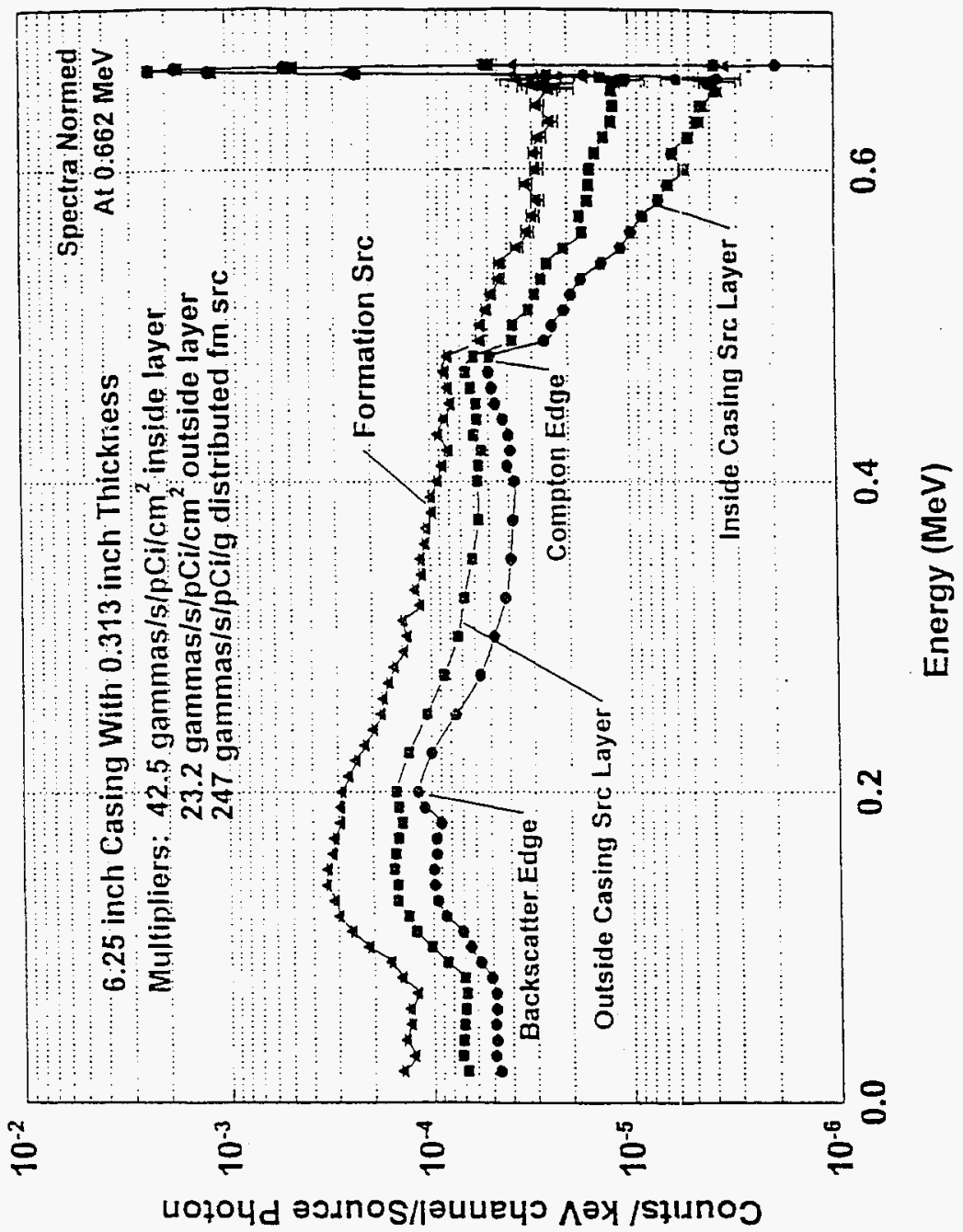


Figure 5.2 Normalized Spacial Response of Gamma Logs as a Funstion of Source-to-Detector Distance [Price, 1996].

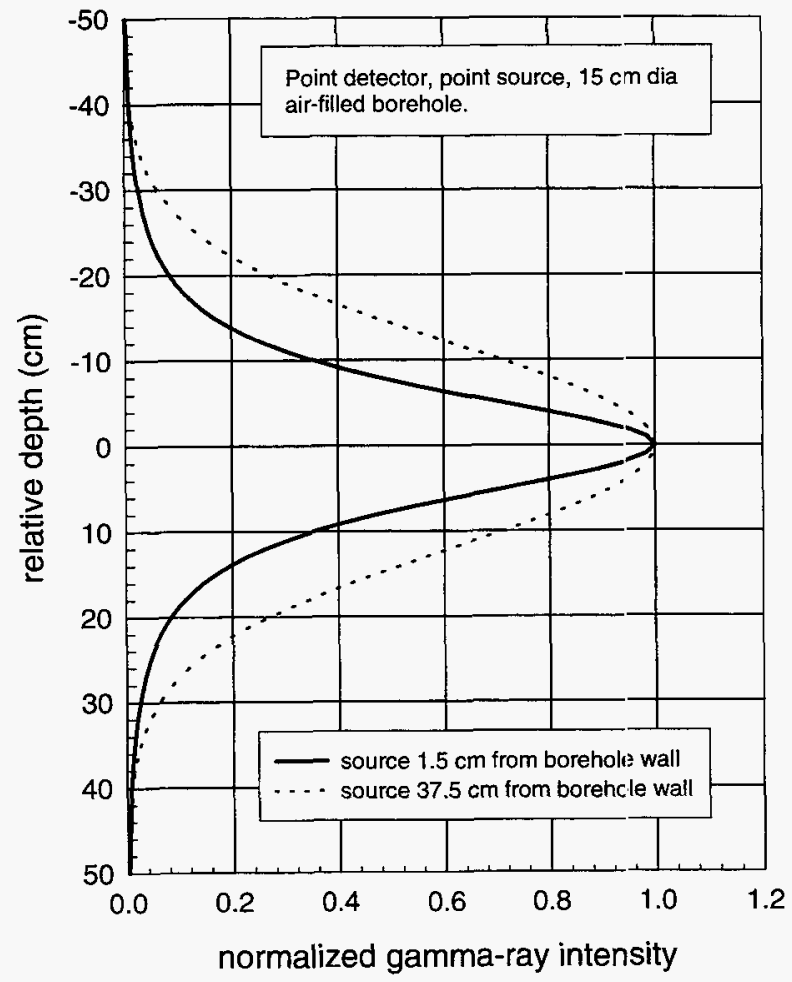


High-resolution SGR logging is an extremely sensitive indicator of gamma-emitting nuclides in the ground. Given appropriate quality control, ${ }^{137} \mathrm{Cs}$ can be unambiguously identified except at very low or high concentrations. At the low concentration end, a detection threshold on the order of $0.1 \mathrm{pCi} / \mathrm{g}$ for ${ }^{137} \mathrm{Cs}$ is probably achievable with a high-resolution SGR logging system such as the SGLS if other gamma-emitters are not present in large quantities. At the high concentration end, the technique is limited by system deadtime along with pulse pileup, both exacerbated by pulse distortion at various parts of the system. The spectral response of the SGLS suffers badly at ${ }^{137} \mathrm{Cs}$ concentrations greater than perhaps $10^{4} \mathrm{pCi} / \mathrm{g}$ and the response actually reverses at approximately $1.6 \times 10^{4} \mathrm{pCi} / \mathrm{g}$, so that concentrations above that level are reported as lower concentrations (see discussion at section 6.7 of this report). The sonde combination of detector and preamplifier transmits analog pulses up the logging cable to the amplifier analog-to-digital converter in the logging truck; so, pulse distortion may develop in the logging cable if analog-to-digital conversion is not carried out in the downhole instrument. Discussion of pulse distortion and pileup are given elsewhere [Bristow, 1994].

\subsection{LOW-RESOLUTION SPECTRAL GAMMA-RAY LOGGING}

A simpler form of spectral gamma-ray logging typically uses a scintillation detector composed of sodium iodide, cesium iodide, or bismuth germanate [Conaway et al, 1980b; Stromswald, 1980], materials that do not require cryogenic temperatures in the logging sonde. Scintillation detectors produce energy spectra with much broader features than the germanium-based RLS instruments, making them less suited for distinguishing the contribution of one gamma-emitting nuclide from a spectrum representing several different radionuclides.

Low-resolution SGR logging systems tend to be less costly to acquire, maintain, and run than a germanium-based system. Generally, dividing a low-resolution spectrum into 256 energy channels is entirely adequate, while each SGLS has sufficient resolution to require 4096 energy channels. Fewer channels means simpler electronics, an important factor contributing to the reduced cost. With simpler electronics it is relatively easy to build the analog-to-digital converter into the logging sonde and transmit the spectra up the logging cable digitally, an advantage over systems like the SGLS that transmit analog pulses up the logging cable. Scintillator-based systems can be designed with low deadtime, allowing logs to be made in high countrate zones, while downhole digitization eliminates pulse distortion in the cable. The major disadvantage of these systems remains the low energy resolution and possibly broad, overlapping photopeaks when multi-component spectra are analyzed. Nonetheless, artificial nuclides can be unambiguously identified under favorable conditions [Conaway, 1991a]. The SX tank farm may be a particularly favorable situation, because ${ }^{137} \mathrm{Cs}$ alone so predominates the gamma-ray flux in the contaminated zones.

A low-resolution spectral gamma-ray logging system might make sense in the vadose zone characterization program for logging boreholes with high-concentrations of gamma emitters, or as a long-term monitoring system to watch for changes in the distribution of gamma emitters over a period of years. Shape factor analysis and spatial response analysis can be performed 
with low-resolution spectral logging. The relative effectiveness of shape factor analysis with low resolution logs remains to be determined.

\subsection{GROSS-COUNT GAMMA-RAY LOGGING}

Gross-count gamma-ray logs respond to gamma radiation without distinguishing the energy of the incident gamma-rays, as opposed the case of spectral gamma-ray logs. A distinction is customarily drawn between gross-count and total-count gamma-ray logs. In total-count logs a low-energy threshold of typically a few hundred $\mathrm{keV}$ is imposed so that gamma-rays with energies that fall below that threshold are not counted, while gross-count systems accept all gamma rays that interact with the detector.

An extensive program of gross-count gamma-ray logging has been conducted at the Hanford tank farms for several decades, primarily for gross leak detection and monitoring. These logs seem to be fairly crude by industry standards, but the data may nonetheless be useful. At SX tank farm, gross-count gamma logs are only available from 1975 forward, many years after a number of the major leak events; earlier logs were run but the data sither were not archived or are not available in a useful form.

At the first Panel meeting, Mr. R.K. Price presented an analysis of historic gross gamma-ray logs in borehole 41-07-08. For a particular anomaly on the logs, a plot of area under the anomaly against time in years showed a steady increase in apparent contamination in that zone (Figure 5.3). A similar plot of background countrates against time showed no significant change, giving confidence to the interpretation that the contamination was indeed increasing with time.

The Panel subsequently looked at the several hundred historical gross-count logs from two boreholes, 41-12-02 and 41-09-04. For each borehole, the logs were sorted first by tool number, then by date; as stated above, the earliest logs were run in 1.975 . We plotted all of the gross-count gamma-ray logs available from the two boreholes sequentially on separate plots and plotted selected logs superimposed to look for changes over time:

The logs in 41-12-02 and 41-09-04 show a tare (step change) in the instrument response between 7-Mar-78 and 4-Apr-78. Between those dates, instrument response dropped by a factor of roughly 4 . The drop was not uniform over the response ra:ge; high countrate response dropped by less, approximately a factor of 3 . This tare indicates that the instrument was modified, replaced, or damaged. It also suggests that there was probably less nonlinearity in the response after the change (less saturation in high radiation zones in the borehole). In addition to the tare described above, other instrument glitches are visible and depth offsets from run to run of several feet are common. 
Figure 5.3 Analysis of Surveillance Logs from Borehole 41-07-08 [Price, 1996].

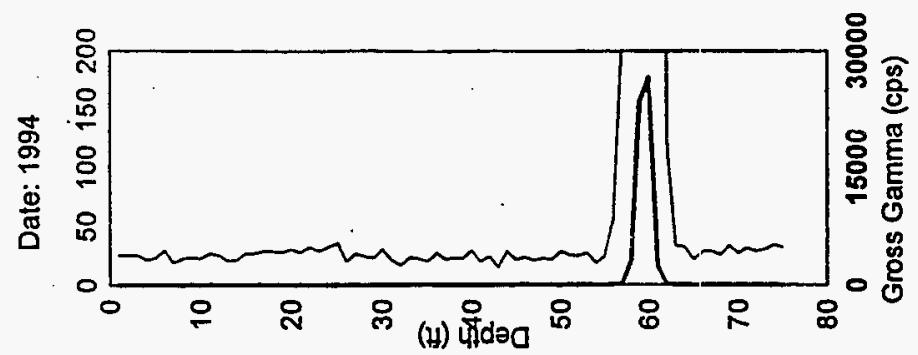

(sdo) punosbxpeg

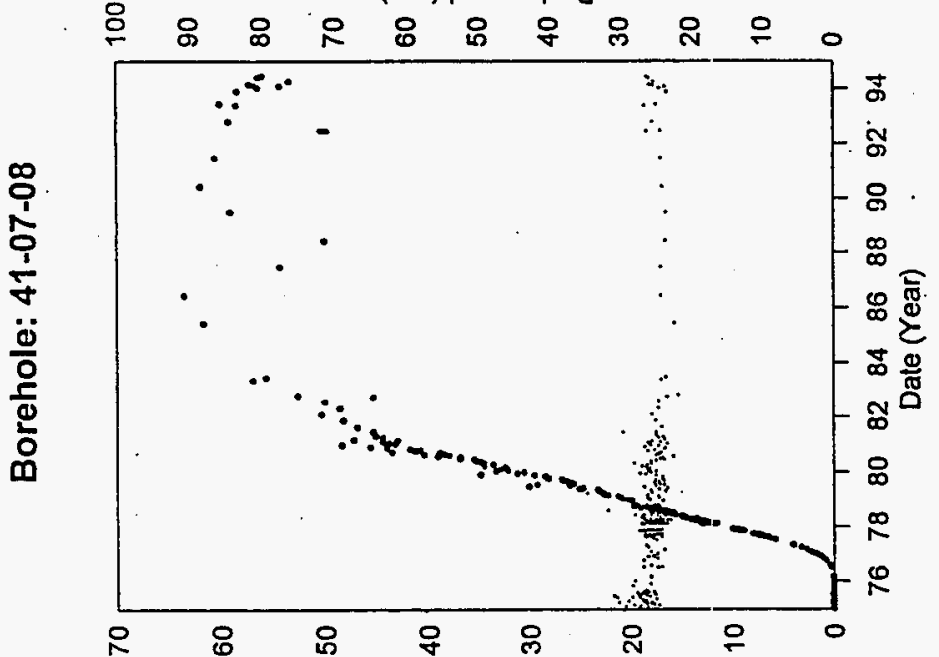

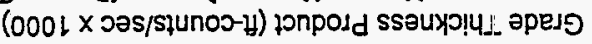

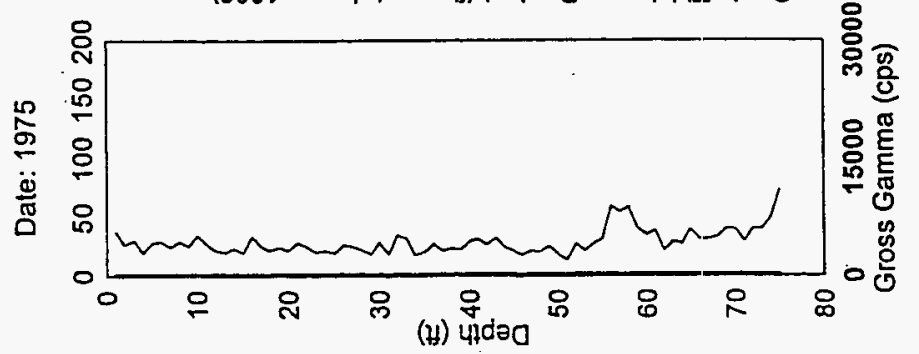


After compensating for the instrument response tare and other problems described above, the logs from borehole 41-12-02 acquired between 1975 and 1994 indicate an increase in gammaray flux from the high-flux zone at about 70 to $74 \mathrm{ft}$, the increase occurring mostly in the earlier years. Overall, the logs show a gradual decrease in countrate that may be consistent with decay of ${ }^{137} \mathrm{Cs}$. Other, more subtle changes may be present that were not revealed in this first look.

Again taking into account the instrument response tare described ea:lier, the logs from borehole 41-09-04 acquired between 1975 and 1982 show a clear insrease in countrates between about 75 feet and 88 feet (the depths could be off by sever.l feet). The increased countrates between 83 and 88 feet are probably caused by migration of radioactive material. The increase between 75 and 83 feet appears to be at least partly due to migration, although an improvement in instrument linearity (less saturation) may also be involved. An examination of four logs selected arbitrarily at roughly two year intervals indicates the increase seems to have taken place gradually over the seven year period covered by the logis. Even the maximum countrate zone increased in countrate, making it unlikely that dry material was falling along the borehole from above, since there are no higher concentration zones to contribute material. Other, more subtle changes may be present that were not revealed in this first look.

Price (1996) examined the gross gamma logs from the 1975 to 1995 period for ten drywells in the SX tank farm. Peaks in gross gamma logs above background occurred in 15 depth zones ranging from 20 feet (leaking pipeline) to 82 feet, which is 27 feet kelow the base of the underground tanks. At five of the contamination zones $(58,62,64,74$ and $77 \mathrm{ft}$ depths) the gamma logs were apparently stable, and decline in gamma counts is attributed to decay as shown for the $77 \mathrm{ft}$ depth of drywell 41-11-10 (Figure 5.4). Four contamination zones (64, 68,74 and $82 \mathrm{ft}$ depths) were all initiated in 1984 and continue to ircrease; see, for example, the $82 \mathrm{ft}$ depth in Figure 5.4. The $68 \mathrm{ft}$ depth at the same drywell shows a decline in gamma counts, but at a rate that is less than that expected from decay (solid line, Figure 5.4). At drywell 41-07-08, gamma counts for the $59 \mathrm{ft}$ depth increased from 1976 to 1986, and then decline at a rate that seems to exceed decay (Figure 5.3). These observations indicate the active influx and efflux of contaminants in the vadose zone. In a sejarate effort, Price (1996) examined gross gamma logs from ten other SX farm boreholes, finding several instances of moving contamination well documented by changes in the log character over the years. Price recommends that the remaining historic gross-gamma surveillance logs should be retrieved and reviewed for indications of dynamic radioactive plume conditions. This recommendation corresponds directly to that developed independently by the Panel.

In addition to increases in gamma-radiation levels that are probably due to increasing contamination levels, gross-count gamma-ray logs can provide othet useful information under favorable conditions. For example, some efforts have been made over the years at Hanford to infer which gamma-emitting nuclides are present in the ground based on gross-count gammaray logs. This involves comparing log amplitudes at a given depth over a number of years and comparing decreases in amplitude with decay-rate calculations for virious radionuclides. 
Figure 5.4 Analysis of Surveillance Logs from Borehole 41-11-10 [Price, 1996].
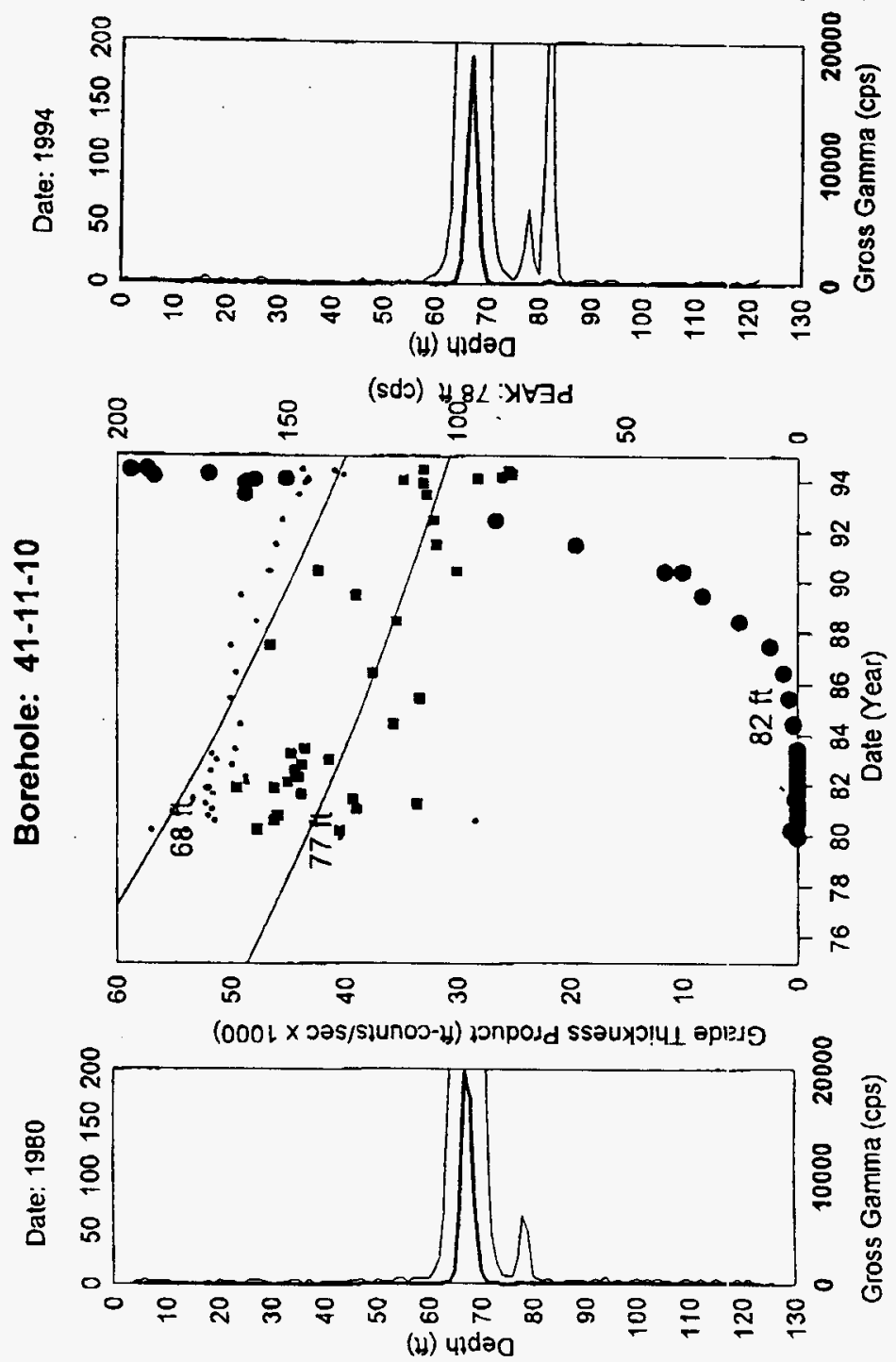
It is the view of the Panel that Hanford should have the capability to measure even the highest gamma-ray fluxes present in these boreholes without instrument saturation, thereby producing logs that are proportional to contaminant concentrations, all else being equal. This is important for hole-to-hole correlation, identifying tank-leak locations, calculating heat generation by radioactive contaminants, performing spectral shape factor analysis and spatial response analysis to distinguish borehole sources from formation sources, and detecting and monitoring movement of contaminants based on periodic logging. Unfortunately, the instruments used for producing the historic gross-count logs seem to exhibit non-linear behavior in high countrate zones, presumably because of instrument effects such as dead time and pulse pile up, and the historic logs may not be proportional to countrate in high countrate zones. Furthermore, the gross-count instruments were relatively insensitive to low levels of radiation and the typical sample interval was one foot, which is rather coarse, so the data do not reveal low concentrations or subtle details.

While the historical gross-count logs may still prove to be useful, it is the Panel's view that gross-count logging should give way to spectral logging in the future. Modern electronics should permit a scintillator-based spectral gamma-ray logging system to be acquired or developed at a reasonable cost that can operate in high garnma-radiation environments while still giving spectral data that are substantially more useful than gross-count data.

\subsection{TEMPERATURE LOGS}

A temperature log in a thermally-stable borehole through a uniform geologic formation would normally show essentially a straight line, with the temperature increasing slowly with depth at a rate corresponding to the local geothermal gradient (the general increase in temperature with depth due to the fact that the center of the earth is much hotter than the surface). Changes in the slope of this line can result from many different factors, including the following:

- Variations in thermal resistivity of the rock with depth (higher resistivity rock produces a higher geothermal gradient) [Beck, 1976; Conaway and Be:k, 1977].

- Thermal effects of drilling and engineering procedures in the borehole.

- Disturbances of the borehole fluid, such as free convection or groundwater flow in the borehole [Diment, 1967; Conaway, 1987].

- Distortion of heat flow by complicated geologic structure [Le:e and Henyey, 1974].

- Surface climatic changes [Beck, 1977].

- Local heat sources, such as cement setting outside the casing or radionuclides in the rock, or heat sinks such as hydrologic recharge from the surface. 
For the Hanford vadose zone characterization program, potentially the most important factor is the last one listed above, local heat sources. The radioactive decay of an atom liberates a minute amount of heat. Decay of large quantities and concentrations of radioactive nuclides can produce greatly elevated temperatures, as in the case of the underground storage tanks at Hanford. Similarly, radioactive contaminants in the formation will :aise the ambient temperature, and substantial contaminant concentrations can result in large temperature increases. This raises the question of whether information about raclioactive contamination in the formation can be gleaned from borehole temperature measurements. It is the Panel's view that the limiting factor here will be how well the temperature increase caused by formationdistributed contamination can be distinguished from the effect of other heat sources such as the underground storage tanks or contamination restricted to the borehoie region; other factors that influence the thermal profile such as soil water drainage may further confuse the picture.

Conventional temperature logs measure the temperature of the borelole fluid; the state of the art for this type of measurement in boreholes is several readings per foot with a precision (and repeatability in a thermally-stable borehole) of $0.0001 \mathrm{C}$, at a logging speed of 10-20 ft/min [Bristow and Conaway, 1984]. While excellent results can be obtained in liquid-filled wells under good conditions, the SX tank farm boreholes are all air-filled and cased. The thermal regime of a borehole air column is delicate and easily disturbed by changes such as the opening of a borehole cover and lowering of an instrument into the hole. Also, the thermal regime of the air column tends to be unstable in the region above a heat source because of thermallydriven natural convection. Because of these problems, conventional temperature logging instruments used in air-filled boreholes cannot be expected to produce anything more than qualitative information.

The relative reliability of conventional temperature measurements in air-filled boreholes is demonstrated in Figure 5.5, which shows 8 temperature logs at SX tarm, two each in four boreholes. In this figure, the effect of the seasonal variations in sur.ace temperature are seen to propagate at least $40 \mathrm{ft}$ down the borehole; this is clearly a borehole effect because the seasonal temperature effect only penetrates a few feet through the ground [Beck, 1977]. Temperature differences from run to run deeper in the borehole reach about $10^{\circ} \mathrm{F}$. Figures 5.6 and 5.7, show all temperature logs currently available from SX farm with maximum temperature, $T_{\max }$, less than $110^{\circ} \mathrm{F}$ and greater than $110^{\circ} \mathrm{F}$, respectively. Note that each curve reaches $\mathrm{T}_{\max }$ at a somewhat higher elevation than the bottom of the torehole. In the case of boreholes on the order of 75 feet deep, $T_{\max }$ typically occurs at about 60 feet, while in boreholes on the order of $130 \mathrm{ft}$ deep, $T_{\max }$ occurs at about 85 feet. There is no obvious spatial relationship correlating this effect with borehole location (see the map shown in Figure 5.8); rather, it appears to either be an effect of the instability of the borehole air column or some other borehole-related error such as a casing effect.

For air-filled boreholes, one way to improve the temperature logging results might be to measure the casing temperature, which should be more representative of formation temperature than measurements in the air column. Casing temperatures could be obtained using a temperature sensor in contact with the casing or, probably better, arı infrared sensor. The 
question of how closely casing temperatures are related to formation temperatures remains to be determined; this should be checked with simulations or experiments. For example, the casing could have a smoothing effect on the borehole temperature p:ofile and the effect of surface temperature 
Figure 5.5 Repeat Runs of Temperature Logs.

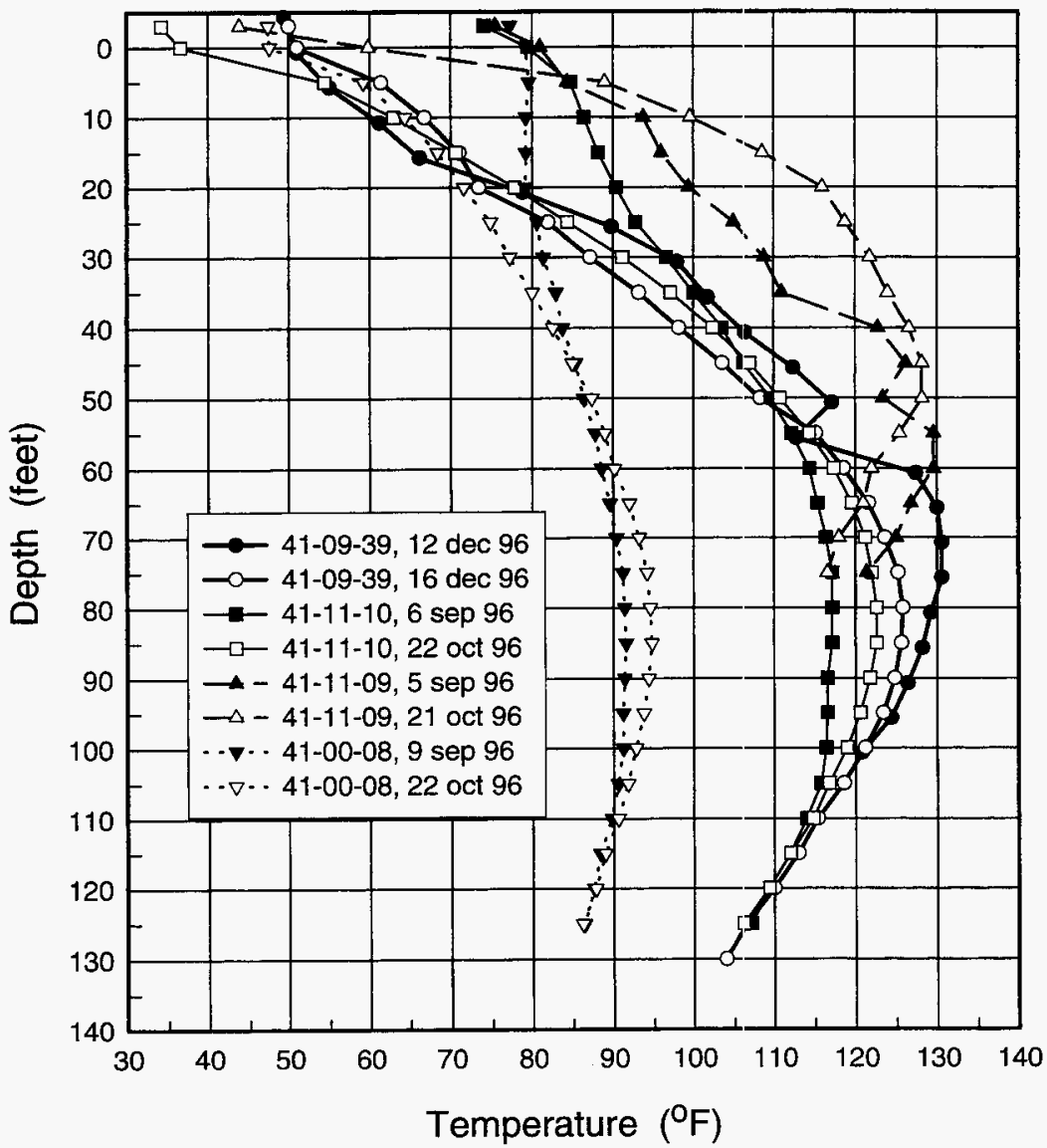


Figure 5.6 Boreholes with $\mathrm{T}_{\max }<110 \mathrm{~F}$.

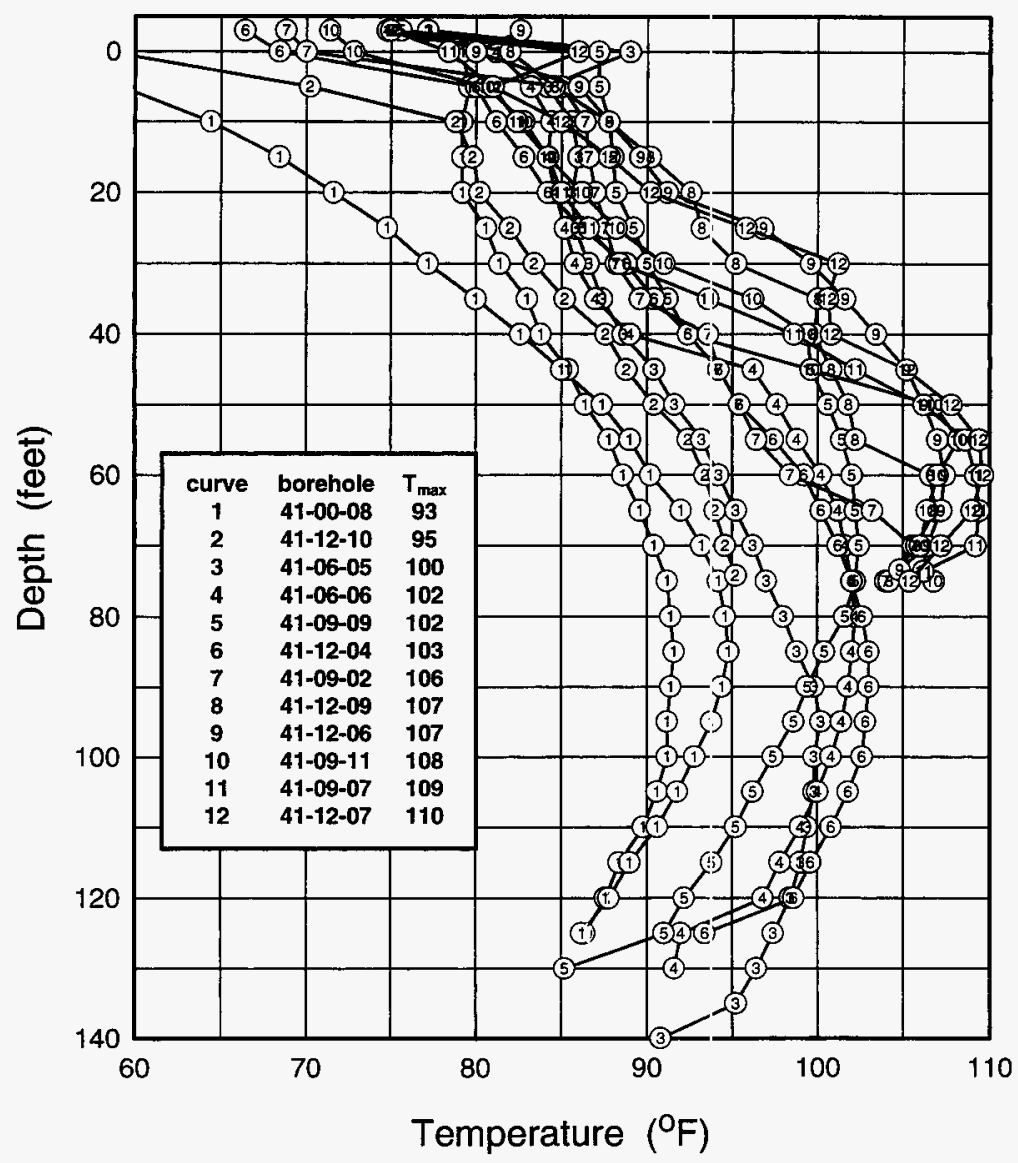


Figure 5.7 Boreholes with $\mathrm{T}_{\max }>110 \mathrm{~F}$

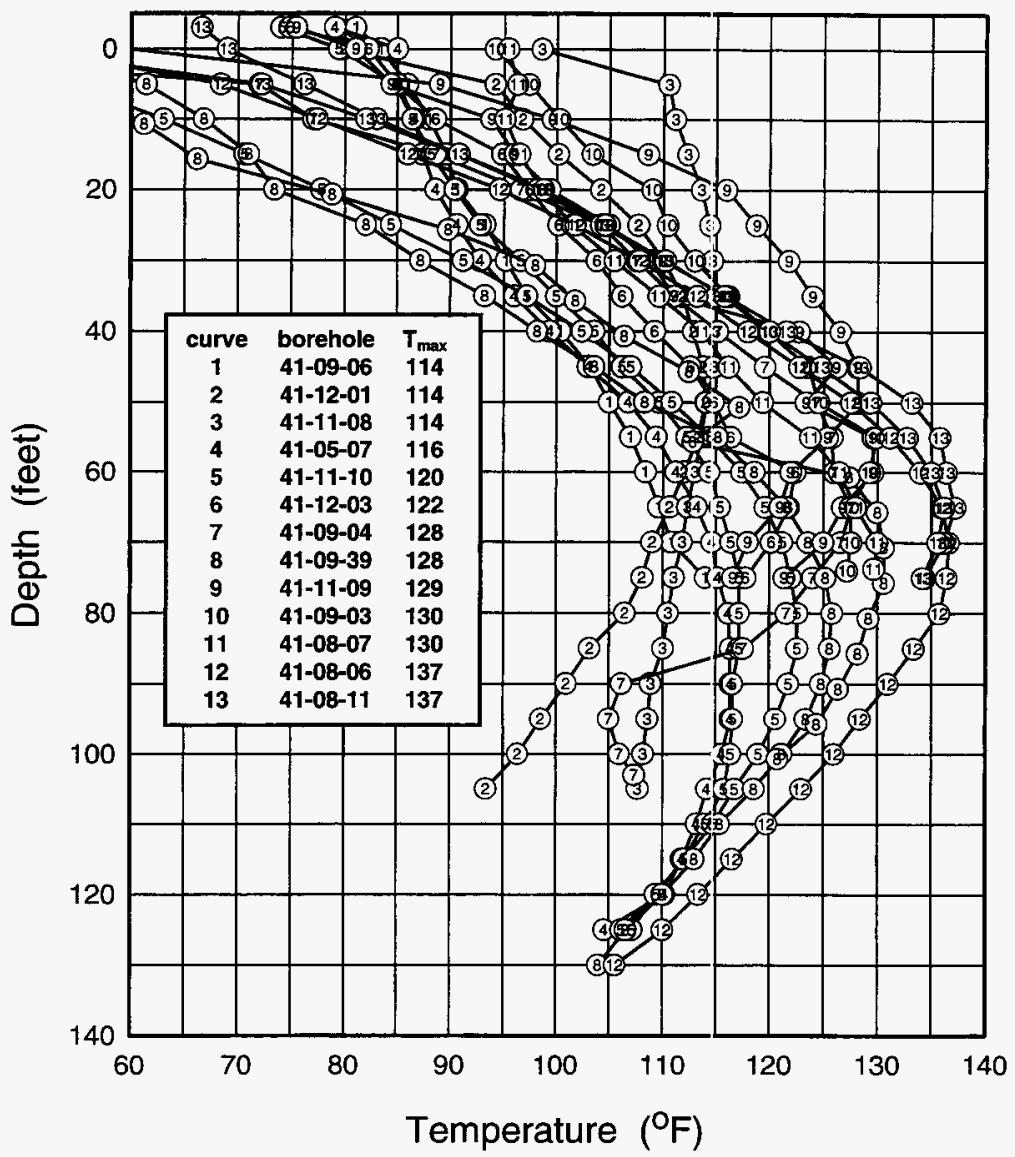


Figure 5.8 Temperature Maxima Plotted as a Function of Borehole Location.

*
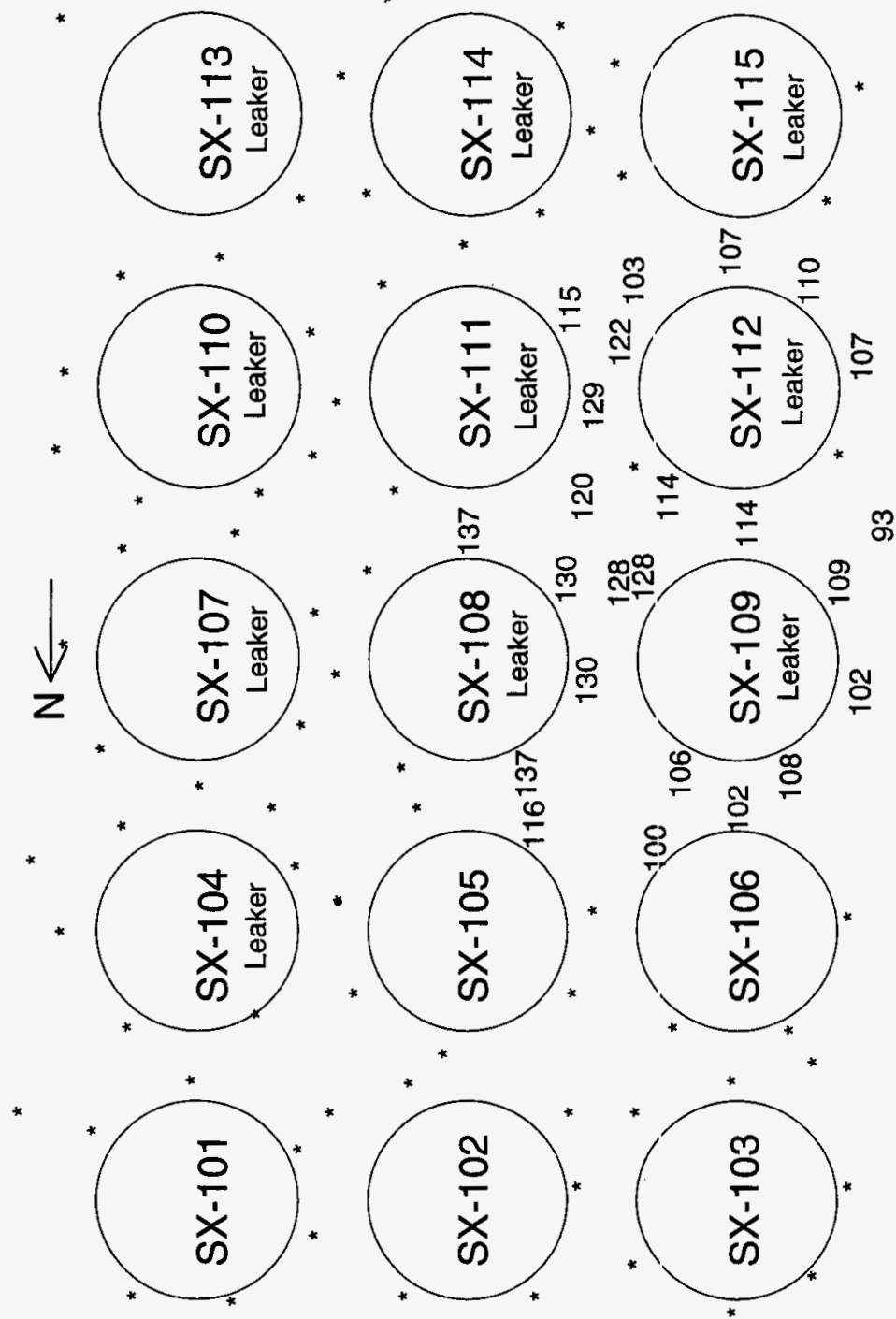
variations on casing temperatures at depth is not known.

Another approach to improving temperature logging results might be to fill the borehole with liquid or gel and measure the temperature of this more stable mediurn after allowing it to reach equilibrium with the surrounding temperanure profile. To avoid infittration into the formation, the liquid could be contained in an impermeable borehole liner, a currently available technology. This approach appears more cumbersome and costly than direct measurement of casing temperature, although both approaches should be checked with computer simulations to see if either gives a significantly better indication of true formation temperature.

Computer simulations of the subsurface thermal regime typically adclress what is known as the forward problem. In the forward problem, a set of ambient conditions is assumed and a simulation is performed to predict the temperature regime over time, and particularly the borehole temperature profile that would be measured at a given time under the assumed conditions. For the tank farms, ambient conditions might include the natural geothermal gradient in the earth, other heat sources such as the tanks and radioactive contaminants in the formation, thermal properties of geologic structure, dynamic effects such as recharge from the surface, and thermal properties of the casing and borehole fluid column as well as the coupling of the casing to the formation. The simulation is repeated for a varisty of different ambient conditions, leading to a sensitivity analysis that tells us how sensitive the measurements will be for extracting desired information such as the distribution of radioactive nuclides in the formation.

The inverse problem is more difficult than the forward problem and is basically the process of starting with one or more borehole temperature profiles and inferring the ambient conditions that resulted in those profiles. There may be many sets of ambient conditions that can produce a given borehole temperature profile within the limits of measurement error, but that does not mean the inverse problem is hopeless. By accurately controlling as many input parameters as possible, such as geologic structure and thermal properties, and by eliminating impossible or improbable scenarios, temperature logs may ultimately provide valuible information cost effectively. For example, the ability to distinguish between formation-distributed contamination and borehole contamination based on temperature log:s would be valuable, as would be the ability to identify zones that are contaminated with radioactive materials such as ${ }^{90} \mathrm{Sr}$ that are not gamma emitters, and therefor not seen in gamma-ray logs.

At the request of the Panel some preliminary simulations of this problem were performed by Daniel P. Stephens \& Associates, Inc. The simulation exercise was necessarily limited by the short time period available for the work, and better-defined simulations are needed to determine what temperature logging offers to the vadose zone characterization program at Hanford. There are several important questions that a valid forwarc model might be able to answer. The first question is how closely casing temperatures are related to formation temperatures; if there is little correlation, then further work is probably pointless. If it turns out that casing temperatures are reasonable indicators of formation temperatures, then a sensitivity analysis can be performed as described above to determire whether temperature 
logging can reasonably be relied upon to provide useful information about radionuclide concentrations. If so, then the best methods for obtaining that information can be developed. If the casing effect is large, it may still be possible to recover reasonably representative formation temperatures by backing out the perturbing effect of the casing. As far as the Panel knows, this has never been done, but seems feasible.

A preliminary analysis of the temperature logs run to date suggests that further work to improve the measurements is warranted. For example, Figure 5.8 shows borehole maximum temperatures plotted on a map of SX farm at the corresponding borehole positions. In spite of the measurement problems described above, there seem to be patterns here that may not be explained entirely by tank temperatures. If the temperature logs obtained so far prove representative, the set of logs for boreholes 41-08-11, 41-08-07, 41-08-06, 41-09-03, 41-0904, 41-09-39, 41-11-10, 41-11-09 and 41-12-03 suggests a temperature anomaly exists between tanks 241-SX-108, $-109,-111$ and -112 (from Figures 5.6 and 5.7). Heat from the tanks appears to increase the temperature of the soil surrounding the tanks to maxima ranging from $95^{\circ} \mathrm{F}$ to $110^{\circ} \mathrm{F}$ (Figure 5.5 and 5.6), while leaked contaminants increase the soil temperature further. However, in the region of interest the anomalously high ternperatures extend to depths below those normally ascribed to the principal portion of liquids leaked from those tanks (Figure 5.7). A complete set of accurate temperature logs for the ertire tank farm might help locate plumes of radioactive contaminants that were previously unknown, including ${ }^{90} \mathrm{Sr}$ which is not a gamma emitter.

The composite temperature-log profile (Figure 5.8) appears to lend some credibility to the concept of a broadly distributed ${ }^{137} \mathrm{Cs}$ plume displayed in the visualizations of the SX Tank Farm Report, at least for the anomalously high-heat zone between tanks 41-SX-108, -109, -111 and -112 . Thus, the graphic which created such a controversy (Figure 1.1) may prove to be a reasonable representation of conditions at that particular location, after all. The temperature logs obtained so far are too crude to permit a firm conclusion, however. Temperature logs have not yet been obtained at any other location, so we are unable tc comment about the universality of the temperature effect at other tank farms, or even at other locations within the SX tank farm.

Compared with many other logging techniques, temperature logging is relatively simple and inexpensive and, unlike some logging techniques, measurements can be made in cased boreholes. It is the Panel's view that any inexpensive technique, such as temperature logging, that can make measurements through the casing in existing tank farm boreholes merits evaluation to see if the data are useful. Temperature logging may prove to be a valuable complement to spectral gamma shape factor analysis for identifying : zones where the formation soils are heavily contaminated. Unlike gamma-logs, which can result in high countrates when only relatively small sources of ${ }^{137} \mathrm{Cs}$ are near the borehole casing, temperature logs measure the heat produced mainly by large quantities of beta- and beta/gamma-emitting radionuclides and are relatively insensitive to small quantities near the borehole. For tank leaks, large quantities of radioactivity are likely to be spread over a reasonably lirge volume of formation soil, so temperature logs effectively "sample" an even larger volume; of soil around or near 
boreholes than do gamma logs, and vastly more than does conventional sampling. The two techniques (gamma and temperature logging) are complementary, because each is more effective at a different level of radioactive contamination.

Shape factor analysis has been quoted to the Panel as applicable to zones of ${ }^{137} \mathrm{Cs}$ contamination of $100 \mathrm{pCi} / \mathrm{g}$ or less; improvement of the method to greater concentrations will require considerable development and may never be achievable beyond a few hundred $\mathrm{pCi} / \mathrm{g}$. From the data obtained so far, heat appears to be added to the formation soils where the ${ }^{137} \mathrm{Cs}$ concentrations overwhelm the gamma-logging instruments, making shape factor analysis impossible.

Shape factor analysis and temperature logging can serve to focus core-sampling and laboratory analysis efforts on those regions of contamination where an appreciable volume of soil is contaminated, but at different levels of contamination. In this way, expensive core-sample collection can be concentrated first at the heat source zones and then, as a borehole is extended, to those regions where shape factor (or spatial) analysis indicates that ${ }^{137} \mathrm{Cs}$ and/or ${ }^{90} \mathrm{Sr}$ are likely to be spread through a volume of formation soil. This would decrease the costs of sampling and analysis markedly from the extraordinarily great costs experienced for coring and analysis performed around tank T-106.

\subsection{OTHER LOGGING TECHNIQUES}

Most existing boreholes at Hanford are cased; uncased boreholes will probably not remain open for long in the poorly-consolidated materials in the vadose zone there. Thus, borehole logging techniques that cannot be used through casing are not considered here. Potentially useful techniques that can be used through casing, other than those considered above, include active nuclear techniques, such as gamma-gamma density and neutron-based water content logging, along with gravity density logging. One other class of measurements that will be briefly considered involve electromagnetic techniques that can be used through plastic casing, but not metal. It is the Panel's view that the capabilities and costs o:: all of these techniques should be ascertained to determine which, if any, might be useful in the vadose zone characterization program. Some efforts along these lines have already been made by PNNL in conjunction with two petroleum industry logging contractors [Gadeken et al, 1995; Ellis et al, 1995] but without cost-benefit analysis. On the other hand, an extersive cost-benefit analysis was produced by a Hanford contractor, but apparently was never released [Golder Associates, 1992]; that study reached questionable conclusions that should be reviewed and perhaps reconsidered.

Gamma-gamma logging is used extensively in the petroleum industry to estimate formation bulk density and porosity. Gamma rays from a source such as ${ }^{137} \mathrm{Cs}$ scatter through the borehole and formation and are detected by one or more gamma-ray detectors at some distance from the source; the use of multiple detectors permits some correction for near-borehole effects. This technique can be used through casing, although, as wilh any other nuclear 
technique, accuracy will be degraded. In particular, the fact that conditions behind the casing, such as void spaces, are not known is a serious impediment; a special type of gamma-gamma logging can help identify void spaces [Chudy, 1981]. A form of ga:nma-gamma density logging that makes use of gamma-ray energy information is used in the petroleum industry to help define lithology [Bertozzi et al, 1981]. A calibration facility for gamma-gamma density logging equipment is available at Hanford; this facility is designed to allow calibration in cased-borehole conditions with and without voids behind the casing [Engelman et al, 1995a]. Because the technique depends on detecting gamma-rays from the source in the downhole instrument, intense formation gamma-ray sources can render the results inaccurate or useless.

Neutron-neutron logging techniques use a neutron source and one or more detectors to estimate formation water content. The scattering and diffusion of neutrons is: affected mostly by light elements, chiefly hydrogen. Neutron scattering techniques are customarily divided into neutron logging measurements and moisture gauge measurements [Hearst and Carlson, 1984]. Moisture gauges are used mostly in soil and near-surface hydrology studies and have a very short source-detector spacing. Neutron logging devices have a relatively long source-detector spacing, often use multiple detectors at different spacings, and are used by geophysical logging contractors in petroleum applications and other fields. By making repeat measurements over time, neutron scattering techniques can be used to monitor changes in water content of the medium that may be associated with recharge or the movement of a contaminant plume. Although neutron scattering techniques can be influenced by the presence of high cross-section elements, such techniques cannot identify specific nuclides. While the neutrons easily penetrate steel casing, accuracy suffers in cased boreholes because of the unknown conditions behind the casing, including the possibility of void spaces. A calibration facility for neutronbased moisture logging equipment is available at Hanford [Engelman et al, 1995b].

Neutron-induced spectral gamma-ray techniques measure gamma-ray energy spectra during and/or after irradiation of the borehole environment by neutrons [LCck and Hoyer, 1974; Hertzog, 1978; Schweitzer and Manente, 1985; Conaway, 1986; Grau and Schweitzer, 1987; Senftle and Miskosell, 1988; Hearst et al, 1991; George and Burnham, 1984; George, 1992; Conaway et al, 1995b]. As such, they are analogous to laboratory techniques such as neutron activation analysis. Neutrons interact with many nuclear species in a variety of ways, such as inelastic scattering, prompt capture, and activation, to produce gamma rays having energy distributions which will enable those specific nuclides to be positive y identified under favorable conditions. Detectable contaminants include chlorine, a component of many organic contaminants, as well as heavy metals and other materials. As in the case of the passive SGR systems discussed above, the detector may be a high energy-resolution, solid-state cryogenic detector or a low energy-resolution scintillator. The logging instrument may contain a radiochemical source or a neutron generator.

Several fission neutron techniques have been developed at least to the prototype stage, mostly for uranium logging [Barnard et al, 1983; Humphreys et al, 1981; Cieorge and Wilson, 1994]. The general approach is to irradiate the borehole environment with neutrons and look for fission neutrons by using time gating or energy discrimination. While these techniques 
respond to fissile material, including certain isotopes of uranium and plutonium, near the borehole, they are not currently nuclide-specific. One such system, a prototype prompt fission neutron (PFN) logging system, was evaluated at the DOE Hanford site in 1993. The equipment had been developed for uranium evaluation during the NURE program. The logging sonde emits bursts of $14 \mathrm{MeV}$ neutrons and detects both thermal and epithermal neutrons as a function of time after each burst. This logging system is sensitive to fissionable nuclides, particularly ${ }^{235} \mathrm{U}$ and ${ }^{239} \mathrm{Pu}$ and to a lesser extent ${ }^{241} \mathrm{Pu}$. The authors report detecting ${ }^{239} \mathrm{Pu}$ concentrations as low as $10 \mathrm{nCi} / \mathrm{g}$ and suggest that a factor of five improvement may be possible with some development. This system also produces a therral decay time (TDT) log that is sensitive to materials having large neutron absorption cross sections, such as chlorine [Ellis, 1987]; several commercial logging companies also offer TDT-type logs.

Sensitive gravity meters are used to help define geologic structure ard estimate density distribution in the ground. These instruments are affected by mass located both above and below a given measurement station as described by Newton's gravitational theory [Telford et al, 1976]. Borehole gravity meters are used to measure relative gravitational acceleration at a number of depths and the data are used to estimate average formation density between measurement stations. This technique is little affected by near-borehole conditions and has a large radius of investigation; as a rule of thumb, the radius of investigation can be thought of as some five times the vertical measurement station spacing [Telford et al, 1976]. It is fairly straightforward, at least in principle, to apply corrections for known features that may affect the results, such as surface topography or the underground storage tanks at Hanford, thereby making the technique more sensitive for identifying subtle density variations. The borehole gravity technique may be useful for helping to determine physical properties of the formation that affect contaminant transport and mapping vertical and lateral density variations due to geologic structure or variations in formation water content [Schultz, 1989; Hearst, 1986].

Electromagnetic induction techniques can be used to estimate formation electrical properties through plastic casing; a variety of fairly well-developed techniques are available, operating over a large range of frequencies [Ellis, 1987]. Electromagnetic indrction logging is routinely used in the petroleum industry to estimate formation resistivities using a variety of frequencies and receiver and transmitter coil spacings, often in the same logging sonde, to achieve various depths of investigation and vertical spatial resolution. A non-nuclear: type of moisture gauge uses electromagnetic induction to estimate formation dielectric constint, inferring formation water content based on the fact that the dielectric constant of water is some 20 time greater than for most solid earth materials [Bell et al, 1987]. A somewhat related technique, nuclear magnetic logging, responds mainly to hydrogen in liquids such as witer and is not sensitive to hydrogen in other materials such as shale, unlike neutron logging that does not make that distinction [Kenyon, 1992]. 
This page intentionally left blank. 


\subsection{MEETINGS AND TELECONFERENCES/INVESTIGATIVE BOREHOLES}

Meetings of the Expert Panel were held on June 3-4, July 16-17, September 11-12, 1996 and January 14-16, 1997 at the offices of Los Alamos Technical Associates (LATA) in Richland, Washington. The entire first day and the morning of the second of each of the 1996 meetings were devoted to presentations by DOE and contractor staffs on subjects relevant to the Panel's deliberations; a tour of the SX tank farm and 200 West Area was provided during the morning of July 17 . The afternoons of June 3, July 17 and September 12 we:e devoted to the Panel's preparation of a contemporaneous consensus summary and recommendations, the product of a closed session limited to the Panel members and a recorder from LATA staff. The consensus summaries and recommendation were presented to DOE during a closeout briefing at the end of each meeting and are provided here. The morning of January 14, 1997 was devoted to reviewing the data package prepared by MACTEC-ERS for the second investigative borehole and hearing a presentation regarding electrical resistivity tomography (ERT) applications. The remainder of the meeting was spent developing concepts and material for this report.

The Panel took a proactive approach in its attempt to resolve the corflicting views presented at the meetings, an approach which included recommendations for installing a series of investigative boreholes, gamma-logging at ten-foot intervals during installation, and for temperature logging of all boreholes, among others. Various issues arising from borehole installation necessitated four teleconferences involving Panelists, DCE and contractor staffs, and Washington Ecology staff; teleconferences were conducted August 21, November 21 and December 17 and 18, 1996, and April 10, 1997. The Panel was provided an opportunity at the end of each teleconference to hold its own independent discussion, unfettered by input or review by DOE or contractor staffs. Transcripts of the November and December, 1996 teleconferences were prepared by contractor staff and are provided here, also. Neither summaries nor recommendations were prepared for the August 1996 teleconference or the January 1997 meeting.

Several telephone conversations among Panel members and between Panelists and GJPO, DOE-RL and contractor staff were unrecorded and are not reported separately except as they contribute to the text of this report. The Panel commends DOE for providing latitude for the Panel to conduct its business in a completely independent manner. Casey Ruud, Project Manager of the Vadose Zone Characterization Project, has been an especially effective and helpful patron for this Panel's work. The high level of independence has been maintained during preparation of this report.

This section of the Panel report consists of chronologically arranged summaries and agendas from the respective meetings and teleconferences. 


\subsection{MEETING OF JUNE 3-4, 1996}

\section{Summary}

Expert Panel Mission: The identification of the specific isotope Cs-137 has raised several significant issues. The first to be addressed: Is Cs-137 migrating downward through the Vadose Zone under the SX tank farm at such a rate that it will contaminate the groundwater?

The first step for the expert panel will be to evaluate and validate ore (or both) of two conceptual models: did the Cs-137 migrate down the boreholes to its present position and/or did it migrate through the formation.

\section{Recommendations}

DOE needs to do drilling data acquisition. Data is to be available for panel review by June 25 , 1996. The panel will then decide if more holes are to be installed. The following is recommended to be used for drilling data acquisition:

- Drill one hole on a line between boreholes 41-09-04 and 41-:2-02, parallel to and laterally five feet from 41-09-04;

- Hole is to be installed using pile driver casing with sealed shoe;

- Resistance (stroke count) is to be measured while driving;

- Hole is to be driven a minimum of $90^{\prime}$ with a goal of $130^{\prime}$;

- $\quad$ Log hole each ten feet of advance using RLS and standard logging protocol, use appropriate tool to avoid detector saturation;

- Data is to be available for panel review by June 25;

- The panel will then decide if more holes are to be installed.

Panel needs chronology with the following information:

- Need to develop a time sequence for borehole development;

- When the tanks started to heat up;

- $\quad$ Need more information to establish when did each tank first leak;

- Panel would like to have Don Wodrich to provide recollecticn of tank activities at the next meeting. When did the SX farm start to leak; does he tave records/reports of "bumping" in the SX farm? 


\section{Additional Information Needed}

- $\quad$ Panel would like to see all gamma logs for 41-06-04 and 41-.2-02

- Horizontal contour maps at five foot intervals of actual cesiun-137 measurements from boreholes for the whole farm--would like to see the same contour maps from the geostatistical model.

- Would like Bob Wilson to come and discuss the data which v/ould allow sorting out of cesium- 137 at various depths from strontium-90, if this data is available.

\subsection{MEETING OF JULY 16-17, 1996}

\section{Summary}

The concept that $\mathrm{Cs}^{137}$ travels through the formation to the groundwater along preferred vertical formation pathways is entirely plausible in this environment. This is the working hypothesis to be disproved:

- Work done until now is unrealistic including models, source terms, starting points

- Geostatistical model in SX tank farms draft report is not likely, but is properly explained in the report. The gamma spectral data are reasonable.

- Model does not represent what the panel suspects is more realistic (see attached figure)

- Strongly recommend all three boreholes be drilled

\section{Additional Information Needed}

- Better estimates of leak volumes from SX 108, 109, 111, and 112, (probable and worst case), using Steve Agnew's historical modeling approach.

- Chronology as spreadsheet (as requested at last meeting) neeiled for SX 108, 109, 111, 112 of :

- What leaked out and when

- When boreholes were drilled

- Annual infiltration rate when the holes were drilled and deepened in that area

- New calculations done by independent group with fresh view's. Calculations can be fairly simple (doesn't require complex computer codes), better no modeling than inappropriate modeling. Start with a hot-caustic-saline solut on ( 8 to 10 molar sodium at 350 degrees $\mathbf{F}$ or more), a hot formation (self heating), preferential vertical pathways to include:

- Heat budget outside the tank (literature search?) 
- Calculate conditions for two extremes:

- $\quad{ }^{137} \mathrm{Cs}$ borehole transport

- meteoric water

- more leaks

- $\quad{ }^{137}$ Cs transport via geologic medium (uniform vs preferred pathway)

- Duplicate T-106 well study to characterize contaminant in vadose zone under SX Farm

- Constructed to groundwater or near groundwater

- $\quad$ Sample

- $\quad$ Provide complete ground water data set

- $\quad$ Radionuclides

- Chemicals

For The Next Meeting

- $\quad$ Start each day from 7:30-8:30 with a closed Panel meeting

- Brief presentation on drilling options available - pro's \& con's (BHI \& John Auten, Don Moak)

- Want to know :

- What kinds of samples and logs can be obtained?

- What kind of seals are used?

- What kind of disturbance does the technique create?

- History on T-106 well \# 299-W10-196 (WHC-SD-EN-AP-078, Rev. 1)

- Costs/sampling

- $\quad$ How it was installed

- $\quad$ Pros \& cons

Recommendations for New Boreholes (Borehole Zero is Outside the Farm)

Borehole Logging

- For First Hole:

- $\quad$ First $\log @ 40 \mathrm{ft}$ to top (i.e., when hole reaches $40 \mathrm{ft}$., stop and $\log$ to surface)

- One log in the detector saturation zone

- Logs will be repeated every $10 \mathrm{ft}$ of advance up to the detector saturation zone

- Depth of final hole $90 \mathrm{ft}$. to $130 \mathrm{ft}$. - deeper is better

- Objective: Reduce downtime of drilling

- Drilling Technique: 15 degree form horizontal cone bottom to minimize spread of contamination (Don Engelman to direct BHI) 
- $\quad$ On 2nd and 3rd Hole - two loggings while driving

- $\quad$ First through maximum detectable zone

- Second after borehole completion

- Choice of hole 2 \& 3 location depends on $\log$ from John Brodeur - Brodeur to get resolved contours to panel within next week - Panel to select hole locations

- Detectors:

- Use $35 \%$ detector

- Brodeur needs to provide profile from geostatistical model of expected Cs counts as a function of depth at hole location with confidence intervals within one week.

- Solicit proposals on other types of logging to determine what else can be done to get data for the geostatistical model (Casey Ruud)

Decision Criteria $\mathrm{Cs}^{137}$

- Establish a formation baseline:

- $\quad$ At $>10 \mathrm{pCi} / \mathrm{g}$ - borehole contamination is questionabe

- $\quad$ At $<10 \mathrm{pCi} / \mathrm{g}$ - formation contamination is questionable

Panel would like to receive weekly status reports on the project via $\epsilon$ :mail or fax.

The panel requested the following documents from the Wodrich presentation:

- History of Bumps in Tanks (WHC-SD-WM-TI-406, Rev. 0) fold major bumps into chronology

- Documents on heat calculations for tanks and soil

- $\quad$ Portland cement summary report by Cheri Defigh-Price as cclauthor (approximately 1983).

\subsection{TELECONFERENCE OF AUGUST 21, 1996}

A transcript is not available for this teleconference; the Panel constructed this summary from notes.

The Panel first suggested during the June 4 meeting that the first of three investigative boreholes proposed by the Panel be installed along a line between boreholes 41-09-04 and 4112-02, approximately five feet from $41-09-04$ (see $A$ at $\{E 145, N 145\}$ in Figure 6.1). Sonic drilling was tested, but found to cause excessive vibration for use in the tank farm. The borehole was installed using the driven-casing technique because that is the best available environment for making direct measurements of ${ }^{137} \mathrm{Cs}$ concentrations with least disturbance by the drilling process. The borehole was logged with the SGLS several times (approximately at 
Figure 6.1 SX Tank Farm Pipeline/Utility GPR Irvestigation.

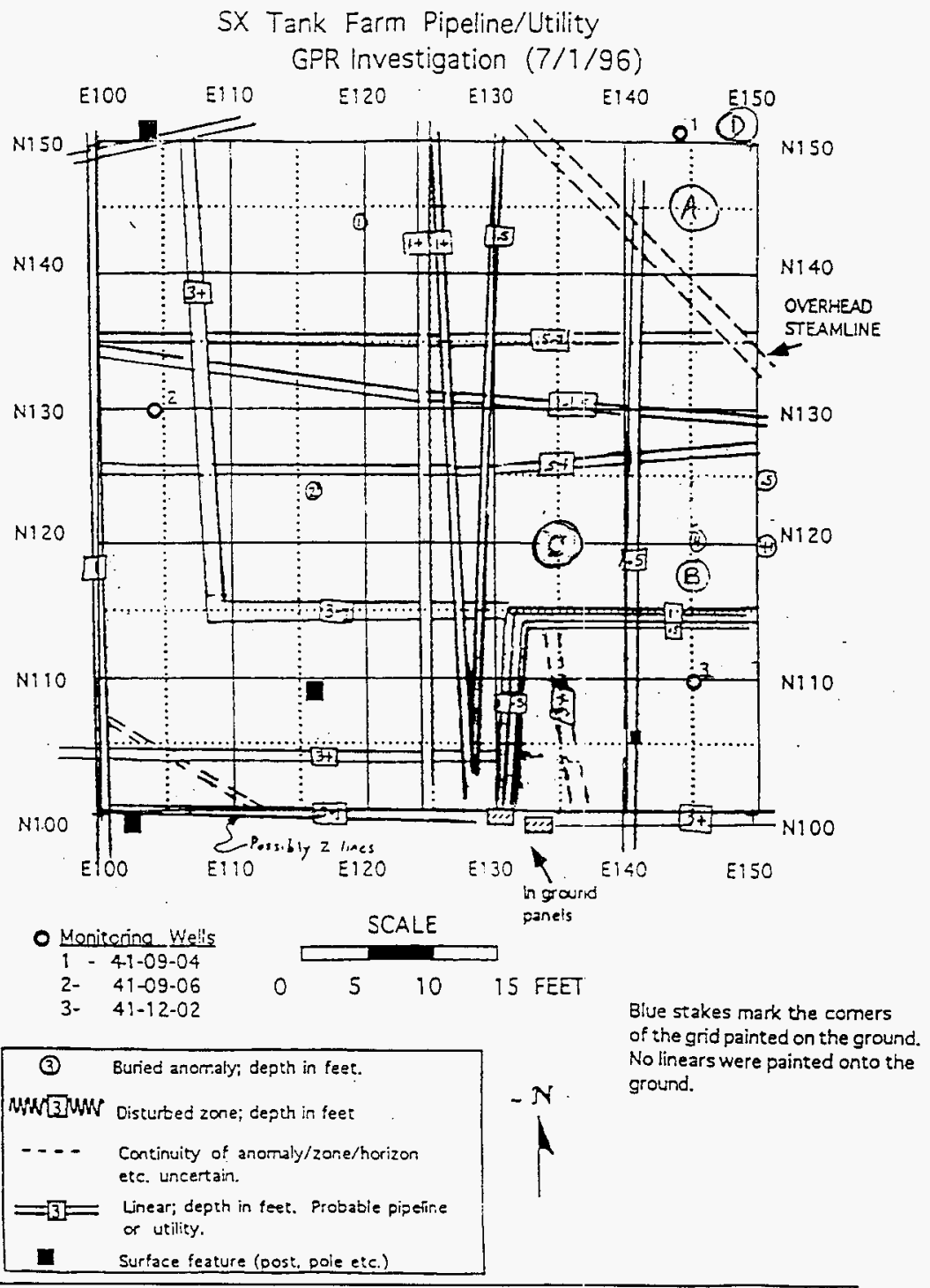


10-ft intervals of borehole advance) during the drilling process to try to detect any drag-down of contaminants during the drilling process.

During the July 16-17 meeting, the results of an evaluation of pipeline/utility documents, investigation using ground penetrating radar, and visual observations of the site led Site contractors to recommend against the location selected by the Panel for the first investigative borehole. An overhead steam line interfered with truck access and ruled against the location. On the basis of preliminary projections by MACTEC-ERS of anticipated ${ }^{137} \mathrm{Cs}$ concentration profiles at depth and interests of tank safety, the Panel recommended a new location for the first investigative borehole at approximately $\{\mathrm{E} 145, \mathrm{~N} 120\}$ (B in Figure 6.1). Subsequently, without further consultation with the Panel, the first investigative bcrehole was installed approximately $10 \mathrm{ft}$ west of that location at approximately $\{\mathrm{E} 135, \mathrm{~N} 120\}$ (C on Figure 6.1)

The first investigative borehole was completed and logged on August 16, 1996. The resulting spectral gamma-ray log (Figure 6.2) clearly differed from that projected prior to drilling (Figure 6.3) by MACTEC-ERS staff for the original proposed location. Although this borehole failed to intercept formation-borne ${ }^{137} \mathrm{Cs}$ at depth, it did provide a measure of the amount of contaminant "dragged" down as drilling proceeded (Figure 6.4). High gamma-ray activity at the closed end of the casing for each run indicates contaninated soil was pushed ahead of the casing despite the conical pitch of the cap. "Peaks" at depths above the bottom of the casing indicate residue which apparently broke off what was trapped at the base and remained between the formation and the casing. The amount of residue transported downward appears to have been compounded by the presence of a small weld-lip on the bottom of the tool.

Retrospectively, the final location selected for the borehole might better have been installed to the east rather than west of the Panel's choice. By moving the location westward, the borehole was outside, or at the very fringe, of formation-borne ${ }^{137} \mathrm{Cs}$. Data presented in the SX TANK FARM REPORT (for example, Figure 6.5) shows that despite exterisive contamination at depth around borehole 41-12-02, the next neighboring borehole, 41-09-06, to northwest (see Figure 6.1, at $\{\mathrm{E} 105, \mathrm{~N} \mathrm{130 \}}$ ) is relatively free of contamination at all depths. Thus, projections on the basis of the contaminant profile of 41-12-02 might better have been based on the profile for 41-09-06, in which case the measured logs may have more closely matched the projected logs.

Thus, the Panel considers the first investigative borehole to have been informative. The results of this borehole show that the MACTEC-ERS visualization of a broadly-spread, formationborne plume was incorrect at this location, although consideration of the location of 41-12-01 from 41-12-02 and an apparently "clean" 41-09-06 was not included in the MACTEC-ERS "forecast" for 41-12-01. The results of the first borehole might equally support the Panel's contention that funneled flow is more likely at the SX tank farm than is uniform flow, a contention which may also explain the clean zone around borehole 41-09-06. Finally, the results also support the contention that ${ }^{137} \mathrm{Cs}$ could appear in gamma logs due to drag-down by the cable drilling method used in the past or subsequent deposition down the annulus created 


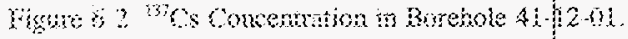

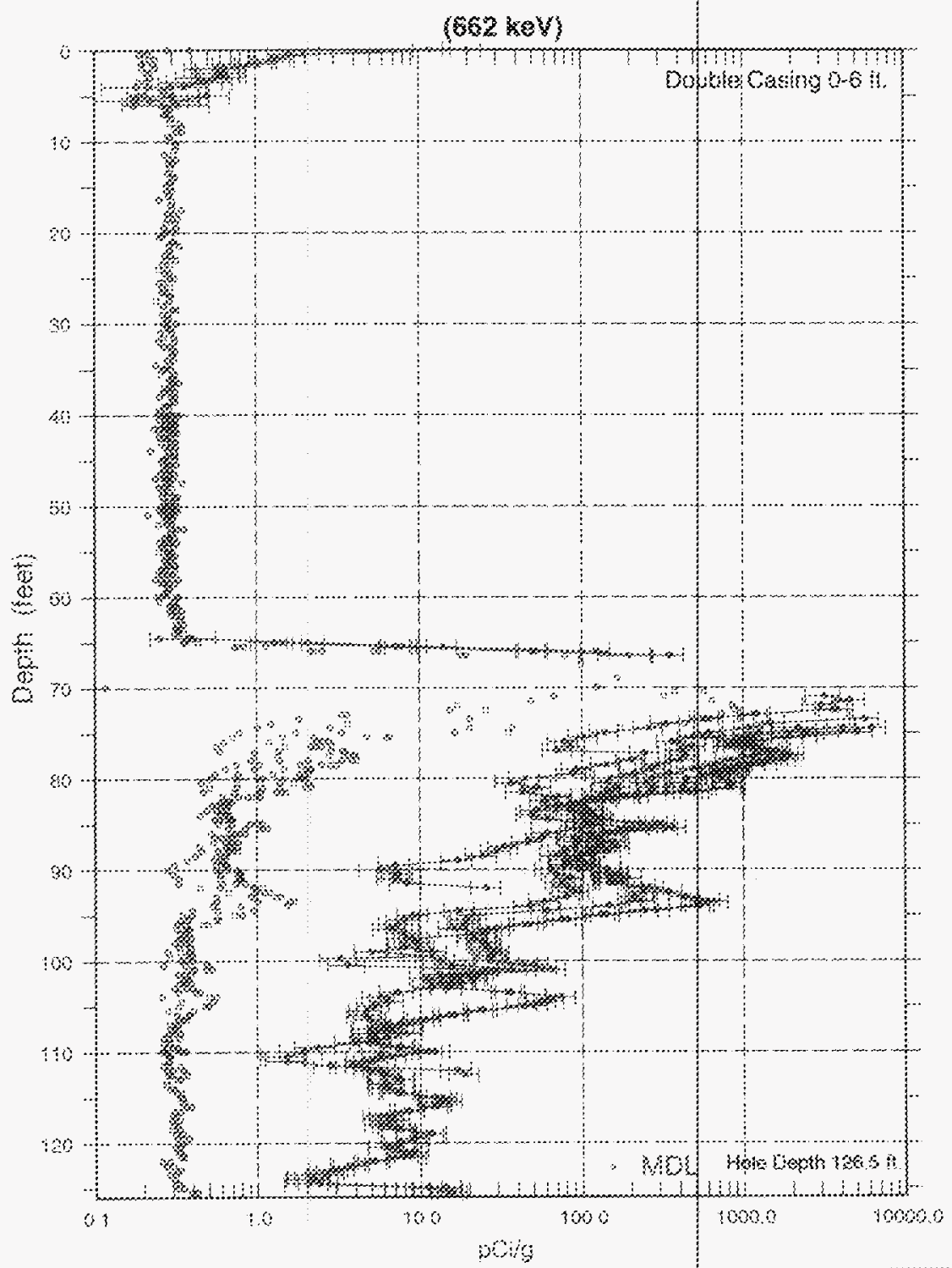


Figure $6.3{ }^{137} \mathrm{Cs}$ Concentration Near Borehole 41-12-02.

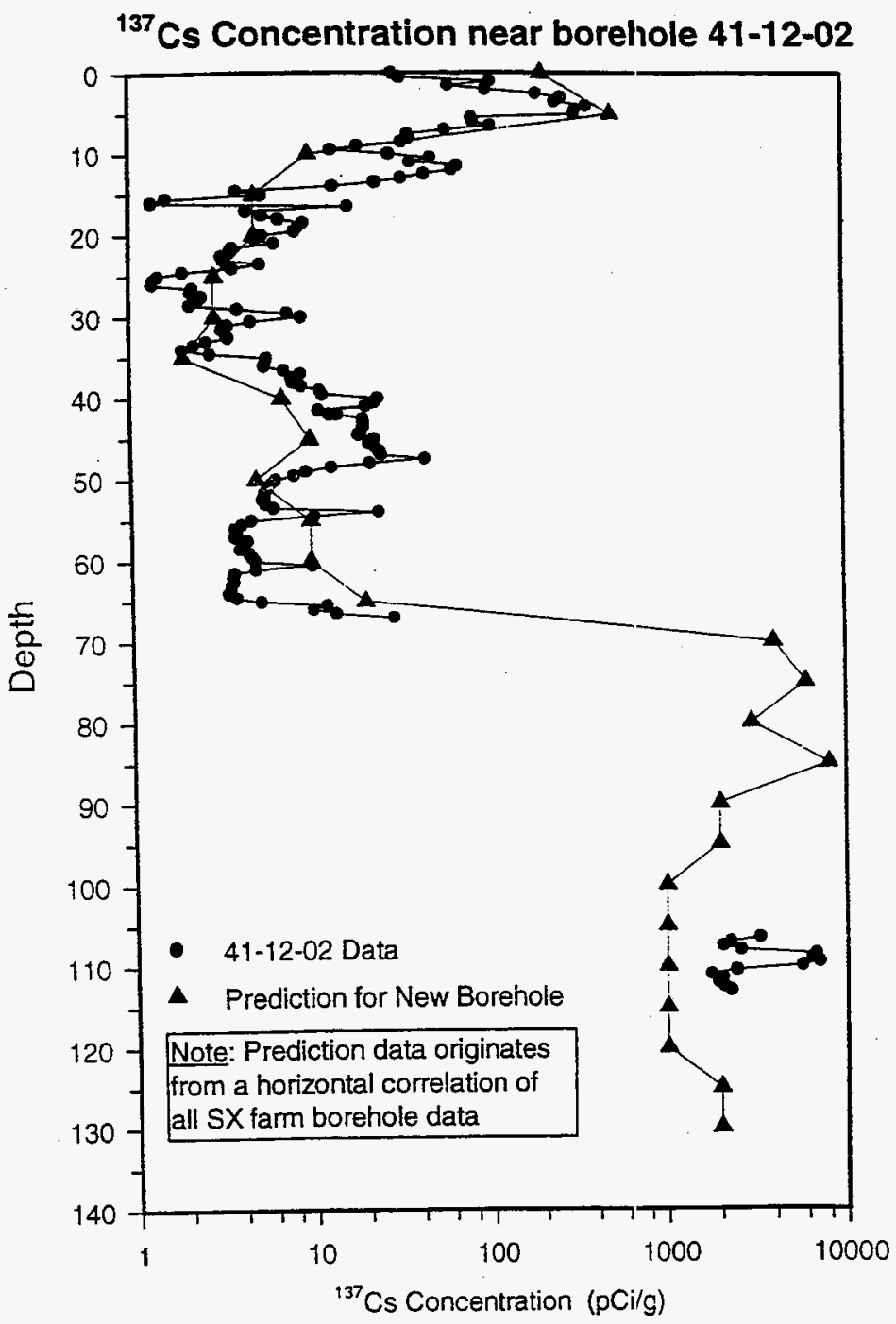




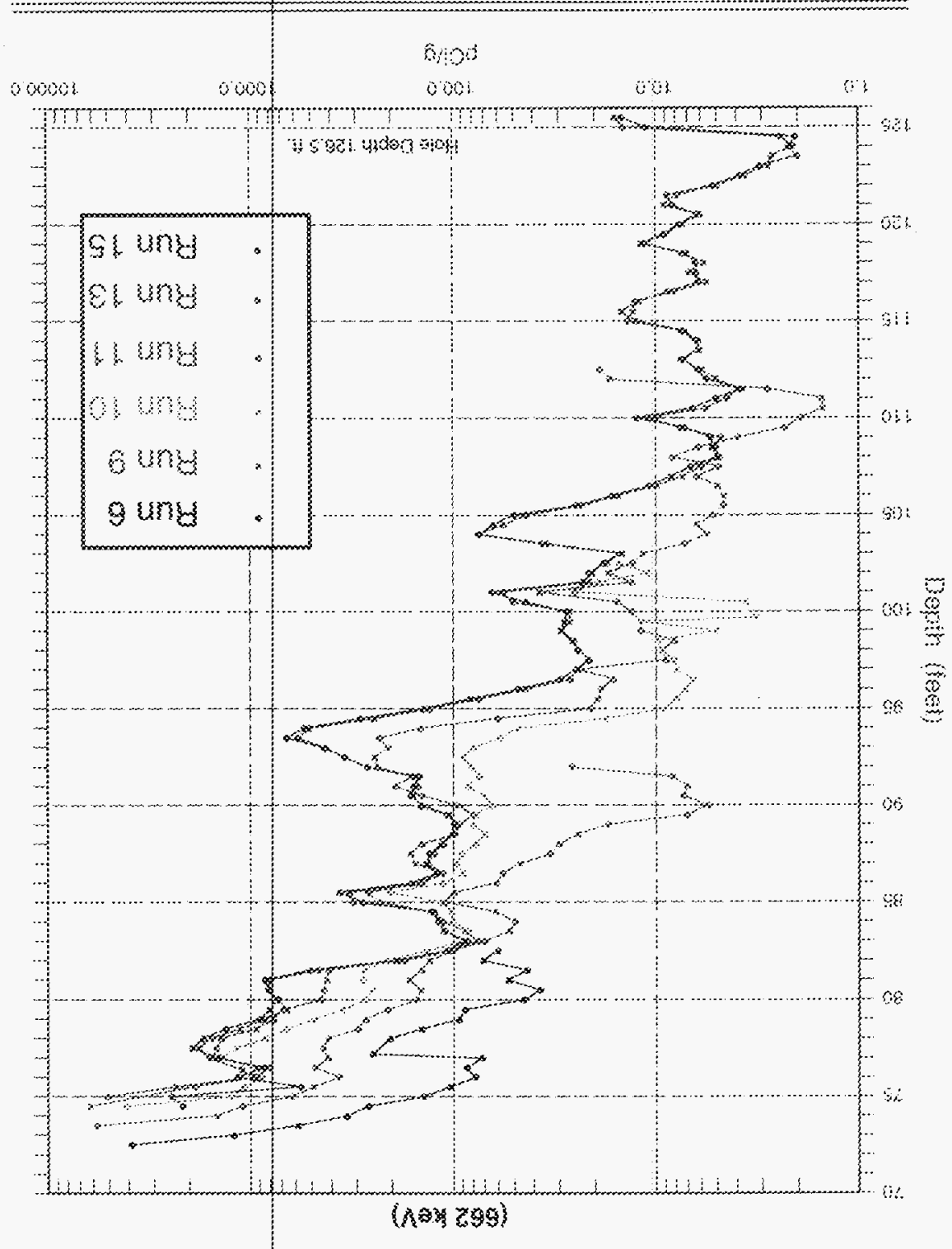

(6) 


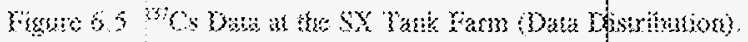

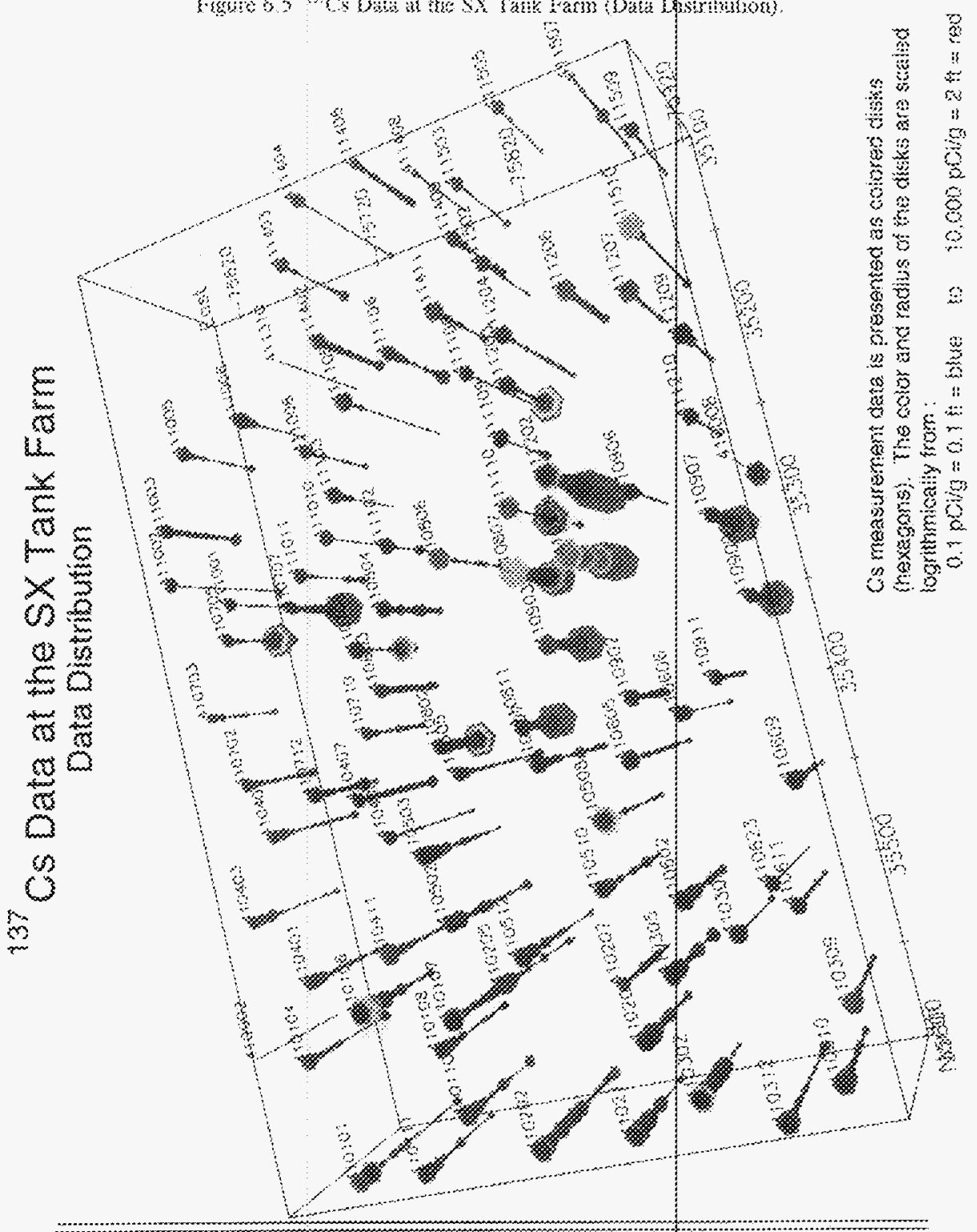


by that method.

The driven-casing method proved cost-effective, without endangering the tanks or staff, and there was no drilling waste to be disposed. The multiple-logging exercise provide a measure of the quantity of ${ }^{137} \mathrm{Cs}$ that might be carried to depth by the method, although the quantities here appear to have been increased by the protruding welding bead.

The Panel was asked during this teleconference to select a location for the second investigative borehole. Temperature measurements (see Section 5.5 of this repoit) performed at the request of the Panel again focused our interest on the zone near borehole 41-09-04. The maximum temperature in borehole $41-12-01$ is approximately $20^{\circ} \mathrm{F}$ less than those for 41-09-03 and 4108-7, north and east of 41-09-04, respectively. Although the temperature profile for 41-09-04 had not been logged, the zone between 41-09-03, 41-09-04 and 41-08-07 provided the most promise as a candidate area for finding formation-borne ${ }^{137} \mathrm{Cs}$. A projection by MACTEC-ERS of ${ }^{137} \mathrm{Cs}$ isopleths at depth (e.g., Figure 6.6) supported that conclusion and a recommendation was made by the Panel to search for a candidate location in the zone defined by boreholes 41 08-07, 41-09-03 and 41-09-04. Following an investigation for sur ace and subsurface obstacles, the second investigative borehole was installed during December, 1996 at approximately $\{$ E150, N150\} (D in Figure 6.1). 


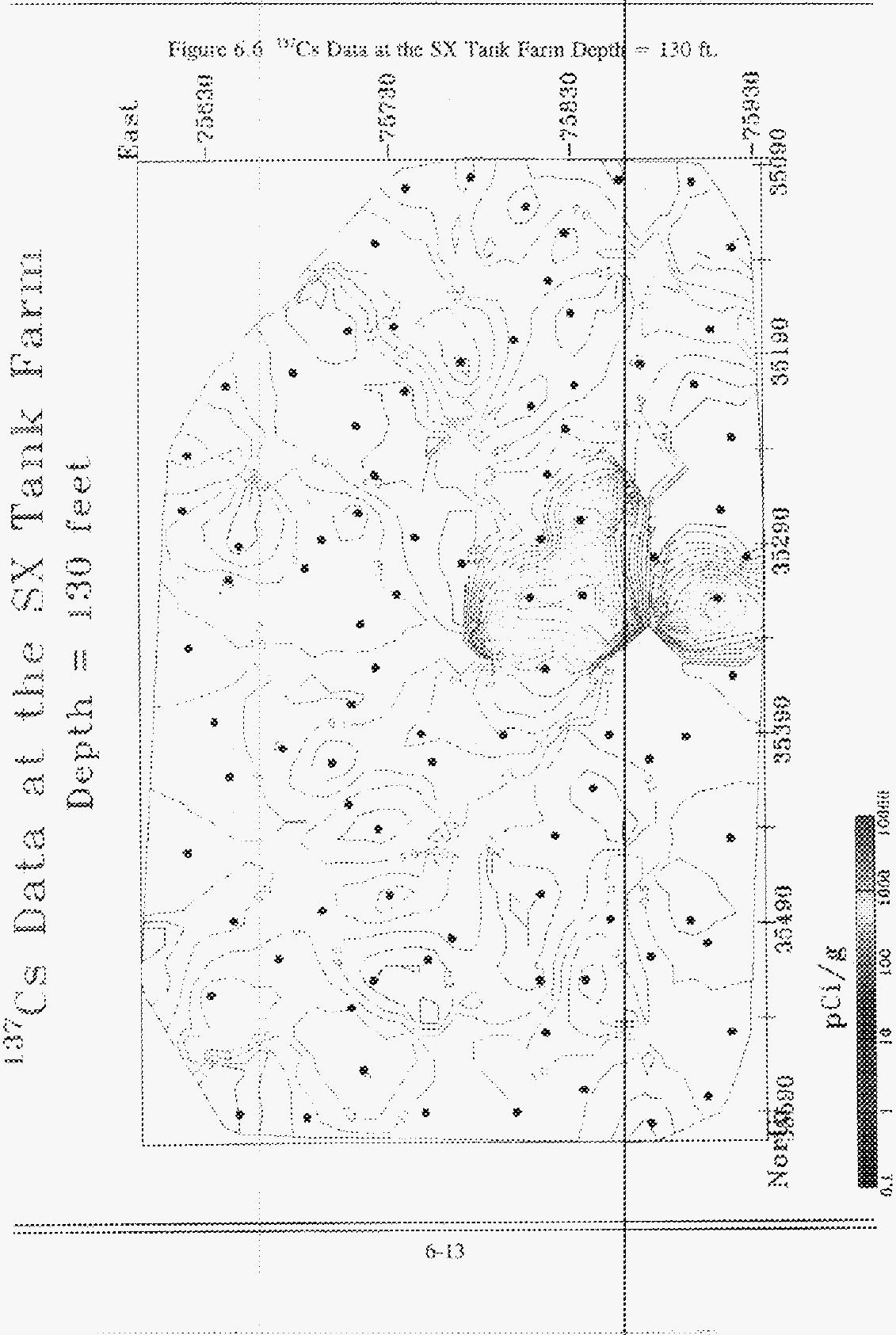




\subsection{MEETING OF SEPTEMBER 11-12, 1996}

\section{Summary}

Regarding the first borehole:

- The drilling and logging were designed to assess drag down of contamination. Dragdown was found to be a significant problem.

- Information regarding drag-down is transferable to other locations and previously used drilling methods. This has important ramifications throughıut the DOE environmental programs nationwide: these results should be published.

- $\quad$ Results from first borehole do not support the geostatistical visualization which predicts very high concentrations of Cs137 below $75 \mathrm{ft}$. at this location (Draft $\mathrm{DOE} / \mathrm{ID} / 12584 / 268)$.

- $\quad$ Results from the first borehole are consistent with Panel's view.

Infiltration into the vadose presented by PNNL is well quantified for gravel surfaces. Reduction of infiltration should reduce contaminant transport through the vadose zone to ground water.

It is not possible to do a valid risk assessment or tank closure plan without valid conceptual models considering extreme physical and chemical conditions of high temperature, density, salinity, $\mathrm{pH}$, heterogenous media with potential natural and manmade vertical pathways. The concept that contamination can not move through the vadose zone is overly optimistic. To develop valid conceptual models the vadose zone must be characterized.

\section{Recommendations}

Recommended location for borehole number 2 is $4 \mathrm{ft}$. east and $2 \mathrm{ft}$. south of borehole 09-04. Use closed-end sonic probe; same drilling and logging requirements as first hole to assess drag down and cesium distribution.

Recommended location for third well is south of borehole 11-10 and east of borehole 12-02. WHC will investigate (e.g., GPR) to verify viability of location. Drilling method to be determined and location confirmed after review of borehole $\# 2$.

\section{Actions}

- Brodeur to provide documentation on all logging systems.

- $\quad$ Can we take a split spoon sample from $5 \mathrm{ft}$. below a drywell. (Engelman to investigate the feasibility).

- Can we sample out of the bottom of a caisson vertically, harizontally or at a slant 
(Engelman will investigate).

- Validate shape factors analysis method experimentally [priorities of work for Bob Wilson].

- Analyze existing logs (shape factor) below the saturation zone in regions for which the method is valid.

- Copies of Caggiano temperature data to panel (complete).

- Re-log temperature measurements in some boreholes (41-08-06, 41-11-09, 41-08-11, 41-11-10, 41-00-08).

- Measure temperature profile and spectral gamma in driven well number zero.

- We would like current gross gamma logs in all boreholes where spectral gamma ray log saturates.

- Historical analysis of gross gamma logs to continue.

\subsection{TELECONFERENCE OF NOVEMBER 21, 1996}

\section{Purpose}

This teleconference discussion was conducted to summarize the Vadose Zone Characterization Program, the Expert Panel meeting held at Hanford on September 11, and 12, 1996, FY 97 budget of constraints $(\$ 4.2 \mathrm{M})$, and to status second and third borehole drilling methods and schedules.

\section{Summary}

- Location of the second borehole (41-09-39) installation will be $4 \mathrm{ft}$ east and $2 \mathrm{ft}$ north of bore hole 41-09-04.

- The use of sonic drilling has been proposed for the $\$ 2$ bore hole to $130 \mathrm{ft}$ as an alternate to percussion primarily to minimize dragdown. A tap outside the farm with the sonic rig was performed to see what kind of forces would be imparted on the tanks. The accelerometers showed a significant increase of force on the tanks, with a magnitude of $1 \mathrm{~g}$ being exerted at 10 feet. With this type of soil 50 to 60 feet of stick is needed to get resonance on the drill pipe instead of the whole rig. The plan is to run a test using percussion down to 50 feet and then, switching rigs and using the sonic to $130 \mathrm{ft}$ monitoring to insure that the forces are within the design limits of the tanks. Comprehensive drilling documentation (for sonic) will be collected and reported to support subsequent drilling method decisions. 
- Currently the FY 97 budget doesn't include any additional d-illing in the single shell tank farms.

- An Expert Panel meeting has been scheduled upon completicn of \#2 borehole in January 1997.

- The Expert Panel members will provide a comprehensive vadose zone program report to meet original deliverable.

- A TWRS Vadose Zone Characterization baseline plan was distributed to the panel members for review and comment.

\section{Recommendations}

- The next proposed bore hole installation is for a slant borehcle with sampling for probe \#3 using the sonic method. The slant hole angled at 45 degrees would start outside the tank farms. This method would actually have a higher probability of hitting a preferential pathway versus vertical if a suitable target area can be selected. A proposed location for the slant drilling is starting from the scuth side of the farms and heading north intersecting the region between SX-111 and 112, 108 and 109 hole.

- A steering panel (for public involvement) will be formed, separate from the independent expert review panel. This steering panel would consist of stakeholders, DOE and some technical people that could help put together a comprehensive long-term picture of the total vadose zone plan for TWRS. This would also include integration of everything from retrieval to closure as well as direction of the whole vadose zone program.

\section{Actions}

- J Brodeur Provide a white paper that would propose a specific target location for a slant hole as an alternative to what we've already selected the \# 2 hole. The sonic drilling rig tilt angle is limited to 45 degrees which will affect the selection of a location outside the tank farrn. Completed.

- MACTEC Provide $\# 2$ borehole logging results to the Expert Panel. Completed.

- Expert Panel The Expert Panel will provide a draft interim Vadose Zone report to LATA for compilation on 12/18/96. New Direction.

- C Ruud

Casey Ruud to put together a proposal for steering panel options and ideas then submit it to the Expert Panel and teleconference attendees for review and comment. This would be distributed prior to the next panel meeting. In process.

- MACTEC MACTEC to review the Sandia Labs drilling program and the 
Measurement While Drilling (MWD) method and see if its potentially usable at Hanford. In process.

\subsection{TELECONFERENCES OF DECEMBER 16-18, 1996}

Summary

Second Borehole Logging Results:

- The second borehole (41-09-39) installation and logging was completed on 12/13/96. The location was approximately $5 \mathrm{ft}$ north east of bore hole 41-09-04. The method for installation was closed end percussion using a 15 degree cone tip. The sonic drilling method was not used due to potential vibration levels exceeding the tank design limits. The Sonic drilling Field note, drilling log, and structural analysis, results will be compiled and documented. Preliminary gamma Logging results were sent to the expert panel for review.

- The teleconference conference resulted in discussion and consensus within the panel on the second bore hole logging data. This information was used to provide a Vadose Zone Characterization Program (VZCP) Expert Panel Statement (attached)on the migration of contaminants (of Cs 137) below $75 \mathrm{ft}$.

The deliverable for an Expert Panel Interim report due on 12/18/96 summarizing the to-date panel activities and findings was superseded by the VZCP Expert Panel Statement. The date for the interim report will slip to $01 / 10 / 97$.

\section{Recommendations}

- K Myers Install a slanted borehole using the sonic method that would be started outside the SX tank farm and intersect the area of 41-09-39 borehole below the 70 to $100 \mathrm{ft}$ level. Location is to be determined after completion of borehole 41-09-39 logging data review.

Actions

- MACTEC Send raw spectral data for entire length of 41-109-39 bore hole. Completed.

- K Myers Provide verification data to insure boreholes 41-09-39 and 41-09-04 are straight and are aligned vertically. In process.

- Expert Panel Provide interim comprehensive Vadose Zone panel report to LATA for drafting. Deliverable slipped to 01/10/97. 


\subsection{MEETING OF JANUARY 14-16, 1997}

A closeout summary of the meeting was not prepared, because most of the time was spent in Panel working sessions concerning this PANEL STATUS REPORT.

Final Spectral-gamma logs (Figure 6.7 and 6.8) of the second investigative borehole, 41-09-39, were reviewed to reaffirm the evaluation based on preliminary logs and presented in the Panel statement of December 17, 1996. The final logs were substantially the same as the preliminary one provided in December, so the Panel statement remained as originally written.

Removal of the weld-lip from the bottom of the tool used for the second investigative borehole appears to have markedly reduced the amount of contaminant carried to depth by installation of the casings.

The Panel was concerned about the effect of high countrates on the SGLS and on the ${ }^{137} \mathrm{Cs}$ concentration values estimated by MACTEC-ERS to develop the logs. Raw gamma-spectral data representing ${ }^{137} \mathrm{Cs}$ concentration at $3,113,93,107,95$, and $103 \mathrm{ft}$ (Figures 6.9a through 6.9f, respectively) were selected for review. Even at $18 \%$ deadtime (Figure $6.9 \mathrm{~b}$ ), pulse pileup begins to degrade the spectrum relative to that in Figure $6.9 \mathrm{a}$ (note the increased countrate from approximately $680 \mathrm{keV}$ to the ${ }^{40} \mathrm{~K}$ peak at $1476 \mathrm{keV}$ and the appearance of a sum peak at $1323 \mathrm{keV}$ ). As the deadtime increased to $86 \%$ and $88 \%$ (Figures $6.9 \mathrm{c}$ and $6.9 \mathrm{~d}$ ), distortion and the sum peak increase and the ${ }^{40} \mathrm{~K}$ peak has disappeared into the "noise" generated by pulse pileup. At $96 \%$ deadtime (Figure 6.9e), pulse pileup is so severe that it has nearly buried the sum peak and has greatly diminished the primary peak at $662 \mathrm{keV}$; the overall countrate also is diminished despite system deadtime correction. At $99.6 \%$ deadtime (Figure 6.9f), the spectrum is essentially featureless and the total countrate is severely diminished; the countrate in the pileup region exceeds that of either the Compton or primarypeak regions. A deadtime/concentration relation was developed (Figrure 6.10).

These spectral data indicate how important it is for MACTEC-ERS to upgrade the SGLS. The current maximum capability of the SGLS, measuring concentrations up to approximately $10,000 \mathrm{pCi} / \mathrm{g}$, results in primary-peak countrates of approximately 12,000 counts per second (Figure 3.1b), rates which are at least threefold poorer than high-countrate systems described in the literature. Detector and electronics optimization may provide as much as a tenfold improvement in the maximum measurable concentration using the SGLS. 


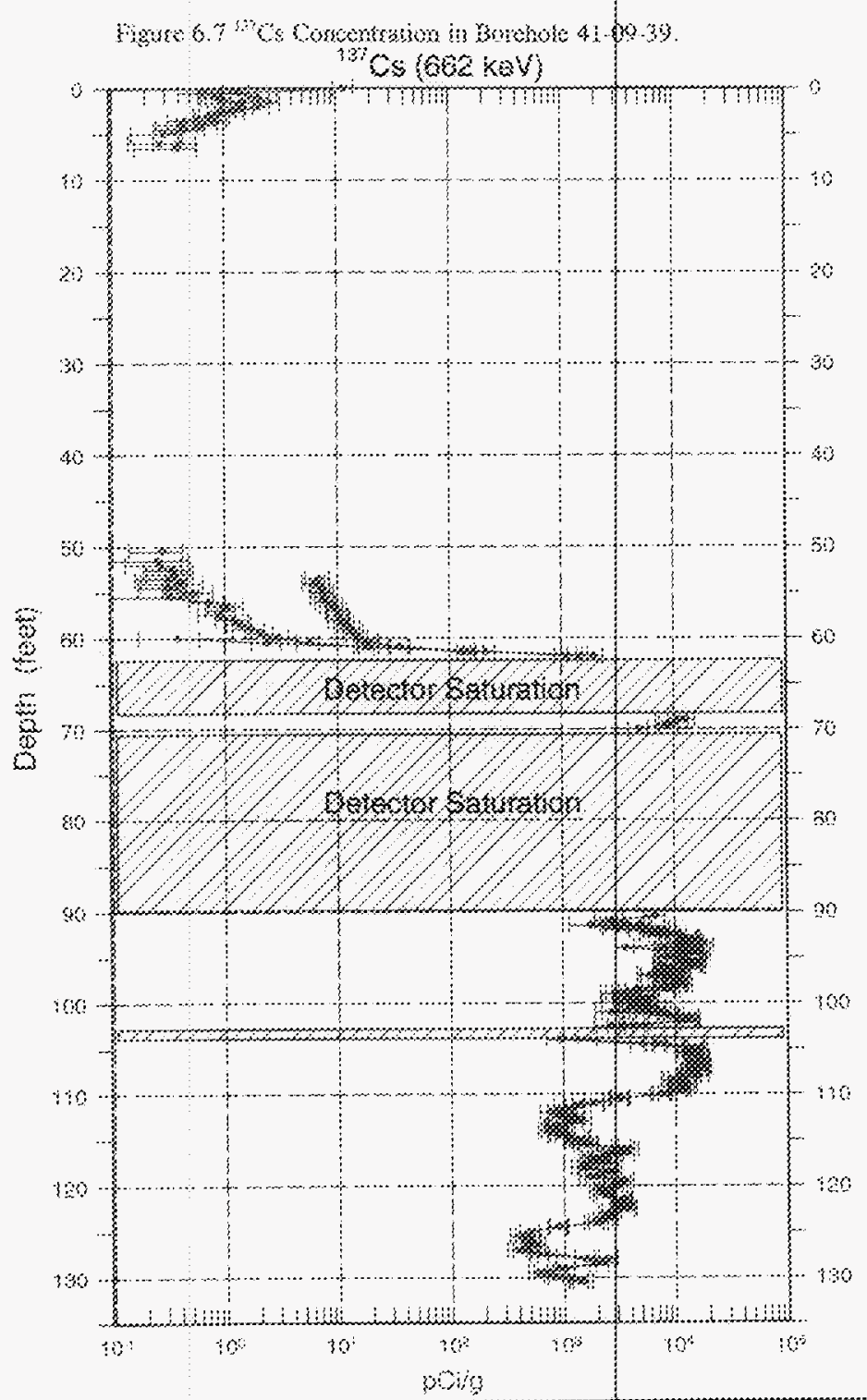




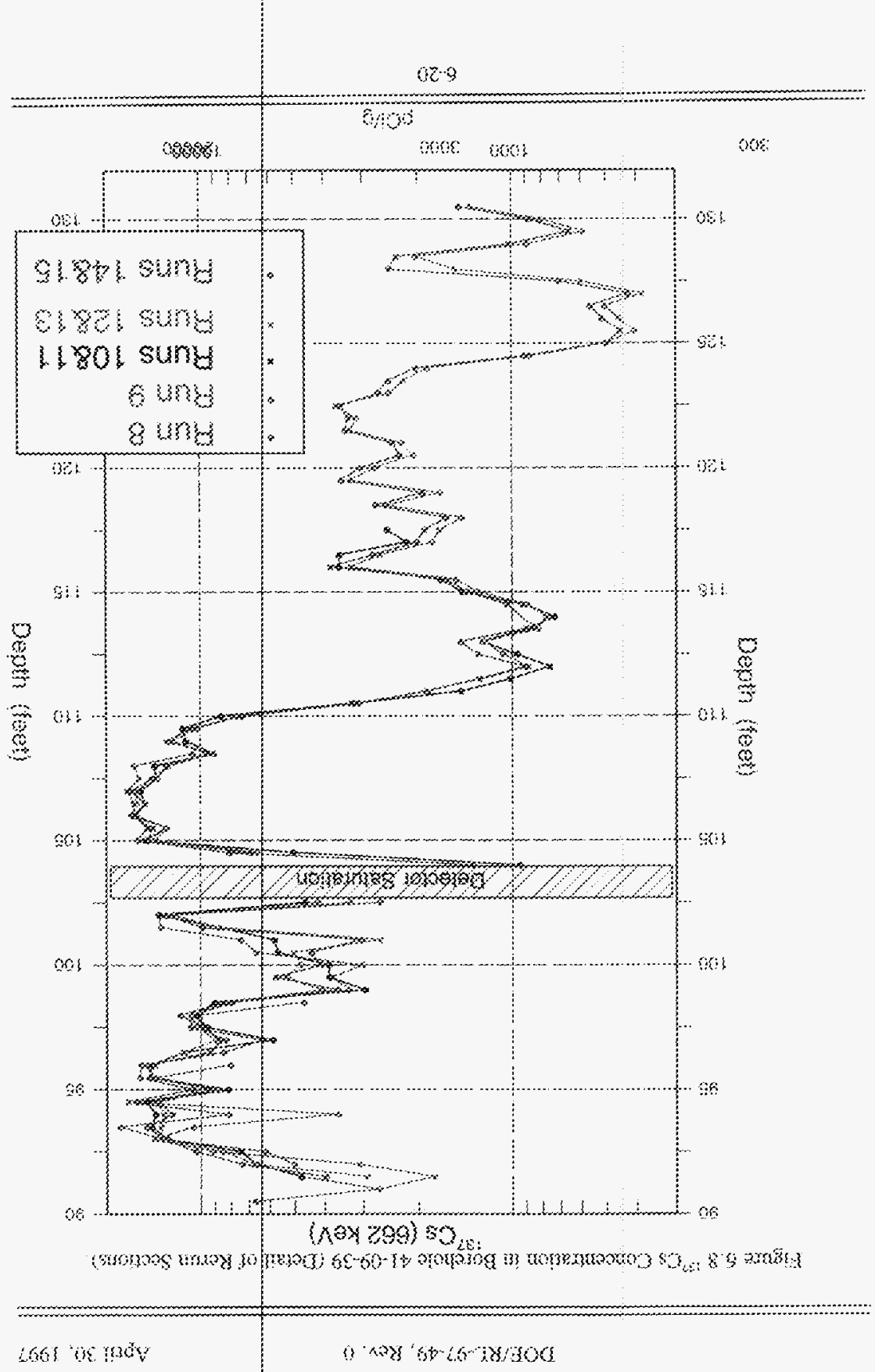


Figure 6.9a-f Gamma Spectra Selected from RLS Log of Borehıle 41-09-39 to Show the Influence of Pulse Pile Up and Distortion on Spectral Resolution and Counting Efficiency.
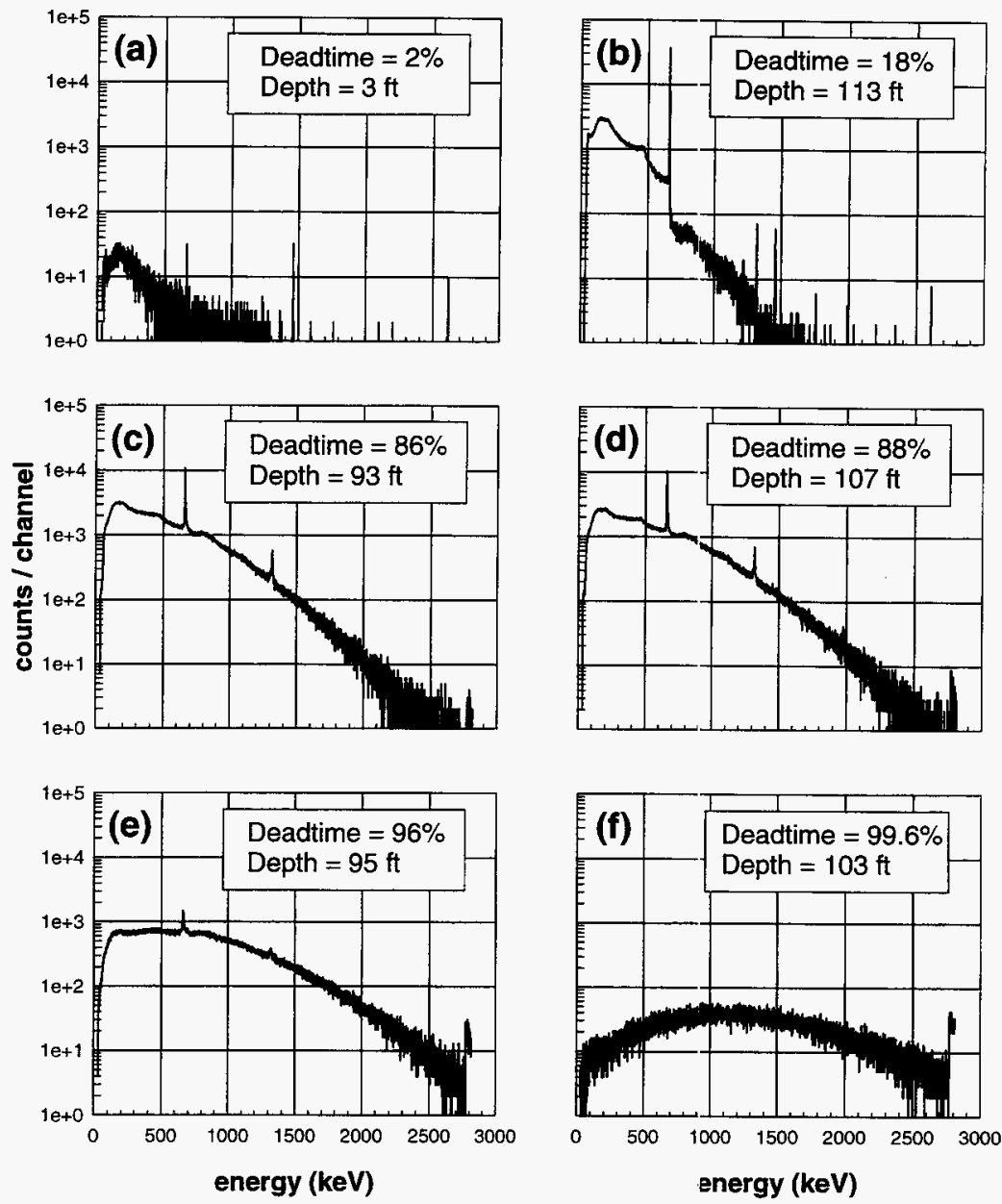


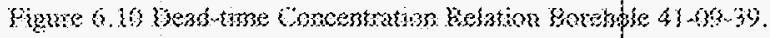

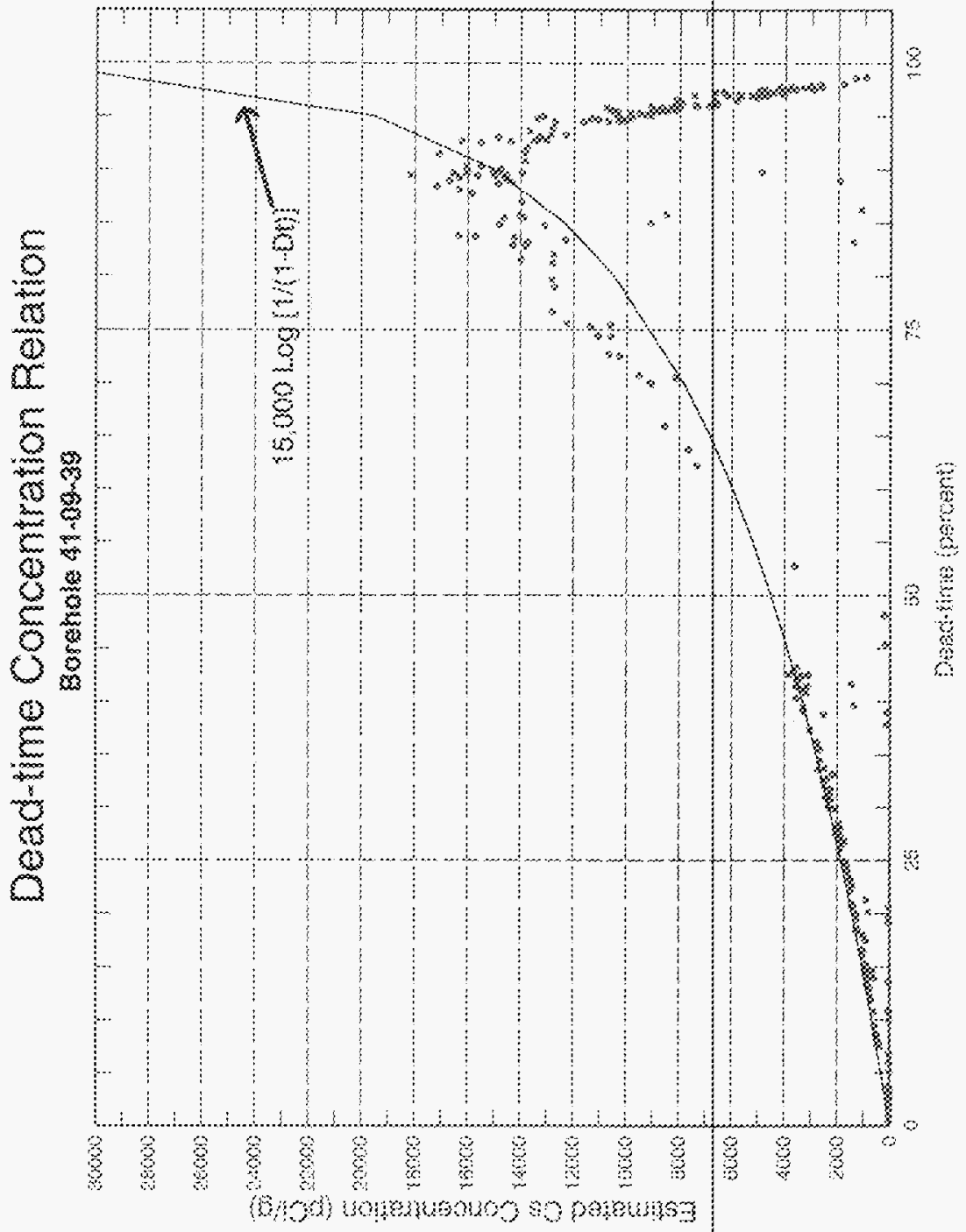




\subsection{TELECONFERENCE OF APRIL 10, 1997}

A teleconference was held in part to achieve resolution of the comments provided by reviewers of the draft report and in part to review additional information obtained since the January meeting. Comment resolution has led to this PANEL REPORT. The additional information [GJPO, 1997b], concerning investigative borehole 41-09-39, reaffirras the conclusions we obtained from preliminary data used to develop our December 17, 1996 statement.

The distance between the existing monitoring borehole 41-09-04 and the investigative borehole 41-09-39 was chosen by the Panel to be sufficiently great such that ${ }^{1: 7} \mathrm{Cs}$ transported down the borehole annulus of 41-09-04 would not significantly affect the gamma flux observed in 41-0939. Yet, the holes were close enough so that concentrations of formation-borne ${ }^{137} \mathrm{Cs}$ surrounding the two should be reasonably similar. A laser survey tc establish the relative position of the bottom of each hole compared to the top found that the bottom of 41-09-39 (at $130 \mathrm{ft}$ ) was 5.75 inches south and 3.5 inches east of the top [Myers, 1997]. The bottom of borehole 41-09-04 (at $103 \mathrm{ft}$ ) was 2.75 inches south and 1.5 inches east of the top. So, the two boreholes are parallel to one another to within an inch or two and the Panel's design objective has been met.

The relative spacing of the two boreholes is important when we consider the correlation of the gamma-log data for the two boreholes [GJPO, 1997b]. We have retained in prior sections of this PANEL REPORT the information and figures used to develop our December 17, 1997 statement to maintain a record of how those conclusions were achieved. The newly obtained logs include measurements using a very low efficiency $\mathrm{Cd}-\mathrm{Zn}$-Te detector which provides countrate data in the high concentration regions where the SGLS saturated (Figure 6.11). The measurements using $\mathrm{Cd}-\mathrm{Zn}$-Te exhibit good general agreement in both countrate and spatial resolution at depths from 60 feet to 100 feet, indicating that the formation soils around each borehole are approximately equally contaminated with ${ }^{137} \mathrm{Cs}$. A maximum ${ }^{137} \mathrm{Cs}$ concentration of approximately $10^{7}$ to $10^{8} \mathrm{pCi} / \mathrm{g}$ at a depth of approximately 80 to 82 feet is obtained by comparing the logs using the uncalibrated $\mathrm{Cd}-\mathrm{Zn}$-Te detector with those using the calibrated SGLS. Borehole 41-09-04 exhibits a zone of contamination betweer 55 feet and 60 feet which borehole 41-09-39 does not; this may be due to borehole contamination or from the proximity of borehole 41-09-04 to the base of tank 241-SX-109 where a leak ozcurred. Between approximately 86 feet and 103 feet (where borehole 41-09-04 ends) there again is good correlation of ${ }^{137} \mathrm{Cs}$ countrates, but at rates approximately three orders of magnitude less than the respective maxima.

A correlation appears to exist between drill resistance (as blows per foot of drill advance) and the gamma-ray logs of borehole 41-09-39 (second and bottom graphs of Figure 6.11), with correlatable peaks at approximately 65,74 and 82 feet. So, the gamma-activity peaks are correlated to apparent increases in formation density at those depths. The low apparent formation density at 55 to 60 feet may explain the absence of a peak in a borehole 41-09-39 in correspondence to that in borehole 41-09-04. The especially great drill resistance (and presumably high formation density) at 82 feet may explain the sharp decrease in ${ }^{137} \mathrm{Cs}$ activity below that depth. The blow count data requested by the Panel appears to offer cost-effective 


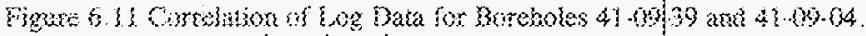
(19a) indo

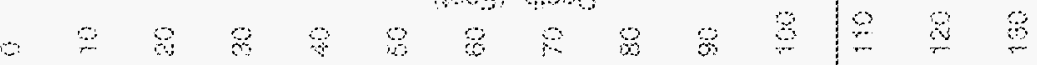

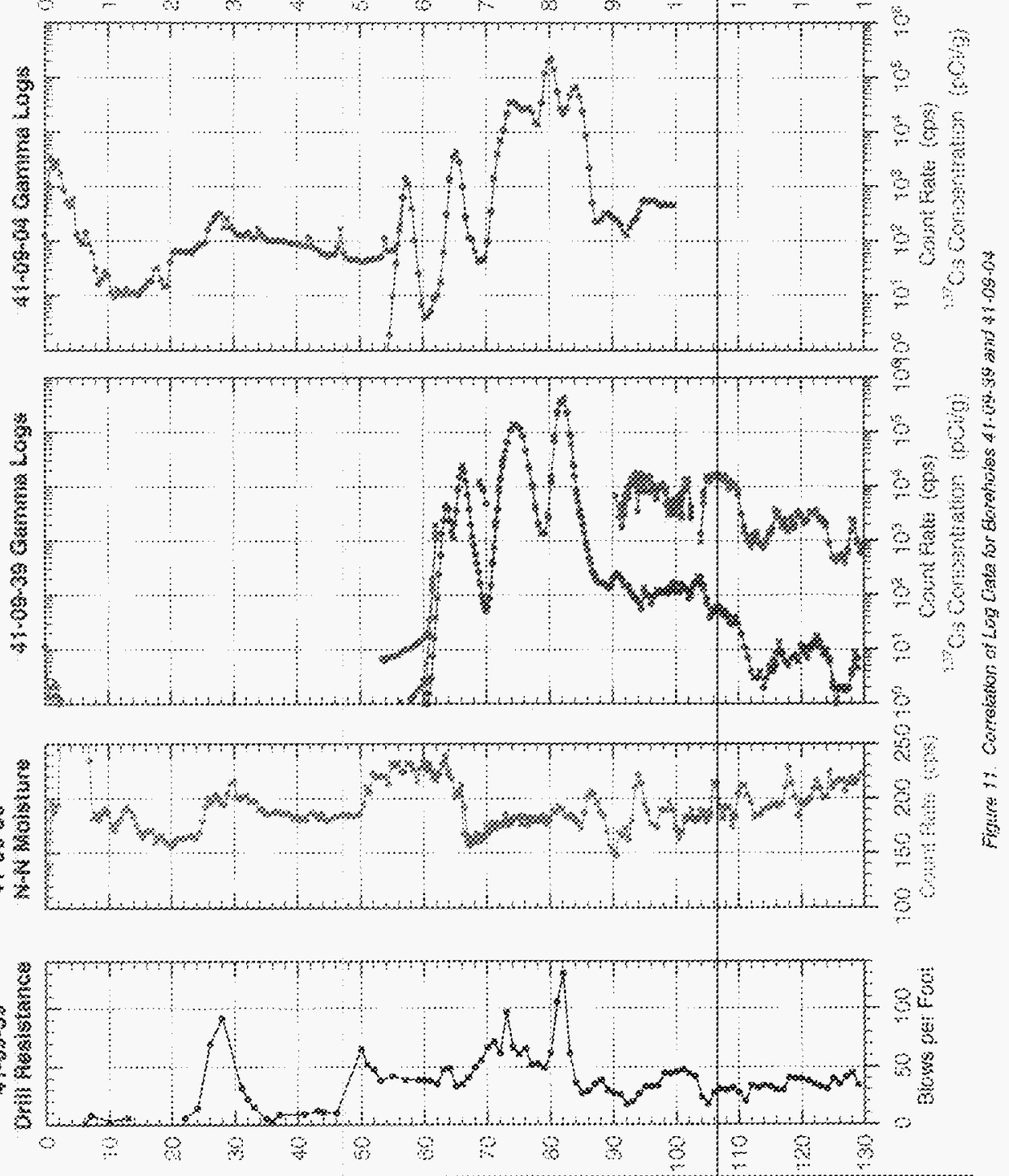


information about formation structure which may prove valuable for predictive modeling wherever simple percussion boreholes are installed for gamma-logging.

Air-temperature logs (Figure 6.12 is provided here for clarity, although the data are also reproduced as curves 7 and 8 of Figure 5.7) also appear to exhibit scime degree of correlation below approximately 50 feet, the point below which air temperature at ground surface appears to have only a small-influence. Both boreholes achieve temperature maxima of $128^{\circ} \mathrm{F}$ at approximately the same depth.

The Panel has not had an opportunity for a comprehensive review of all the data recently obtained for boreholes 41-09-04 and 41-09-39. A brief inspection of: the gamma logs for the two boreholes reveals several interesting features in support of our conclusion that the region near and between the two boreholes and to 130 feet at borehole 41-09-39, must have become contaminated primarily, if not entirely, by formation transport of ${ }^{137} \mathrm{Cs}$. Since borehole 4109-39 was logged as it was driven, and did not reveal significant drag down of ${ }^{137} \mathrm{Cs}$, the contaminating ${ }^{137} \mathrm{Cs}$ had already to have moved through the formation before the casing was driven to the depths penetrated by borehole 41-09-39. The small distance from approximately 86 feet, the maximum depth of the principal zone of contamination, : 0 the bottom of borehole 41-09-04 at 103 feet does not detract from the fact that formation transport had to have continued for the next $27 \mathrm{ft}$ at the location of borehole 41-09-39. The close spatial and countrate correlation of ${ }^{137} \mathrm{Cs}$ activity beginning from the depth of the tank bases and the sharp decrease in both boreholes below approximately 84 feet strongly suggest a relatively uniform lateral distribution of ${ }^{137} \mathrm{Cs}$ throughout the intervening formation, and likely past the bottom of borehole 41-09-04. The experimentally determined countrates in borehole 41-09-39 for the activity peaks at approximately 65,74 and 82 feet exceed those in borehole 41-09-04 by modest factors (perhaps two to five, based solely on the graphical data), the reverse of what would be expected should borehole 41-09-04 be the pathway for contaminants appearing in borehole 41-09-39. Furthermore, the casing of borehole 41-09-39 is nearly twice the thickness of the casing of borehole $41-09-04$, resulting in substantially greater attenuation of gamma radiation entering borehole 41-09-39, so the actual gamma flux external to that casing must be even greater at corresponding depths than that external to borehole 4.1-09-04.

The experimental evidence gathered for us by MACTEC-ERS (see Siections 3 and 4.1 and Figure 3.1) that oniy minuscule microcurie quantities of ${ }^{137} \mathrm{Cs}$ along a borehole casing, such as that for borehole 41-09-04, are required to produce the observed countrates means that insufficient contaminant is available there for lateral, then downward, transport through the formation at borehole 41-09-39, in keeping with the activity ratios describes previously. Liquids carrying solute ${ }^{137} \mathrm{Cs}$ would only have moved along the casing annulus of borehole 41 09-04 during periods of saturated flow (i.e., while the tank was actively and forcefully leaking) and thence by formation flow; during periods of unsaturated flow, the liquid and solute ${ }^{137} \mathrm{Cs}$ would remain in the formation soils over the entire transit to depth (see section 4.3.2). Contaminant from the base of borehole 41-09-04 (approximately 103 feet) could contribute to the ${ }^{137} \mathrm{Cs}$ peak observed in borehole 41-09-39 at approximately 104 teet; however, the small feature may equally be due to the increase in formation density at approximately 97 to 104 feet 


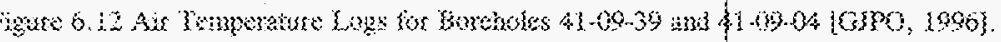

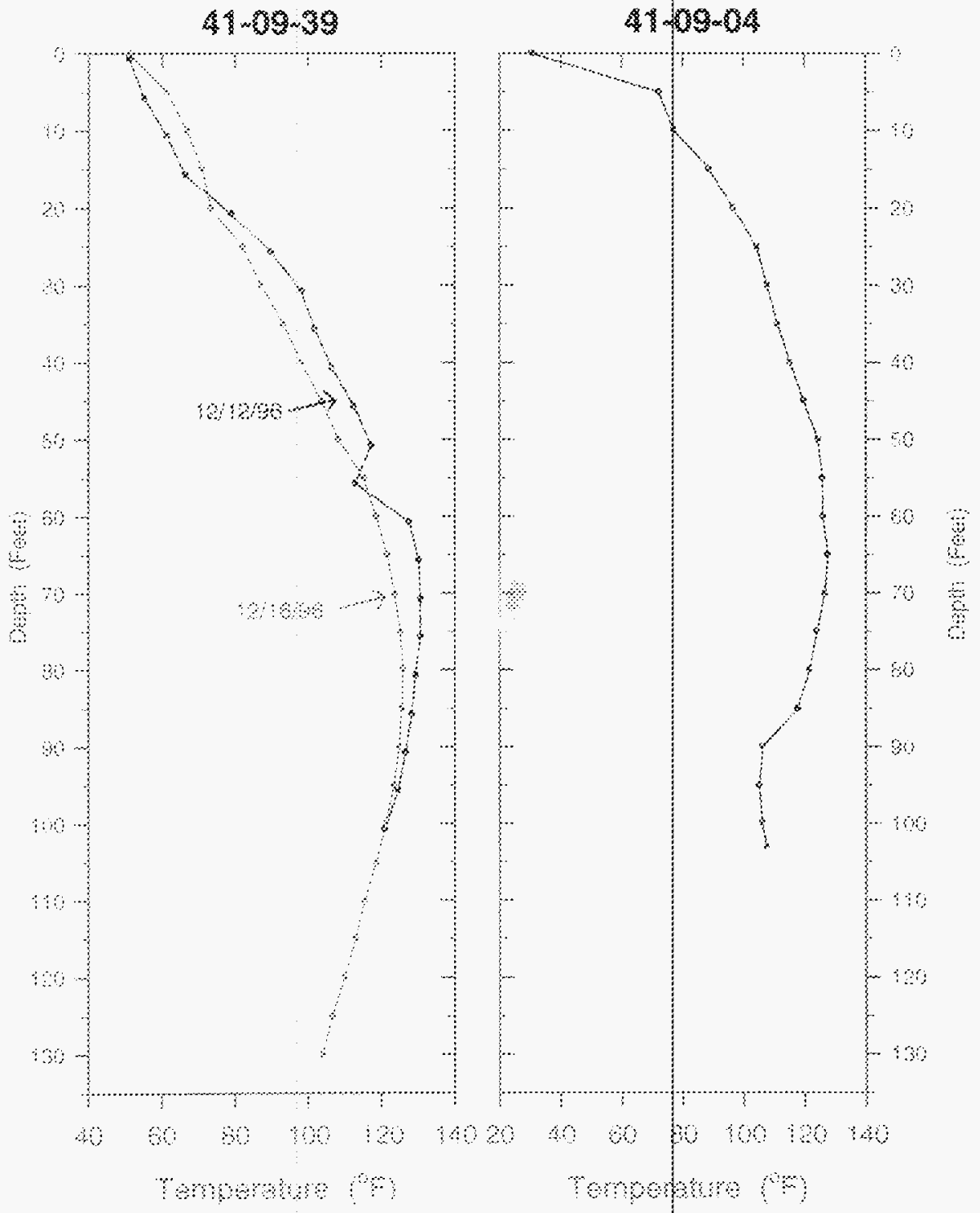


exhibited in the drilling resistance logs. Despite the qualitative nature of the logging data provided to the Panel so far for the investigative borehole, it appears that the ${ }^{137} \mathrm{Cs}$ countrates observed all along the investigative borehole 41-09-39 are due almost entirely to formationborne ${ }^{137} \mathrm{Cs}$.

The data reproduced here from the report by MACTEC-ERS of the logs for boreholes 41-0904 and 41-09-39 indicate that the interrelationship of logging data can provide a variety of contaminant- and formation-related data which can be used toward developing predictive transport models. And, all was accomplished at relatively small expense compared to other investigative boreholes installed at Hanford in the past. 
This page intentionally left blank. 


\subsection{CONCLUSIONS AND RECOMMENDATIONS}

Conclusion: The investigative borehole, $41-09-39$ revealed substantial concentrations of ${ }^{137} \mathrm{Cs}$ in the formation to a depth of at least 130 feet, the bottom of the borehole. Although the transport of ${ }^{137} \mathrm{Cs}$ to that depth may have been aided by movement along nearby borehole 41 09-04, that borehole ends at approximately 100 feet, so the material traveled through the formation for at least 30 feet below that depth. Some drag-down may have occurred in the emplacement of 41-09-39 below $100 \mathrm{ft}$ but that would not be sufficient to explain the large concentrations shown on the log.

Conclusion: Development of more representative simulation models; requires better characterization of the vadose zone.

Recommendation: Extend boreholes 41-09-39 and 41-09-04 to groundwater. Collect continuous samples and perform sensitive gamma-radiation scans of the samples. Log the extended boreholes during and after installation. Analyze for contaminants and physical and chemical transport properties.

Conclusion: The investigative borehole, 41-12-01, emplaced by the driven casing technique, unambiguously revealed drag-down of existing contamination during borehole emplacement, probably increased by a protruding welding bead at the base of the casing.

Recommendation: Any drilling program for vadose zone characterization or groundwater monitoring should include safeguards to minimize and, if possible, quantify contamination carry-down during drilling. Even better is to avoid drag down completely by using slant-hole or horizontal drilling methods to reach target locations beneath the heavily contaminated zone along and below the bases of the tanks.

Conclusion: It is entirely plausible that ${ }^{137} \mathrm{Cs}$ could travel to the groundwater along preferential formation pathways in the vadose zone at Hanford. Any assumption that this could not happen is not warranted given the sparseness of current knowlec ge about contaminant transport, in general. Before productive calculations can be made, current conditions must be estimated. Simulation from the extreme conditions (hot, dense, caustic saline solutions) that historically existed at the SX tank farm may aid definition of curren: conditions.

Conclusion: The PNNL transport model simulations presented to the Expert Panel at the second meeting was grossly inadequate for ${ }^{137} \mathrm{Cs}$. The model parameters were unrealistic, including source terms, initial conditions, and probable transport mechanisms, and the assumptions were not consistent with current research indicating the likelihood of preferential flow in unsaturated media. This would imply that any modeling for other contaminants done with similar assumptions could be equally deficient, which would cast doubt on the validity of any regulatory or planning document based on this or similar modeling efforts, including the recently issued Environmental Impact Statement for TWRS. 
Recommendation: It is imperative that a comprehensive characterization of the vadose zone be undertaken to give clear focus and definition for computer simulations.

Recommendation: New transport calculations should be performed by a group independent of Hanford's institutional interferences and having a state-of-the-art unilerstanding of transport mechanisms in unsaturated media. The source term should include a hot, caustic, saline solution (8 to 10 molar sodium, $0.5 \mathrm{M}$ or more in hydroxide ion, and at $350^{\circ} \mathrm{F}$ or more) and a hot formation, including self heating by the radionuclides moving into the formation. Transport mechanisms should include meteoric water and leaks, as well as the possibility of expedited transport driven by the pressure of superheated tank liquid flashing into steam as it enters the unsaturated formation at lower static pressure. The calculation should consider the feasibility of borehole transport of ${ }^{137} \mathrm{Cs}$ and transport of ${ }^{137} \mathrm{Cs}$ through the formation, including along preferential vertical pathways.

Conclusion: A General Accounting Office Report [GAO, 1992] recommends increasing the use of borehole logging techniques because of their cost-effectiveness and relative safety. For investigating the vadose zone in the region of the tank farms, borehole logging makes sense because a great deal of data can be obtained economically in the hundreds of boreholes already available. Before collecting extensive amounts of data with a variety of logging techniques, it is important to establish which logging techniques provide useful dala under Hanford vadose zone conditions.

Recommendation: Available borehole logging techniques should be screened to determine which might be useful in vadose zone characterization and monitoring. Pilot studies should then be conducted with selected techniques to determine which can produce valid, useful data cost effectively.

Conclusion: The draft SX TANK FARM REPORT meets reasonable standards for quality. In general, assumptions are listed, methodology and equipment are desiribed and references given, conclusions are explained and supported with facts where available, alternative conclusions are considered or at least mentioned, judgment calls are identified as such, and uncertainties are duly noted.

Conclusion: The SGLS baseline logging program has been valuable for locating gammaemitting contamination in the upper vadose zone at SX tank farm. However, it does not constitute a complete vadose zone characterization program.

Recommendations: The baseline logging program should continue, but the vadose zone characterization program should be expanded to include among other options: temperature logging, shape-factor and spatial-response analysis, density and moisture logging, and possibly electromagnetic induction techniques.

Conclusion: The SGLS equipment and logging procedures have been subjected to peer review and found to represent currently-accepted professional practice. The SGLS is capable of 
detecting ${ }^{137} \mathrm{Cs}$ unambiguously at levels below $1 \mathrm{pCi} / \mathrm{g}$. There is no doubt that ${ }^{137} \mathrm{Cs}$ has reached the depths indicated in the SGLS logs.

Conclusion: The calibrated and qualified SGLS system does not work well in high gamma radiation environments such as found in some of the SX tank farm boreholes. Hanford does not have a calibrated and qualified capability to measure without instrument saturation the highest gamma-ray fluxes present in these boreholes. This capability is important for hole-tohole correlation, locating tank leak locations, calculating heat generation by radioactive contaminants, performing spectral shape factor analysis to distinguish borehole sources from formation sources, and detecting and monitoring movement of contaminants based on periodic logging.

Recommendation: Hanford should develop a calibrated and qualified high-flux spectral gamma measurement capability for borehole logging, including a proper program which would include preparing a QA plan, developing logging procedures, extensive calibration and instrument characterization and developing data analysis and interpretation methods/procedures.

Conclusion: Current published research indicates the high probability of preferential flow rather than uniform flow in unsaturated media. To understand contaminant migration in the vadose zone, it is essential to understand flow along preferential pathways such as boreholes, discontinuous geologic structure, including fractures and clastic dikes, and other, more subtle changes in formation properties. None of these preferential pathways seems to be well enough understood to allow representation in modeling calculations with corfidence.

Recommendation: It is essential that the concept of preferential flow become part of the conceptual models used in evaluating vadose zone contamination at Hanford. Preferential flow must be well handled in any computer models used in the vadose zone characterization.

Conclusion: The historic gross-count gamma-ray logs are crude, but still may yield useful information based on changes in the logs over time. Additional information should be cost effective, because new measurements will not be required.

Recommendation: The existing gross gamma logs should be carefully analyzed for information related to the history and mechanisms of contaminant leaks and movement. The historic record can be continued as routine monitoring of the borehcles is performed.

Conclusion: Conventional spectral gamma-ray log analysis techniques cannot distinguish between borehole contamination and formation-distributed sources.

Recommendations: Methods should be developed to distinguish between borehole contamination and formation contamination. Use of spectral shape actor analysis and spatial response analysis for identifying the radial position of ${ }^{137} \mathrm{Cs}$ relative to the borehole are potentially important and should be pursued. Because the potential benefits of shape factor 
analysis are important, we recommend that the ongoing study be continued, but carefully focused on demonstrating feasibility as a practical tool and for defining improvements in SGLS instrumentation necessary to extend spectral shape factor analysis to greater system countrates.

Conclusion: Because radioactive contaminants decay producing heat, temperature logs may be useful for distinguishing contaminants distributed in the formation from borehole contamination. However, the logs produced to date represent borehole air temperatures and are only qualitative, because the thermal regime of the borehole air column is unstable and easily disturbed. The fact that these logs have limited value is not the fault of the contractor making the measurements because the urgent requests for data did not allow time to develop optimal equipment or techniques.

Conclusion: The temperature logs prepared at the Panel's request suggest that a substantial temperature anomaly exists at depth in the formation sediments between tanks 241-SX-108, $109,-111,-112$.

Recommendation: Hanford should have the capability of obtaining accurate temperature logs that are as representative as possible of formation temperatures. For example, infrared measurement of casing temperature should be considered.

Conclusion: To understand the distribution of contaminants in the groundwater, as well as in the vadose zone, it is necessary to characterize the vadose zone.

Conclusion: Characterization of the vadose zone is an essential step toward understanding contamination of the groundwater, assessing the resulting health risks, and defining the groundwater monitoring program necessary to verify the risk assessments.

Conclusion: A reliable quantitative model, or even a valid conceptual model, of groundwater contamination cannot be developed without reliable data regarding contaminant transport properties of the vadose zone, a subject which is poorly understood. The ongoing Vadose Zone Characterization Program has concentrated mostly on logging existing boreholes. Little data is available at SX tank farm below 130 feet, leaving a gap in our understanding of contaminant transport below that depth to groundwater at approximately 200 feet.

Recommendation: The Vadose Zone Characterization Program shculd be expanded to encompass the entire vadose zone, including deepening existing boreholes and using slant-hole drilling to avoid heavily contaminated zones near the tank bases.

Recommendation: Drill a slant borehole, starting at the west end of the farm and passing between and beneath several tanks. The location and orientation of this borehole will be specified after boreholes 41-09-04 and 41-09-39 are extended. This slant borehole should be constructed to groundwater and a complete groundwater data set, including radionuclides and chemicals, should be obtained. The borehole should be logged and the samples analyzed for contaminants as well as the physical and chemical transport properties. 
Conclusion: In the draft SX TANK FARM REPORT, a geostatistical model is used to generate visualizations suggesting massive transport of ${ }^{137} \mathrm{Cs}$ in balloon-shaped contamination zones around and below several tanks. The geostatistical model is probably not capable of producing realistic visualizations of contaminant distributions in the vadose zone, unless some closely spaced borehole data are included in the visulation.

Recommendation: An assessment of existing computer simulation programs is needed to determine which is best suited to simulating contaminant transport in the Hanford vadose zone. This should be done before large sums of money are spent on additional modeling.

Recommendation: Modelers of contaminant transport in the Hanford vadose zone should look to the petroleum industry, geothermal research, Sweden's KBS program, and DOE's high-level waste glass and waste-disposal programs for concepts to be incorporated into their simulation models

Recommendation: The spatial correlation analysis semivariogram of the geostatistical model should be revised periodically to incorporate new data from new borehole logs. Kriging with the revised geostatistical model will provide new guidance on contaminant distribution. Logs with borehole contamination should be excluded from the geostatistical analysis.

Conclusion: The Panel concurs with key conclusions of the recently published findings of the National Academy of Sciences/National Research Council [NAS/NRC, 1996b] regarding vadose zone contamination, as stated in our original 3-page statement following the drilling of the investigative borehole 41-09-39. The results derived from the two investigative boreholes reinforce the NAS/NRC conclusions, some of which are listed here:

- "An important component of a long-term commitment to remediating the single-shell tanks at the Hanford Site is an adequate understanding of ... the extent to which the soil and groundwater beneath the tanks have been contaminated. Characterization should continue until such an understanding has been obtained" (p. 28).

- "A spatial correlation analysis of SGLS data from the SX Tank Farm should be undertaken with geostatistics after new borehole log data are obtained. Data effected by borehole contamination should be excluded from geostatistical analysis" (p. 36).

- "It is not at all evident how a preferred tank waste retrieval and treatment remediation alternative can be selected rationally without simultaneously considering what is to be done with contamination left behind" (p. 37).

- "Adequate characterization of the tank wastes and surroundirg contaminated environment will be required for processing of waste that is removed for treatment and for in situ disposition of wastes not removed from the tanks (either by choice or necessity). A better understanding of what has already leaked and how rapidly it is moving toward the groundwater is needed for assessing risks. Significant uncertainty 
currently exists concerning the sources and migration paths of cesium and technetium that have been found at some depth beneath the tank farms. Leakage from the tanks caused by sluicing, as well as the risk associated with waste ieft in the tanks, must be analyzed during the first phase in the context of overall risks. The mechanisms and rates of migration of cesium and other radionuclides originat.ng from the tank farms and from other waste disposal facilities at the Hanford Site also need to be better understood" (p. 52).

- "The analysis should also give more details about the levels of existing contamination in the soil and ground water under the tanks and estimates of long-term impact of such contamination under baseline conditions. The DEIS notes that groundwater protection standards are already exceeded for a number of radionuclides of interest, but it does not provide quantitative information" (p. 57). 


\subsection{REFERENCES}

Agnew, S.F., 1995. Hanford Defined Wastes: Chemical and Radioruclide Compositions, LAUR-94-2657, Rev. 2. Los Alamos National Laboratory, Los Alamos, NM.

Agnew, S.F., R.A. Corbin, T.B. Duran, J.R. Fitzpatrick, K.A. Jurgensen, T.P. Ortiz, and B.L. Young, 1996. Hanford Tank Chemical and Radionuclide Invertories: HDW Model Rev. 3, LA-UR-96-858. Los Alamos National Laboratory, Los Alamos, NM.

Arnold, D. M., and J. Butler, 1988. Logging calibration technology and facilities. IEEE Trans. Nucl. Sci. 35, 844-846.

Barkatt, Aa., W. Sousanpour, Al. Barkatt, M. A. Boroumand and P.B. macedo, 1984. "Leach Behaviour of SRL TDS-131 Defense Waste Glass in Water at High/Low Flow Rates", in Proc. 1983 Mat. Res. Soc. Symp. 26, 643-653, ed. G. L. McVay. Elsevier Science Publishing Co., Inc., New York, NY 10017.

Barnard, R. W., W. A. Stephenson, J. H. Weinlein, Jensen, D. H. and D. R. Humphreys, 1983. Experiences with a PFN uranium logging system. IEEE Trans. Nuc. Sci. NS-30, 16641667.

Beard, S.J., P. Hatch, G. Jansen and E.C. Watson, Jr., 1967. Purex TX-105-A Waste Storage Tank Liner Instability and Its Implications on Waste Containment and Control, ARH78 (Atlantic Richfield Hanford Co.); in J. Jo and B.L. Jones, 1990; The History and Existing Evaluations of the Tank Bump, WHC-SD-WM-TI-406, Rev. 0. Westinghouse Hanford Co., Richland, WA.

Beck, A. E., 1976. The use of thermal resistivity logs in stratigraptic correlation. Geophysics 41, 300-309.

Beck, A. E., 1977. Climatically perturbed temperature gradients and their effect on regional and continental heat-flow means. Tectonophysics 41, 17-39.

Belknap, W. B., J. T. Dewan, C. V. Kirkpatrick, W. E. Mott, A. J. Pearson and W. R. Rabson, 1959. A. P. I. calibration facility for nuclear logs. In SPWLA Reprint Volume "Gamma Ray. Neutron and Density Logging", Society of Professional Well Log Analysts, Houston TX (1982).

Bell, J. P., T. J. Dean, and M. G. Hodnett, 1987. Soil moisture measurements by an improved capacitance technique, Part I. Sensor design and performance. J. Hydrology 93, 7990 .

Bertozzi, W., D. V. Ellis and J. S. Wahl, 1981. The physical foundation of formation 
lithology logging with gamma rays. Geophysics 46, 1439-1455.

Brevick, C.H., 1995. Historical Tank Content Estimate for the Southwest Ouadrant of the Hanford 200 West Area, WHC-SD-WM-ER-352, Rev. Oa. Westinghouse Hanford Co., Richland, WA.

Brevick, C.H., L.A. Gaddis and W.W. Pickett, 1994. Historical Tink Content Estimate for the Southwest Quadrant of the Hanford 200 West Area, WHC-SD-W/M-ER-352, Rev. 0. Westinghouse Hanford Co., Richland, WA.

Bristow, Q., 1994. Pulse Pileup can be Hazardous to the Health of your Spectra, but the Distortion can be Corrected. Radioactivity and Radiochemistry, 5, 22-38.

Bristow, Q. and J.G. Conaway, 1984. Application of inverse filtering to gamma-ray logs: A case study. Geophysics 49, 1369-1373.

Bristow, Q. and J.G. Conaway, 1984. Temperature gradient measurements in boreholes using low noise high resolution digital techniques. In Geol. Surv. Can. Piper 84-1B, p. 101-108.

Brodeur, J.R., C.J. Koizumi, W.H. Ulbricht, and R.K. Price, 1991. Calibration of a highresolution passive gamma-ray logging system for nuclear waste assessment, WHC-SA-1175FP. In Proc. 4th Ann. Int. MGLS/KEGS Symo on Borehole Geoph., Toronto, Ont., Can., Aug. 18-22, 1991.

Caggiano, J.A., 1996. Assessment Groundwater Monitoring Plan for Single Shell Tank Waste Management Area S-SX, WHC-SD-EN-AP-191, Rev. 0. Westinghıuse Hanford Co., Richland, WA.

Chudy, S., 1981. Photon log. In Trans. Society of Professional Well Log Analysts $22^{\text {nd }}$ Annual Logging Symposium.

Conaway, J. G., 1980. Uranium concentrations and the system response function in gamma ray logging. In Geol. Surv. Can. Paper 80-1A, p. 77-87.

Conaway, J. G., 1981. Deconvolution of gamma-ray logs in the case of dipping radioactive zones. Geophysics 46, 198-202.

Conaway, J. G., 1983. Digital Filtering of Geophysical Logs. In Ievelopments in Geophysical Exploration Methods - 5, A.A. Fitch, (ed.), Ch. 3 (p. 55-105). Applied Science Publishers, London.

Conaway, J. G., 1986. Use of a pulsed neutron induced gamma ra' $L$ spectroscopy logging system for accurate determination of equivalent $\mathrm{CO}_{2}$ concentrations: A feasibility study, LAUR 86-1230, 93 pp. Los Alamos National Laboratory. Los Alamos, NM. 
Conaway, J. G., 1987. Temperature logging as an aid to understanding groundwater flow in boreholes. In Proc. Second Annual Symposium of the Minerals ancl Geotechnical Logging Society, Golden, October 1987, p. 51-59.

Conaway, J. G., 1989. Distortion of geophysical logs near bed boundaries and in complex lithologies. In Proc. Fifth Symposium on Containment of Undergrcund Nuclear Explosions, C. W. Olson, ed., Santa Barbara, September 1989, 2: 337-354 (LLNL pub. CONF-8909163).

Conaway, J. G., 1991. Identification of artificial gamma-emitting ruclides using a scintillation-based gamma-ray spectral logging system. In Proc. Fourth Annual Symposium on Borehole Geophysics for Geotechnical and Groundwater Applications, Minerals and Geotechnical Logging Society, Toronto, August 26-30, 1991.

Conaway, J. G., 1991. Effects of formation chemical composition, bulk density and water content on spectral gamma-ray log calibration, LA-UR-91-685, 9pp. Los Alamos National Laboratory, Los Alamos, NM.

Conaway, J. G., 1995. Statistically robust mapping of gamma-emitting contaminants in the ground. Waste Management 95 Conference Proceedings (CD ROM).

Conaway, J. G. and A. E. Beck, 1977. Fine-scale correlation between temperature gradient logs and lithology. Geophysics 42, 1401-1410.

Conaway, J. G., and J. R Hearst, 1993. Mapping contaminants with nuclear borehole logging techniques. LA-UR-92-3963. American Chemical Society National Meeting, March, 1993, Denver, CO.

Conaway, J. G., K. V. Allen, Y. B. Blanchard, Q. Bristow, W. G. Hyatt and P. G. Killeen, 1979. The effects of borehole diameter, borehole fluid and casing thickness on gamma ray logs in large diameter boreholes; In Geol. Surv. Can. Paper 79-1C, p. 37-40.

Conaway, J. G., Q. Bristow and P. G. Killeen, 1980. Optimization of gamma-ray logging techniques for uranium. Geophysics 45, 292-311.

Conaway, J. G., P. G. Killeen and W. G. Hyatt, 1980. A comparison of bismuth germanate, cesium iodide and sodium iodide scintillation detectors for gamma ray spectral logging in small diameter boreholes. In Geol. Surv. Can. Paper 80-1B, 173-177.

Conaway, J. G., R. D. Wilson, D. J. Krier, M. A. Mathews, and J. W. Barber, 1993. Errors in spectral gamma-ray logs resulting from radon daughters in boreholes. Nuclear Geophysics 7, 55-64.

Conaway, J. G., S. C. Frankle and B. C. Letellier, 1995a. A new, computationally efficient computer program for simulating spectral gamma-ray logs, LA-UR. 96-34. In Proc. 6th 
International Minerals and Geotechnical Logging Society Symposiun on Borehole Geophysics for Minerals. Geotechnical and Groundwater Applications, Santa Fe, October 1995.

Conaway, J. G., D. C. George, J. L. Mikesell, R. D. Wilson, J. L. Burnham, J. R. Duray, S. C. Frankle, J. R Hearst, P. J. Jaegers and P. H. Nelson, 1995b. Contaminant detection thresholds for the multispectral borehole logging system. Waste Management 95 Conference Proceedings (CD ROM).

Cunnane, J.C., J.K. Bates, C.R. Bradley, E.C. Buck, W.L. Ebert, X. Feng, J.J. Mazer, D.J. Wronkiewicz, J. Sproul, W.L. Bourcier, B.P. McGrail and M.K. Altenhofen, 1994. HighLevel Waste Borosilicate Glass: A Compendium of Corrosion Characteristics, DOE-EM0177. U.S. Department of Energy. Available from National Technical Information Service, Springfield, VA.

Czubek, J. A., 1962. The influence of the drilling fluid on the gamna-ray intensity in the borehole. Acta Geophysica Polonica 10, 25-30.

Czubek, J. A., 1969. Influence of borehole construction on the results of spectral gammalogging. In Nuclear Techniques and Mineral Resources, IAEA Proceedings Series, IAEA, Vienna.

Czubek, J. A., and T. Zorski, 1976. Recent advances in gamma-rav log interpretation. International Atomic Energy Agency Advisory Group Meeting on Evaluation of Uranium Resources, Rome, Ttaly.

Daily, W., A. Ramirez, D. LaBreque and J. Nitao, 1992. Electrical Resistivity Tomography of Vadose Zone Water Movement. Water Resources Research 28, 1.429-1442.

Diment, W. H., 1967. Thermal regime of a large-diameter borehole: instability of the water column and comparison of air- and water-filled conditions. Geophysics 32, 720-726

DOE, 1996. Tank Waste Remediation System. Hanford Site. Richland. Washington: Final Impact Statement. (Volume 1 and Appendices F and K). U.S. Department of Energy (and Washington State Department of Ecology), Richland ,WA 99352.

Dove, P.M. and J.D. Rimstidt, 1993. Silica Water Interactions. In SILICA: Physical Behavior. Geochemistry and Materials Applications, P.J. Heaney, C.T. Prewitt and G.V. Gibbs (Eds.), REVIEWS in MINEROLOGY Volume 29, pp. 259-308. Minerological Society of America, Washington, D.C.

Drever, J.I., 1988. The Geochemistry of Natural Waters (Second Edition), p. 141. Prentice Hall, Englewood Cliffs, NJ. 
Ellis, D. V., 1987. Well Logging for Earth Scientists. Elsevier Science Publishing Co., New York.

Ellis, D. V., R. A. Perchonok, H. D. Scott and C. Stoller, 1995. Adapting wireline logging tools for environmental logging applications. In Trans. Society of Professional Well Log Analysts $36^{\text {th }}$ Annual Logging Symposium, Paris, 1995.

Engelman, R. E., R. E. Lewis, and D. C. Stromswold, 1995a. Calibration models for density borehole logging - construction report, PNL-10800 (UC-606). Pacific Northwest National Laboratory, Richland WA.

Engelman, R. E., R. E. Lewis, D. C. Stromswold, and J. R Hearst, 1995b. Calibration models for measuring moisture in unsaturated formations by neutron logging, PNL-10801 (UC-606). Pacific Northwest National Laboratory, Richland WA.

Flury, M. H. Fluhler, W.A. Jury and J. Leuenberger, 1994. Susceptibility of soils to preferential flow of water: A field study. Water Resources Research 30, 1945-1954.

Gadeken, L. L., H. D. Smith, Jr., R. E. Lewis, and R. E. Engelman, 1995. Adaptation of geophysical logging tools for monitoring and characterization of the unsaturated zone.

Presented at the Superfund XVI Conference, Nov. 1995 (preprint available).

Gee, G.W., M.J. Fayer, M.L. Rockhold, and M.D. Campbell, 1992. Variations in Recharge at the Hanford Site. Northwest Science 66, 237-249.

General Accounting Office (GAO), 1992. Nuclear Waste: Improvements_Needed in Monitoring Contaminants in Hanford Soils, GAO/RCED-92-149. General Accounting Office, Washington, D.C.

George, D. C., 1992. Neutron activation logging system for the mixed waste landfill integrated demonstration. Internal report, Chem Nuclear Geotech, U.S. Department of Energy, Grand Junction, CO.

George, D. C. and J. L. Burnham, 1984. Neutron activation logging demonstration at Hanford. Internal report, Bendix Field Engineering Corporation, U.S. Department of Energy, Grand Junction, CO.

George, D. C., and R. D. Wilson, 1994. Demonstration of prompt fission neutron logging tool response to fissile elements. Internal report, U.S. Department of Energy, Grand Junction, $\mathrm{CO}$.

Golder Associates, 1992. Cost-benefit study of the application of borehole geophysics to Hanford CERCLA programs. Westinghouse Hanford Company report WHC-SD-EN-EE-010, Draft. 
Grand Junction Projects Office (GJPO), 1996. SX Tank Farm Repcirt, GJ-HANDOE/ID/12584-268 (GJPO-HAN-4). U.S. Department of Energy, 'Grand Junction, CO.

Grand Junction Projects Office (GJPO), 1997. Assessment of Log Data for Borehole 41-09-04 in the SX Tank Farm. U.S. Department of Energy, Grand Junction, CO.

Grand Junction Projects Office (GJPO), 1997. Assessment of Log l)ata for Borehole 41-09-39 and Correlation With Borehole 41-09-04 in the SX Tank Farm, GJC-97-4-TAR (GJO-HAN-9). U.S. Department of Energy, Grand Junction, CO.

Grau, J. A., and J. S. Schweitzer, 1987. Prompt gamma-ray spectral analysis of well data obtained with $\mathrm{NaI}(\mathrm{Tl})$ and $14 \mathrm{MeV}$ neutrons. Nuclear Geophysics 1, 157-165.

Grolimund, D., M. Borkovec, K. Barmettler and H. Sticher, 1996. Colloid-Facilitated Transport of Strongly Sorbing Contaminants in Natural Porous Media: A Laboratory Column Study. Environ. Sci. Technol. 30, 3118-3123.

Hearst, J.R., 1979. Calibration of Neutron Log in Partially Saturatsd Media. In Society of Professional Well Log Analysts $20^{\text {th }}$ Annual Symposium_Transactiors. Tulsa, Paper B.

Hearst, J.R, 1986. Investigation of Subsurface Structure with Borehole Gravimetry. In Trans. Soc. Mining Eng., AIME, V. 282, p. 1817.

Hearst, J. R and R. C. Carlson, 1994. A comparison of the moisture gauge and the neutron $\log$ in air-filled boreholes. Nuclear Geophysics 8, 165-172.

Hearst, J. R, J. G. Conaway, D. E. Trcka, and J.A. Grau, 1991. A. comparison of energywindow and spectral-fitting methods for the estimation of carbonate content in rocks using neutron-induced gamma rays. In Proc. 4th International Symposium for Minerals. Geotechnical and Groundwater Applications, Minerals and Geotechnical Logging Society, Toronto, Canada.

Hearst, J. R, J. R. Brodeur, C. J. Koizumi, J. G. Conaway, J. L. Mikesell, P. H. Nelson, D. C. Stromswold, and R. D. Wilson, 1993. DOE capabilities for in-situ characterization and monitoring of formation properties in the vadose zone. UCRL-JC-1 13790, 15pp. Submitted to the journal Radwaste.

Hertzog, R. C., 1978. Laboratory and field evaluation of an inelastic-neutron scattering and capture gamma ray spectroscopy tool. In Proc. 53rd Annual Fall Technical Conf. and Exhib., Soc. Petrol. Eng., paper 7430. Houston, Oct. 1-3.

Humphreys, D. R., R. W. Barnard, H. M. Bivens, D. H. Jensen, W. A. Stephennson and J. H. Weinlein, 1981. Uranium logging by the prompt fission neutror technique. IEEE Trans. Nucl. Sci., Vol. NS-28, 1691-1695. 
ICF Kaiser, 1996. Historical Vadose Zone Contamination of S and SX Tank Farms, WHCSD-WM-ER-560, Rev. 0. Westinghouse Hanford Co., Richland, WA.

Jo, J. and B.L. Jones, 1990. The History and Existing Evaluations of the Tank Bump, WHCSD-WM-TI-406, Rev. 0. Westinghouse Hanford Co., Richland, WA.

Kenyon, W. E., 1992. Nuclear magnetic resonance as a petrophysical measurement. Nuclear Geophysics 6, 153-171.

Killeen, P. G., and J. G. Conaway, 1978. New facilities for calibrating gamma-ray spectrometric logging and surface exploration equipment. Canadian Mining and Metallurgical Bull., May, 1978, 4 pp.

Koizumi, C. J., 1993. Calibration standards for passive gamma-ray logging at the Hanford site, WHC-SD-EN-TI-192, Westinghouse Hanford Co., Richland WA.

Koizumi, C. J., 1996. Calibration plan for spectral gamma-ray logging systems, P-GJPO1778, Rev. 1. U.S. Department of Energy, Grand Junction, CO.

Koizumi, C.J., W.H. Ulbricht and J.R. Brodeur, 1991. Intrinsic germanium gamma-ray data from the new American Petroleum Institute spectral gamma-ray calibration models. In Proc. 4th Ann. Int. MGLS/KEGS Symp. on Borehole Geoph., Toronto, Ont., Can., Aug. 18-22, 1991.

Koizumi, C.J., R.K. Price and R.D. Wilson, 1992. Calibration of the RLS HPGE system for 200 Aggregate Area Management Study screening measurements. WHC-SD-EN-TRP-001. Westinghouse Hanford Co., Richland, WA.

Koizumi, C.J., J.R. Brodeur, R.K. Price, J.E. Meisner, and D.C. Stromswold, 1994. Highresolution gamma-ray spectrometry logging for contamination assessment. Nuclear Geophysics 2, 149-164.

Kung, K-J. S., 1990. Preferential Flow in a Sandy Vadose Zone: 2. Mechanism and Implications. Geoderma 46, 59-71.

Landstrom, O., C-E. Klockars, O. Persson, E-L. Tullborg, S.A. Larson, K. Andersson, B. Allard, and B. Torstenfelt, 1983. Migration Experiments in Sudsvik, SKBF/KBS Teknisk Rapport 83-18. Svensk Karnbransleforsorjning AB/Avdelning KBS, Stockholm.

Lee, T-C. and T. L. Henyey, 1974. Heat flow refraction across dissimilar media. Geophysical Jour. Royal Astr. Soc. 39, 319-333.

Lock, G. A., and W. A. Hoyer, 1974. Carbon-oxygen (C/O) log: Use and interpretation. $J$. Pet. Tech., Sept. 1974, 1044-1054. 
Mathews, M. A., J. H. Scott and C. M. LaDelfe, 1985. Test pits for calibrating well logging equipment in a fractured hard rock environment, Los Alamos Unclassified Report LA-UR-85859, 84 pp. Los Alamos National Laboratory, Los Alamos, NM.

Mathews, M. A., H. R. Bowman, Huang Long-ji, M. J. Lavelle, A. R. Smith, J. R Hearst, H. A. Wollenberg, Jr. and S. Flexser, 1987. Low radioactivity spectral gamma calibration facility, LA-UR-86-980, 20 pp. Los Alamos National Laboratory, Los Alamos, NM.

Meyers, G., 1997. Boreholes 41-09-04 and 41-09-36 (sic): Laser Survey Field Report, Letter Report. BABCO, Richland, WA.

National Academy of Sciences/National Research Council (NAS/NRC), 1996a. Barriers to Science: Technical Management of the Department of Energy Environmental Remediation Program. National Academy Press, Washington, DC.

National Academy of Sciences/National Research Council, 1996. The Hanford Tanks: Environmental Impacts and Policy Choices. National Academy Press, Washington, D.C.

Neilsen, E.H., 1992. Tank 241-SX-115 Leak Assessment, WHC-MR-0302 (UC-721). Westinghouse Hanford Co., Richland, WA.

Nelson, P., and F. Paillet, 1991. Review of Hanford-site borehole geophysical capabilities and their application for past-practice remedial investigations. Unpublished report prepared for the Environmental Protection Agency.

Nichols, W.E., N.J. Aimo, M. Oostrom and M.D. White, 1995. STOMP. Subsurface Transport Over Multiple Phases:_Application Guide, PNL-XXXX (UC-814). Pacific Northwest National Laboratory, Richland, WA.

Pinault, J.L. and C. Gatear, 1989. MOCA: An advanced Monte Carlo code running on microcumputers for spectral responses of neutron-gamma logging tools. Nuclear Geophysics $3,487-500$.

Price, R.K., 1996. Evaluation of Historical Dry Well Surveillance Logs, WHC-SD-ENV-TI001, Rev. 0, Westinghouse Hanford Co., Richland, WA. (unpublished)

Raymond, J.R. and E.G. Shdo, 1966. Characterization of Subsurface Contamination in the SX Tank Farm, BNWL-CC-701. Pacific Northwest National Laboratory, Richland, WA.

Sanders, L.G. and P.B. Kemshell, 1984. Computer modeling as an aid to neutron and gammaray $\log$ interpretation. Transactions of the SPWLA Twenty-Fifth Annual Logging Symposium, Paper QQQ. 
Saiers, J.E., and G.M. Hornberger, 1996. The role of colloidal kaolinite in the transport of cesium through laboratory sand columns. Water Resources Research 32, 33-41.

Schultz, A. K., 1989. Monitoring fluid movement with the borehole gravity meter. Geophysics 54, 1267-1273.

Schweitzer, J. S., 1991. Nuclear techniques in the oil industry. Nhclear Geophysics 5, 65-90.

Schweitzer, J. S., and R. A. Manente, 1985. In situ neutron-induced spectroscopy of geological formations with germanium detectors. Amer. Inst. Petrol. Conf. Proc. 125, 824827.

Scott, J. H., 1963. Computer analysis of gamma-ray logs. Geophysics 28, 457-465.

Scott, J. H., P. H. Dodd, R. F. Droullard, and P. J. Mudra, 1961. Quantitative interpretation of gamma-ray logs. Geophysics 26, 182-191.

Senftle, F. E. and J. L. Miskesell, 1988. Borehole capture gamma-ray spectrometry in very dry rock. Nuclear Geophysics 2, 151-162.

Steele, W. D., and D. C. George, 1986. Field calibration facilities for environmental measurement of radium, thorium and potassium, second edition, G.I/TMC-01, UC-70A. U. S. Dept. of Energy, Grand Junction, CO.

Stromswold, D. C., 1980. Comparison of scintillation detectors for borehole gamma-ray logging. In Trans. 21st Annual Logging Symposium of the Society of Professional Well-Log Analysts, July, 1980.

Stromswold, D.C., 1994. Technical evaluation of software for ganma-ray logging system. PNL-98807. Pacific Northwest National Laboratory, Richland, WA.

Telford, W. M., L. P. Geldart, R. E. Sheriff, and D. A. Keys, 1976. Applied Geophysics. Cambridge University Press, Cambridge, U.K..

Till, J.E. and H.R. Meyer, 1983. Radiological Assessment: A Tettbook on Environmental Dose Analysis, NUREG/CR-3332 (ORNL-5988), pp. 4-12 to 4-15. U.S. Nuclear Regulatory Commission, Washington, D.C.

Tittle, C. W., 1989. A history of nuclear well logging in the oil industry. Nuclear Geophysics 3, 75-85. 
U.S. Department of Energy and Washington State Department of Ecology, 1996. Final Environmental Impact Statement for the Tank Waste Remediation System. Hanford Site, Richland. Washington (Volume 1 and Appendices F and K), DOE/EIS-0189. U.S. Department of Energy, Richland, WA.

Verghese, K., R.P. Gardner, M. Mickael, C.M. Shyu and T. He, 1988. The Monte CarloLibrary Least-Squares analysis principle for borehole nuclear well lcgging elemental analyzers. Nuclear Geophysics 2, 183-190.

Ward, A.L., W. Gee and M.D. White, 1997. A Comprehensive Aralysis of Contaminant Transport in the Vadose Zone Beneath Tank SX-109, PNNL-11463 (VC-702). Pacific Northwest National Laboratory, Richland, WA.

Wilson, R. D., and J. G. Conaway, 1993. Simulations of spectral gamma-ray logging tool response to formation and borehole wall source distributions. Nuclear Geophysics 7, 33-53.

Wilson, R. D., D. C. Stromswold, M. L. Evans, M. Jain and D. A. Close, 1979a. Spectral gamma-ray logging II: Borehole correction factors. In Trans. Society of Professional Well Log Analysts Annual Logging Symposium, Tulsa, paper EE.

Wilson, R. D., D. C. Stromswold, M. L. Evans, M. Jain and D. A. Close, 1979b. Spectral gamma-ray logging III: Thin bed and formation effects. In Trans. Society of Professional Well Log Analysts Annual Logging Symposium, Tulsa, paper FF. 